\title{
COOPERATION RESOURCES, ABSORPTIVE CAPACITY AND FIRM-LEVEL INNOVATION
}

\author{
Dissertation \\ zur Erlangung des akademischen Grades \\ doctor rerum politicarum \\ (Dr. rer. pol.) \\ vorgelegt dem \\ Rat der Wirtschaftswissenschaftlichen Fakultät \\ der Friedrich-Schiller-Universität Jena
}

am 16 Oktober 2013

von: Abiodun Adeyemi Egbetokun, MSc.

geboren am: 27.03.1978

in: Oyo, Nigeria 


\section{Gutachter}

1. Prof. Dr. Uwe Cantner, Friedrich-Schiller-Universität, Jena

2. Prof. Dr. Ulrich Witt, Max-Planck Institut für Ökonomik, Jena

3. Prof. Jorge Niosi, PhD, Université du Québec à Montréal

Datum der Verteidigung: February 20, 2014 


\section{Table of Contents}

List of Figures

List of Tables vi

List of Abbreviations

Acknowledgements viii

Authorships ix

Dedication

Summary xi

1 Introduction 1

1.1 Basic Concepts . . . . . . . . . . . . . . . 3

1.2 Cooperation Resources and Innovation . . . . . . . . . . . 6

1.3 Research Gaps . . . . . . . . . . . . . . . . . . . . . 11

1.3.1 Contextual contingencies . . . . . . . . . . . . . 11

1.3.2 Distinguishing formal and informal interactions . . . . . . 13

1.3.3 From social capital to technological knowledge . . . . . . . . 13

1.3.4 Networks in different stages of industry evolution . . . . . . 14

1.3.5 The role of absorptive capacity . . . . . . . . . . . . . 14

1.4 Structure of the Thesis . . . . . . . . . . . . . . 15

I EMPIRICAL ANALYSES

2 Interactive Learning and Firm Capabilities in Nigeria 20

2.1 Introduction . . . . . . . . . . . . . . . . . . 20

2.2 Theoretical Background . . . . . . . . . . . . . . 22

2.2.1 Competencies, capabilities: an operational distinction . . . . 24

2.2.2 Two distinct modes of interaction: formal, informal . . . . . 25

2.2.3 Learning and innovation in developing countries . . . . . . 26 
2.2.4 Interactive learning and capability accumulation . . . . . . 28

2.2.5 Absorptive capacity and capability accumulation . . . . . . 30

2.3 The Empirical Context . . . . . . . . . . . . . . . . . . . 31

2.3.1 The socioeconomic environment . . . . . . . . . . . 31

2.3.2 Trade and industrial structure . . . . . . . . . . . . . . 32

2.3.3 The business environment . . . . . . . . . . . . . . 33

2.3.4 The innovation environment . . . . . . . . . . . . . . . 33

2.3.5 Industrial performance indicators . . . . . . . . . . . . . . 34

2.3.6 Implications for the study . . . . . . . . . . . . . . . . . 35

2.4 Data and Econometric Methodology . . . . . . . . . . . . 35

2.4.1 The database . . . . . . . . . . . . . . . . 35

2.4.2 Measures . . . . . . . . . . . . . . . . . 36

2.4.3 Estimation issues . . . . . . . . . . . . . . . . . 39

2.5 Econometric Results . . . . . . . . . . . . . . . . . . 41

2.5.1 Patterns of capabilities and interactive learning . . . . . . 41

2.5.2 Estimation results and discussion . . . . . . . . . . . . 45

2.6 Conclusions . . . . . . . . . . . . . . . . . . . . . . . 49

3 Linkage Variety and Firm Capabilities in Nigeria

3.1 Introduction . . . . . . . . . . . . . . . . . 51

3.2 Hypotheses . . . . . . . . . . . . . . . . . 54

3.2.1 Variety of linkages . . . . . . . . . . . . . 54

3.2.2 Variety of linkages and innovation types . . . . . . . . 55

3.2.3 The interaction of formal and informal linkages . . . . . . 56

3.2.4 The role of absorptive capacity . . . . . . . . . . 57

3.3 Data and Method . . . . . . . . . . . . . . . 58

3.3 .1 The database . . . . . . . . . . . . . . . . . . . . . . . . . . . . . . . . .

3.3 .2 Measures . . . . . . . . . . . . . . . . . . 59

3.3 .3 Estimation . . . . . . . . . . . . . . . . 63

3.4 Results and Discussion . . . . . . . . . . . . . . 65

3.4.1 Descriptive results . . . . . . . . . . . . . . 65

3.4.2 Estimation Results . . . . . . . . . . . . . . . . . . . . . . . . . . . . .

3.5 Conclusions and Implications . . . . . . . . . . . . . 76

II THEORETICAL ANALYSES 79

4 Absorptive Capacity and Inter-firm Cooperation 80

4.1 Introduction . . . . . . . . . . . . . . . . . 80

4.2 Theoretical Background . . . . . . . . . . . . . 82

4.2.1 From social capital to knowledge fit . . . . . . . . . . . . 82

4.2.2 Spillovers and absorptive capacity . . . . . . . . . . . 83 
4.2.3 Absorptive capacity and R\&D investment allocation . . . . . 85

4.2.4 Cognitive distance . . . . . . . . . . . . . . . 87

4.2.5 Some modelling antecedents . . . . . . . . . . . . . 87

4.3 The Model . . . . . . . . . . . . . . . . . . . . . . . . . . . 88

4.3 .1 R\&D investments . . . . . . . . . . . . . . . . . 90

4.3.2 Knowledge generation . . . . . . . . . . . . . . . . 90

4.3.3 Absorptive capacity . . . . . . . . . . . . . . . . . . 92

4.3.4 Innovation and profit . . . . . . . . . . . . . . . 96

4.4 Optimal decision making . . . . . . . . . . . . . . . . . 97

4.4 .1 Investment trade-off . . . . . . . . . . . . . . . . . 97

4.4.2 Partnership formation . . . . . . . . . . . . . . . . . . . . . . . . . . . . . . . .

4.4.3 Comparative statics . . . . . . . . . . . . . . . . . . . . . . . 99

4.5 Conclusion . . . . . . . . . . . . . . . . . . . . . 104

5 Absorptive Capacity and Network Dynamics 106

5.1 Introduction . . . . . . . . . . . . . . . . . 106

5.2 Cognitive Distance Dynamics . . . . . . . . . . . . . . . 107

5.3 Networks in Industry Evolution . . . . . . . . . . . . . . . . . . . . 109

5.4 The Model . . . . . . . . . . . . . . . . . . . . . . . . . 111

$5.4 .1 \quad$ R\&D investments . . . . . . . . . . . . . . . . . . 112

5.4 .2 Knowledge generation . . . . . . . . . . . . . . . . 113

5.4 .3 Cognitive distance . . . . . . . . . . . . . . . . . . . 114

5.4 .4 Absorptive capacity . . . . . . . . . . . . . . . . 114

5.4 .5 Profit generation . . . . . . . . . . . . . . 115

5.4 .6 Innovation and learning . . . . . . . . . . . . . . 115

5.4.7 Investment optimisation and partnership formation . . . . . 117

5.5 Numerical Experiment . . . . . . . . . . . . . . . . . . . . . . 119

5.6 Results . . . . . . . . . . . . . . . . . . . . 121

5.6.1 Network measures and characteristic networks . . . . . . . 122

5.6 .2 Different knowledge regimes . . . . . . . . . . . . . . . 126

5.6.3 Robustness checks . . . . . . . . . . . . . . . . . 139

5.7 Conclusion . . . . . . . . . . . . . . . . . . . . . . . . 140

\section{CONCLUDING THOUGHTS 143}

6 Conclusion 144

6.1 Overview of Main Findings . . . . . . . . . . . . . . . . . . . . . . . 144

6.1.1 Interactive learning and innovation . . . . . . . . . . . 144

6.1.2 Coevolutionary processes . . . . . . . . . . . . 145

6.1.3 On the importance of absorptive capacity . . . . . . . . . . . 146

6.2 Novelty . . . . . . . . . . . . . . . . . . . . . 146 
6.3 Policy and Practical Implications . . . . . . . . . . . . . . . 147

6.4 Constraints and Future Outlook . . . . . . . . . . . . . . . . 148

$\begin{array}{ll}\text { Appendices } & 150\end{array}$

A Appendices to Chapter 2 151

A.1 The Logit and Multivariate Probit Specifications . . . . . . . . . . . 151

A.1.1 The logit model . . . . . . . . . . . . . . . . . . . . 151

A.1.2 The multivariate probit model . . . . . . . . . . . . 152

A.2 The Obstacles Measure . . . . . . . . . . . . . . . . . . 153

A.3 First Stage Probit Results . . . . . . . . . . . . . . . . . . 154

B Appendices to Chapter 3

B.1 Sectoral Patterns in the Sample . . . . . . . . . . . . . . . 155

B.2 The Partial Proportional Odds Ordered Logit Model . . . . . . . . 157

B.3 First Stage Probit Selection Equation . . . . . . . . . . . . . . 159

B.4 Baseline Models . . . . . . . . . . . . . . . . . . . . . . . 160

C Appendices to Chapter $4 \quad 161$

C.1 Resolving the Investment Trade-off . . . . . . . . . . . . . . . . . . 161

C.2 Heuristic Optimisation . . . . . . . . . . . . . . . . . . . . 164

D Appendices to Chapter [5] 166

D.1 Formal Definitions on Network Analysis . . . . . . . . . . . . . 166

D.1.1 Networks . . . . . . . . . . . . . . . . . 166

D.1.2 Unweighted measures . . . . . . . . . . . . . . . . . . . . . . . . . . . . . . . . . . . . . .

D.1.3 Weighted measures . . . . . . . . . . . . . . 167

D.2 Further Results . . . . . . . . . . . . . . . . . . . . . 168

$\begin{array}{ll}\text { Deutschsprachige Zusammenfassung } & \mathbf{1 7 3}\end{array}$

$\begin{array}{ll}\text { References } & 180\end{array}$

\begin{tabular}{ll} 
Erklärung 207 \\
\hline
\end{tabular} 


\section{List of Figures}

4.1 Novelty potential and understandability as functions of cognitive

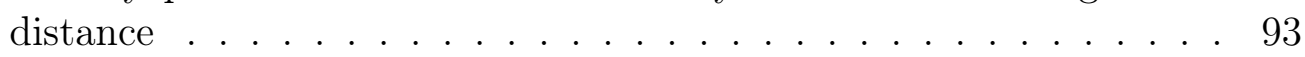

4.2 Absorptive capacity function . . . . . . . . . . . . . . . . . . . . . . . . . . . . . . .

4.3 Dynamics in absorptive capacity function . . . . . . . . . . . 94

4.4 Comparative statics for investments $\left(\rho_{i}\right)$ and profits $\left(\Pi_{i}\right) \ldots \ldots$

5.1 Characteristic networks . . . . . . . . . . . . . . . . . 122

5.2 Descriptive network information . . . . . . . . . . . . 125

5.3 Network characteristics and involuntary spillovers $\left(\delta_{n}\right) \quad \ldots . . .129$

5.4 Network characteristics and voluntary spillovers $\left(\delta_{c}\right) \ldots . . . . .133$

5.5 Correlations under varying involuntary spillovers $\left(\delta_{n}\right)$ : firms' network position and performance . . . . . . . . . . . 136

5.6 Correlations under varying voluntary spillovers $\left(\delta_{c}\right)$ : firms' network position and performance . . . . . . . . . . . . 138

C.1 $F\left(\rho_{i}\right)$ for different $\rho_{i}$ and empirical distribution of $F\left(\rho_{i}\right)$ for different

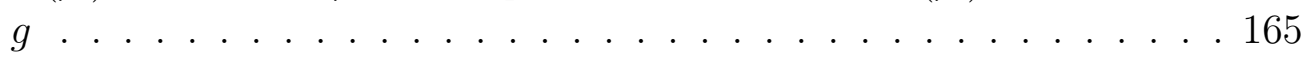

D.1 More network characteristics and involuntary spillovers $\left(\delta_{n}\right) \quad$. . . . 169

D.2 More network characteristics and voluntary spillovers $\left(\delta_{c}\right) \ldots . . .170$

D.3 Further correlations under varying involuntary spillovers $\left(\delta_{n}\right)$ : investments, distances and performance ... . . . . . . . 171

D.4 Further correlations under varying voluntary spillovers $\left(\delta_{c}\right)$ : investments, distances and performance . . . . . . . . . 172 


\section{List of Tables}

2.1 Description of independent variables . . . . . . . . . . . . 37

2.2 The indicators of technological capabilities . . . . . . . . . . 42

2.3 Pattern of collaboration in Nigerian manufacturing firms, 2003-2006 43

2.4 Sources of information for innovation in Nigerian manufacturing firms, 2003-2006 . . . . . . . . . . . . . . . 4 44

2.5 Relationship between overall capabilities and interactive learning logistic regression results . . . . . . . . . . . . 46

2.6 Relationship between different capabilities and interactive learning - multivariate probit results . . . . . . . . . . . 48

3.1 Description of dependent variables . . . . . . . . . . . . . 61

3.2 Description of independent variables . . . . . . . . . . . 62

3.3 Correlation matrix of independent variables . . . . . . . . . . . 64

3.4 Share of innovative firms, 2005-2007 . . . . . . . . . . . 65

3.5 Pattern of collaboration in Nigerian firms, 2005-2007 . . . . . . . . 66

3.6 Sources of information for innovation in Nigerian firms, 2005-2007 . 67

3.7 Innovativeness and variety of linkages - generalised ordinal logit

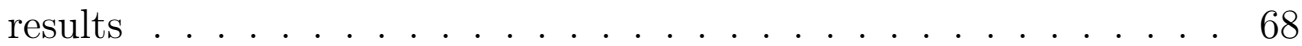

3.8 Different innovation types and variety of linkages - generalised ordinal logit results . . . . . . . . . . . . . . . 73

4.1 Comparative static results . . . . . . . . . . . . . . . . . . 100

A.1 Correlation between different innovation types . . . . . . . . . 152

A.2 Results of factor analysis . . . . . . . . . . . . . . . 154

A.3 Results of first-stage probit model . . . . . . . . . . . . . . 154

B.1 Share of innovative firms, $2005-2007 \ldots \ldots$. . . . . . . . 155

B.2 Pattern of collaboration in Nigerian manufacturing and service firms, $2005-2007 \ldots \ldots \ldots \ldots \ldots$

B.3 Sources of information for innovation in Nigerian manufacturing and service firms, $2005-2007 \ldots \ldots \ldots \ldots$

B.4 Probit selection model . . . . . . . . . . . . . . . . . . . . 159

B.5 Baseline models . . . . . . . . . . . . . . . . . . . . 160 


\section{List of Abbreviations}

$\begin{array}{ll}\text { ABM } & \text { Agent Based Model } \\ \text { ASTII } & \text { African Science, Technology and Innovation Indicators Initiative } \\ \text { CIS } & \text { Community Innovation Surveys } \\ \text { DFG } & \text { Deutsche Forschungsgemeinschaft } \\ \text { GDP } & \text { Gross Domestic Product } \\ \text { ICTs } & \text { Information and Communication Technologies } \\ \text { ISIC } & \text { International Standard Industrial Classification } \\ \text { MAN } & \text { Manufacturers Association of Nigeria } \\ \text { NACETEM } & \text { National Centre for Technology Management } \\ \text { NBS } & \text { National Bureau of Statistics } \\ \text { NEPAD } & \text { New Partnership for African Development } \\ \text { PPOM } & \text { Partial Proportional Odds Model } \\ \text { R\&D } & \text { Research and Development } \\ \text { RBV } & \text { Resource-based view } \\ \text { RTG } & \text { Research Training Group } \\ \text { US } & \text { United States }\end{array}$




\section{Acknowledgements}

This thesis was completed only because I received a lot of help.

The research was financially supported by the German Research Foundation (DFG), through the Research Training Group (RTG) 1411. Willie Siyanbola and the management of the National Centre for Technology Management (NACETEM), Nigeria gave me time off to concentrate. Simon Wiederhold, Ljubica Nedelkoska and Tina Wolf all helped me to settle well in Jena. When it mattered most, Simone Vannucinni 'gave' me his desk and Igor Asanov offered me an attractive office environment. Marco Röhl, Olga Markelova, Marcela Galvis Restrepo and Paola Càceres provided tremendous research assistance. I am indebted to Darasimi Oshodi, Johannes Karl Herrmann, Martin Kalthaus and Matti Grosse for language help.

I am particularly indebted to Uwe Cantner whose guidance and inspiration I could never have done without. I benefitted from discussions with Antoine Vernet, Bart Verspagen, Bengt-Åke Lundvall, Boladale Adebowale, HansGeorg Gemünde, Holger Graf, Jorge Niosi, Kenneth Carlaw, Luigi Orsenigo, Mike Scherer, Nicolas Jonard and Robin Cowan. I got useful feedback from colleagues now and then - including Elisabeth Bublitz, Levan Bzhalava, Matthias Piontek, Robert Gold and Simone Vannucinni. I owe Ivan Savin especially in the modelling aspects.

I am always grateful that my parents did their best to send me to school, and I am glad they are seeing results. My immediate family was very supportive, giving up work, school and play while bearing with my long absence and sometimes 'selfish' concentration. And I thank God - not least for Barnabas who came just when I needed much steam. His arrival provided me a very strong reason to finish. 


\section{Authorships}

This thesis includes articles that have been written alone or in cooperation with others. In the co-authored articles, every author contributed majorly to the completion of the work.

Chapter 2 is an extension of Egbetokun (2012).Chapter 3 is a revised version of the single-authored paper, The more the merrier? Network portfolio size and innovation performance in Nigerian firms. Chapters [4 and [5] are based on co-authored work: the former being Egbetokun and Savin (2014) and the latter, Savin and Egbetokun (2013). 


\section{Dedication}

To Oluwatosin, Grace and Barnabas.

Without your sacrifice,

this would have only been a dream. 


\section{Summary}

This thesis is about the importance of firms' absorptive capacity and the use of externally generated knowledge in the innovation process. A central message in recent literature is that firms become more efficient at innovating if they can effectively augment their in-house efforts with external knowledge. For this to happen, firms require an adequate stock of prior knowledge, commonly known as absorptive capacity. Networks of firms and other economic agents are a basic infrastructure for knowledge diffusion. And a firm's absorptive capacity conditions the amount of external knowledge it can appropriate. Although this much is known about networks, absorptive capacity and innovation, there are yet some important gaps in the literature.

First, there is a need for more detailed micro-level studies in developing countries. Second, little is known about the differential roles of formal and informal interactions. Third, the benefits that accrue from networking have been adduced largely to social capital; the importance of the nature of knowledge is almost completely ignored. Fourth, how networks vary in structure and importance as industries evolve is an interesting subject which has been hardly explored. Finally, the role of absorptive capacity in the network-innovation relationship is surprisingly under-explored. For the foregoing reasons, it is instructive to take another look at the relationship of innovation with network resources and the role that absorptive capacity plays in this relationship.

Using data from Nigeria, the two empirical chapters in this thesis examine how a firm's use of external knowledge conditions its innovative ability and the build-up of capabilities. In two theoretical chapters, a complex model of absorptive capacity and innovation networks is developed and extensively analysed. The entire analyses are guided by insight from evolutionary economics, strategic management and latecomer learning literatures. The evolutionary perspective is especially useful because it views innovation and the economy in a way that is closer to reality than what any other theoretical tradition offers. 
Innovation is essentially a process of knowledge recombination and takes place through learning by boundedly rational agents. The agents of innovation, especially firms, are diverse in terms of capabilities and behaviour. Thus, the economy is always in a dynamic state in which diverse actors, technologies and institutions coexist and act upon one another. The foregoing premises are combined with the view in strategic management that the firm, as a bundle of resources, is not complete in and of itself but requires complementary resources outside its boundaries. And for the analyses of developing country firms, it is more appropriate to focus on the process of technological learning which culminates in the accumulation of capabilities through which firms can innovate.

After an introductory chapter that outlines the direction of the thesis, Chapter 2 focuses on interactive learning and the build-up of technological capabilities by firms in developing countries. The chapter begins with the observation that much of the empirical literature describes paths of capability accumulation by latecomer firms, with a strong emphasis on the mastery of foreign technologies. This leaves room for more empirical studies that analyse learning from sources within the local innovation system. Furthermore, in some analyses of learning through local interactions, informal interactions tend to be emphasised at the expense of formal collaborations. Although it can be argued that the latter are less prevalent, ignoring them causes the role of interactive learning in latecomer innovation to be underestimated.

To overcome the confusion in many studies that treat technological capabilities as inputs and outcomes simultaneously, the chapter first clearly distinguishes competencies from capabilities and then presents the latter as outcomes of technological learning that are signaled by a firm's innovative activities. These activities may be technological (product- or process-related) or nontechnological (marketing- or organisation-related). Studies that take this multidimensional view of innovation are sparse, particularly in developing countries. An operational distinction is also made between formal and informal modes of interaction between a firm and actors within the local innovation system. These conceptual clarifications are applied to data from a pioneer innovation survey of Nigerian manufacturing firms. It is shown that firms' capabilities are strongly associated with formal and informal interactive learning. This relationship, however, varies with different capability types. For instance, process-related capabilities show no statistical relationship with informal interaction while organisational capabilities are not significantly associated with formal interaction. On the whole, it seems as if the firm-level capabilities derived more from informal than formal interactions. The implications of this 
for developing country firms is that a focus on the less costly informal forms of interaction may hold better promise as a driver of innovativeness.

Chapter 3 extends the preceding chapter by taking into account the variety of sources that firms draw upon as they seek to accumulate capabilities through external knowledge. The chapter relies on a more recent and richer innovation survey dataset on Nigerian firms. Although maintaining a portfolio of external knowledge sources has been consistently established as beneficial for innovation, it is unknown whether this holds irrespective of a firm's level of innovativeness. By employing ordinal measures of innovation performance and a partial proportional odds model, the varying importance of interactive learning as a firm becomes more innovative is highlighted in this chapter. While the number of informal sources is generally positively associated with innovation performance, this is only true at low levels of innovativeness for the number of formal interactions. The more innovative the firm becomes, the less useful it seems to be to maintain formal linkages with multiple partners. This draws attention to the limits of interactive learning, especially through formal collaborations. It also questions an unqualified commendation of the so-called open innovation paradigm.

In addition to the foregoing, an attempt is made to operationalise absorptive capacity and examine its role in interactive learning. It has been suggested that though most innovative activities do not arise from it, internal $R \& D$ is still important for the build-up of innovative capabilities in developing countries. This argument, however, is in need of empirical validation. We attempt to provide such by including a measure of $R \& D$ cumulativeness in the analyses. In this perspective, it is not the mere engagement in R\&D that matters but its continuity which confers a cumulative learning advantage on the firm. Absorptive capacity is shown to play an important role but not so much in moderating the effect of linkages as in directly improving the firm's ability to innovate.

An important limitation of the empirical analyses in the preceding chapters is the constrained measure of absorptive capacity. Measures of R\&D or training do not allow one to effectively distinguish efforts directed towards increasing inventive ability from those aimed at enhancing learning ability. Chapter 4 presents a representative agent model which offers a better representation of absorptive capacity. In so doing, recent empirical findings are taken into account and absorptive capacity is explicitly modeled within the framework of interactive learning. The absorptive capacity of firms develops as an outcome of the interaction between absorptive $R \& D$ and cognitive distance from volun- 
tary and involuntary knowledge spillovers.

Generally, the reciprocal terms of cooperation especially in $R \& D$ require a firm to share some of its knowledge with the partner in order to gain access to the latter's knowledge base. The inherent risk is that if the partner can learn faster and is more capable to innovate, a firm may be strengthening its own competitors. For this reason, voluntary spillovers or appropriability conditions between cooperation partners become a very critical factor to consider in cooperation. For the same reason, a firm will take the R\&D efforts of its potential partner seriously since that is the main source of absorptive capacity. When these are combined with the challenge of cognitive distance, two practical question arises: when is it better for a firm to cooperate? And how can an appropriate partner be selected? The model in Chapter 4 addresses these questions, taking a knowledge-based view of alliances. In the model, inter-firm cooperation is driven by cognitive distance, appropriability conditions and external knowledge. The conditions under which a cooperative strategy is superior to non-cooperation are then examined. The results show that cognitive distance and appropriability conditions between a firm and its cooperation partner have an ambiguous effect on the profit generated by the firm. Thus, a firm chooses to cooperate and selects a partner conditional on the investments in absorptive capacity it is willing to make. This way, a trade-off is made between understandability and novelty.

Chapter 5 builds upon and extends the analyses in the preceding chapter by simulating a dynamic multi-agent model of innovation networks. The chapter further extends the existing literature on strategic R\&D alliances with the inclusion of endogenous absorptive capacity. Building on research on alliance formation, the chapter focuses on dynamic aspects of cooperation wherein the cognitive overlap between partners increases with intensity of cooperation. In the model, networks emerge as a result of bilateral cooperation over time between firms occupying different locations in the knowledge space. Social capital is ignored, and firms ally purely on the basis of knowledge considerations. Partner selection is driven largely by absorptive capacity which is itself influenced by cognitive distance and investment allocation between inventive and absorptive R\&D.

Within different knowledge regimes which characterise different stages in industry evolution, the chapter studies the structure of networks that emerge and how firms perform within such networks. This analysis is a much-needed addition to the literature because it has been pointed out that a lot is still to be known about the dynamics of collaborations in innovation networks as well 
as the role of networks in different stages of industry evolution. The model replicates some stylised empirical results on network structure and the contingent effects of network position on innovative performance. For instance, networks that exhibit small world properties are observed, and these properties are generally robust to changes in the knowledge regime. The model also throws up some novel insights. First, it is shown that the influence of network structure on innovativeness does indeed vary with industry evolution. As the prevailing knowledge regime shifts from tacitness to codification, certain network strategies such as occupying brokerage positions or maximising accessibility to potential partners become less important. Furthermore, absorptive capacity demonstrably plays an important role in network evolution: firms with different network strategies indeed differ in the build-up of absorptive capacity.

In all, the research embodied in this thesis makes at least three original contributions. First, fresh evidence is provided on the relationship between innovation and interactive learning in a latecomer economic context. Second, cooperation networks are shown to vary in importance as industries evolve. Third, it is shown that firms' absorptive capacity indeed influences the rate and direction of network evolution. From a methodological perspective, the combination of microeconometrics, social network analysis and agent-based modeling makes this collection even more informative.

For policy, the indications are clear. It is useful to drive interactions among firms and with other economic agents but the limits of networking must be kept in sight. Besides, given the emphasis that many developing countries especially in sub-Saharan Africa place on university-industry interaction, it is important to point out that variety is needed. The combination of external sources of innovation is far more beneficial than overly exploiting any single source. Finally, the coevolutionary process between networks and industry evolution is a very important issue. If network-induced policy mechanisms such as cluster and incubation initiatives are not ill-informed in this regard, then they should be more effective. 


\section{Chapter 1}

\section{Introduction}

It is the maxim of every prudent master of a family, never to attempt to make at home what it will cost him more to make than to buy... What is prudence in the conduct of every private family, can scarce be folly in that of a ...kingdom 1

- Adam Smith (1723-1790)

The main aim of this thesis is to extend what is known about the importance of firms' absorptive capacity and the use of externally generated knowledge in the innovation process. The research embodied in this collection makes at least three original contributions. First, fresh evidence is provided on the relationship between innovation and interactive learning in a latecomer economic context. It has been consistently argued that evidence from such contexts is sparse in the literature. In particular, it is demonstrated that the well-known positive relationship between interactive learning and innovation is not constant but actually varies as a firm's level of innovativeness changes. Second, networks are shown to vary in importance as industries evolve. In the early stages of an industry when knowledge is highly tacit, firms benefit more from centralised network positions; the reverse is the case as the industry becomes more mature. Third, it is shown that firms' absorptive capacity indeed influences the rate and direction of network evolution. Networks emerge or change depending on firms' partnership decisions which are shaped by their absorptive capacity and that of the potential partners.

The analyses are guided by insight from evolutionary economics, strategic management and latecomer learning literatures. The evolutionary perspective is

\footnotetext{
${ }^{1}$ The Wealth Of Nations, Book IV Chapter II, pp. 456-7, paras 11-12.
} 
especially useful because it views innovation and the economy in a way that is closer to reality than what any other theoretical tradition offers. Innovation is essentially a process of knowledge recombination and takes place through learning by boundedly rational agents. The agents of innovation, especially firms, are diverse in terms of capabilities and behaviour (Dosi and Marengo, 2007). Thus, the economy is always in a dynamic state in which diverse actors, technologies and institutions coexist and act upon one another. Consequently, the central question is not one of optimal resource allocation in equilibrium but of how and why endogenous change occurs within firms, institutions and economies (Witt, 2008; Nelson and Winter, 1982). The foregoing premises are combined with the view in strategic management that the firm, as a bundle of resources, is not complete in and of itself but requires complementary resources outside its boundaries (Penrose, 1959). And for the analyses of developing country firms, it is more appropriate to focus on the process of technological learning which culminates in the accumulation of technological capabilities through which firms can innovate (Bell, 1984; Bell and Pavitt, 1993).

More than ever before, firms now have to deploy knowledge created outside their boundaries to complement their in-house efforts. This need is aggravated by the recent changes in the nature of technological competition. In today's business environment, technological advances occur rapidly such that firms' knowledge stocks could quickly become obsolete. Keeping up with advances in technology and ameliorating knowledge obsolescence require firms to maintain an up-to-date knowledge base. This knowledge typically accumulates from two extremes: in-house R\&D or from spillovers and other forms of knowledge generated outside the boundary of the firm. These are not without their limitations. On the one hand, rising costs of research impose a limitation on generating own knowledge. Moreover, imperfect appropriability and the proliferation of knowledge diffusion platforms such as ICTs undermine autarkic innovation behaviour. On the other hand, knowledge is difficult to buy and sell due to its tacit nature. The aforementioned limitations make the combinatorial approach very attractive. Maintaining a certain amount of in-house efforts allows the firm to create some proprietary knowledge while also improving its absorptive capacity, the so-called second face of R\&D. At the same time, external knowledge provides complementary assets and supplies missing input into the firm's knowledge base. Absorptive capacity indeed helps firms to become more adept at sourcing and deploying external knowledge.

Analyses of the relationship between innovation and extra-firm knowledge is rooted in a rather long research tradition. Before elaborating on this and the contributions made in this thesis, it is beneficial to set forward some funda- 
mental concepts. This is not a mere outline of definitions; rather it is an attempt to clarify the key concepts applied throughout this thesis. Some of these concepts, as the reader may be aware of, are subject to ambiguity and multiple definitions. In what follows, they are placed in context for the purpose of the research contained in this thesis. Subsequently, an attempt is made to take stock of relevant research to date. This chapter closes with a highlight of the main research questions and a summary of the chapters in this thesis.

\subsection{Basic Concepts}

\section{Innovation}

For most intents and purposes, innovation is adequately defined as "the implementation of a new or significantly improved product (good or service), or process, a new marketing method, or a new organisational method in business practices, workplace organisation or external relations/.../The minimum requirement...is that the product, process, marketing method or organisational method must be new (or significantly improved) to the firm" (OECD, 2005, p. 46).

In the context of developing countries innovation has been described as a process by which firms master and implement the design and production of goods and services which are new to them, irrespective of whether they are new to their competitors - domestic or foreign (Mytelka, 2000) 2 The process defined here is not limited to technical functions but also includes organisational and marketing functions (Ernst, 2007; UNU-INTECH, 2004). This offers a more complete picture of the innovation landscape.

\section{Absorptive capacity}

We follow Cohen and Levinthal (1990) in conceptualising absorptive capacity as a firm's ability to value, assimilate, and apply new knowledge. This capacity essentially defines a firm's learning and problem-solving ability, and it involves a combination of search effort and internal knowledge bases (Kim, 1998; Mowery and Oxley, 1995). Lim (2009) distinguished three types:

\footnotetext{
2 This definition basically extends an earlier one by Nelson and Rosenberg (1993) by including services.
} 
i. disciplinary: very important in the early stages of an industry. Relies on exploratory or basic R\&D and aims to develop general scientific knowledge. Its build-up requires the hiring of disciplinary scientists/engineers and forming close links with the scientific community.

ii. domain-specific: very important in the late-early stage and intermediate stages of an industry. Relies on applied R\&D and aims to generate knowledge for solving specific technical problems. Its build-up requires the hiring of specialist scientists/engineers and funding external R\&D in specific areas.

iii. encoded: highly crucial in the late stages of an industry when knowledge is largely codified. The aim is to acquire knowledge already embedded in tools and processes. It relies on knowledge integration processes and requires interaction with potential knowledge sources.

Clearly, these types all center on a firm's express ability to learn - that is, to acquire and assimilate knowledge. Innovation further requires transformation and exploitation of knowledge in which a firm's level of internal capabilities plays an even more important role 3

\section{Capabilities}

Following Dutta et al. (2005, p. 278), we define capabilities as the efficiency with which a firm uses the inputs available to it (i.e., its resources, such as $\mathrm{R} \& \mathrm{D}$ expenditure), and converts them into whatever output(s) it desires (i.e., its objectives, such as developing innovative technologies). Although they are often used as synonyms, capabilities are distinct from competencies. Competencies may be perceived as stemming from the tangible and intangible resources held by the firm and through which it learns. Capabilities are the outcome of the learning process and they allow the firm to efficiently transform its competences to tangible products and services (Bell, 1984; von Tunzelmann, 2009).

In a specific sense, technological capabilities refer to the resources needed to generate and manage technical change, and all the processes that contribute towards the accumulation of these capabilities are broadly termed technological learning (Bell and Pavitt, 1993). With these definitions, it is easy to see that

\footnotetext{
${ }^{3}$ For a more rigorous discussion on these aspects, see Zahra and George (2002) and Todorova and Durisin (2007).
} 
the amount or extent of technical change generated by a firm-mostly in the form of new products and processes - reflect its level of technological capabilities. But capabilities are not only technological; non-technological functions that lead on to marketing and organisational innovation are equally important (OECD, 2005). One may then, sensu amplo, distinguish between technological and non-technological capabilities which lead on to technological and non-technological innovations respectively.

\section{Cognitive distance}

Cognitive distance refers to the difference in the knowledge stocks of actors (Nooteboom, 1999a , b). For the analyses in this thesis the expression is used in relation to a focal firm and its potential partner. It is also used interchangeably with technological distance, since a firm's cognition simply derives from its stock of technological knowledge. Obviously, at high levels of cognitive proximity, mutual understanding is high. However, innovation potential will be low since there is hardly anything new. This is the basis of the inverted ' $U$ '-shaped relationship between cognitive distance and innovation often reported (see, for instance Lin et al., 2012).

\section{Interactive learning}

Innovation is an interactive process (Lundvall, 1988) requiring that innovators relate with a broad range of actors (Lundvall, 1992). It has also been argued to be a social process contingent upon the institutional structures within which it is embedded (Ovelaran-Oyeyinka, 2006a , b) . The popular innovation systems approach is actually based on the main idea that innovativeness is strongly influenced by the institutional and socio-economic context within which firms operate (Edquist, 2005; Lundvall et al., 2009). The recent open innovation paradigm also relies heavily on the idea that firms require a combination of external and internal ideas for enhanced innovative success. We refer to the entire process by which firms acquire and assimilate innovation information and knowledge from external sources as interactive learning. This may happen through formal collaboration or informal linkages.

Amara et al. (2008) discuss extensively five forms of learning: learning by searching, training, using, doing and interacting. Regarding the latter, the authors note that "[f]orging formal and informal linkages with clients, suppliers, 
industry associations, research organizations and government agencies provides additional inputs into the learning process which create new opportunities to have access to knowledge facilitating the development of innovations...(p. 453, emphasis added.)" As will be seen later in Chapters 2 and 3, our operationalisation of linkages goes along this direction.

In the terminology of network theory, the linkages are known as ties. When looking at a single firm, one sees an ego-centric network - a network comprising the focal firm and the economic agents (alters) to which it is tied. Considering many firms at the same time, say, in an industry, presents the scenario of an industry network where ties are more intricately interwoven. Both approaches are applied in different parts of this thesis.

\subsection{Cooperation Resources and Innovation}

The discussion on firms' use of network resources in their innovation efforts is related to the so-called 'make-or-buy' strategic decision. Although the 'makeor-buy' debate is often connected to research and development (R\&D) and joint ventures, it is no less relevant to the decision of a firm to cooperate in its innovation efforts. By participating in networks, firms gain specific innovative advantages. Several theoretical ingredients are important to the discussion of the relationship between externally-generated knowledge and innovation. Some of the most notable include:

i. the firm as a bundle of resources (Penrose, 1959): the fundamental idea in the resource-based view (RBV) is that the firm is a collection of tangible and intangible resources (notably knowledge) with which it builds competences and capabilities and hence, innovate. Securing sustainable access to knowledge and converting it to profit is the main problem of the firm.

ii. the firm as a continuously learning problem-solving agent Schumpeter, 1934, 1942; Nelson and Winter, 1982): in the evolutionary view, a firmbeing one of numerous economic agents - is essentially an entity which continuously learns from its experience and that of others, to develop routines to solve technical and non-technical problems. Solving problems this way gives rise to innovation in the form of new or recombined knowledge (Dosi, 1988). Firms vary in their abilities to achieve this; the variety gives rise to competition which, in turn, spurs innovation and continuous change (Witt, 2003). 
iii. division of labour (Smith, 1776): one of the specific reasons firms benefit from engaging in networks and using externally-generated knowledge relates to the ideas popularised in economics by Adam Smith. The basic idea is that by specialising in what they each do best, a group of cooperating workers will be collectively more productive. With regard to firms, this idea implies that the division of innovation-related tasks - whereby each cooperating firm contributes some expertise - facilitates the innovation process. Under such circumstances, cooperating firms can share risks and lower their transaction costs (Barr, 2002).

iv. knowledge spilloverst (Marshall, 1890; Jacobs, 1969; Arrow, 1962a, b) : by definition, knowledge spillovers are a form of externalities in which, without full compensation, one firm's innovations lead to productivity enhancements in other firms (Dasgupta and Stiglitz, 1980; Romer, 1986). By interacting with other firms and economic agents, firms gain access to such externalities - opportunities to learn and improve their innovative ability and productivity, without incurring costs associated with knowledge production.

v. complementarity between internal and external knowledge (Mowery, 1983; Teece, 1986; Cohen and Levinthal, 1989): the extent to which technological spillovers are useful to a firm depends on its existing knowledge stock. Possessing a stock of prior knowledge enables the firm to value and assimilate incoming spillovers; simultaneously, the incoming knowledge should complement what the firm already knows.

vi. transaction costs (Williamson, 1979, 1998): cost is an important variable in economic activities, especially in innovation. The knowledge required for innovation is very costly to create in-house and is, at the same time very difficult to transfer in market-based transactions. Between these two extremes, firms have the option of accessing external intangible assets to complement their in-house capabilities through formal or informal cooperation (Brusoni et al., 2001).

A central argument in transaction cost economics is that cost matters in the organisation of economic activities, especially contractual relations (Williamson, 1979). With respect to production, knowledge is a major input and firms' decision to carry out knowledge-related transactions in decentralised markets or to integrate vertically is heavily dependent on costs (Shelanski and Klein, 1995;

\footnotetext{
${ }^{4}$ Disambiguating the terms is not important to the discussion here. The interested reader may refer to Van der Panne (2004), Beaudry and Schiffauerova (2009), Glaeser et al. (1992) and Griliches (1998) for comprehensive discussions.
} 
Williamson, 1998). Research in evolutionary economics has shown that the implicit characteristics of knowledge plays a role in this decision (Brusoni et al., 2001). Some specific characteristics of knowledge that can lead to market failures in its transaction have also been emphasised. First, the partly tacit nature of knowledge makes it very difficult to transfer (Nelson and Winter, 1982). Second, imperfect appropriability conditions create a disincentive for marketbased transactions involving knowledge-related resources (Pisano, 1990).

Thus, avoiding market imperfections and the associated costs incentivises firms to internalise their innovation activities. However, internal costs may soar as a result of the necessary investments in learning and capacity building (Barney, 2001) as well as the 'added bureaucratic costs that accrue upon taking a transaction out of the market and organils/ing it internally' (Williamson, 1998, p. 39). Between the choices, which Brusoni et al. (2001, p. 600) refer to as 'the two extremes of decentrali/s/ed markets and integrated hierarchies', firms have the option of accessing external intangible assets to complement their in-house capabilities through formal or informal cooperation. This combinatorial solution is mainly attractive when the risks of cooperation are lower than those associated with pure market transactions and vertical integration.

The foregoing arguments are consistent with the RBV. Based on the seminal work of Penrose (1959), a firm is seen as a collection of resources (Wernerfelt, 1984, 2007) with which it builds strategic competences (Prahalad and Hamel, 1990). The resources can be classified into tangible and intangible ones; knowledge-related resources are intangible (Barney, 2001; Mowery et al., 1998) and therefore have strong tacit characteristics. Tacitness facilitates the appropriation of knowledge by limiting imitation but, as mentioned earlier, it simultaneously militates against the market-based transfer of knowledge-related resources. In fact, the market transaction of knowledge-related resources becomes increasingly difficult as the knowledge becomes more tacit (Teece et al., 1994). This market failure problem is overcome, to a large extent, through the institution of formal and informal cooperation (Cantner and Meder, 2007).

Besides the 'make-or-buy' dilemma, which is sometimes solved through cooperation, the firm faces another dilemma that accompanies the cooperative solution itself. In its external search, when a firm finds relevant knowledge resources, it has to make a decision on whether to acquire them or simply access them without necessarily securing ownership. Firms often find it preferable simply to gain access to complementary resources without having to devote their attention to acquiring ownership of such knowledge resources (Cantner and Meder, 2007). This option is attractive because it gives firms 
the opportunity to apply knowledge resources without fully bearing the costs of protecting them from erosion. Moreover, firms with a relatively weaker knowledge base can enjoy learning opportunities through interaction with the original knowledge owners. This is particularly true because technological knowledge is often tacit and the receiving firm may have difficulties in understanding and deploying it. A third reason why firms may prefer simply to access complementary knowledge resources rather than procure them relates to cost. It might be cheaper simply to share the knowledge base of an external agent than to develop it in-house or buy it from the original owner. This is particularly true when the knowledge does not have significant strategic potential in the sense that it is not widely applicable to the receiving firm's production activities and leaving it outside the boundary of the firm does not pose an immediate threat of competition.

By cooperating to gain access to additional knowledge assets for its innovation efforts, a firm maximises value by combining its partners' resources with its own and gaining access to complementarities (Gulati, 1995). In the literature, two approaches have been established by which firms typically gain access to external knowledge. A firm could collaborate formally with the potential knowledge source (Tether, 2002). Such collaborations usually involve the signing of some legally binding documents as in $\mathrm{R} \& \mathrm{D}$ joint ventures or technological agreements (Hagedoorn, 2002). Collaboration is often reciprocal in the sense that the knowledge-seeking firm has to give something in return for the knowledge it gains (Fehr and Gächter, 2000). This, in itself, constitutes a risk as the the firm may, through its shared knowledge, strengthen its own competition (Arrow, 1962b). Reciprocity, in turn, depends on the nature and source of the knowledge. For instance, when the collaboration partner is a non-business entity such as a university or public research institute, the firm may contribute in the form of research funding. However, when the partner is another firm, the knowledge-seeking firm has to share some of its knowledge with the partner in order to gain access to the latter's knowledge base. The second way in which firms gain access to complementary knowledge resources is simply to tap into the identified external knowledge sources. This often occurs through informal knowledge diffusion or information exchange (Garcia-Torres and Hollanders, 2009; Tödtling et al., 2009) and is especially useful when knowledge is neither tacit nor complex and specialised.

From the foregoing, it becomes clear that a firm's decision either to collaborate with or simply to tap into external knowledge sources is shaped by several factors, including the level of complexity or 'stickiness' of the knowledge and the source from which the knowledge is to be accessed. Nevertheless, the 
whole discussion can be summarised in the hypothesis that the deployment of external knowledge should be positively associated with innovation performance. This hypothesis is supported in different strands of the literature, including marketing (Gemünden et al., 1996), innovation systems (Edquist, 1997; Freeman, 1995; Lundvall, 1992), business management (Jaruzelski and Dehoff, 2007) and several areas of economics and policy research (Dodgson, 1993; Dreier and Jørgensen, 2005; Håkansson, 1989; Hoppe and Ozdenoren, 2005; Panda and Ramanathan, 1996).

Moreover, several studies have analysed the issues that firms face when they seek external knowledge. These issues relate to the choice of partners and knowledge sources (Howells et al., 2004) as well as the choice of strategy to adopt in accessing external knowledge (Nieto and Santamaría, 2007). The general result is that partner choice and innovation strategy need to be in tandem. For instance, when compared with incremental innovation, radical innovation seems to benefit less from the use of multiple external knowledge sources (Laursen and Salter, 2006).

In addition to that, the distance between a firm and its potential partner is important. Several forms of distance, including cognitive, organisational, social, institutional and geographical, are considered relevant in economic discussions on innovation (Boschma, 2005). These forms of distance all have implications for the diffusion of knowledge. Dettmann and von Proff (2010) demonstrated that organisational and institutional proximity facilitate joint patenting over large geographical distances. Wuyts et al. (2005) noted that organisational and strategic proximity could be very important in the formation of alliances. Jaffe (1989) showed that geographical proximity matters in knowledge transfer since knowledge tends to decay over distance. Breschi and Lissoni (2005, 2009) argued that geography is important only because of social distance: individual carriers of knowledge tend to relocate within the same geographical space so that their networks remain localised.

For the discussions in this thesis, attention is paid to the cognitive dimension of distance. Indeed, recent research evidence suggests that when talking about knowledge flows, cognitive proximity is relatively more important than other forms of proximity (Marrocu et al., 2013). This has an important implication for inter-firm interactions: a firm needs to choose a partner that is close enough in the knowledge space to be understood yet far enough to hold complementary knowledge (Boschma, 2005; Nooteboom et al., 2007). In this choice process, absorptive capacity - which represents a firm's ability to value, acquire and assimilate external knowledge (Cohen and Levinthal, 1989) - plays a defining 
role. A firm can only benefit from knowledge spillovers if it is able to recognise their value and understand them. Consequently, in a network, the partners a firm will choose, its resultant network position and the effect of external knowledge depend largely on internal learning capacity.

\subsection{Research Gaps}

As is obvious from the foregoing, a central message in recent literature is that firms become more efficient at innovating if they can effectively augment their in-house efforts with external knowledge (see Özman, 2009; Pittaway et al., 2004; Freeman, 1991, for reviews). For this to happen, firms require an adequate stock of prior knowledge, commonly known as absorptive capacity (Cantner and Pyka, 1998). This capacity conditions the extent to which a firm can exploit external knowledge which diffuses from the efforts of other organisations. Networks of organisations are considered a basic infrastructure for knowledge diffusion (Cassi et al., 2008; Graf, 2006; Breschi and Malerba, 2005).

Yet, there are some important gaps in the literature. This thesis is poised to contribute towards filling these gaps. First, much more is still to be known about the developing country context. Second, little is known about the differential roles of formal and informal interactions. Third, most of the benefits that accrue from networking have been adduced to social capital; the importance of the nature of knowledge is almost completely ignored. Fourth, how networks vary in structure and importance as industries evolve is an interesting subject which has been hardly explored. Finally, the role of absorptive capacity in the network-innovation relationship is surprisingly under-explored.

For the foregoing reasons, it is instructive to take another look at the relationship of innovation with network resources and the role that absorptive capacity plays in this relationship. In what follows, each of the identified gaps is discussed more extensively.

\subsubsection{Contextual contingencies}

As Tödtling et al. (2009) note, "there are no clear and general results regarding the relationship between networking and innovation. Findings seem to depend on the specific circumstances and conditions, such as sectors and firm sizes 
covered, countries and regions, and time period investigated". Thus, while studies like those by Mention (2011) and Tether (2002) suggest that cooperation, especially with universities and research organisations, has a positive influence on more radical forms of innovation, other studies, such as that by Frenz and letto Gillies (2009), suggest that cooperation is much less useful than in-house efforts. Such complexities and contingencies highlight the need for context-specific studies to facilitate a proper understanding of the cooperation-innovation nexus.

Freitas et al. (2011) imply as much by noting that national and industrial contexts shape the way in which firms use information sources. Consequently, lessons for policy and practice in the developed country context where most of the current knowledge arises from cannot necessarily apply to developing countries. For instance, it can be argued that firms operating within more advanced innovation systems may rely more on R\&D sources, while those within weaker systems may not (Frenz and letto Gillies, 2009).

Clearly, context matters! Different actions and outcomes occur under different conditions. Thus, what works in one context might fail in another (Nooteboom, 1994). Consequently, one would not expect, for instance, that the theoretical and empirical findings from the developed country context will be directly applicable to developing contexts. With this in mind, part of the agenda in this thesis is to examine the relation between interactive learning and innovation in a developing country with a weak innovation system. Since innovation and interactions are both costlier in such a context when compared with a more developed country context, we are interested in the extent to which firms acquire innovation information from external sources and how this relates to their innovative outcomes. Besides, the literature is heavily focused on technological product and process innovation. Hence, the evidence on the antecedents of non-technological marketing and organisational innovation is limited (Ganter and Hecker, 2013).

It is to be noted that our analyses in this regard are not comparative in the sense of placing data from developed and developing countries side by side. Rather, the modest aim is to provide fresh evidence from a country study in the sub-Saharan African context about which much more is still to be learned. 


\subsubsection{Distinguishing formal and informal interactions}

Souitaris (2001) categorised the efforts firms make to establish knowledge flow channels into those involving the scanning of external information and those involving cooperation with external organisations. Thus, the networking strategies of firms can be seen as consisting of informal information exchange (Sattler et al., 2003) and formal collaboration/cooperative agreements (Powell et al., 1996) with diverse actors which lie within the firm's ego network (Lundvall, 1988).

Such distinction is essential for the analysis of interactive learning. Previous empirical analyses do indeed point in the direction that formal interactions are more commonly associated with technological innovation (Tether, 2002). There are also reasons to expect that informal linkages will be more strongly associated with non-technological innovation especially in a developing country. This is because innovation in this context is less advanced and highly constrained (OECD, 2005) while informal interactions are cheaper (Bönte and Keilbach, 2005) and easier to manage (Pyka, 1997).

In relation to the foregoing, the empirical question that this thesis addresses concerns the relationship between the two distinct modes of interaction and different types of innovation. We do this with pioneer datasets from a very large developing country, Nigeria.

\subsubsection{From social capital to technological knowledge}

The notion of social capital describes the number of economically valuable ties that a firm has. In innovation studies, this is believed to be responsible for most of the benefits that firms derive from networking or interactive learning. In fact, a stylised fact in the literature is that highly connected firms tend to outperform peripheral ones because of their informational and control advantages (Gulati, 1998). A contrasting explanation that has been emphasised recently by Cowan and Jonard (2009) and Wersching (2010), among others, is knowledge fit: a firm might as well form a tie solely because of the knowledge it will gain and completely independently of its or the partner's network embeddedness. In this sense, what matters much more is a firm's cognitive distance to its potential partner as well as the absorptive capacities - both of the focal firm and its potential partner.

These aspects are explored in this thesis through an agent-based model (ABM). 
The key issue here is whether the well-known empirically observed properties of networks can be observed in the absence of social capital.

\subsubsection{Networks in different stages of industry evolution}

Malerba (2006) already hinted that the research on networks so far is rich but limited in some important respects. Among other things, he singled out the role of networks at different stages of an industry's history. So far, there are surprisingly almost no studies that consider this issue. But for a few recent studies like Balland et al. (2013) and Ter Wal (2013), analyses of the relationship between networking and innovation have largely ignored industry life cycle and technology evolution. Even in intertemporal analyses such as the one by Ahuja (2000), and more recently by Giuliani (2013), the focus is on the evolution of firms rather than of the industry as a whole. In Balland (2012), evolution of the whole $\mathrm{R} \& \mathrm{D}$ collaboration network in the navigation systems industry was examined. Albeit, the time span considered (2004-2007) is too short to afford a proper observation of intertemporal patterns. Inevitably, the specific implications of changes in technological regimes are ignored.

One such implication is that the nature and extent of knowledge spilloversand by extension, the importance of networks - will vary as industry evolves. The modelling exercise reported in this thesis examines how variations in the extent of voluntary and involuntary spillovers - which capture industry evolution - influence network emergence and evolution. The agent based models $(\mathrm{ABM})$ permit the examination of network evolution over long periods of time. Importantly, it allows to trace the path of network evolution and the varying importance of specific network strategies over the entire time period.

\subsubsection{The role of absorptive capacity}

A lot of research has been carried out on absorptive capacity 5 It is accepted that benefits from external knowledge are conditioned by a firm's in-house learning capacity (Lin et al., 2012). Particularly in the context of cooperation, the amount of external knowledge appropriated by a firm derives from the interaction of absorptive capacity with knowledge spillovers.

\footnotetext{
${ }^{5}$ See Todorova and Durisin (2007) and Zahra and George (2002) for comprehensive reviews.
} 
This reduces in value as the technological distance between partners increase (Nooteboom et al., 2007). Consequently, a firm's absorptive capacity will influence its decision to form ties and with whom. Building upon these, it is claimed in this thesis that absorptive capacity plays a crucial role in the emergence and evolution of innovation networks. This role is surprisingly under-explored in the literature. Few related empirical studies (e.g., Giuliani and Bell, 2005; Giuliani, 2013) are either cross-sectional or do not explore the influence of absorptive capacity per se but only turn to it in explaining their results. Most dynamic model 6 do not explicitly conceptualise absorptive capacity but generally assume it to be constant for all firms in an industry. This is a rather far-fetched assumption.

In light of these, an important part of the agenda in this thesis is to reformulate the absorptive capacity construct originally developed by Cohen and Levinthal (1989) to make it more appropriate for the context in which firms cooperate. Then, this formulation is applied in studying how innovation networks emerge and evolve from bilateral R\&D cooperation with endogenous absorptive capacity.

\subsection{Structure of the Thesis}

This thesis is organised into three parts and comprises four individual research articles. The articles have been adjusted to ensure the coherence of this collection. The entire contents are framed with this introduction and a concluding chapter.

This introductory chapter provides a prelude to the subject of the thesis and presents the main research questions. The different relevant theoretical and empirical traditions are also summarised therein. In Part I there are two chapters, each of which focuses on a specific empirical question. Part II comprises two theoretical chapters. The two chapters collectively analyse the role of absorptive capacity and the prevailing knowledge regime in the evolution of innovation networks. The lone chapter in Part III concludes the thesis. It essentially distills some implications for policy and practice from the other chapters, points out the limitations of the analyses and outlines some directions for future research. In the following, each of the five chapters that address specific research questions is summarised.

\footnotetext{
${ }^{6}$ see Cowan (2005) for a review
} 


\section{Chapter 2}

The focus of this chapter is on interactive learning and the build-up of technological capabilities by firms in developing countries. Combining insight from the literature on strategic management, evolutionary economics, innovation systems and latecomer technological capabilities, the chapter analyses the relationship between interactive learning and innovation in a sample of Nigerian manufacturing firms. Innovative activities are perceived as signals of a firm's level of technological capabilities. A novel aspect of the analysis is the operational distinction made between formal and informal modes of interaction between a firm and actors within the local innovation system. It is shown that firms' capabilities are strongly associated with formal and informal interactive learning. This relationship, however, varies with different capability types. In particular, process-related capabilities show no statistical relationship with informal interaction while organisational capabilities are not significantly associated with formal interaction. On the whole, it seems as if firm-level capabilities derived more from informal than formal interactions. Implications are drawn from these for developing country firms.

\section{Chapter 3}

This chapter extends the preceding one by taking into account the number of sources that firms draw upon as they seek to accumulate capabilities through external knowledge. It also attempts to operationalise absorptive capacity and examine its role in interactive learning. The chapter starts with the observation that a positive relationship between firms' networking activities and innovativeness has been consistently established in the literature. However, it is unknown whether this relationship holds irrespective of a firm's level of innovativeness. Moreover, studies considering different innovation types, and on developing countries are scarce. This chapter also relies on innovation survey data on Nigerian firms. The results show a positive relationship between a firm's innovation performance and the size of its external knowledge portfolio. A particularly interesting finding in the chapter is that the relationship varies across different innovation types and with increasing innovation performance. While the number of informal sources is generally positively associated with innovation performance, this is only true at low levels of innovativeness for the number of formal interactions. The more innovative the firm becomes, the less useful it seems to be to maintain formal linkages with multiple partners. This draws attention to the limits of interactive learning, especially through formal 
collaborations. It also questions an unqualified commendation of the so-called open innovation paradigm.

\section{Chapter 4}

An important limitation of the analyses in the preceding chapters is the constrained measure of absorptive capacity. Measures of $R \& D$ or training do not allow one to effectively distinguish efforts directed towards increasing inventive ability from those aimed at enhancing learning ability. This chapter presents a representative agent model which offers a better representation of absorptive capacity than what was achieved in the preceding empirical analyses. It begins by noting that cooperation can benefit and hurt firms at the same time. An important question then is: when is it better to cooperate? And, once the decision to cooperate is made, how can an appropriate partner be selected? In this chapter we present a model of inter-firm cooperation driven by cognitive distance, appropriability conditions and external knowledge. To date, theoretical analyses of networks have shied away from explicitly modelling absorptive capacity. This chapter tackles this challenge and offers a revision of the original Cohen and Levinthal model. In so doing, recent empirical findings are taken into account and absorptive capacity is explicitly modeled within the framework of interactive learning. Absorptive capacity develops as an outcome of the interaction between absorptive $R \& D$ and cognitive distance from voluntary and involuntary knowledge spillovers. It is, in fact, concave in cognitive distance. We apply that to the analysis of firms' cooperation and $R \& D$ investment preferences. The results show that cognitive distance and appropriability conditions between a firm and its cooperation partner have an ambiguous effect on the profit generated by the firm. Thus, a firm chooses to cooperate and selects a partner conditional on the investments in absorptive capacity it is willing to make.

\section{Chapter 5}

This chapter builds upon and extends the analyses in the preceding chapter by simulating a dynamic multi-agent model of innovation networks. The chapter further extends the existing literature on strategic R\&D alliances with the inclusion of endogenous absorptive capacity. The networks emerge as a result of bilateral cooperation over time between firms occupying different locations in the knowledge space. Social capital is ignored, and firms ally purely on 
the basis of knowledge considerations. Partner selection is driven largely by absorptive capacity which is itself influenced by cognitive distance and investment allocation between inventive and absorptive R\&D. Cognitive distance between firms changes as a function of the intensity of cooperation and innovation. Within different knowledge regimes which characterise different stages in industry evolution, the chapter studies the structure of networks that emerge and how firms perform within such networks. The model replicates some stylised empirical results on network structure and the contingent effects of network position on innovative performance. For instance, networks that exhibit small world properties are observed, and these properties are generally robust to changes in the knowledge regime. The model also throws up some novel insights. First, it is shown that the influence of network structure on innovativeness does indeed vary with industry evolution. As the prevailing knowledge regime shifts from tacitness to codification, certain network strategies such as occupying brokerage positions or maximising accessibility to potential partners become less important. Furthermore, absorptive capacity demonstrably plays an important role in network evolution: firms with different network strategies indeed differ in the build-up of absorptive capacity. 


\section{Part I}

\section{EMPIRICAL ANALYSES}




\section{Chapter 2}

\section{Interactive Learning and Firm Capabilities in Nigeria}

\subsection{Introduction}

This chapter aims to answer the following research question: what is the relationship between interactive learning and the build-up of technological capabilities in an import-dominated developing country? In discussions on economic development and catch-up, the role of enterprise-level innovation has been emphasised. Innovative firms, especially in manufacturing, are seen as drivers of structural change and productivity enhancements at the national level. This is particularly true for developing countries which can potentially benefit from their technological distance to the frontier (Szirmai, 2011; Fagerberg et al., 2010; Fagerberg, 1987). However, the innovation environment in these countries is usually harsh. Infrastructure, human capital and institutions - elements which are required for learning and capability building - are highly constrained (Oyelaran-Oyeyinka, 2006b; Biggs et al., 1995).

How can firms manage to learn and innovate in such environments? This particular question has received significant attention in the literature on innovation in latecomer firms (see Dutrénit, 2004; Sutz, 2012, for reviews). Innovation is seen as typically consisting of incremental technical change that is new to the firm but not necessarily to the market (Mytelka, 2000). Besides, marketing and organizational innovations are of major importance to firms in this context (OECD, 2005). The common understanding is that by building up their technological capabilities, firms in latecomer contexts can indeed gener- 
ate endogenous technical change (Amsden, 1992; Kim, 1997; Figueiredo, 2003). Technological capabilities refer to the resources needed to generate and manage technical change (Bell and Pavitt, 1993). To build this capability, firms are required to engage in a process of technological learning. In particular, interactive learning has been identified as a specific means by which technological capabilities are accumulated (Lundvall, 1988; Oyelaran-Oyevinka, 2007). Also, imported technologies constitute a significant source of technological knowledge (Figueiredo, 2002a).

Much of the empirical literature 11 describes paths of capability accumulation by latecomer firms (Figueiredo, 2002a, p. 686), with a strong emphasis on the mastery of foreign technologies (e.g., Naravanan and Bhat, 2009). This leaves room for more empirical studies that analyse learning from sources within the local innovation system. Furthermore, in some analyses of learning through local interactions between firms and other economic agents (e.g., Oyelaran-Oyeyinka, 2006a, Chapter 5), informal interactions tend to be emphasised at the expense of formal collaborations. Although it can be argued that the latter are less prevalent, they are nevertheless very important. In fact, ignoring them implies that the role of interactive learning in latecomer innovation will be underestimated. Besides, apart from a few exceptions like Iammarino et al. (2008), most studies treat technological capabilities as inputs and outcomes at the same time, leading to some fuzziness in the understanding of the learning-capability relationship.

In answering our key question, innovation is broadly defined to include "all types of search and improvement effort" by the firm (Lall, 1992, p. 166) for the purpose of generating technical change. Technological capabilities, the outcome of learning and accumulation of new knowledge particularly from local sources such as customers and universities, lie at the root of this process. Thus, a firm's innovative activities 2 constitute useful proxies for its level of capabilities (Iammarino et al., 2008). These are disaggregated into product, process, marketing and organisational 3 Two modes of interaction, formal

\footnotetext{
${ }^{1} \mathrm{~A}$ large proportion of this comprises descriptive case studies and surveys involving relatively few firms. While in-depth case studies are, in their own right, informative, they offer limited insight on inter-firm or sectoral differences (Molina-Domene and Pietrobelli, 2012).

${ }^{2}$ Note here the distinction between 'innovative' and 'innovation' activities. The latter include R\&D, training, purchase of equipment, and other activities carried out in preparation for innovation. They are related to the competencies that the firm inputs into the innovation process. The former describe the technical functions carried out by the firm as outcomes of the innovation process and signal its level of technological capabilities. See von Tunzelmann (2009) for a more complete discussion.

${ }^{3}$ This disaggregation is based on the Oslo Manual ( $\left.\mathrm{OECD}, 2005\right)$ as adopted for the first
} 
and informal, are distinguished. Formal interaction involves a collaboration agreement while informal interaction means that an external source acts as source of information for innovation (Freitas et al., 2011). These distinctions enrich the analyses since, as will be shown later, the relationship between different modes of interaction and innovative activities are not necessarily the same.

The research question is addressed using data from a pioneer innovation survey of Nigerian manufacturing firms. The conceptual basis is discussed in the next section, followed with a characterisation of the empirical context for the analyses and how it may lead to different results than what is already established in the literature. The data and results are thereafter described. It is shown that the firms tend to rely more on market-based than science-based sources of external knowledge. In a multivariate probit analysis, it is demonstrated that the use of external knowledge is positively associated with firms' probability to innovate. The chapter concludes by drawing some implications from these results.

\subsection{Theoretical Background}

The literature on firm-level innovation, technological capabilities and learning in developed countries is particularly vast. It is however limited in relevance for developing countries due to the significant contextual differences (Bell and Pavitt, 1993). There is a heavy bias in this literature towards technological product and process innovation. Besides, a vast majority of the studies define innovation very narrowly and measure it through patents or products that are new to the market. Yet, some of the principles and relationships established in this literature are context-neutral. Thus, as noted by Cooper (1991), the literature holds some relevance for developing countries. Therefore, this chapter combines insight from this body of research, particularly strategic management and evolutionary perspectives, with the research on latecomer technological capabilities to form its conceptual basis.

The extensive theoretical and empirical analyses of learning and innovation by firms in developed countries has the notion of core competence or capabilities at its heart 4 A core technological capability is perceived as a resource, ability

set of innovation surveys in Africa. For a detailed discussion, see UNU-INTECH (2004) and AU-NEPAD (2010).

${ }^{4}$ It is common to see the terms 'capability' and 'competence' used synonymously in the 
or routine that allows a firm to create technology-based competitive advantage (Prahalad and Hamel, 1990). In this context, creating new products and processes through formal R\&D is central Cohen (2010). Given the dynamic nature of the market, firms may be too rigid to react when confronted with new situations to which old capabilities are ill-fitted (Leonard-Barton, 1992). Dynamic capabilities refer to the resources and routines through which a firm transforms its operational capabilities in response to changes in the business environment (Collis, 1994; Teece and Pisano, 1994; Eisenhardt and Martin, 2000; Winter, 2003). These capabilities are strongly linked to firm-level performance (Teece et al., 1997; Teece, 2007). Organisational learning - deliberate or not - is central to the development of capabilities (Huber, 1991; Andreu and Ciborra, 1996; Zollo and Winter, 2002). Firms that can learn and act fast tend to outperform the slower ones (Zott, 2003).

This learning-capability relationship is important even for firms in developing countries although full-fledged innovation capabilities driven by formal R\&D tend to develop at a relatively late stage in these countries. The bulk of the literature in developing countries has been concerned with the accumulation of a minimum base of capabilities by firms which then enable them to carry out innovative activities (Dutrénit, 2004). In place of core or dynamic capabilities, the concept of technological capabilities is applied in this literature 5 Technological capabilities - accumulated via the process of technological learning (Figueiredo, 2003) - describe a firm's ability to make efficient use of technological knowledge (Westphal et al., 1985).

strategic management literature. Wang and Ahmed (2007) discuss this type of definitional complexities that pervade in the literature. Leonard-Barton (1992, p. 111-2) demonstrates how this happens. After defining core capabilities as those that "differentiate a company strategically", she notes that the expression is described with several alternative ones like 'distinctive competences', 'firm-specific competence', 'core or organisational competencies'. For a similar occurrence in evolutionary economics, see Malerba and Orsenigo (2000, p. 291). For simplicity and consistency, let us stick with 'capabilities' for now. A conceptual clarification comes in the next section.

${ }^{5}$ Several other terms such as technological effort, technological mastery, technological capacity which refer to this concept can be found in the literature but technological capabilities is the more widely used expression. For more comprehensive discussions, see Bell and Pavitt (1993), Lall (1992) and the first chapter in Sivanbola et al. (2012). 


\subsubsection{Competencies, capabilities: an operational distinc- tion}

Some confusions in terminologies can be avoided by distinguishing between competencies and capabilities, which, though closely related, are not the same. Competencies may be perceived as stemming from the tangible and intangible resources held by the firm through which it learns and accumulates knowledge while capabilities are the outcome of the learning process. In other words, while competencies relate to input.6 6 , capabilities tend to frame outputs (von Tunzelmann and Wang, 2003, 2007; von Tunzelmann, 2009). Consequently, capabilities have been recognised as the efficiency with which a firm uses inputs and converts them into desired outputs - in this case, innovation (Dutta et al., 2005).

Therefore, whereas competencies may be acquired from outside, a firm's capabilities are endogenously developed and show up in its capacity to innovate either by assimilating, exploiting and modifying acquired technologies, creating new technologies or developing new products and processes (Kim, 1997). This representation of capabilities echoes the distinction by Malerba and Orsenigo (2000, p. 297) between knowledge as an input in the production process and knowledge as the ability to actually produce new artifacts and novel knowledge 7 . The former is largely codified and defines the range of what the firm knows while the latter is tacit and describes the range of what the firm is able to do.

By implication, "Is/ince capabilities are an intermediate step between resources and outputs, one can hope to see the inputs that a firm uses and the outputs it achieves, but one can only infer its abilities in converting one to the other" (Dutta et al., 2005, p. 278-9). For methodology, this means that capabilities are better proxied by the technological and non-technological innovative activities of the firm (Iammarino et al., 2008, 2013).8 Following our earlier broad definition of innovation, a distinction can then be made on one hand between product- and process-related activities as technical functions to which

\footnotetext{
${ }^{6}$ The inputs could be, for instance, R\&D personnel or other forms of human capital already developed elsewhere and hired by the firm.

${ }^{7}$ It should be pointed out, though, that these authors also used the term competencies

${ }^{8}$ Note the use of the word 'proxied'. This is by no means a light-hearted connotation. Rather, it is to emphasise the idea that capabilities are intangible knowledge assets which cannot be observed directly but rather manifest in new products, processes or organisational approaches. This is the same sense in which R\&D investments or percentage of highly qualified staff are taken as proxies for absorptive capacity.
} 
a firm applies its capabilities, and on the other hand between marketing- and organisational-related activities as non-technical functions which also signal the presence of firm-level capabilities. Such multidimensional view of innovation affords a more comprehensive understanding (Carvalho et al., 2013).

\subsubsection{Two distinct modes of interaction: formal, informal}

Two modes of linkages through which interactive learning occurs can be distinguished (Souitaris, 2001); and there is evidence of a positive relationship between both types of interactions and the innovation performance of firms (Freeman, 1991). The first mode is formal collaboration with the potential knowledge source (Tether, 2002) which usually involves the signing of legally binding contracts. Examples of such would include R\&D joint ventures (Hagedoorn, 2002) or technological agreements (Hagedoorn, 1993).

The second mode is informal knowledge diffusion or information exchange. In this mode, an economic agent acts as a source of information for the firm's innovation efforts (Hagedoorn et al., 2000; Garcia-Torres and Hollanders, 2009; Tödtling et al., 2009). For instance, a firm may carry out joint R\&D with a university or another firm but it may also receive - voluntarily or involuntarily information from them about a new technology. Either of these kinds of interaction might be enough for implementing an innovation. Informal interactions are often driven by interpersonal relations rather than official communication, and admittedly, a lot of such interactions might even go unnoticed. For instance, in an extensive literature review, Freeman (1991, p. 500) noted that "Ia/lthough rarely measured systematically, informal networks appeared to be most important. Multiple sources of information and pluralistic patterns of collaboration were the rule rather than the exception."

In their discussion on open innovation, Dahlander and Gann (2010) make a distinction similar to the above. According to them, pecuniary inbound innovation describes the process of "acquiring input to the innovation process through the market place...how firms license-in and acquire expertise from outside" (p. 705). Clearly, these types of interactions are formal in nature. In contrast, non-pecuniary inbound innovation refers to the use of external sources of innovation. This is essentially informal in the sense that the parties involved do not necessarily have to agree on information sharing and thus excludes the need for fees or contractual obligations.

The foregoing distinction is central to our empirical analyses of interactive 
learning in a developing country, and is far from being perfunctory. An obvious implication of the nature of formal interactions is that in terms of costs, they will be more expensive and potentially less frequent than informal interactions (Bönte and Keilbach, 2005). Moreover, there is some evidence that informal interactions are more common and easier to manage (Pyka, 1997). Consequently, when firms operate in traditional industries where knowledge is predominantly codified and in resource-poor environments where, for instance, legal institutions are weak or financing is difficult, informal interactions may be more important (Murphy, 2002).

The distinction between formal and informal modes of interactive learning has been largely ignored in the empirical analyses of linkages/cooperation and innovation, but for a few notable exceptions like Freitas et al. (2011) and Bönte and Keilbach (2005). Some studies in developing countries (e.g., (Oyelaran-Oyeyinka, 2007; Goedhuys, 2007b; Iammarino et al., 2008) clearly distinguish between local and foreign linkages. Yet, the specific format of the linkages is left unexplored. Moreover, informal interaction between firms and universities has received much attention in the literature (Hagedoorn et al., 2000) perhaps because it seems more commonplace (Rosenberg and Nelson, 1994). This has invariably led to a neglect of informal interactions between industry and other types of partners within an innovation system. In addition, most analyses are limited to products and processes at the expense of non-technological innovation in marketing and workplace organisation which also can benefit from external knowledge.

These gaps are especially pronounced in the literature on developing countries mostly due to data limitations. The recent innovation surveys in Africa now offer opportunities for these kinds of analyses. In this chapter and the next one, an attempt is made to address the gaps with data from an innovation survey in Nigeria.

\subsubsection{Learning and innovation in developing countries}

In developing countries, innovation is often perceived to take place when products and processes that are new to a country or to an individual enterprise are commercially introduced, irrespective of whether they are new to the world (UNCTAD, 2007). Clearly, the acquisition and mastery of technologies developed elsewhere plays a crucial role in this process 9 Consequently,

\footnotetext{
${ }^{9}$ How important a role technology diffusion plays in latecomer contexts is open to debate. On the one hand, there is the notion that a large proportion of innovative changes in late-
} 
minor and incremental changes, including innovative approaches to organisation and marketing, are a major part of innovation in developing countries (Dahlman et al., 1987). In particular, marketing and organisational innovations are of major importance for firms in this context (OECD, 2005).

One of the main differences between firms in developed and developing countries is the costly nature of innovation. In backward economies it is much more difficult to find sufficient financial, knowledge and institutional support for innovation (Schmitz, 1982). In the specific case of Nigeria, Biggs et al. (1995) noted that the context for manufacturing is of a harsh economic and institutional nature. One specific way by which firms substitute for their resource deficiencies is through networking. In an earlier study, we found that among all the potential sources of innovation information, the sectoral network institution created by the firms themselves particularly supported technological learning and innovativeness (Egbetokun et al., 2010). In Tanzania, the evidence presented by Goedhuys (2007a) showed that collaboration can support innovation in local firms in developing countries, even when they invest less in new machinery, training and R\&D. In particular, these firms prove to be more embedded in the domestic industrial structure and also source information from the Internet. Furthermore, in a comparative study of two enterprise clusters in Nigeria, Oyelaran-Oyeyinka (2005) reported that informal collaboration among enterprises (induced mainly by competitive forces) grew over time.

It is therefore without question that networking is important for innovation, and even more so in developing countries. However, the relationship between different networking strategies and innovation types is still under-explored. Furthermore, the evidence on the benefits of external interaction is not conclusive, even for developed countries. For instance, while there are empirical studies suggesting that firms become better at innovating as they use more external knowledge sources (Leiponen and Helfat, 2010), there are also some suggesting that internal knowledge sources rather than external are more likely to be effective in increasing innovation performance (Frenz and letto Gillies, 2009). Nonetheless, the literature seems to agree that in both developed and developing countries, the innovation activities of firms are strongly determined by relations between themselves and their suppliers and customers (Laursen and Salter, 2006; Goedhuys, 2007a, b). In a sense, this challenges

comer economies derive from the adoption, diffusion and adaptation of imported technologies (Bell and Pavitt, 1993). On the other hand, it has recently been argued that technology adoption and diffusion may play a more limited role in driving innovation and growth in African manufacturing that is currently believed (Fafchamps and Söderbom, 2013). 
the policy emphasis that has been placed on university-industry interactions. While research-industry linkage is undoubtedly important (Oyewale, 2010), its role in innovation within developing countries like Nigeria may be more limited than is currently believed.

\subsubsection{Interactive learning and capability accumulation}

The development and strengthening of technological capabilities occurs via the process of technological learning (Bell and Pavitt, 1993). Technological learning is a costly process (Figueiredo, 2002b) and requires complex interactions among firms and other economic agents within specific institutional frameworks and geographical boundaries (Lundvall, 1992; Edquist, 1997). This notion is central to evolutionary perspectives of technological learning and innovation systems (Lundvall et al., 2002, 2009; Malerba, 2002; Malerba and Mani, 2009). It is maintained that firms do not innovate in isolation, even if they want to. No single firm can possibly possess all the knowledge and capabilities required to innovate. There will always be certain inputs into the innovation process, especially knowledge and capabilities, which the firm does not possess in-house. Such missing inputs are typically sought outside the boundaries of the firm. Besides, the process of technological learning and capability building is highly context-specific and path-dependent; nascent institutions and what the firm already knows play key roles in defining the rate and direction of capability build-up and possible technical change.

In developed countries where advanced in-house capabilities are pervasive, it is not unusual for firms to thrive on the production and use of codified scientific and technical knowledge. However, given the systemic nature of innovation, it is believed that in addition to in-house $R \& D$, firms need to form linkages with several external sources of knowledge. Such linkages are necessitated by the fact that no single firm can possibly possess all the knowledge and capabilities required to innovate. Therefore, as part of the innovation process, firms need to engage in a search for complementary knowledge and capabilities beyond their boundaries (Chesbrough, 2003b). However, market failures make the market transactions of such knowledge and capabilities very difficult (Mowery et al., 1998; Pisano, 1990). The formation of linkages - either formal or informal - to external knowledge sources helps firms to solve some of the problems and to improve their efficiency by pooling resources and accessing complementarities (Belderbos et al., 2004; Cassiman and Veugelers, 2006).

Several studies present results from different industries and countries suggest- 
ing that the search for and use of external knowledge indeed enhance firm-level innovativeness. Freitas et al. (2011) in a cross-country analysis, showed that the formation of formal and informal linkages with external knowledge sources is beneficial for firm-level technological performance. In his seminal works, von Hippel $(1988 ;$ 2005) documents extensive empirical evidence on the role of users and suppliers in the innovation process. Chesbrough's (2003a) 'open innovation' model is based on the idea that a firm needs to learn from a wide range of external knowledge sources to complement its in-house innovative knowledge. Jensen et al. (2007), in an analysis of Danish firms, noted that science-based learning needs to be complemented with learning by doing, using and interacting (DUI). Firms combining the two modes were shown to be more likely to innovate new products or services than those relying primarily on any one mode. Based on an empirical analysis of American manufacturing firms, Malerba (1992) argued that technological learning is the bedrock of incremental technical change. He showed particularly that firms accumulate knowledge capital through a variety of internal and external learning processes which include learning by doing, using and interacting.

Undoubtedly, it is widely accepted that external knowledge sourcing significantly influences the technological learning process. This is true in both developed and developing countries alike (Freeman and Soete, 1997). Specifically, Goedhuys et al. (2008) present evidence from Tanzania on the particular importance of informal market institutions, especially business associations, in enhancing firm-level productivity. For a sample of Nigerian manufacturing firms, Oyebisi et al. (1996) and Oyelaran-Oyeyinka (2006a) report extensive collaboration among firms and weak research-industry collaboration. In his study of manufacturing firms in a Nigerian cluster, Oyelaran-Oyeyinka (2005) found that the firms feel compelled to collaborate not only as a means of intra-cluster learning but also to overcome external competition. Regular horizontal relationship between suppliers, traders and subcontractors in Nigerian clusters have also been reported (Adebowale and Ovelaran-Ovevinka, 2012). Goedhuys (2007b), based on a sample of Tanzanian manufacturing firms, reported that the local firms are resource-poor and hence could only invest little in training and research, development and design activities than their larger or foreign counterparts. These disadvantages are, however, offset partly through embeddedness in the local industrial structure via collaboration with other local actors. Both local and global interaction were found by Iammarino et al. (2008) to be associated with firm-level technological capabilities in the electronics industry in Mexico. In his analyses of the largest steel firms in Brazil, Figueiredo (2002a, 2003) showed that the search for external knowledge is a 
significant part of the technological learning process. Goedhuys and Veugelers (2012), based on an analysis of Brazilian manufacturing firms, demonstrated that successful product and process innovation occured mostly through acquisition of embodied technology often in combination with internal technological efforts; relying only on internal knowledge was shown to be less effective.

Indeed, latecomer firms traditionally lack significant in-house scientific capacities and a large proportion of them actually rely on technologies acquired from more advanced countries (Figueiredo, 2002a; Oyelaran-Oyeyinka, 1997). Learning by doing and using 10 , i.e the use, mastery, adaptation and modification of embodied technologies, are therefore particularly important for these firms (Bell and Pavitt, 1993). In a study of the Indian manufacturing industry, Aggarwal (2000) noted that external technology plays two crucial roles in developing countries: providing the basis for upgrading of existing local technologies to international standards and plugging holes in the domestic technological capability. The firms can also build up their technological capabilities through interactive learning by forming linkages with other actors (such as customers, suppliers and universities) within the domestic innovation system (Lundvall, 1988). Interactive learning is beneficial for latecomer capability building in many ways: in disseminating information about innovations, lowering transaction costs, increasing the potential for the division of labour between enterprises and fostering collective action (Barr, 2002).

\subsubsection{Absorptive capacity and capability accumulation}

The acquisition of external knowledge does not guarantee successful technological learning. This is due, in part, to the generally tacit and dynamic nature of technological knowledge, making it difficult or very costly to effectively communicate the full range of skills and knowledge required for executing complex tasks. To effectively understand and deploy acquired knowledge, firms require a complementary in-house stock of knowledge - an absorptive capacity, which typically derives from internal R\&D efforts (Cohen and Levinthal, 1989) and human capital (Hoffman et al., 1998; Romijn and Albaladejo, 2002).

Besides facilitating the assimilation of external knowledge, absorptive capacity also significantly enhances a firm's knowledge-creating ability. The ease, rate and efficiency with which a firm can make something new depends a lot on

\footnotetext{
${ }^{10}$ The ideas of learning by doing and learning by using are by no means new. Arrow $(1962 \mathrm{~b})$ is credited with popularising learning by doing into the economic literature while Rosenberg (1982) is credited with learning by using.
} 
its existing knowledge stock, which, in turn, is enhanced as the firm innovates (Lane et al., 2002).

In developing countries where private basic R\&D is not common (Ilori et al., 2000), a major part of absorptive capacity develops through practical problemsolving and experimentation on the shop floor as well as more narrowly focused applied R\&D (Dahlman et al., 1987; Romijn, 1997). The role of the development of human capital through investments in formal and informal training has been especially emphasised (Wignaraja, 2002; Bell, 1984) 11 This is particularly important since most developing country firms are in traditional manufacturing and services - industries that are essentially mature - and do not operate close to the technology frontier.

Innovation in these contexts tends to thrive on imported technologies and as such does not rely as much on basic R\&D as it does on assimilation of embodied technology. For this, the least costly type of absorptive capacity, which does not rely much on internal $R \& D$ but rather on knowledge embedded in tools and processes, is of the highest relevance. This is what Lim (2009) labeled encoded absorptive capacity, the development of which requires "internal efforts aimed at rapidly acquiring and integrating knowledge already encoded by others" (p. 1277).

The foregoing observation is also reflected in AU-NEPAD (2010, p. 82) that innovation "can and does happen without the need for in-house RED within the firm, but this raises questions about the source of the knowledge supporting the creation of value in the firm." In this chapter and the next, the aim is to shed light on the role of domestic sources of knowledge outside the boundaries of the firm in the innovation process.

\subsection{The Empirical Context}

\subsubsection{The socioeconomic environment}

In a study of firm-level capabilities and innovation in sub-Saharan Africa, Nigeria is an attractive case given its large population and economic importance in the sub-continent. With a GDP of $\$ 145$ billion in 2006 and $\$ 244$ billion in

\footnotetext{
${ }^{11}$ Almeida and Carneiro (2009) showed that on-the-job training is a good investment which tends to yield comparable returns (approximately 8.6\%) to either investments in physical capital or schooling.
} 
2011 (World Bank, 2013), it is one of the largest economies in Africa. With a population estimate of almost 160 million (UN-DESA, 2013) as well as GDP and GNI per capita, in purchasing power parity, that have roughly doubled in the last one decade (World Bank, 2013), it is arguably the largest market in Africa.

\subsubsection{Trade and industrial structure}

The market potential is mostly not realised partly due to the resource-based nature of the economy and the concentrated structure of the nation's international trade. For instance, the economy is apparently over-exposed to external shocks given that the trade to GDP ratio, which was only about $46 \%$ in 1980 , had risen to about 78\% in 2003 (Chinedu et al., 2010). Besides, trade is concentrated heavily on primary products. The value of total exports in 2007 comprised $98 \%$ minerals (mostly crude oil) 12 and over $50 \%$ of total imports value comprised foods, beverages and processed industrial supplies (NBS, 2010), making the country a net importer of food and consumer products.

The private sector in Nigeria comprises a large informal component and a comparatively small formal component. The formal component in both manufacturing and services consists of a few very large firms and a large number of small and medium enterprises. However, when compared with services, the manufacturing sector appears to be more organised. For instance, while the manufacturing sector has a central association, the Manufacturers Association of Nigeria (MAN), and several sectoral associations, no such central association exists in the service sector although there are a few sectoral associations as well. At the time the data used in this thesis was collected, MAN was self-organised into ten sectoral groups comprising a total of 75 sub-sectors and 1 export group. Membership of the export group included all firms that sell their products outside Nigeria. This kind of self organisation is less developed in the service sector.

\footnotetext{
12 By the end of 2010, crude oil earnings accounted for $80 \%$ of foreign exchange (NBS, 2010) but a very low proportion of employment is attributed to the petroleum sector (Chinedu et al., 2010).
} 


\subsubsection{The business environment}

Several studies discuss extensively the business environment and the challenges of private sector firms, especially in manufacturing, in Nigeria. For instance, using data from the World Bank Enterprise Surveys, Radwan and Pellegrini (2010) showed in an international comparison of eight mostly developing countries that Nigerian firms faced the worst electricity constraints in 2006. More than $90 \%$ of Nigerian firms had experienced power outages during that year, compared with $21 \%$ in Venezuela. In addition, they identified finance and transport as major constraints which, in combination, lead to high production costs in the country.

Due to its highly infrastructure-dependent nature, the effects of poor infrastructure on manufacturing are more pronounced. The majority of Nigerian manufacturing firms perceive physical infrastructure and access to credit as their most pronounced problems (Söderbom and Teal, 2002). According to Radwan and Pellegrini (2010, p. 20), "the manufacturing sector in Nigeria has to bear additional indirect costs up to 16 percent of sales because of bottlenecks in the business environment. Losses due to power outages amount to 10 percent of sales, while production lost while in transit (4 percent of sales) is also significant." Consequently, although the domestic market is large, demand for local manufactures is not guaranteed as firms are continuously faced with pressure from foreign products which are often cheaper.

Besides, the business registration process is comparatively long, expensive and often corrupted (World Bank and International Finance Corporation, 2006) 13 Many firms therefore prefer to remain in the informal sector, partly to avoid the burden of the formalisation process and partly to also avoid the responsibilities such as taxation and regulation that come with being in the formal sector.

\subsubsection{The innovation environment}

Nigeria's innovation environment is similar to that of most other developing countries where the majority of firms do not perform basic R\&D into new products and processes, innovation is mostly incremental in nature and the

\footnotetext{
${ }^{13}$ Reviewing several iterations of the World Bank Doing Business Report, Davis and Kruse (2007, p. 1102) pointed out the initial conclusion of regulation in developing countries being more cumbersome, even sometimes completely outdated, in all aspects of business activity
} 
business environment is a major obstacle to firm performance 14 The national innovation system is weak and fragmented; research-industry linkage is nearly non-existent and many institutions needed for innovation-including venture capital, legal institutions and science and technology parks - are either underdeveloped or entirely missing (Ovelaran-Oyevinka et al., 1996; Ovebisi et al., 1996; Oyewale, 2010).

However, the constraints do not imply the absence of technological capabilities or interactive learning. In fact, as noted by Oyelaran-Oyeyinka (2005) and Fafchamps (2001), overcoming some of the "holes" in the business environment is one of the incentives that drive the formation of external linkages. For instance, in some sectors, the self-organised industry associations function as pressure groups, provide a platform for inter-firm learning and help in enforcing contracts (Egbetokun et al., 2012), ultimately 'supplanting the state' by making up for the failure of government institutions (Ovelaran-Ovevinka, 2007). This is consistent with the observations of Biggs and Shah (2006) on small and medium-sized firms in sub-Saharan Africa. According to them, these firms "get around market failure and the lack of formal institutions protecting property rights and contracts by creating private governance systems in the form of long-term business relationships and networks, as firms do in other parts of the world" (p. 3045). Several other studies (e.g., Schmitz, 1995) have highlighted the importance of externalities that derive from these types of networks. Particularly in Africa, their roles as a source of technical expertise, as facilitators of credit or market access and as conduits for information exchange has been highlighted (Barr, 2000; Fisman, 2001).

However, firms' participation in these networks is often optional and thus, they are limited in scope and authority. Consequently, the effects of unfavourable macroeconomics conditions such as weak legal institutions and poor contract enforcement on the private sector are not entirely mitigated and still contribute to a high failure rate (Africa Vanguard, 2009).

\subsubsection{Industrial performance indicators}

The challenges discussed above apparently reflect in the performance of the manufacturing sector. According to official figures from the National Bureau

\footnotetext{
${ }^{14}$ See Hadjimanolis (2000, p. 236) for a discussion of contextual differences between developed and developing countries, and Bigsten and Söderbom (2006) for a discussion of the specific situation in African countries. For more general discussions on developing countries, see Schmitz (1982) and Niosi (2002, 2010).
} 
of Statistics (NBS, 2010), most of the GDP in 2007 came from agriculture (about 42\%), service (about 27\%) and crude oil (about 20\%) while manufacturing contributed only about $4 \%$. In the last one decade, manufacturing value added averaged around 3\% of GDP, far below the 13\% average in sub-Saharan Africa. Over the same period, the ratio of manufactured exports (an average of about $3 \%$ of total merchandise exports) far exceeded that of imports (average of over $70 \%$ of merchandise imports). For instance, in 2006, manufactured exports were only about $1 \%$ of merchandise exports while imports were over $70 \%$ (World Bank, 2013).

\subsubsection{Implications for the study}

The characteristics of the research context does have some implications for the empirical design and the expected results. As already explained, innovation is defined rather broadly to capture new-to-firm technical change which is expected to be a major part of what the firms do. Also, in place of R\&D as a proxy for the firm's internal knowledge accumulation efforts, staff training and innovation budget - which includes mostly expenses made into non-R\&D innovation activities - are used.

With regards to the results, it is expected that market sources of knowledge (e.g., customers, suppliers and other firms) will be more dominant. Also, turning to external sources will show a positive association with firm-level capabilities but informal interactions should be more influential. Moreover, we expect to observe variations with respect to different types of capabilities. For instance, the strongest association of informal interactions should be with organisational or marketing innovative activities while the strongest association of formal interactions should be with either product or process capabilities.

\subsection{Data and Econometric Methodology}

\subsubsection{The database}

The data used in this chapter came from a survey of Nigerian manufacturing firms implemented at the end of 2007. The sample comprised 250 firms (with a response rate of $68 \%$ ) selected randomly from the ISIC 3-digit industry classes 
10 to 31 . The survey included only firms that had at least 10 employees, and the firms reported for the 2003-2006 period 15

The survey questionnaire asked firms directly whether they had been able to introduce an innovation during the specified period or whether they had abandoned it at some point after they had started. Table 2.2 provides a list of the questionnaire items. Innovation is defined broadly to include changes in products, production processes, marketing approaches or organisational practices (UNU-INTECH, 2004). The basic requirement for any of these changes to be regarded as innovative is newness to the firm.

Twelve possible collaboration partners were listed in the survey instrument: competitors, customers, suppliers, associated companies within a firm's corporate group, consulting and marketing firms, private research institutes, public research institutes, universities or other higher education institutions, government ministries, financial institutions, training institutions and industry associations. One question asked firms to indicate whether or not they engaged in collaboration or any form of joint activity with each of these actors ( 1 if yes and 0 otherwise). In another question, nine possible external sources of information were listed in the survey instrument and each firm was asked to indicate the degree of use of each source. An unused source had a score of zero.

\subsubsection{Measures}

Table 2.1 contains a summary of all the variables used in the estimations. Although there are a few significant correlations, the coefficients are too low to imply serious multicollinearity problems. The average variance inflation factor of 1.2 and condition number of 9.13 are well below the acceptable limits and suggest that there are no severe multicollinearity problems among the variables (O'Brien, 2007). Of special interest is the low correlation between the variables capturing the two different modes of interactive learning. While it is possible that the questionnaire items for the two variables have elicited the same information from the respondents, the very low association between them suggests otherwise. A description of the variables follow.

\footnotetext{
${ }^{15}$ Details on the survey methods and data are available in NACETEM (2010). A general comment on the representativeness of the sample: it is generally difficult to plan a stratified sample in the research context (Adeoti, 2012) but the survey attempted this based on the MAN list of establishments.
} 
Table 2.1: Description of independent variables

\begin{tabular}{|c|c|c|c|c|c|c|c|c|c|c|c|}
\hline \multirow[b]{2}{*}{ Variable name } & \multirow[b]{2}{*}{ Description } & \multirow[b]{2}{*}{ Median } & \multirow[b]{2}{*}{ Mean (SD) } & \multicolumn{8}{|c|}{ Correlation } \\
\hline & & & & FORMAL & INFORMAL & AGE & OWNERSHIP & STRUCTURE & TRAINING & ICT & INNO_BUDG \\
\hline FORMAL & $\begin{array}{l}=1 \text { if the firm engages in joint } \\
\text { activity with any of } 12 \text { listed } \\
\text { actors }\end{array}$ & 1.00 & $0.78(0.41)$ & - & & & & & & & \\
\hline INFORMAL & $\begin{array}{l}=1 \text { if the firm uses any of } 9 \\
\text { listed external knowledge } \\
\text { sources }\end{array}$ & 1.00 & $0.55(0.49)$ & $0.29^{*}$ & - & & & & & & \\
\hline OWNERSHIP & $\begin{array}{l}\text { Categorical indicator of } \\
\text { ownership shares by domestic } \\
\text { or foreign individuals, firms or } \\
\text { government }\end{array}$ & 1.00 & $2.09(1.87)$ & 0.05 & 0.04 & 0.05 & - & & & & \\
\hline $\begin{array}{l}\text { MANAGE- } \\
\text { MENT }\end{array}$ & $\begin{array}{l}\text { Log. of the number of levels } \\
\text { in the firm's organisational } \\
\text { structure }\end{array}$ & 1.09 & $0.93(0.83)$ & $0.18^{*}$ & 0.08 & 0.14 & $0.17^{*}$ & - & & & \\
\hline INNO_BUDG & $\begin{array}{l}=1 \text { if the firm has a separate } \\
\text { budget for innovation }\end{array}$ & 1.00 & $0.52(0.50)$ & $0.20^{*}$ & -0.01 & 0.02 & 0.08 & 0.06 & $0.23^{*}$ & $0.16^{*}$ & - \\
\hline
\end{tabular}

Note: ${ }^{*} p<0.05$. Average variance inflation factor $=1.2$. Condition number $=9.13$. No. of observations $=170$. 


\section{Dependent variables}

The questionnaire items (Table 2.2) allow a distinction between four different types of capabilities according to the conceptual framework: product, process, marketing and organisational. The relevant items were summed up and dichotomised to create indicators for each type of capability. A dichotmised sum of the four binary measures provided an overall indicator of capabilities. These measures implicitly assume that all the functions have equal importance. On the one hand, this is consistent with previous research (Wignaraja, 2002; Molina-Domene and Pietrobelli, 2012). On the other hand, since the focus of this chapter is on whether or not a firm possesses capabilities and not on the level of capabilities, these simple measures seem appropriate.

\section{Independent variables}

The explanatory variables were constructed as follows. The variable FORMAL is a binary variable indicating whether or not a firm collaborated with any actor during the reference period. The binary value was obtained from dichotomising the sum of the scores on all the twelve questionnaire items relating to collaboration. In other words, all scores greater than or equal to 1 were recoded as 1 . The variable INFORMAL captures whether or not a firm had made use of any external knowledge sources. Its construction, using the nine questionnaire items relating to external information sources, is similar to that of FORMAL.

\section{Control variables}

As suggested in the literature, the age of a firm (Balasubramanian and Lee, 2008; Hansen, 1992) and its management (van der Panne et al., 2003) affect its innovation potential. AGE was measured as the logarithm of the age of the firm in 2006. In order to account for the non-linear relationship between age and the likelihood of innovation that has been reported earlier in the literature (Huergo and Jaumandreu, 2004), the quadratic term $\mathrm{AGE}^{2}$ was included in the estimations. The measure MANAGEMENT was created as the logarithm of the number of hierarchical levels in the firm's organisational structure. The underlying intuition is that decentralised organisations have less bureaucratic bottlenecks (and, thus, faster decision-making processes), making them more effective in realising their goals (Zheng et al., 2010). How- 
ever, speed in the decision-making process can sometimes be detrimental as it makes the firm prone to errors and to overlooking opportunities especially in a resource-poor environment. To account for this potential non-linearity, the quadratic term of MANAGEMENT was also included in the analyses. Also included were other variables like ownership (Aralica et al., 2008) and training (Romijn and Albaladejo, 2002), which have been identified as also affecting the potential for innovation. Control for firm ownership was included as a categorical variable (OWNERSHIP). This variable captures the different types of ownership, coded from 1 to 7 in the following order: domestic private ownership, domestic public ownership, ownership by a foreign corporation, ownership by a foreign individual, joint ventureship or private limited liability. Dummy variables were included for whether the firm had implemented any staff training (TRAINING) programmes during the reference period and possessed a separate budget for innovation (INNO_BUDGET). These two factors can be thought of as potentially contributing positively to a firm's absorptive capacity and productivity (Adebowale and Oyelaran-Oyeyinka, 2012). The use of the Internet for business purposes (ICT) was also controlled for, because in the context of developing countries, the adoption of new technologies such as the Internet is seen as an important way for firms to enhance or augment their capabilities (Ovelaran-Oyeyinka and Lal, 2006). Besides, information and communication technologies are an important means by which firms can rapidly access and exchange information (Pyka, 1997), which is partly why Freeman (1991, p. 509) referred to them as "networking technologies par excellence."

\subsubsection{Estimation issues}

Before proceeding with the econometric methodology, some caveats should be mentioned. First, the cross-sectional nature of the data has some important implications. The analyses are confined to the knowledge acquisition process; knowledge conversion and exploitation can unfortunately not be explored. Nonetheless, this constraint appears less limiting once it is noted that knowledge needs to be internalised before it can be converted. Moreover, the analyses reveal very little about the direction of causality. While it is true that capability accumulation is an outcome of learning processes, it may also be that firms with already high levels of capabilities are more likely to form linkages. Thus, the results should be taken as implying association and not causality. Nevertheless, it can be argued that firms form linkages for the purpose of accumulating capabilities and not the other way round, hence the dependent and 
independent status of the main variables. Second, since the data comes from a survey and not case studies, it is not possible to shed much light on firms' internal processes that constrain or facilitate learning and capability accumulation. Notwithstanding, the analyses provide insight on aggregate learning behaviour and the capabilities possessed by Nigerian firms.

Given the binary nature of the dependent variables, discrete choice models were employed to estimate their response to the explanatory variables 16 First, a logit model was estimated to relate overall technological capabilities with interactive learning 17 In analysing the four capability types, some methodological issues need to be dealt with. Estimating models for the whole sample will be confronted with a zero-inflation problem. Two types of zeros are present in the variables for each innovation type: firms that did not innovate at all and firms that did not implement the innovation type in question. This is overcome by analysing only the subsample of innovative firms. However, the non-innovators cannot simply be deleted from the analyses as this potentially introduces a selection bias. To avoid this, the analyses were done in two stages.

In the first stage, a probit model was estimated for the probability of a firm being innovative. To control for endogeneity in the dependent variables, a simultaneous system of four probit equations was estimated in the second stage 18 The first stage equation included a set of variables inspired by previous research (Vega-Jurado et al., 2009; Molina-Domene and Pietrobelli, 2012). Firm age and dummies for having an innovation budget and staff training were included. In addition, a measure for innovation obstacles faced by the firms was constructed and included to take into account difficulties associated with the innovative efforts of the firms 19 The results of the first stage probit are contained in Appendix A.3. The second stage estimation excluded the noninnovators but included the predicted probability, PR(INNOVATE), from the first stage model. This two-stage approach - applied in earlier studies like Vega-Jurado et al. (2009) and Haas and Hansen (2005) - is suitable when the selection outcome, in this case, the binary measure of overall capabilities, is observed and not estimated 20

\footnotetext{
${ }^{16}$ See Greene (2002) for a discussion of these types of models.

${ }^{17}$ Appendix A.1.1 contains details.

${ }^{18}$ See Appendix A.1.2 for details. This approach is an improvement over separate logit estimations applied in some recent studies (e.g., Carvalho et al., 2013). A similar method has been used by, among others, Schmidt (2010).

${ }^{19}$ See Appendix A.2 for details on this measure.

${ }^{20} \mathrm{~A}$ Heckman probit selection model is not applicable because it does not permit simultaneous equations in the second stage.
} 


\subsection{Econometric Results}

\subsubsection{Patterns of capabilities and interactive learning}

Of the 170 firms in the sample, about $84 \%$ had carried out at least one innovative activity during the 2003-2006 reference period (Table 2.2). Of these, about $89 \%$ had been involved in formal cooperation or joint action with one or more actors against only $29 \%$ of non-innovators. About $63 \%$ of the innovative firms informally interacted with external sources of knowledge in their innovative efforts as opposed to only $19 \%$ of non-innovators. Bearing in mind that the innovative activities signal the firm's level of capabilities, these results suggest a strong association between interactive learning and the build-up of technological capabilities by the firms. In the next section, this relationship is further examined in a multivariate framework. The rest of this section concentrates on describing the patterns of technological capabilities and external sources of knowledge among the sampled firms.

As shown in Table 2.2, the firms display a relatively high rate of innovation, particularly in products and processes. These results are in keeping with Goedhuys (2007b); firms in latecomer economies are indeed capable of accumulating sufficient technological capabilities that manifest in innovative efforts. This, of course, follows the broad definition of innovation that is applied. A narrower definition is likely to dismiss many of the efforts as merely imitative. Such approaches have, however, been criticised for their limited relevance for policy and practice in developing countries (Mytelka, 2000).

The high rate of innovation is probably explained by the recent expansion in the domestic market. Apart from an increasing population and potential workforce, both GDP and GNI per capita, in purchasing power parity, have roughly doubled in the last one decade (World Bank, 2013). Also, coping with competition from foreign imports may have created some sort of innovation pull on the firms. Since product changes are often accompanied with changes to processes, the concomitant high extent of process capabilities is to be expected. Concurrently, marketing and organisational changes are required to capture new customers, keep existing ones and accommodate higher intensity of workflows.

The pattern of the collaboration among the sampled firms is detailed in Table 2.3. from which the apparent importance of customers and the weak connection between firms and institutional organisations like research institutes and educational institutions are evident. The results for the entire range of 
Table 2.2: The indicators of technological capabilities

\begin{tabular}{|c|c|c|c|}
\hline \multirow[t]{2}{*}{ Variable } & \multirow[t]{2}{*}{ Items } & \multicolumn{2}{|c|}{$\begin{array}{c}\text { Percentage } \\
(\mathrm{n}=170)\end{array}$} \\
\hline & & Success & Abandoned \\
\hline \multirow[t]{4}{*}{ Product } & Introduced new product & 49.4 & 0.6 \\
\hline & Improved an existing product & 59.4 & 0.6 \\
\hline & Developed a new product & 41.8 & 1.2 \\
\hline & Total & 70.0 & \\
\hline \multirow[t]{5}{*}{ Process } & Introduced new process & 52.4 & 0.6 \\
\hline & Improved an existing process & 51.8 & 1.2 \\
\hline & Developed a new process & 44.1 & 1.2 \\
\hline & Modified licence & $69.1^{*}$ & - \\
\hline & Total & 72.9 & \\
\hline \multirow[t]{4}{*}{ Marketing } & Introduced a new marketing technique & 39.4 & 8.2 \\
\hline & Entered a new domestic market & 25.3 & 15.3 \\
\hline & Entered a new market abroad & 12.4 & 14.1 \\
\hline & Total & 45.3 & \\
\hline \multirow[t]{6}{*}{ Organisational } & Changes in management routine & 32.4 & 1.2 \\
\hline & Introduced new quality control methods & 40.0 & 16.5 \\
\hline & Introduced maintenance routines & 37.7 & 12.4 \\
\hline & Changed plant layout & 20.6 & 18.2 \\
\hline & Introduced waste management procedures & 31.2 & 12.4 \\
\hline & Total & 58.8 & \\
\hline Overall Total & & 84.1 & \\
\hline
\end{tabular}


informal knowledge sources for Nigerian manufacturing firms (Table 2.4) indicate that the most important sources are customers, then suppliers. Alongside these, a range of other sources, such as industry associations and fairs and exhibitions, are among the key sources of knowledge for capability building. Notable is the fact that institutional sources are among the least important sources of knowledge to the firms. These results indicate, as expected, that market sources dominate in the firms' interactive learning activities. The reasons for this are not far-fetched. Embeddedness in the local industrial and market structures helps firms in developing countries to overcome many of the constraints to the capability-building process (Barr, 2000; Fisman, 2001; Ovelaran-Oyevinka, 2007, 2005; Goedhuvs, 2007b) and compensate for the failure of the state (Oyelaran-Oyevinka, 2006a).

Table 2.3: Pattern of collaboration in Nigerian manufacturing firms, 2003-2006

\begin{tabular}{lccc}
\hline & \multicolumn{3}{c}{ Percentage } \\
\cline { 2 - 4 } Collaboration partners & $\begin{array}{c}\text { All firms } \\
(n=170)\end{array}$ & $\begin{array}{c}\text { Innovators } \\
(n=143)\end{array}$ & $\begin{array}{c}\text { Non-innovators } \\
(n=27)\end{array}$ \\
\hline \hline Customers & 55.2 & 62.9 & 14.8 \\
Marketing Firms & 45.3 & 51.1 & 14.8 \\
Associated Companies & 44.1 & 51.1 & 7.4 \\
Private Research Institutes & 36.5 & 42.0 & 7.4 \\
Suppliers & 35.9 & 39.9 & 14.8 \\
Competitors & 34.7 & 40.6 & 3.7 \\
Industry Associations & 34.7 & 40.6 & 3.7 \\
Financial Institutions & 31.2 & 37.1 & 0.0 \\
Public Research Institutes & 30.0 & 35.0 & 3.7 \\
Training Institutions & 28.8 & 33.6 & 3.7 \\
Government Ministries & 24.7 & 28.7 & 3.7 \\
Higher Education Institutions & 24.1 & 28.7 & 0.0
\end{tabular}

Note: Multiple response items. The survey questionnaire asked firms to indicate whether they "engaged in any formal form of cooperation or joint activity" with any of the listed actors.

There are demand-side and supply-side explanations for the weak researchindustry connection. On the one hand, the relatively weak connection between firms and research-based sources might be linked to low levels of absorptive capacity in the firms and the level of difficulties associated with their innovation efforts. It is plausible that the firms do not rely much on universities and research institutions because they may find it difficult to appropriate scientific knowledge. Moreover, the innovation types in Nigerian firms, as captured in 
Table 2.4: Sources of information for innovation in Nigerian manufacturing firms, 2003-2006

\begin{tabular}{|c|c|c|c|c|c|}
\hline \multirow[b]{2}{*}{ Information Sources } & \multirow[b]{2}{*}{ Mean Rank } & \multicolumn{4}{|c|}{ Percentage $(n=143)$} \\
\hline & & $\begin{array}{c}\text { Very } \\
\text { Important }\end{array}$ & $\begin{array}{l}\text { Moderately } \\
\text { Important }\end{array}$ & $\begin{array}{c}\text { Not } \\
\text { Important }\end{array}$ & Not Used \\
\hline Customers & 1.62 & 46.9 & 9.8 & 2.1 & 41.3 \\
\hline Suppliers & 1.29 & 30.1 & 16.1 & 6.3 & 47.6 \\
\hline Industry Associations & 1.24 & 27.3 & 18.9 & 4.2 & 49.7 \\
\hline Fairs and Exhibitions & 1.22 & 22.4 & 23.8 & 7.7 & 46.2 \\
\hline Government Ministries & 1.17 & 21.7 & 23.1 & 6.3 & 49.0 \\
\hline $\begin{array}{l}\text { Professional Journals } \\
\text { and Trade }\end{array}$ & & & & & \\
\hline Publications & 1.17 & 22.4 & 22.4 & 5.6 & 49.7 \\
\hline Consulting Firms & 1.15 & 21.0 & 23.1 & 5.6 & 50.3 \\
\hline $\begin{array}{l}\text { Educational and } \\
\text { Research Institutions }\end{array}$ & 1.11 & 24.5 & 16.1 & 5.6 & 53.8 \\
\hline Client Firms & 1.05 & 23.8 & 13.3 & 7.0 & 55.9 \\
\hline
\end{tabular}

Note: Multiple response items. Percentages sum up to 100 across rows. The survey questionnaire asked firms to rate "the importance of the [listed] sources of information for [their] innovation". Only the innovationactive firms were included in this table.

this study, broadly include imitation and incremental changes that do not necessarily rely on science. On the other hand, the weak connection may be due to systemic characteristics, as suggested earlier by Frenz and letto Gillies (2009). Considering the huge costs of $R \& D$, which are usually beyond the reach of most firms in developing countries, it stands to reason that firms will source new knowledge from publicly funded universities and research institutes. However, most of these organisations, at least in the Nigerian context, are poorly funded and often themselves dependent on foreign donors. Thus, their output may not necessarily be relevant to domestic industrial needs.

Moreover, a huge communication gap may exist between the research and the industrial sector due to the cultural and methodological incongruence between them. For instance, firms are typically uncomfortable with the open dissemination of research results, which is completely normal for researchers (Fontana et al., 2006). In addition, in several universities, the curricula are outdated, so the teaching and research fall far behind industry in time. There is also a difference in the research motivations. Firms typically prefer research targeted towards profit, while research organisations typically concen- 
trate more on advancing the frontier of knowledge.21 Specifically, until very recently, in Nigeria the largest and best universities and research organisations were publicly (even if poorly) funded, so their research objectives do not necessarily coincide with the profit-oriented demands of industry.

\subsubsection{Estimation results and discussion}

Before turning to the estimation results, it is instructive to recall the expected results. On the overall, informal linkages should show a stronger positive correlation with firm-level capabilities. However, relative to the non-technological capabilities, stronger correlations are expected between formal linkages and product- and process-related capabilities. The converse is expected for informal linkages.

\section{Interactive learning and firm-level capabilities}

The results of the estimations to assess the relationship between interactive learning and technological capabilities are reported in Table 2.5. The marginal effects show difference in probabilities while the odds ratios compare the probabilities of a firm innovating conditional on the respective independent variable. Formal interaction is associated with an increase of $12 \%$ in the probability of innovating while informal interaction is associated with about $13 \%$ increase. The odds ratios indicate that the probability of a collaborating firm also innovating is five times as high as for a firm that does not collaborate. With informal interaction, the ratio is approximately seven. These values suggest that both formal and informal modes of interactive learning are positively and significantly associated with an increasing probability that a firm possesses sufficient capabilities to innovate. The results further suggest that forming informal linkages is slightly more strongly associated with the accumulation of technological capabilities by the Nigerian firms.

In general, these results are consistent with the extant literature. An important new insight that the results provide relate to the distinction between formal and informal interactions. Although the coefficient of informal linkages does not surpass that of formal linkages by a wide margin, for firms operating

\footnotetext{
${ }^{21}$ As Rosenberg and Nelson (1994) noted, "The vast bulk of industry R\&SD is focused directly on shorter term problem-solving, design and development. Universities are not particularly good at this sort of work. Industry is more effective in dealing with problems that are located close to the market place."
} 
Table 2.5: Relationship between overall capabilities and interactive learning logistic regression results

\begin{tabular}{|c|c|c|}
\hline Overall Capabilities & Odds Ratio & $\begin{array}{c}\text { Average } \\
\text { Marginal Effects }\end{array}$ \\
\hline FORMAL & $\begin{array}{l}5.428^{* *} \\
(3.238)\end{array}$ & $\begin{array}{l}0.116^{* *} \\
(0.036)\end{array}$ \\
\hline INFORMAL & $\begin{array}{l}6.826^{* *} \\
(4.902)\end{array}$ & $\begin{array}{l}0.131^{* *} \\
(0.045)\end{array}$ \\
\hline TRAINING & $\begin{array}{l}0.748 \\
(0.479)\end{array}$ & $\begin{array}{c}-0.020 \\
(0.044)\end{array}$ \\
\hline MANAGEMENT & $\begin{array}{c}5.253 \\
(5.629)\end{array}$ & $\begin{array}{c}0.113 \\
(0.065)\end{array}$ \\
\hline MANAGEMENT $^{2}$ & $\begin{array}{r}0.427^{*} \\
(0.182)\end{array}$ & $\begin{array}{r}-0.058^{*} \\
(0.025)\end{array}$ \\
\hline AGE & $\begin{array}{c}2.552 \\
(2.430)\end{array}$ & $\begin{array}{c}0.064 \\
(0.065)\end{array}$ \\
\hline $\mathrm{AGE}^{2}$ & $\begin{array}{c}0.810 \\
(0.201)\end{array}$ & $\begin{array}{c}-0.014 \\
(0.017)\end{array}$ \\
\hline OWNERSHIP & $\begin{array}{c}0.889 \\
(0.139)\end{array}$ & $\begin{array}{c}-0.008 \\
(0.010)\end{array}$ \\
\hline ICT & $\begin{array}{c}4.540 \\
(4.121)\end{array}$ & $\begin{array}{l}0.103 \\
(0.059)\end{array}$ \\
\hline INNO_BUDGET & $\begin{array}{l}28.668^{* *} \\
(29.666)\end{array}$ & $\begin{array}{c}0.229^{* *} \\
(0.052)\end{array}$ \\
\hline CONSTANT & $\begin{array}{c}0.080^{*} \\
(0.077)\end{array}$ & \\
\hline $\mathrm{N}$ & 170 & \\
\hline McFadden's $R^{2}$ & 0.480 & \\
\hline Log lik & -38.67 & \\
\hline Akaike's IC & 99.35 & \\
\hline$\chi^{2}$ & $\begin{array}{l}36.52^{*} \\
918\end{array}$ & \\
\hline
\end{tabular}


in resource-poor and harsh institutional environments such a small difference might significantly affect innovative success. For instance, in an earlier case study in Nigeria, it was found that informal linkages with some clients was a significant driver of innovative efforts in one of the largest firms in the cable and wire manufacturing sub-sector (Egbetokun, 2009).

Of all the control variables, only the existence of an innovation budget has a significant coefficient. Of course this does not imply that firm characteristics such as age, ownership and internal learning efforts through staff training are not important. It simply suggests that Nigerian manufacturing firms, similar to Chilean firms where technical manpower and training expenditures (Molina-Domene and Pietrobelli, 2012) or Mexican firms where age (Iammarino et al., 2008) do not show significant association with technological capabilities, follow a different pattern from what is expected. For instance, since the accumulation of capabilities take time, one would expect a significant coefficient for age. However, the sampled firms are quite young (average age $=11$ years) and as such might not have accumulated the sort of advanced capabilities with which age may be strongly associated. The use of ICT is very pervasive among the firm and may therefore not be a source of difference in capabilities. Interestingly, the management structure shows an inverted-U relationship with the probability of innovating. Firms' capabilities peak under a moderately flat organisational structure. Where there is too much or too little bureaucracy, capability build-up through interactive learning may suffer. However, this non-linear effect might be driven by the presence of a few enterprises much larger than the rest of the sample: the average number of levels and 75th percentile of the organisational structure are about three and five respectively.

\section{Interactive learning and different firm-level capabilities}

In Table 2.6, the relationships observed in Table 2.5 are broken down according to the four capability types proxied by innovative activities. The coefficients are examined at three levels of significance $(5 \%, 1 \%$ and $0.1 \%$ respectively) to give an idea of the strength of association that they purport. As before, the controls are generally insignificant and have therefore been omitted. The results tell a consistent story: the relationship between interactive learning and capability accumulation is generally positive. The striking thing to note here is how the relationship differs for different capabilities. From a methodological perspective, this suggests two things. First, the relationship between interactive learning and capability accumulation is more nuanced when capabilities are 
considered at a lower level of disaggregation. Second, the bias towards technological product and process innovation that prevails in the literature does not provide a complete picture.

Table 2.6: Relationship between different capabilities and interactive learning multivariate probit results

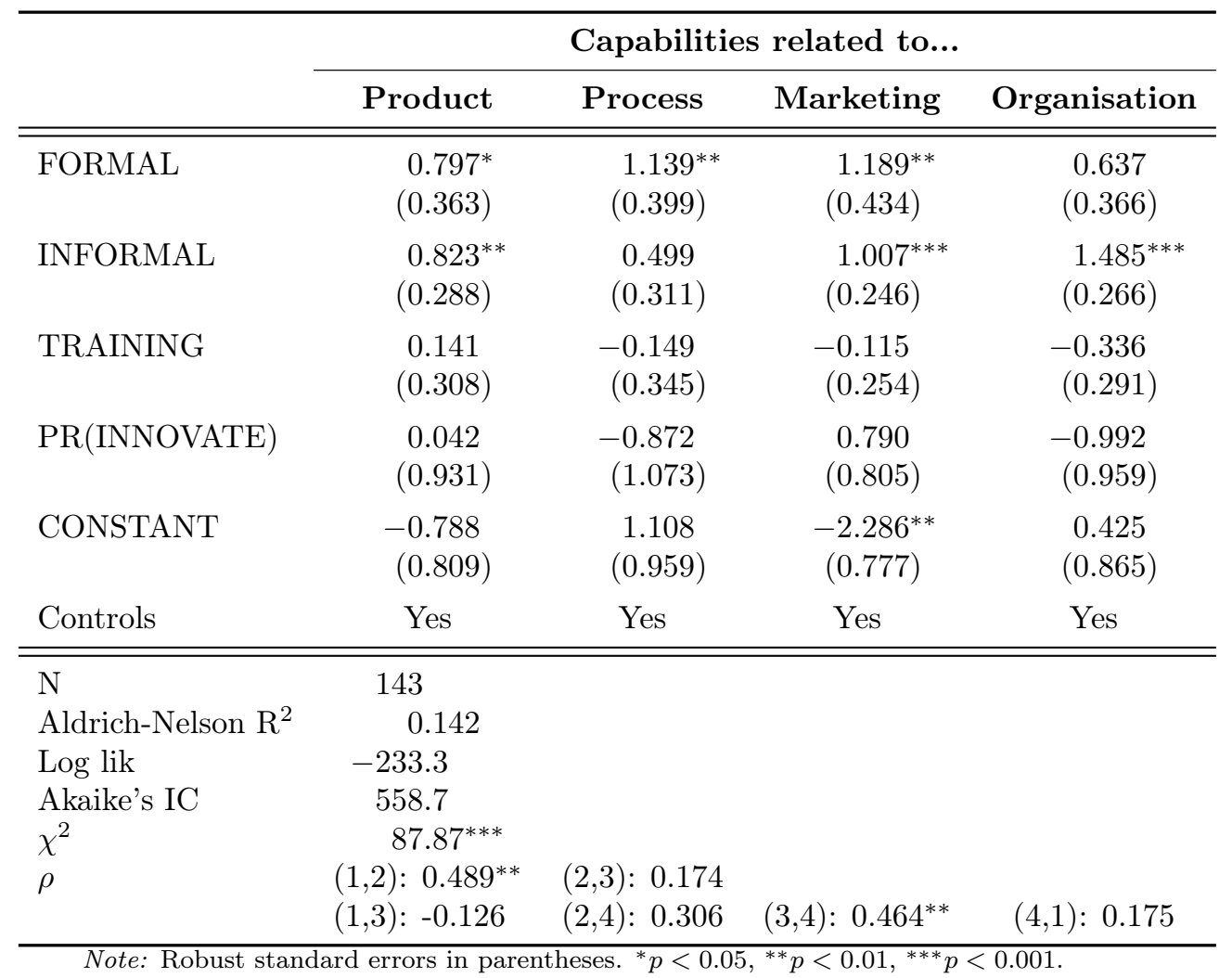

Indeed, as anticipated, marketing and organisational capabilities seem to show a stronger association with the informal mode of interactive learning. This finding is intuitive when one considers, for instance, that most of the activities captured by the organisational innovation measure are those that the firms can either perform efficiently in-house or for which they can secure assistance from external agents without the need to collaborate formally. The same cannot be said of technological product and process innovative activities. From a managerial perspective, these results are important as they provide some hints regarding what firms need to pay attention to when making knowledge search decisions. 
The coefficient of informal linkages for process-related capabilities is insignificant, as is the coefficient of formal linkages for organisational capabilities. Yet, that the coefficient of INFORMAL is bigger than that of FORMAL in the case of product innovation partially lends further support to the earlier observation that firms in a latecomer context like Nigeria may benefit more from informal linkages. Surprisingly, the strongest association of capabilities with formal linkages is not seen in product- and process-rleated but marketing-related capabilities. This particular finding appears to be counter-intuitive since the knowledge intensity of marketing and organisational innovations should ordinarily be less than that of product or process innovation. However, for firms in developing countries such as Nigeria, where there is a great deal of informality in the manufacturing sector, it has been argued that marketing and organisational innovations are of major importance (OECD, 2005). Thus, the foregoing results find an explanation in the fact that the firms might be devoting a comparatively higher level of attention to making marketing and organisational changes, a behaviour that could be reflected in their knowledge search decisions.

\subsection{Conclusions}

This chapter examined the relationship between interactive learning and the innovative capabilities of firms in a developing country, using a unique data set within the context of the manufacturing sector in Nigeria. The most important external sources of knowledge for firm-level capability building were market-based: customers, suppliers of machinery and equipment as well as industry associations. Worthy of note is the fact that research-based and government sources are among the least important sources of knowledge to the firms. In sum, firms' innovation activities seemed to be strongly determined by relations between themselves and their suppliers and customers in Nigeria. I have offered demand- and supply-side explanations, which are valid not only for the Nigerian context but also for similar contexts.

By distinguishing between formal and informal modes of interaction and focusing on both technological and non-technological capabilities, this study offers an analytical extensions to the literature. The econometric results support the expectation of a positive relationship between the probability of a firm innovating and both formal and informal forms of interaction. On the overall, capabilities seemed to benefit more from informal than formal linkages. These results highlight the importance of informal interactions in enhancing 
firm-level capabilities, at least in the context studied here.

The results may hold important implications for firms not only in Nigeria but also in other developing countries especially in Africa. As previous studies have also demonstrated, it is very beneficial that firms devote attention to the buildup of their capabilities - technological and non-technological. This allows them to innovate and create or maintain a competitive edge and consequently play more effective roles in driving national development. Such competitiveness is of particular importance for firms operating in contexts where imported consumer goods are ubiquitous. Learning by interacting has been demonstrated to be very crucial for these firms. The acquisition and deployment of knowledge developed elsewhere assists the firms to cover up 'holes' in their internal capabilities and reduce the risk of failure by minimising their self-reliance. It is indeed well-known that innovation is a social process which is more likely to fail when firms try to embark on it all alone. This is especially true in resource-poor environments.

Another result that is of practical importance is the relative importance of informal linkages. Being potentially less demanding in terms of resource requirements and legal implications, firms in developing countries may find this form of linkages to be very useful. Moreover, considering the centrality of marketing and organisational capabilities to these firms, the need for informal linkages - from which these capabilities tend to derive more - is underscored by this study. 


\section{Chapter 3}

\section{Linkage Variety and Firm Capabilities in Nigeria}

\subsection{Introduction}

The locus of innovation is shifting away from the individual firm to the network within which the firm is embedded (Powell et al., 1996). Here, the network is understood as a firm's set of relationships with other organisations (Pérez Pérez and Sanchez, 2002) including but not limited to suppliers and customers (von Hippel, 1988), universities (Laursen and Salter, 2004), competitors and financial institutions (Souitaris, 2001). Networks are important because of their role as an infrastructure for knowledge diffusion. This is especially crucial in the knowledge-based economy within which firms now operate; change is rapid and no single firm can possibly possess all the knowledge and capabilities necessary to innovate (Chesbrough, 2003c).

Firms pursue different strategies to acquire knowledge relevant for innovation from several possible sources. These strategies could be formal, involving active participation in joint $R \& D$ and other technological innovation projects (Tether, 2002; WIPO, 2011). They could also be informal-simply 'talking to' actors as sources of information without any formal arrangements (von Hippel, 1987; Freitas et al., 2011) 11 One major difference between these

\footnotetext{
${ }^{1}$ According to Pyka (1997, p. 201), "Informal networking means any action that can contribute to disclosure, dissemination, transmission and communication of knowledge. Many different methods such as talking, listening, showing, debating etc. at different occasions such as exhibitions and conferences, and even telephone calls, can be employed in some haphazard
} 
two approaches is that formal collaboration often involves pecuniary commitments which is not necessarily the case with informal knowledge sourcing. Networking strategies could also be intensive or extensive, the former implying 'depth' or intensive use of certain knowledge sources and the latter implying 'breadth' or the so-called 'portfolio' approach whereby the firm engages many actors (Duysters and Lokshin, 2011).

This chapter focuses on the latter aspect, that is, the portfolio approach. In particular, we define the variety of linkages as the number of different actors with whom a firm interacts either formally or informally. With this, we distinguish between variety of formal linkages, that is, the number of collaboration partners, and variety of informal linkages, that is, the number of external information sources that a firm uses.

In the recent theoretical and empirical literature on innovation, a consistent positive relationship has been established between firms' networking activities and innovativeness. In general, three major results are established: first, the innovation landscape is now such that firms can no longer 'go it alone'; second, firms increasingly network with and draw upon multiple external sources to complement internally-generated knowledge; and third, such networking enhances innovation performance. By participating in networks or establishing external linkages, firms gain access to knowledge, lower transaction costs, division of labour, shared risks and higher probability of innovation success (Malerba and Nicholas, 2009; Pittaway et al., 2004). Several empirical contributions have indeed shown that the use of external knowledge sources or collaboration partners tends to make firms more innovative de Man and Duysters, 2005; Lee et al., 2010; Tomlinson, 2010). However, a better and more holistic understanding of the relationship between networking and innovation involves certain dimensions which are relatively under-explored in the existing literature.

One particular example is the relationship between a firm's level of innovativeness and the strategies it adopts in networking. Studies have shown that variety of knowledge sources, up to a certain limit improves innovation performance (Leiponen and Helfat, 2010; Amara and Landry, 2005). But it is still unknown whether this holds true at all levels of innovativeness. Dutta and Weiss (1997) tackled this question using a sample of US-based electrical and electronic machinery firms and indeed found variations in the firms' pattern of partnerships as technological innovativeness increased. Firms that were highly innovative were shown to have fewer joint ventures than either of marketing or licensing

way to convey and receive knowledge and the underlying concepts." 
agreements. However, their analyses included only pecuniary partnerships and precluded any form of informal linkages. By employing innovation measures which take into account the total number of innovative activities that a firm successfully implements and distinguishing between formal and informal linkages, this chapter explores the relevance of linkage variety at different levels of innovativeness.

In addition, the question of whether or not there are variations in the relationship of formal and informal linkages with different innovation types is taken up again in this chapter. Recall that in Chapter 2, it was already argued that different innovation types do not respond in the same way to the two different forms of linkages. The extension made in this chapter is to account for the size of a firm's portfolio of each type of linkages. By using broad definitions of innovation and distinguishing between four types as in the preceding chapter, we test the expectation that formal interactions are more strongly associated with technological innovation and informal interactions are more strongly associated with non-technological innovation. As noted by Pittaway et al. (2004), the literature until recently had focused more on product and process innovations, often placing emphasis on R\&D or the development of new-to-the-world products and processes.

The other issue addressed in this chapter is the possibility of interaction effects arising from the simultaneous use of both formal and informal networking strategies by firms. In the literature, except for a few exceptions like Bönte and Keilbach (2005) and Freitas et al. (2011), formal and informal interactions have generally been considered in isolation. Consequently, the innovation process seems simplified and the possible simultaneity of formal and informal interactions is not well understood. By putting them in the same estimation framework, we take into account the simultaneity and possible interaction effect of formal or informal networking strategies.

In addressing all of the research questions, the absorptive capacity of the firms is taken into account. Since the acquisition and exploitation of externally generated knowledge has associated costs, mostly in the form of learning and capacity building investments (Cohen and Levinthal, 1994), we expect that the absorptive capacity of firms will play a role in the network-innovation relationship. Moreover, it has been suggested that internal R\&D is still important for the build-up of innovative capabilities in developing countries even though most of the innovative activities do not originate therefrom. This argument, however, is badly in need of some empirical validation. We attempt to provide such by including a measure of R\&D-based cumulativeness in the analyses. 
In this perspective, it is not the mere engagement in R\&D but its continuity which confers a cumulative learning advantage on the firm.

By addressing the foregoing issues, this chapter contributes to the literature in several ways. First, similar to Ganter and Hecker (2013), we note that there are very few (if any) micro level studies which explicitly link networking to different innovation types beyond product and process innovations. Second, much of the evidence presently available is heavily tilted towards the developed country context. The empirical evidence on learning and collaboration for innovation is very thin for the less developed countries even though linkages are fully recognised as important determinants of knowledge flows and firm learning in their context (Goedhuys, 2007a). This is particularly true for Africa where, due to the scarcity of micro-level innovation data, most existing studies are either based on clusters or case studies. The analyses in this chapter are based on the first CIS-type innovation survey dataset collected from manufacturing and service enterprises in Nigeria. The dataset allows to operationalise the research questions by focusing on the ego-centric networks of the individual firms and not on the details of the sectoral or industrial network structure. Third, the distinction between formal and informal networking strategies enriches the analysis particularly because each of these modes of interaction involves different levels of efforts by the firm. Finally, attention is drawn to the utility of interactive learning at different levels of innovativeness. As the results show, the relevance of networking depends on the firm's current level of innovativeness.

\subsection{Hypotheses}

\subsubsection{Variety of linkages}

Much evidence exists in support of the fact that engaging multiple actors and knowledge sources is beneficial for innovation (Amara et al., 2008; Faems et al., 2005; Belderbos et al., 2004; Duysters and Vanhaverbeke, 1996). This positive relationship is known to have a finite maximum beyond which diminishing returns to breadth might begin to appear (Duvsters and Lokshin, 2011) possibly due to the attention allocation problem (Ocasio, 1997). However, besides being limited in terms of evidence from the developing country context, the empirical literature seems to deal more with the issue of informal network partnersgenerally conceptualised as the breadth of external knowledge sources. Studies 
looking at the formal dimension of networking typically isolate each potential partner and focus almost exclusively on the research-intensive sources such as universities (e.g., Jaffe, 1989; Laursen and Salter, 2004; Tether, 2002). Studies looking at both formal and informal networking strategies in combination tend to under-explore the breadth dimension by treating each actor in isolation (e.g., Freitas et al., 2011). These, at best, present a partial picture of reality. Formal and informal interactions are not mutually exclusive and, in fact, often co-occur in a firm's portfolio of external knowledge sources. Consequently, both formal and informal networking strategies are combined in the following hypothesis:

H1: The variety of formal (collaboration) and informal (external information sources) linkages is positively associated with a firm's innovation performance.

\subsubsection{Variety of linkages and innovation types}

The notion of formality in relation to partnerships suggests that they involve management approval and commitment as well as mutual legally binding documents such as memorandums of understanding (MoUs) and technical agreements (Hagedoorn, 2002). Informal networking strategies would then consist mainly in the use of external information sources as inputs into the innovation process, without any contractual agreements (Garcia-Torres and Hollanders, 2009). However, with a few exceptions like Bönte and Keilbach (2005) and Freitas et al. (2011), formal interactions are usually considered in isolation from informal interactions in the literature. This begs the question of whether or not these different networking strategies lead to different innovation types, especially when considered simultaneously.

Tether (2002) had earlier shown that firms are more likely to engage in cooperative arrangements when they are attempting to introduce 'new to the market' products and processes. Tödtling's et al (2009) results indicate that such firms tend to cooperate more with universities and research institutions while firms that focus on less advanced innovations tend to draw on knowledge links with business services. Consequently, one would expect that for innovations that are more advanced in terms of novelty or technological nature, firms will depend more on formal collaboration. In a developing country, where firms tend to mainly innovate by imitating or making organisational changes and are situated within contexts that thrive on informality (OECD, 2005), it makes sense to expect a stronger positive relationship between informal knowledge 
sourcing and non-technological innovation.

The foregoing arguments are combined into the following hypotheses:

H2a: The variety of formal linkages (i.e. collaboration) is more strongly associated with product and process innovation.

H2b: The variety of informal linkages (i.e. external information sources) is more strongly associated with marketing and organisational innovation.

\subsubsection{The interaction of formal and informal linkages}

In general, the literature is replete with both anecdotal and empirical evidence in favour of a complementary relationship between internal and external knowledge in innovation. Cassiman and Veugelers (2006) make a review of this strand of literature and deploy a thorough methodological approach to provide conclusive support for this hypothesis. An important gap that persists beyond this conclusion is the interaction among different external sources of know-how. Often, firms simultaneously use many external information sources as inputs into their innovation process and at the same time formally collaborate with multiple partners. When this happens, it becomes difficult to tell precisely where the effect of networking on innovation is coming from: formal, informal or an interaction of both?

Recent empirical contributions have examined this question but with limitations. Using CIS data on 18 European countries, Garcia-Torres and Hollanders (2009) showed that the significance of extramural R\&D expenditures cancel out in the presence of informal knowledge diffusion. The direct implication of this is that the positive effect of extramural $R \& D$ is actually driven by informal knowledge diffusion. However, these authors focused only on product innovation. In contrast, Freitas et al. (2011), also using CIS data but for cross country analyses in four countries, include measures for process innovations but they consider each potential partner in isolation. They found a complementary relationship between formal and informal linkages with the same actors. Using measures that account for both formal and informal linkages, the following hypothesis is tested in this chapter:

\footnotetext{
${ }^{2}$ At the individual level, Rank (2008) showed that sometimes informal interactions simply substitute for formal interactions among managers who are responsible for strategic decision making in organisations. It can be argued that this phenomenon will reflect at the organisational level through the decisions made by such managers.
} 
H3: There is a significant interaction between formal and informal linkages.

\subsubsection{The role of absorptive capacity}

Research in evolutionary economics particularly emphasises the role of knowledge from outside the firm's boundaries. External knowledge from the firm's environment is an important source of variety. Such knowledge allows the firm to innovate by making new combinations of knowledge (Nelson and Winter, 1982). For appropriating such knowledge, and to achieve recombinant novelty, firms require a certain level of absorptive capacity (Nooteboom et al., 2007) which is largely determined by in-house R\&D (Cohen and Levinthal, 1989). For this reason, it is expected that the extent to which firms will learn from external knowledge sources is affected by their in-house R\&D efforts.

For instance, among UK firms, Laursen and Salter (2004) found that R\&D expenditure is associated with the use of knowledge from universities. But when the breadth and depth of external search activities were considered together with R\&D intensity, a substitution relationship was found (Laursen and Salter, 2006). What one might infer from the foregoing is that although firms require R\&D-driven absorptive capacity to internalise spillovers, the need to search far and wide for these spillovers is de-emphasised when firms invest highly in R\&D. However, these results were obtained only for product innovation. In developing countries where firms are mostly small or medium-sized with very little $\mathrm{R} \& \mathrm{D}$ resources, the attractiveness of research-based knowledge sources such as universities is questionable. Moreover, given the relatively less radical nature of innovation in these countries, it will be useful to understand how absorptive capacity moderates the interaction between external search for knowledge and other innovation types besides product innovation. Therefore, it is hypothesised that:

H4: Absorptive capacity moderates the relationship between interactive learning and innovation. 


\subsection{Data and Method}

\subsubsection{The database}

Apart from South Africa where several rounds of innovation surveys have been implemented, African countries are just beginning to collect their own firmlevel innovation data. The scarcity of these types of microlevel data until recently has constrained innovation research in Africa AU-NEPAD, 2010; Gault and Mawoko, 2011; Muchie and Baskaran, 2011) 3 3 Most studies, to date, are based on case studies or individual surveys with widely varied methods and sampling approaches.

The dataset, comprising a total of 472 service and manufacturing firms, came from Nigeria's first official innovation survey which was carried out under the ASTII of the NEPAD 4 The empirical context is already extensively discussed in the previous chapter. The definitions, method and questions used in the survey were based on the Oslo Manual and the CIS but adapted for the African context 5 Firms with at least 10 employees were selected via a multi-stage (random) sampling process 6 The firms reported for the 2005-2007 period, giving information on, among other things, their collaboration partners and external knowledge sources.

Before proceeding to describing the variables, an important clarification needs to be made regarding the conjoined analysis of service and manufacturing firms. Some studies like Hoffman et al. (1998) and Vega-Jurado et al. (2009) argued that the innovation process varies substantially between manufacturing and services and thus, both sectors are best analysed separately. However, it has been demonstrated that service and manufacturing share some fundamentals in the innovation process: both sectors are not particularly distinguishable with respect to the patterns and intensity of innovative activity

\footnotetext{
${ }^{3}$ Data from the World Bank Enterprise Surveys and the Regional Programme for Enterprise Development, though useful, do not provide as much relevant information as a systematic innovation survey. This is because they focus more on the effects of the business environment on firm performance rather than the learning processes of the firms. Thus, while they contain information on the innovative activities of the firms, they have very limited in information on local interactions.

${ }^{4}$ Details on the survey methods and data are available in Sivanbola et al. (2013) and AU-NEPAD (2010).

5 This adaptation derived largely from UNU-INTECH (2004) and the South African Innovation Survey questionnaire which was based on the third Community Innovation Survey.

6 The industrial classes were based on the 3-digit ISIC Revison 3. Firms were selected from Class 15-37 (manufacturing) and Class 40-93 (service).
} 
as well as the use of network resources (de Jong and Marsili, 2006; Archibugi, 2001; Carvalho et al., 2013). Consequently, we argue that the innovation process is not so different between these two broad industries as to confound an analysis of the relationship between innovation and networking. In fact, the rise of product-accompanying services (Schmoch, 2003) in many firms further accentuates this. Appendix B.1 indeed shows that there is little difference between our sample of manufacturing and service firms in terms of innovation rate and formal or informal interactions. Clearly, the use of external knowledge is important in both sectors, even if to varying degrees 7

\subsubsection{Measures}

In the survey, firms were asked whether they had introduced an innovation during 2005-2007. This was done in a total of 10 items for product (2 items), process (3 items), marketing (2 items) and organisational (3 items) innovations. They were also asked whether they collaborated with any of six possible external collaboration partners: customers, suppliers, competitors, consultants or private $\mathrm{R} \& \mathrm{D}$ labs, universities or other higher education institutions, and public research institutes. In another question, the firms were asked to indicate on a 0 (not used)-1-2-3 (very important) scale the importance of each of nine possible sources of information for innovation: suppliers, customers, competitors, consultants or private R\&D labs, universities or other higher education institutions, public research institutes, conferences or trade fairs, scientific journals or trade publications, and professional or industry associations. Relevant variables were constructed using these questions.

\section{Dependent Variables}

The dependent variables are defined in Table 3.1. Innovation is resolved into four different types: product and process innovations being technological; marketing and organisational innovations being non-technological (OECD, 2005, p. 47). The variables for product (SPROD, range 0-2), process (SPROC, range 0-3), marketing (SMARK, range 0-2) and organisational (SORG, range 0-3) innovations were obtained as the sum of the items for each innovation type. These variables, similar to those applied in previous studies like Gronum et al.

\footnotetext{
${ }^{7}$ The possible variation was captured as an intercept effect by including a dummy variable indicating if a firm is into services or manufacturing. See the baseline results in Appendix B.4.
} 
(2012), provide an ordinal measure of the scope of innovation in the firms. The overall scope of innovation, SINNO (range 0-4), was derived as the sum of the dichotomised measures of the four different innovation types. Using ordinal measures enriches the analyses since it makes it possible to rank firms in terms of innovative performance 8 Although the survey distinguished between new-to-the-firm and new-to-the-market product innovations, that distinction is not applied here because it is restricted to only product innovation.

\section{Explanatory Variables}

The explanatory variables are defined in Table 3.2. As a measure of the variety of formal linkages, the variable BCOLLAB (Cronbach's $\alpha=0.92$ ) captured the number of external actors a firm collaborated with. It was obtained as the count of all non-zero responses given by each firm for all collaboration partners, and therefore ranges from 0 to 6 . Variety of informal linkages is captured in the variable BEXTERN (Cronbach's $\alpha=0.89$ ). Its construction, using the 9 questionnaire items relating to external knowledge sources, is similar to BCOLLAB. Square terms of the breadth measures were included to control for potential non-linearity. Similar variables have been extensively applied in the literature (Laursen and Salter, 2006; Leiponen and Helfat, 2010; Duysters and Lokshin, 2011). Many previous studies concentrate on disembodied knowledge such as R\&D and invariably ignore an important aspect of knowledge acquisition, that is, the acquisition of embodied technology. Following Vega-Jurado et al. (2009), we include not only measures for whether the firm purchased disembodied knowledge (EXTERNAL R\&D) but also embodied technological capital through new machinery and equipment (MACHINERY) as well as other forms of external knowledge (OTHER EXTERNAL) such as product or process licenses. It is anticipated that knowledge acquired through this means will complement the firm's explicit interactive learning efforts.

Measuring absorptive capacity is by no means straightforward. To be as comprehensive as possible given the available dataset, we included multiple meas-

\footnotetext{
8 The variables are potentially limited in an important respect: the implicit assumption that all innovative activities are qualitatively equal. This limitation is attenuated since the rank values have purely ordinal meaning. In other words, higher scores correspond only to a higher innovation scope but not necessarily to a better performance in the market. For instance, a firm with an SINNO score of 4 is not necessarily twice as innovative as one with a score of 2 but clearly demonstrates higher innovative capability. Ultimately, this limitation does not pose a major restriction on the analyses because the variables are not interpreted qualitatively.
} 
Table 3.1: Description of dependent variables

\begin{tabular}{|c|c|c|c|c|c|c|}
\hline Variable & Description & Min & $\operatorname{Max}$ & Median & Mean & $\mathrm{SD}$ \\
\hline SINNO & $\begin{array}{l}\text { Overall scope of innovation: the number of } \\
\text { different innovation types that the firm } \\
\text { performed. Obtained from the sum of the } \\
\text { dummies of the four different innovation } \\
\text { types }\end{array}$ & 0 & 4 & 3 & 2.85 & 1.11 \\
\hline SPROD & $\begin{array}{l}\text { Product innovation scope: the number of } \\
\text { activities amounting to product innovation } \\
\text { that the firm had carried out. Constructed } \\
\text { as the sum of the responses on two } \\
\text { questionnaire items: new good or new } \\
\text { service }\end{array}$ & 0 & 2 & 1 & 1.15 & 0.85 \\
\hline SPROC & $\begin{array}{l}\text { Process innovation scope: the number of } \\
\text { activities amounting to process innovation } \\
\text { that the firm had carried out. Constructed } \\
\text { as the sum of the responses on three } \\
\text { questionnaire items: new production } \\
\text { methods, new logistics/distribution methods } \\
\text { or new process supporting activities }\end{array}$ & 0 & 3 & 2 & 1.85 & 1.21 \\
\hline SMARK & $\begin{array}{l}\text { Marketing innovation scope: the number of } \\
\text { activities amounting to marketing } \\
\text { innovation that the firm had carried out. } \\
\text { Constructed as the sum of the responses on } \\
\text { two questionnaire items: changes in } \\
\text { design/packaging, changes in } \\
\text { sales/distribution methods. }\end{array}$ & 0 & 2 & 1 & 0.99 & 0.88 \\
\hline SORG & $\begin{array}{l}\text { Organisational innovation scope: the } \\
\text { number of activities amounting to product } \\
\text { innovation that the firm had carried out. } \\
\text { Constructed as the sum of the responses on } \\
\text { three questionnaire items: new knowledge } \\
\text { management systems, major changes to } \\
\text { workplace organisation, and new way of } \\
\text { relating with other firms or public } \\
\text { institutions }\end{array}$ & 0 & 3 & 2 & 1.67 & 1.17 \\
\hline
\end{tabular}


Table 3.2: Description of independent variables

\begin{tabular}{|c|c|c|c|c|c|c|}
\hline Variable & Description & Min & Max & Median & Mean & SD \\
\hline BCOLLAB & $\begin{array}{l}\text { Breadth of collaboration: the number of } \\
\text { actors a firm collaborates with }\end{array}$ & 0 & 6 & 0 & 0.89 & 1.80 \\
\hline BEXTERN & $\begin{array}{l}\text { Breadth of knowledge sources: the number } \\
\text { of external information sources that a firm } \\
\text { uses }\end{array}$ & 0 & 9 & 5 & 4.93 & 3.14 \\
\hline MACHINERY & $\begin{array}{l}=1 \text { if firm acquired } \\
\text { machinery/equipment/other capital goods } \\
\text { in } 2005-2007\end{array}$ & 0 & 1 & 0 & 0.28 & 0.45 \\
\hline EXTERNAL R\&D & $\begin{array}{l}=1 \text { if firm outsourced/acquired extramural } \\
\text { R\&D in } 2005-2007\end{array}$ & 0 & 1 & 1 & 0.62 & 0.49 \\
\hline OTHER EXTERNAL & $\begin{array}{l}=1 \text { if firm acquired other forms of external } \\
\text { knowledge (e.g., licenses) in } 2005-2007\end{array}$ & 0 & 1 & 0 & 0.34 & 0.47 \\
\hline SIZE & $\begin{array}{l}\text { Log. of the firm's number of employees in } \\
2007\end{array}$ & 2.30 & 8.26 & 4.09 & 4.29 & 1.33 \\
\hline GROUP & $=1$ if the firm belongs to a group & 0 & 1 & 0 & 0.28 & 0.45 \\
\hline TRAINING & $\begin{array}{l}=1 \text { if the firm implemented staff training } \\
\text { programmes in } 2005-2007\end{array}$ & 0 & 1 & 0 & 0.69 & 0.46 \\
\hline CONRAD & $\begin{array}{l}=1 \text { if the firm performed in-house } \mathrm{R} \& \mathrm{D} \\
\text { continuously in } 2005-2007\end{array}$ & 0 & 1 & 0 & 0.20 & 0.40 \\
\hline LOCATION & $=1$ if the firm is located in Lagos & 0 & 1 & 0 & 0.41 & 0.49 \\
\hline EXPORT & $=1$ if the firm exported in $2005-2007$ & 0 & 1 & 0 & 0.29 & 0.45 \\
\hline SERVICE & $=1$ if services firm & 0 & 1 & 0 & 0.35 & 0.48 \\
\hline
\end{tabular}

Note: No. of observations $=472$.

ures of the absorptive capacity construct. The first, CONRAD, in line with earlier studies (e.g., Cassiman and Veugelers, 2002), is a dummy variable indicating continuous $R \& D$ performance. The rationale is that firms that devote more attention to R\&D by performing it more consistently will eventually possess a cumulative learning advantage 9 Inspired by previous studies on the importance of human capital accumulation for firm-level technological learning (Romijn and Albaladejo, 2002; Wignaraja, 2002; Bell, 1984), the second measure, TRAINING, is a dummy representing whether the firm had staff training programmes during the reference period.

\footnotetext{
${ }^{9}$ Admittedly, with this measure one cannot distinguish between Cohen's and Levinthal's (1989) two faces of R\&D: invention and learning. The models in Chapters 4 and 5 surmount this limitation.
} 


\section{Controls}

An extensive body of evidence exists (see Keizer et al., 2002; Aralica et al., 2008; Cohen, 2005, 2010, for reviews) on the fact that innovation shows a relationship with a considerable number of firm heterogeneity variables such as size, ownership, age, location, staff characteristics and exporting. Moreover, in the Nigerian context, the effect of constraints in the business environment on firm-level productivity and innovativeness has been shown to vary with certain firm characteristics such as size, location and ownership (Radwan and Pellegrini, 2010). Thus, as far as the data would allow, the following controls for firm heterogeneity are included 10: the log of employees (SIZE), and dummies for whether the firm is located within or outside Lagos (LOCATION) 11 exports to at least one foreign market (EXPORT), belongs to a group (GROUP) or is from service or manufacturing (SERVICE) 12 The correlation matrix is given in Table 3.3 .

\subsubsection{Estimation}

Ordered logit, the parameters of which can be estimated by maximum likelihood, is appropriate for the multivariate analyses since the dependent variables are ordinal (Wooldridge, 2010). The conventional ordinal logit procedure requires proportional odds 13 In practice this assumption is often violated. Besides, allowing for non-proportionality allows one to check if independent variables behave differently as the dependent variable changes. This is indeed a main interest of the analyses herein. In light of these, partial proportional odds ordered logit models are estimated to test the hypotheses. Appendix

\footnotetext{
${ }^{10}$ Notably, firm age could not be controlled for despite its recognised importance in directly or indirectly affecting firm-level innovativeness. An attempt to obtain this information from secondary sources was not successful because reliable official records on many of the firms were not available.

${ }^{11}$ It is widely believed that most of the industrial activities in Nigeria take place in the Lagos area. Estimates of up to $70 \%$ of Nigerian manufacturing enterprises being located in Lagos have been reported (Adeoti, 2012; Corporate Guides, 2011). Firms in this location are therefore expected to be exposed to Marshallian externalities by being much closer to a milieu of competitors and potential partners.

${ }^{12}$ Including sector dummies did not change the results qualitatively. This is to be expected because the sample is somewhat homogenous. For instance, the manufacturing sample comprises firms from mostly mature industries and the service sample consists of predominantly technology-using sectors.

${ }^{13}$ This means that the relationship between explanatory and outcome variables is independent of the number of outcome categories such that only one set of coefficients is possible.
} 
Table 3.3: Correlation matrix of independent variables

\begin{tabular}{|c|c|c|c|c|c|c|c|c|c|c|c|c|}
\hline \multirow[b]{2}{*}{ Variable } & \multicolumn{11}{|c|}{ Correlations } & \multirow[b]{2}{*}{12} \\
\hline & 1 & 2 & 3 & 4 & 5 & 6 & 7 & 8 & 9 & 10 & 11 & \\
\hline BCOLLAB & 1.00 & & & & & & & & & & & \\
\hline BEXTERN & 0.32 & 1.00 & & & & & & & & & & \\
\hline MACHINERY & 0.29 & 0.23 & 1.00 & & & & & & & & & \\
\hline EXTERNAL R\&D & 0.11 & 0.33 & 0.28 & 1.00 & & & & & & & & \\
\hline OTHER EXTERNAL & 0.25 & 0.24 & 0.31 & 0.21 & 1.00 & & & & & & & \\
\hline SIZE & 0.13 & 0.17 & 0.18 & 0.16 & 0.09 & 1.00 & & & & & & \\
\hline GROUP & 0.11 & 0.10 & 0.23 & 0.09 & 0.11 & 0.27 & 1.00 & & & & & \\
\hline TRAINING & 0.19 & 0.39 & 0.19 & 0.39 & 0.28 & 0.16 & 0.07 & 1.00 & & & & \\
\hline CONRAD & 0.33 & 0.24 & 0.32 & 0.17 & 0.19 & 0.24 & 0.13 & 0.25 & 1.00 & & & \\
\hline LOCATION & 0.01 & 0.19 & 0.03 & 0.03 & $0.01-$ & -0.05 & 0.04 & 0.11 & 0.10 & 1.00 & & \\
\hline EXPORT & 0.15 & 0.21 & 0.05 & 0.03 & 0.01 & 0.30 & 0.18 & 0.11 & 0.14 & 0.15 & 1.00 & \\
\hline SERVICE & -0.07 & 0.15 & $0.02-$ & -0.10 & $0.04-$ & -0.24 & -0.02 & $0.06-$ & -0.04 & 0.50 & 0.07 & 1.00 \\
\hline
\end{tabular}

Note: Correlations $\geq|0.10|$ are significant at the $5 \%$ level. Average Variance Inflation Factor $=1.33$, Condition number $=14.52$. No. of observations $=472$.

B.2 describes this model in detail. Suffice it to say here that the model estimates multiple coefficients for each variable that violates the proportional odds assumption. Comparing these coefficients allows one to trace changes in the effect of the independent variables over the range of the ordinal dependent variable. They suggest increasing log-odds when positive and decreasing log-odds otherwise.

The results reported in Table 3.7 provide the test of the first hypothesis while those in Table 3.8 test the second hypotheses. As in the previous chapter, selection bias was avoided in the analyses of the different innovation types by estimating in two stages. Here, the first stage equation (results in Appendix (B.4) includes the variables SIZE, GROUP, TRAINING, EXPORT and OBSTACLES. Similarly, the obstacles measure (Cronbach's $\alpha=0.965$ ) is derived by combining 13 questionnaire items through factor analysis. The results for the third and fourth hypotheses are reflected, respectively, in the interaction terms in both tables. In all cases, two models are reported - one with continuous R\&D and the other with staff training as the proxy for absorptive capacity. 


\subsection{Results and Discussion}

\subsubsection{Descriptive results}

Of the 472 firms in the sample, about $97 \%$ had carried out at least one innovation during 2005-2007. The rate of innovation (Table 3.4) seems unusually high, most likely for two reasons. First, the definitions used in the survey are broad and encompass imitation as well as acquired products and processes that are new only to the firm. Second, innovative firms were apparently more responsive to the survey. Compared to informal knowledge sourcing, formal collaboration was much less prevalent among the entire sample of firms and its scope was rather low (Table 3.3) but the innovators appeared to be more active in networking. Of the innovators, $26 \%$ had been involved in formal cooperation or joint action with one or more actors and $85 \%$ made use of external sources of knowledge. In contrast, only $8 \%$ of non-innovators collaborated with external actors and only $17 \%$ used some external knowledge sources. The proportion of innovators that used external knowledge sources is significantly higher than non-innovators.

Table 3.4: Share of innovative firms, 2005-2007

\begin{tabular}{lc}
\hline Variable & Percentage $(\mathbf{n = 4 7 2})$ \\
\hline \hline All innovation & 97.5 \\
Product & 70.8 \\
Process & 78.2 \\
Marketing & 61.0 \\
Organisational & 75.2 \\
\hline
\end{tabular}

The pattern of the collaboration partners frequently employed by the sampled firms (Table 3.5) reveals the apparent importance of suppliers and customers. In a few interviews that were carried out as part of the pilot survey, it was found that the main collaborative activities that firms carried out with customers involved the identification and penetration of promising markets. This was particularly prevalent in sectors that produce fast-moving consumer goods where many firms have several kinds of formal arrangements to annually reward existing wholesalers/distributors with the highest sales and market expansion during each given year. Under this arrangement, customers bring new markets to the attention of the firms who assess the markets, and advise and 
support the customers to distribute the firm's product in the identified market. The results for the entire range of knowledge sources (Table 3.6) indicate that the most frequently used sources are customers, then suppliers. As noted in the previous chapter, other sources including competitors and industry associations are also highly important. Scientific sources are among the least used sources of knowledge. Consistent with previous studies (e.g., Zeng et al., 2010), the results indicate that Nigerian firms' innovation activities are strongly determined by relations with their suppliers and customers.

Table 3.5: Pattern of collaboration in Nigerian firms, 2005-2007

\begin{tabular}{lcc}
\hline \multirow{2}{*}{ Collaboration Partners } & \multicolumn{2}{c}{ Percentage } \\
\cline { 2 - 3 } & $\begin{array}{c}\text { All firms } \\
(n=472)\end{array}$ & $\begin{array}{c}\text { Innovators } \\
(n=460)\end{array}$ \\
\hline \hline Suppliers & 19.7 & 20.2 \\
Customers & 18.4 & 18.9 \\
Private Research Institutes & 16.3 & 16.7 \\
Competitors & 14.6 & 15.0 \\
Universities & 10.6 & 10.9 \\
Public Research Institutes & 9.5 & 9.8 \\
\hline
\end{tabular}

Note: Multiple response items. The survey questionnaire asked firms to indicate whether they "collaborated on any of [their] innovation activities" with any of the listed actors. None of the 12 non-innovating firms indicated having collaborated during the reference period.

While the relatively weak relevance of science-based sources to firms' innovation efforts might be connected to firm-level absorptive capacity, the result may be an indicator of a deeper challenge in the entire innovation ecosystem. On the one hand, output from the universities and research institutes may not be relevant to domestic industrial needs. One possible reason for this is the nature of funding. It has been noted that in the absence of proper domestic funding, many African researchers rely on external donors, aid agencies and grant-giving bodies to sponsor their work (Soboyejo, 2006). On the other hand, even if firms are incentivised to source new knowledge from publiclyfunded universities and research institutes, the quality of output from these institutions might not be satisfactory. Taken together, the foregoing results suggest the need for a shift in policy paradigm. Although universities and research institutes are and will remain relevant to industry, it is clear that a wider scope of knowledge sources will have higher innovation returns than any single source, no matter how important that source is. 
Table 3.6: Sources of information for innovation in Nigerian firms, 2005-2007

\begin{tabular}{lccc}
\hline & \multicolumn{3}{c}{ Percentage } \\
\cline { 2 - 4 } Information sources & $\begin{array}{c}\text { All firms } \\
(n=472)\end{array}$ & $\begin{array}{c}\text { Innovators } \\
(n=460)\end{array}$ & $\begin{array}{c}\text { Non-innovators } \\
(n=12)\end{array}$ \\
\hline \hline Customers & 75.0 & 76.5 & 16.7 \\
Suppliers & 72.2 & 73.9 & 8.3 \\
Competitors & 65.8 & 67.1 & 16.7 \\
Industry associations & 60.6 & 62.0 & 8.3 \\
Conference, fairs & 56.6 & 57.8 & 8.3 \\
Scientific journals and & & & 8.3 \\
trade publications & 52.3 & 53.5 & 8.3 \\
Private Research Institutes & 44.7 & 45.7 & 0.0 \\
Public Research Institutes & 33.3 & 34.1 & 0.0 \\
Universities & 32.4 & 33.3 & \\
\hline
\end{tabular}

Note: Multiple response items. The survey questionnaire asked firms "how important to [their] innovation activities were each of the [listed] information sources". Categories of degree of importance were 0 (not used)-1(Low)-2(Medium)-3(High). Percentages calculated with dichotomised responses.

\subsubsection{Estimation Results}

\section{Variety of linkages and innovation performance}

Hypothesis 1 testing the relationship between innovation performance and the size of the portfolio of partners is largely supported (Table 3.7). Model 1 contains the results when staff training and continuous $R \& D$ proxy absorptive capacity. As a robustness check, an alternative measure, RDPERF, which has a value of 2 if the firm continuously performs R\&D, 1 if occasionally and zero otherwise, was included in Model 2. This broader measure might better capture the firm's knowledge stock (Vega-Jurado et al., 2009). Model 3 is similar to Model 1 except that it excludes other knowledge-seeking activities such as acquisition of machinery and equipment. This is with a view to examining their importance in the relationships observed in Models 1 and 2. 
Table 3.7: Innovativeness and variety of linkages - generalised ordinal logit results

\begin{tabular}{|c|c|c|c|}
\hline & \multicolumn{3}{|c|}{ Overall scope of innovation (SINNO) } \\
\hline & $(1)$ & $(2)$ & $(3)$ \\
\hline$\overline{\text { BCOLLAB }}$ & $\begin{array}{r}10.093(0.761)^{*} \\
-10.390(0.795)^{*} \\
-10.492(0.793)^{*} \\
-10.312(0.808)^{*}\end{array}$ & $\begin{array}{r}10.248(0.944)^{*} \\
-10.446(0.951)^{*} \\
-10.515(0.952)^{*} \\
-10.360(0.951)^{*}\end{array}$ & $\begin{array}{r}8.772(1.056)^{*} \\
-8.995(1.078)^{*} \\
-8.904(1.067)^{*} \\
-8.832(1.065)^{*}\end{array}$ \\
\hline BEXTERN & $0.154(0.063)^{*}$ & $\begin{array}{r}-0.928(0.244)^{*} \\
1.000(0.240)^{*} \\
1.101(0.244)^{*} \\
1.108(0.246)^{*}\end{array}$ & $\begin{array}{r}0.606(0.125)^{*} \\
-0.513(0.127)^{*} \\
-0.389(0.125)^{*} \\
-0.401(0.126)^{*}\end{array}$ \\
\hline CONRAD & $\begin{array}{r}14.685(0.880)^{*} \\
-13.713(1.060)^{*} \\
-14.162(0.926)^{*} \\
-13.983(0.912)^{*}\end{array}$ & & $\begin{array}{r}18.014(2.130)^{*} \\
-15.921(2.254)^{*} \\
-17.032(2.151)^{*} \\
-16.979(2.143)^{*}\end{array}$ \\
\hline RDPERF & & $0.675(0.176)^{*}$ & \\
\hline TRAINING & $\begin{array}{r}3.936(0.535)^{*} \\
-3.225(0.507)^{*} \\
-3.000(0.547)^{*} \\
-3.395(0.579)^{*}\end{array}$ & $0.453(0.246)$ & \\
\hline MACHINERY & $\begin{array}{r}14.683(0.631)^{*} \\
-13.830(0.788)^{*} \\
-13.962(0.686)^{*} \\
-14.533(0.668)^{*}\end{array}$ & $\begin{array}{r}14.886(0.779)^{*} \\
-13.935(0.894)^{*} \\
-14.296(0.819)^{*} \\
-14.860(0.812)^{*}\end{array}$ & \\
\hline EXTERNAL R\&D & $0.517(0.216)^{*}$ & $0.487(0.211)^{*}$ & \\
\hline OTHER EXTERNAL & $-0.042(0.208)$ & $0.007(0.201)$ & \\
\hline BCOLLAB $^{2}$ & $\begin{array}{r}-2.902(0.205)^{*} \\
2.874(0.213)^{*} \\
2.913(0.209)^{*} \\
2.912(0.209)^{*}\end{array}$ & $0.002(0.035)$ & $\begin{array}{r}-2.440(0.331)^{*} \\
2.455(0.337)^{*} \\
2.425(0.334)^{*} \\
2.438(0.333)^{*}\end{array}$ \\
\hline BEXTERN ${ }^{2}$ & $-0.022(0.012)$ & $-0.022(0.012)$ & $-0.031(0.012)^{*}$ \\
\hline
\end{tabular}


Table 3.7 - Innovativeness and variety of linkages (...continued from previous page)

\begin{tabular}{|c|c|c|c|}
\hline & \multicolumn{3}{|c|}{ Overall scope of innovation (SINNO) } \\
\hline & $(1)$ & $(2)$ & $(3)$ \\
\hline BCOLLAB*BEXTERN & $-0.026(0.034)$ & $\begin{array}{r}-1.512(0.175)^{*} \\
1.486(0.176)^{*} \\
1.559(0.175)^{*} \\
1.538(0.175)^{*}\end{array}$ & $\begin{array}{r}0.539(0.151)^{*} \\
-0.556(0.155)^{*} \\
-0.502(0.155)^{*} \\
-0.520(0.155)^{*}\end{array}$ \\
\hline BCOLLAB*CONRAD & & & $-0.015(0.064)$ \\
\hline BEXTERN*CONRAD & & & $\begin{array}{r}-1.154(0.420)^{*} \\
0.919(0.427)^{*} \\
1.115(0.423)^{*} \\
1.089(0.422)^{*}\end{array}$ \\
\hline BCOLLAB*RDPERF & & $0.007(0.062)$ & \\
\hline BEXTERN*RDPERF & & $-0.108(0.050)^{*}$ & \\
\hline BCOLLAB*TRAINING & $\begin{array}{r}4.615(0.330)^{*} \\
-4.258(0.352)^{*} \\
-4.215(0.362)^{*} \\
-4.322(0.439)^{*}\end{array}$ & & \\
\hline BEXTERN*TRAINING & $-0.022(0.077)$ & & \\
\hline Controls & Yes & Yes & Yes \\
\hline _cons_1 & $4.172(0.510)^{*}$ & $6.602(0.697)^{*}$ & $3.733(1.032)^{*}$ \\
\hline -cons_2 2 & $0.409(0.435)$ & $0.425(0.410)$ & $0.734(0.394)$ \\
\hline cons 3 & $-1.401(0.433)^{*}$ & $-1.484(0.406)^{*}$ & $-1.299(0.381)^{*}$ \\
\hline _cons_4 & $-2.459(0.473)^{*}$ & $-2.831(0.447)^{*}$ & $-2.599(0.415)^{*}$ \\
\hline $\bar{N}$ & 472 & 472 & 472 \\
\hline McFadden $\mathrm{R}^{2}$ & 0.115 & 0.131 & 0.115 \\
\hline Log lik & -579.4 & -568.9 & -579.3 \\
\hline Akaike's IC & 1236.9 & 1209.8 & 1236.5 \\
\hline chi-sq & $2051.4^{*}$ & $757.2^{*}$ & $1305.1^{*}$ \\
\hline
\end{tabular}

${ }^{*} p<0.05$. Standard errors in parentheses. 
Consistent with previous research, the variety of linkages generally show significant positive association with innovation performance, as suggested by the constant component of the coefficients. The result is partly sensitive to the different specifications of absorptive capacity. While BCOLLAB has constant components that are always positive, the constant components of BEXTERN are only positive in Models 2 and 3. The significant positive relationships can be explained by the need for wide searching and experimentation before finding the right knowledge sources. By maintaining active interactions with a broad range of actors, firms will put themselves in a better position to achieve and sustain innovation. As Leiponen and Helfat (2010) noted, if the search for innovation is a probabilistic draw, the likelihood of success increases with the number of draws made. In other words, the larger the number of linkages a firm forms the more likely it is to form the right ones.

It is interesting to note that the association between linkages and innovation is somewhat affected by the acquisition of embodied technology. For formal linkages, the coefficients in Model 3 are in most cases smaller than the corresponding ones in Models 1 and 2. A similar result is found for informal linkages. While the coefficients in Model 3 turn negative as innovativeness increases, they remain constant in Model 1 and turn increasingly positive in Model 214 These point to the complementary effects of knowledge embodied in machinery and equipment as well as disembodied in external R\&D.

A particularly new insight provided by the results in Table 3.7 relates to the diminished importance of variety of linkages as innovativeness increases. This result is only weakly observed with informal linkages: in Model 3 the positive coefficient significantly reduces in magnitude as innovativeness increases but a different pattern is seen in Models 1 and 2. The evidence is much stronger in the case of formal linkages. Here, variety is good for innovation but clearly at low levels of capabilities only. At higher levels of capabilities (i.e. a score of SINNO greater than or equal to 1), maintaining a large portfolio of sources could be a liability rather than an asset. This is reflected in the significantly negative coefficients of BCOLLAB in all but the first row across all models.

Several reasons may be adduced for this finding. First, given the resource constraints that the firms face, forming too many linkages may lead to inefficiency as resources (time, funds and management) become spread too thin. This is related to the attention allocation issue that Ocasio (1997) discussed.

\footnotetext{
${ }^{14}$ For instance, at SINNO greater than 1 , the coefficient is 0.072 (that is, $-0.928+1$ ) and at SINNO greater than 3, the coefficient is 0.180 (that is, $-0.928+1.108$ ).
} 
The second reason for this result is that at very low levels of capabilities, marginal improvements are relatively easy to achieve and therefore, a larger number of knowledge sources positively influences capability accumulation. However, once basic capabilities are accumulated, what matters is no longer the number of linkages but their quality. Having mediocre sources might generate negative feedback loops with the firm's technological learning path. For instance, engaging with a redundant source may yield low benefits while increasing the opportunity costs to the firm.

Thirdly, more innovative firms already possess a significant pool of in-house capabilities and thus, a higher likelihood to generate knowledge spillovers. By definition, knowledge spillovers can potentially strengthen the competition and expose the firm to possible erosion of its competitive position (Arrow, 1962b). This holds true, though to a lesser extent, even if the linkages are formed with non-firm agents such as customers and universities which do not directly compete with the firm. It is impossible to completely stop these entities from sharing what they learn from the firm with its competitors. These problems are typically not associated with informal linkages.

Finally, the business context may also play a role. On the one hand, since the firms' typical innovation efforts are imitative and not particularly risky, costly investments in formal collaboration may be detrimental. On the other hand, because of the weak institutional and contract enforcement environment, collaborating enterprises may actually suffer losses due to expropriation and failed contracts.

Consistent with previous studies (e.g., Duysters and Lokshin, 2011), the coefficients of the quadratic terms in Table 3.7 are generally negative, indicating a turning point in the positive benefits of linkage variety, at least in the sample analysed here. At the constant components, the turning point is at about 3 sources, implying the need for firms to carefully select the actors that they will include in their portfolio of knowledge sources. Beyond this turning point, the cost of every additional linkage may outweigh the benefits (Ahuja, 2000).

\section{Linkage variety and different innovation types}

The results of the regression models for each innovation type are contained in Table 3.8. The odd-numbered models contain results when continuous R\&D proxies absorptive capacity and the even-numbered ones when staff training does. For instance, Model 1 reports the results for product innovation with 
R\&D as proxy for absorptive capacity and model 2 reports the same but with staff training as proxy for absorptive capacity.

In contrast to what was hypothesised in $\mathrm{H} 2 \mathrm{a}$, variety of formal linkages is not significantly associated with product and process innovations but rather with marketing innovation. The sign on the coefficients are also contrary to expectation. It seems to be that a larger variety of linkages is detrimental to marketing innovation, at least in the context studied here. This may be so because of the nature of marketing innovation as defined for this study: it involves changes to product or service design and packaging as well as in sales and distribution methods. Collaborating in these activities is particularly risky since it entails sharing some knowledge that may underlie the firm's market positioning. Also contrary to what hypothesis $\mathrm{H} 2 \mathrm{~b}$ states, the variety of informal linkages is more strongly associated with product and process innovation. In fact, it is not significantly associated with organisational innovation and shows negative significance for high levels of marketing innovation.

Taken together, these results provide no support for H2a and H2b as stated. Rather, they seem to support the opposite hypothesis that the variety of informal linkages is more strongly associated with technological innovation while non-technological innovation is only partly (and negatively) connected to linkages. Two possible explanations can be given for this finding. First, product and process innovations, by definition, require more knowledge input some of which the firm may not already possess. There is therefore the need to search for this knowledge externally. As already argued, Nigerian firms are more likely to approach their knowledge acquisition pursuits informally than through formal collaborations. Second, the kind of knowledge required for making marketing and organisational changes are comparatively less sticky and easily transferable. For this reason, interacting with a large number of external partners in relation to these innovation types particularly exposes firms to erosion of competitive advantage. 
Table 3.8: Different innovation types and variety of linkages - generalised ordinal logit results

\begin{tabular}{|c|c|c|c|c|c|c|c|c|}
\hline & \multicolumn{8}{|c|}{ Scope of ... innovation } \\
\hline & \multicolumn{2}{|c|}{ Product (SPROD) } & \multicolumn{2}{|c|}{ Process (SPROC) } & \multicolumn{2}{|c|}{ Marketing (SMARK) } & \multicolumn{2}{|c|}{ Organisational (SORG) } \\
\hline & $(1)$ & $(2)$ & $(3)$ & $(4)$ & $(5)$ & $(6)$ & $(7)$ & $(8)$ \\
\hline BCOLLAB & $-0.013(0.153)$ & $-0.236(0.212)$ & $-0.010(0.130)$ & $-0.126(0.174)$ & $-0.312(0.153)^{*}$ & $-0.526(0.196)^{*}$ & $-0.088(0.154)$ & $-0.137(0.196)$ \\
\hline BEXTERN & $0.094(0.047)^{*}$ & $0.142(0.061)^{*}$ & $0.169(0.045)^{*}$ & $0.174(0.065)^{*}$ & $\begin{array}{r}0.078(0.050) \\
-0.208(0.046)^{*}\end{array}$ & $\begin{array}{c}0.057(0.072) \\
-0.216(0.046)^{*}\end{array}$ & $0.007(0.05)$ & $0.007(0.068)$ \\
\hline CONRAD & $0.803(0.345)^{*}$ & $1.099(0.317)^{*}$ & $0.923(0.282)^{*}$ & $1.120(0.275)^{*}$ & $0.411(0.277)$ & $0.193(0.249)$ & $0.776(0.308)^{*}$ & $0.358(0.251)$ \\
\hline TRAINING & $0.417(0.381)$ & $0.542(0.403)$ & $0.308(0.363)$ & $0.342(0.366)$ & $\begin{array}{r}2.036(0.406)^{*} \\
-0.960(0.248)^{*}\end{array}$ & $\begin{array}{r}2.250(0.425)^{*} \\
-0.944(0.251)^{*}\end{array}$ & $\begin{array}{r}0.493(0.372) \\
0.238(0.252) \\
-0.489(0.346)\end{array}$ & $0.560(0.350)$ \\
\hline MACHINERY & $0.524(0.253)^{*}$ & $0.535(0.251)^{*}$ & $\begin{array}{r}1.383(0.491)^{*} \\
-1.289(0.438)^{*} \\
-1.035(0.477)^{*}\end{array}$ & $\begin{array}{r}1.246(0.501)^{*} \\
-1.150(0.460)^{*} \\
-0.815(0.496)\end{array}$ & $0.069(0.236)$ & $0.025(0.234)$ & $0.185(0.217)$ & $0.128(0.215)$ \\
\hline EXTERNAL R\&D & $0.223(0.219)$ & $0.183(0.219)$ & $0.474(0.213)^{*}$ & $0.427(0.214)^{*}$ & $0.144(0.219)$ & $0.141(0.222)$ & $0.097(0.21)$ & $0.095(0.217)$ \\
\hline OTHER EXTERNAL & $\begin{array}{c}0.278(0.260) \\
-0.580(0.227)^{*}\end{array}$ & $\begin{array}{r}0.303(0.262) \\
-0.586(0.229)^{*}\end{array}$ & $\begin{array}{c}-0.609(0.286)^{*} \\
0.787(0.191)^{*} \\
0.205(0.278)\end{array}$ & $\begin{array}{c}-0.571(0.287)^{*} \\
0.748(0.192)^{*} \\
0.150(0.280)\end{array}$ & $\begin{array}{r}-0.305(0.234) \\
0.691(0.196)^{*}\end{array}$ & $\begin{array}{r}-0.317(0.235) \\
0.698(0.195)^{*}\end{array}$ & $0.346(0.191)$ & $0.350(0.194)$ \\
\hline BCOLLAB $^{2}$ & $-0.016(0.048)$ & $-0.014(0.046)$ & $-0.005(0.04)$ & $0.007(0.041)$ & $\begin{array}{r}-0.089(0.054) \\
0.25(0.053)^{*}\end{array}$ & $\begin{array}{r}-0.075(0.052) \\
0.258(0.055)^{*}\end{array}$ & $0.008(0.040)$ & $0.002(0.039)$ \\
\hline BEXTERN $^{2}$ & $\begin{array}{r}0.000(0.014) \\
-0.035(0.011)^{*}\end{array}$ & $\begin{array}{c}0.008(0.014) \\
-0.034(0.011)^{*}\end{array}$ & $-0.022(0.012)$ & $-0.019(0.012)$ & $-0.011(0.013)$ & $-0.015(0.014)$ & $0.01(0.013)$ & $0.004(0.013)$ \\
\hline
\end{tabular}


Table 3.8 - Different innovation types and variety of linkages (...continued from previous page)

\begin{tabular}{|c|c|c|c|c|c|c|c|c|}
\hline & \multicolumn{8}{|c|}{ Scope of $\ldots$ innovation } \\
\hline & \multicolumn{2}{|c|}{ Product (SPROD) } & \multicolumn{2}{|c|}{ Process (SPROC) } & \multicolumn{2}{|c|}{ Marketing (SMARK) } & \multicolumn{2}{|c|}{ Organisational (SORG) } \\
\hline & $(1)$ & $(2)$ & $(3)$ & $(4)$ & $(5)$ & $(6)$ & (7) & $(8)$ \\
\hline BCOLLAB*BEXTERN & $0.025(0.033)$ & $0.025(0.037)$ & $\begin{array}{r}-0.071(0.032)^{*} \\
0.083(0.018)^{*} \\
0.090(0.023)^{*}\end{array}$ & $\begin{array}{r}-0.120(0.040)^{*} \\
0.107(0.031)^{*} \\
0.163(0.038)^{*}\end{array}$ & $\begin{array}{r}0.120(0.040)^{*} \\
-0.200(0.046)^{*}\end{array}$ & $\begin{array}{r}0.097(0.040)^{*} \\
-0.208(0.047)^{*}\end{array}$ & $0.009(0.041)$ & $-0.019(0.035)$ \\
\hline BCOLLAB*CONRAD & $-0.012(0.079)$ & & $-0.006(0.069)$ & & $0.096(0.072)$ & & $-0.037(0.064)$ & \\
\hline BEXTERN*CONRAD & $0.088(0.049)$ & & $0.051(0.042)$ & & $-0.076(0.044)$ & & $-0.111(0.049)^{*}$ & \\
\hline BCOLLAB*TRAINING & & $0.268(0.180)$ & & $\begin{array}{r}0.401(0.210) \\
-0.144(0.156) \\
-0.410(0.183)^{*}\end{array}$ & & $0.330(0.161)^{*}$ & & $0.153(0.157)$ \\
\hline BEXTERN*TRAINING & & $-0.099(0.073)$ & & $-0.032(0.074)$ & & $0.026(0.086)$ & & $0.009(0.084)$ \\
\hline Controls & Yes & Yes & Yes & Yes & Yes & Yes & Yes & Yes \\
\hline _cons_1 & $-7.183(8.694)$ & $-6.853(9.285)$ & $-8.68(8.216)$ & $-9.171(8.473)$ & $42.192(9.711)^{*}$ & $43.813(9.586)^{*}$ & $12.968(7.319)$ & $9.606(6.243)$ \\
\hline cons_2 & $-8.446(8.691)$ & $-8.151(9.282)$ & $-9.801(8.221)$ & $-10.356(8.482)$ & $25.021(9.608)^{*}$ & $26.542(9.008)^{*}$ & $12.998(7.516)$ & $8.767(6.24)$ \\
\hline cons_3 3 & & & $-10.638(8.217)$ & $-11.262(8.48)$ & & & $-5.835(8.417)$ & $7.486(6.229)$ \\
\hline $\bar{N}$ & 460 & 460 & 460 & 460 & 460 & 460 & 460 & 460 \\
\hline McFadden $\mathrm{R}^{2}$ & 0.137 & 0.137 & 0.138 & 0.144 & 0.0889 & 0.0883 & 0.0604 & 0.0475 \\
\hline Loglik & -422.8 & -422.7 & -509.1 & -505.5 & -450.6 & -450.9 & -585 & -593.1 \\
\hline Akaike'sIC & 893.6 & 893.4 & 1072.3 & 1069 & 955.2 & 955.9 & 1220.1 & 1228.2 \\
\hline chi-sq & $105.7^{*}$ & $102.9^{*}$ & $128.5^{*}$ & $142.9^{*}$ & $76.78^{*}$ & $75.03^{*}$ & $68.65^{*}$ & $54.36^{*}$ \\
\hline
\end{tabular}




\section{Formal and informal linkages}

The significant interaction hypothesised between formal and informal linkages is assessed by checking the interaction term (BCOLLAB*BEXTERN) in Tables 3.7 and 3.8. Positive and significant coefficients are expected, indicating a form of complementarity between formal and informal interactive learning.

Considering overall innovation performance (Table 3.7), the results are unclear. The coefficient is only significant in Models 2 and 3, but the sign is not always positive; it is consistently positive only at high levels of innovativeness (i.e. SINNO $>2$ ). This lends only partial support to H3. When considering the different innovation types (Table 3.8), the interaction coefficient is significant only for process and marketing innovation. For process innovation, this interaction first suggests a substitution relationship but turns into a complementary one at higher levels of innovation performance. The reverse is the case for marketing innovation.

These results give partial support to the third hypothesis. Moreover, the change in sign of the significant coefficients suggests that beyond certain levels of innovation performance, the combination of formal and informal approaches to networking becomes more (less) effective, particularly for process (marketing) innovation. This is probably due to apparent competition for resources and attention when the firm already has multiple collaboration partners and external knowledge sources.

\section{Absorptive capacity, linkages and innovation}

As the results in Table 3.7 show, absorptive capacity, in terms of continuous R\&D (CONRAD) and staff training (TRAINING), plays a positive role in overall innovation performance, although it tends to reduce in importance as innovativeness increases. At first glance, it is tempting to take this as suggestion for a diminished importance of absorptive capacity as innovativeness increases. But this interpretation is hard to advance because existing evidence seems conclusive on the idea that the more innovative a firm is, the higher its learning capacity since innovation leads to the creation of new knowledge which further intensifies absorptive capacity (Lane et al., 2002). In fact, as the constant positive coefficient of the alternative measure (RDPERF) suggests, the changing coefficients rather reflect an issue with the measure. While RDPERF is relatively more comprehensive, CONRAD and TRAINING capture 
only specific aspects of absorptive capacity accumulation, the one focusing on cumulativeness of $\mathrm{R} \& \mathrm{D}$ and the other instantaneous training efforts. With this in mind, it is easy to see why the coefficients will reduce in magnitude with the level of innovativeness: the returns to cumulative R\&D and training efforts are more likely to diminish than to remain constant or to rise.

The moderating role of absorptive capacity hypothesised in H4 finds only weak support. The interaction terms of training and continuous R\&D in Table 3.8 are hardly significant. In Table 3.7, the results are somewhat more robust. Training interacts positively and significantly with formal linkages but the magnitude of the moderating effect reduces as innovativeness increases (Model 1). In contrast, R\&D seems to substitute for informal linkages (Model 3) irrespective of the level of innovativeness (Model 2).

The substitution relationship is similar to what Laursen and Salter (2006) obtained for UK manufacturing. The 'not invented here' (NIH) syndrome (Katz and Allen, 1982) 15 is clearly not a satisfactory explanation for our results as inventive R\&D is not pervasive in the Nigerian firms. It seems more intuitive to argue that the firms suffer an attention allocation problem (Ocasio, 1997) as they have to balance between in-house knowledge creation and multiple external knowledge sources.

\subsection{Conclusions and Implications}

This chapter addressed questions concerning the relationship between networkingin terms of collaboration and use of external sources of knowledge - and innovativeness of firms. The first question relates to the importance of the variety of a firm's linkages. The second explores the relationship between networking strategies and different innovation types. The third relates to the possibility of interaction effects arising from simultaneous use of both formal and informal linkages by firms. The fourth question was on the role that absorptive capacity plays in the foregoing relationships.

These issues were explored using a unique dataset within the context of the manufacturing and service sectors in Nigeria. From the descriptive results we conclude that innovation in Nigerian manufacturing and services is more influenced by inter-firm linkages as well as interaction with market-based sources.

\footnotetext{
${ }^{15}$ This is the situation which typically occurs within organisations when internal knowledge becomes "sufficiently overlapping and specialized that it impedes the incorporation of outside knowledge" (Cohen and Levinthal, 1990, p. 133).
} 
Scientific sources such as universites and research institutes were found to be of relatively less importance.

The regression results support the hypothesis of a positive relationship between firms' innovativeness and the variety of both formal and informal network partners. Controlling for the level of innovativeness in a generalised ordinal logit procedure allowed us to examine this result as a firm becomes more innovative. Interestingly, it was found that the utility derived from linkage variety reduces significantly as firms become more innovative. This suggests the need for firms to pay particular attention to selecting appropriate partners. It also draws attention to the question of whether firms need to even form linkages at all once they are able to achieve innovation on their own.

The relationship between linkages and innovativeness was also found to be partly positive and not uniform for the four innovation types considered here. For product and process innovations, informal linkages are relatively more important than having formal collaboration. A non-robust significant interaction was also found between formal and informal linkages, which suggests that combining formal and informal linkages depends a lot on the firm's innovation focus. As the level of innovativeness rises, the combination becomes more effective for process innovation and less effective for marketing innovation. Absorptive capacity was shown to play an important role but not so much in moderating the effect of linkages as in directly improving the firm's ability to innovate. In general, the results point towards a difference in the way different innovation types are affected by networking. In this regard, product and process are more similar and both contrast with marketing and organisational innovation.

This study has some connotations for policy making. Despite the interest and commitment that government has in supporting university-industry interaction as a key driver of industrial innovation, the results herein show that the innovation activities of firms are still fashioned more by their relationships with their customers and suppliers. In comparison to these sources of innovation, universities and research institutes are of much less relevance. In a sense, it could then be put forth that placing emphasis on university-industry interaction as a stimulant to innovation seems a misplaced priority - trying to stimulate relationships which may have a faint impact on firm-level innovative performance. Consequently, increased attention needs to be paid to diversification of knowledge sources rather than emphasising a particular knowledge source. This is not to argue that universities are not useful for innovation. The point being made is that in a latecomer setting like Nigeria, where innovation 
takes place much less radically than in advanced settings, firms will benefit more from a broad base of knowledge than from any single knowledge source. This is even truer when the relatively low quality of the universities is taken into account.

For firms, the need to be more open in their innovation efforts and to engage with various actors is highlighted by the results. This has been a main conclusion from several previous studies and this study also confirms the relevance of this for developing country firms. An additional insight provided by this study is the fact that care has to be exercised in selecting an approach to networking and in choosing the specific partners to include in the portfolio of partners. This is because networking does not seem to hold significant benefits for all innovation types. Moreover, firms are not likely to reap the full benefits of either their collaborative or information sourcing activities unless they know when to combine both strategies, and more importantly, when to reconsider their networking decisions. In fact, we can argue based on the results in this chapter that the best networking strategies will be those that take into account the firm's current innovative efforts. More or less of specific kinds of linkages will be required depending on what types of innovation the firm seeks to achieve.

This chapter is a modest step forward in understanding the relationships between networking and innovativeness in the developing country context. To aid comparison and validation of findings, more country studies of this nature are desirable. The relationship between collaboration and external knowledge sourcing is itself an interesting issue that should be better understood. For instance, it would be useful to know what types of firms use what sources of information and when. Additionally, a focus on the aspect of diversity of linkages and the various contingencies involved will be interesting. For instance, Oerlemans et al. (2013) already show that the relationship between alliance portfolio diversity not only varies between radical and incremental innovation, it is also contingent upon the use of technology management tools by the firm. This, indeed, is worth further study. Finally, the spatial dimension which recent studies such as Grillitsch et al. (2013) exemplify is also worth further exploration. It helps to know, for instance, whether domestic sources are preferable to international ones. 


\section{Part II}

\section{THEORETICAL ANALYSES}




\section{Chapter 4}

\section{Absorptive Capacity and Inter-firm Cooperation}

\subsection{Introduction}

This chapter presents a new theoretical model of absorptive capacity and cooperation between firms. The aim is not to completely capture the motivations for cooperation; rather, we focus on a very specific effect, that is, knowledge sharing or what De Bondt (1996) termed the "voluntary exchange of useful technological information." In this sense the model shares the features of Cowan's et al (2007) model of bilateral collaboration where firms form alliances purely based on the production of shared knowledge.

Inter-firm cooperation for learning and innovation has become more common in recent years, mainly due to rapid technological progress and changes in the business environment. Accelerating technological knowledge and rising costs of R\&D make it virtually impossible for any firm to maintain in-house all the capabilities and knowledge required for production. Moreover, increasing specialisation creates a situation where firms occupy relatively narrow positions in the knowledge space. Consequently, firms often need knowledge 11 that lies outside

\footnotetext{
${ }^{1}$ Henceforth, knowledge in this sense includes technologies that firms use in innovation. Innovation here refers to a technically new product which develops as an outcome of $R \& D$ (see the Oslo Manual, OECD, 2005). Consequently, by R\&D profit we imply profit due to innovation.
} 
their core competence. The formation of alliances with other organisations has proven to be an effective way to access external knowledge to complement endogenous capabilities (Powell and Grodal, 2005; de Man and Duysters, 2005; Brusoni et al., 2001; Bamford and Ernst, 2002; Powell, 1998).

For alliances to have the desired effects, firms require absorptive capacity to understand and apply externally generated knowledge. This capacity is developed by investing in R\&D (Cohen and Levinthal, 1989, henceforth CL) 2 Moreover, the effectiveness of alliances is known to have an inverted ' $U$ '-shaped relation with cognitive distance. In alliance formation, therefore, firms need to balance between their technological heterogeneity and overlap with potential partners (Nooteboom, 1999b). This creates a proximity trade-off and has been a major focus in the recent literature 3

However, other issues are also important. Reciprocal terms of cooperation require a firm to share some of its knowledge with the partner in order to gain access to the latter's knowledge base (Fehr and Gächter, 2000). This is like a 'two-edged sword': if the partner can learn faster and is more capable to innovate, a firm then runs the risk of making its partner better at its own expense. For this reason, voluntary spillovers or appropriability conditions between cooperation partners become a very critical factor to consider in cooperation. For the same reason, a firm will take the R\&D efforts of its potential partner seriously since that is the main source of absorptive capacity. When these are combined with the challenge of cognitive distance, an important practical question arises: when is it better for a firm to cooperate?

In this chapter, we approach the question from a theoretical perspective by looking at the contribution of absorptive capacity (driven by cognitive distance, appropriability conditions and external knowledge) to firms' $\mathrm{R} \& \mathrm{D}$ profit. To do this, we develop a model of inter-firm cooperation in which partners increase their knowledge stock by sharing complementary knowledge. The amount of external knowledge absorbed depends on absorptive capacity, and the new knowledge affects firm performance through innovation-driven profit. For a

\footnotetext{
${ }^{2}$ Although recent studies have argued that absorptive capacity, being a multidimensional concept, is not fully proxied by R\&D or staff quality alone (Freitas et al., 2011; Zahra and George, 2002), we assume that a significant portion of it is embodied in R\&D performance. Therefore, our conceptualisation of absorptive capacity in this chapter derives mainly from a firm's R\&D investments.

${ }^{3}$ Some studies (e.g., Cantner and Meder, 2007; Mowerv et al., 1996) have also shown that cognitive proximity increases over time. This affects the learning and innovation potential of an alliance and reduces the likelihood that the same partners will cooperate persistently. This dynamic is important and is addressed in the next chapter.
} 
representative agent, we examine the conditions under which the cooperative strategy is superior to non-cooperation in terms of profit generated.

Two things set our model apart. First, a firm develops absorptive capacity not as a side-effect of total $R \& D$ but by devoting a share of its total $R \& D$ budget explicitly to it. This creates an investment trade-off. Second, accounting for cognitive distance allows us to distinguish voluntary spillovers within an alliance from other forms of external knowledge. With these elements, we are able to modify the original absorptive capacity model of CL for the context of inter-firm alliances. We use that to study how cooperation affects firm performance in terms of profit. But the analyses in the present chapter treat cognitive distance as exogenous. This simplification allows us to focus on the specific effect in which we are interested: how the profits of a representative firm evolve with regard to its cooperation strategy. In the next chapter, we extend our model to analyse the dynamic scenario in which firms' absorptive capacity and their cognitive distance are affected by past decisions.

This study contributes to understanding cooperation and R\&D investment preferences of firms and, therefore, has important theoretical and practical applications. The theoretical predictions of our model are more relevant in the context of interactive learning, and our comparative results offer some practical insight on alliance formation decision-making.

\subsection{Theoretical Background}

\subsubsection{From social capital to knowledge fit}

Innovation is, by nature, a highly uncertain process which involves recombination of knowledge (Dosi, 1988). Recombination is facilitated when knowledge diffuses effectively. Networks are often perceived as an infrastructure for knowledge diffusion (Cowan, 2005; Graf, 2006). These networks usually arise out of voluntary cooperation either among firms or between firms and other economic agents. A standard result in studies of strategic alliances and networking is that firms benefit through cooperation. The benefits show up in terms of accessing complementary resources, division of labor, risk sharing, reduction of uncertainty and improved chances of innovative success through multiple search efforts (Pittaway et al., 2004; Powell, 1998). Two alternative explanations for the emergence of and benefits derived from networks can be found in literature. 
From the social capital perspective, network position is considered to be very crucial, such that more central firms tend to outperform peripheral ones both in terms of successful alliances and innovativeness (Gulati, 1995; Powell et al., 1999). For this reason, alliances are thought to be largely motivated by social capital considerations (Coleman, 1988; Ahuia, 2000; Burt, 2004; Gilsing et al., 2008) and most of the empirically observed properties of innovation networks are explained by the fact that firms are seeking to increase their number of economically valuable connections. In particular, some authors argue that it is strategically important to combine both relational and structural embeddedness in networks (Moran, 2005; Rowley et al., 2000). In this regard, small world structures are thought to be particularly beneficial for innovation and the diffusion of knowledge (Schilling and Phelps, 2007).4

From a knowledge perspective, alliances can be heavily motivated by technological fit. That is, the extent to which partners potentially learn from each other (Cowan, 2005; Wersching, 2010). On the one hand, what is missing from a firm's stock of knowledge and competences influences its decision to cooperate and its choice of partners. In this sense, multiple partnerships may not be necessary and a firm may stop its partnership search once it locates a technologically fit partner. On the other hand, a firm's suitability is assessed by potential partners on the basis of what is present in its knowledge base. Thus, firms' internal knowledge deficiencies and externally available complementarities play a significant role in the emergence of innovation networks. In this regard, small world structures are important because they preserve the quantity and diversity of knowledge (Baum et al., 2003), thereby affecting the learning and innovation potential of alliances.

The analyses in this chapter and the next are carried out from the knowledge perspective. In this regard only very few studies exist, and we believe that a knowledge-based perception of alliance will nicely complement the social capital emphasis in the extant literature.

\subsubsection{Spillovers and absorptive capacity}

Technological progress develops along certain trajectories within a given technological paradigm. Each of these trajectories contains some technological opportunities which are either intensive or extensive. In the former case, firms ex-

\footnotetext{
${ }^{4}$ With respect to a network of firms, a small world is a network in which distinct regions with dense interconnectedness (or cliques) of firms are linked by relationships (or clique spanning ties) that act as information conduits between them (Watts and Strogatz, 1998).
} 
plore opportunities on a particular trajectory by investing in own $R \& D$. In the latter case, firms make use of external knowledge generated by other firms and public research. For this, however, at least a share of the external knowledge must not be a private good (i.e., not appropriated by the owner). The magnitude of this share depends on the effectiveness of the mechanisms by which knowledge is protected - the appropriability conditions (Dosi, 1982).

In the literature, there is a long discussion on the trade-off between knowledge spillovers and appropriability conditions starting from Arrow (1962a). It is argued that spillovers create a negative appropriability incentive. Reducing the innovation rent, large spillover possibilities result in lower (than optimal from a social point of view) level of $R \& D$ investments. However, due to the heterogeneity of firms, knowledge transfer via these spillovers contributes to technological progress and can be beneficial for recipient firms (de Fraja, 1993) 5 Those spillovers are nevertheless only effective if the recipient of knowledge has a sufficient capacity to absorb it.

Absorptive capacity, that is the ability to value, assimilate and apply new knowledge, was originally conceptualised by CL as a byproduct of a firm's R\&D efforts. By allowing the firm to complement its own knowledge with incoming spillovers, this capacity enhances a firm's problem-solving ability (Kim, 1998). Zahra and George (2002) extended the concept of absorptive capacity by differentiating between potential and realised absorptive capacity. Potential absorptive capacity involves the acquisition and assimilation of knowledge spillovers, while realised absorptive capacity guarantees the application of this knowledge through the development and refinement of routines that facilitate its transformation and exploitation.

As already hinted, spillovers generally arise from two sources: public and private R\&D. Compared to public R\&D, spillovers from private $R \& D$ are often not easily accessible. Moreover, in the context of today's rapidly changing and highly competitive business environment, spillovers from other firms' R\&D sometimes provide more relevant complementary resources. Thus, firms often feel the need to engage in cooperation with other firms to gain access to such knowledge spillovers. In this context, both dimensions of absorptive capacity are at work. Potential absorptive capacity helps the firm to identify an appropriate partner and learn from it, while realised absorptive capacity enables the firm to deploy the knowledge acquired in innovation which enhances profit. Indeed, recent empirical work on inter-firm learning and alliances has shown

\footnotetext{
${ }^{5}$ Recently, the social returns to R\&D have been estimated by Bloom et al. (2013) to be at least twice as high as the private returns.
} 
that firms with higher absorptive capacity tend to benefit more from external knowledge (e.g., de Jong and Freel, 2010; Lin et al., 2012).

When a firm engages in cooperation, in addition to involuntary spillovers from other sources it can also appropriate voluntary spillovers from its partners (Gulati, 1998). But securing access to voluntary spillovers through partnerships has a potentially negative side effect because of the reciprocity that characterises cooperative arrangements. In exchange for accessing a (potential) partner's knowledge stock, a firm also needs to open up its own knowledge base (Fehr and Gächter, 2000). Consequently, spillovers from the firm's R\&D efforts do not only reduce its own appropriation, they potentially improve its competitor's R\&D performance 6 This is a cost of partnership which constitutes another form of the negative appropriability incentive.

The negative incentive is lowered because the partner firm does not possess perfect absorptive capacity to appropriate all the spillovers (CL, p. 575-6; Hammerschmidt, 2009, p.426). Thus, what a firm worries about is not necessarily the total spillovers it generates, but how much its partner can absorb. That is, the effective spillovers which increase as the absorptive capacity of this (competing) partner increases.7 Moreover, the firm also benefits from cooperation because it has access to a pool of knowledge larger than just its own, particularly when the partner holds complementary technological knowledge thereby creating a higher potential to innovate.

\subsubsection{Absorptive capacity and $\mathrm{R} \& \mathrm{D}$ investment alloca- tion}

The discussion so far is based on a perception of absorptive capacity as a passive by-product of $\mathrm{R} \& \mathrm{D}$ investments made to generate inventions. However, it can be argued that the allocation of $R \& D$ resources is not a simple and unidirectional decision. A distinction can be made between absorptive $R \& D$ and inventive $R \& D / 8$ Absorptive $R \& D$ refers to the investments made to benefit

\footnotetext{
${ }^{6}$ This point is important for our model and will be applied later in formulating the firm's profit.

${ }^{7}$ In our model we are concerned with firms competing on the same technological trajectory. In the extreme case that the cooperating partners operate in different industries, competition between them is mostly negligible. In this case, spillovers do not constitute a disincentive to cooperation and R\&D investments (Cantner and Pyka, 1998, p. 374).

${ }^{8}$ This way, we explicitly capture the two faces of R\&D which the earlier empirical analyses could not.
} 
from knowledge spillovers while inventive R\&D is the effort made by a firm to generate original knowledge (Hammerschmidt, 2009; Cantner and Pyka, 1998). This distinction reflects the difference between "the exploration of new possibilities and the exploitation of old certainties" (March, 1991, p. 71)9 as well as the common classification of R\&D into basic and applied research. As Cassiman et al. (2002) showed, by doing basic R\&D a firm can effectively access incoming knowledge spillovers which then help to increase the efficiency of own applied R\&D.

In this sense, absorptive capacity is no longer a passive by-product of $R \& D$, but an explicit part of the firm's strategy. This strategic necessity is even more important when the external knowledge (which a firm desires to appropriate) is not close to its prior knowledge. This is also true when the knowledge, such as that which comes from universities and research institutes, is not directly applicable to the needs of the firm. In this case, CL (p. 572) argue that a firm's capacity to appropriate the knowledge increases as the firm invests more in R\&D. This argument is extended with the distinction between inventive and absorptive $R \& D$; it can now be noted that it is not routine $R \& D$ but explicit investments in the form of absorptive $R \& D$ that facilitates the build-up of absorptive capacity. At the same time, firms need to build up a certain level of capacity to generate own knowledge through inventive R\&D 10 Consequently, firms are faced with the strategic decision of how to optimally allocate resources between inventive and absorptive R\&D, which, though complementary, are mutually exclusive. This constitutes an investment trade-off that holds important implications for a firm's learning abilities and cooperation preferences.

\footnotetext{
${ }^{9}$ Even in this framework the understandability-novelty trade-off exists. In the context of exploitation, wherein firms are concerned with improving their performance along the same technological trajectory, a high level of mutual understanding is required to reduce transaction costs (Drejer and Vindig, 2007; Cantner and Meder, 2007). Notwithstanding, since technological opportunities within a certain trajectory tend to decrease continuously according to Wolff's law (Cantner and Pyka, 1998), firms seek for more explorative or extensive opportunities, the aim of which is to generate novelty. Consequently, increasing cognitive distance positively influences the value of interactive learning because it raises the novelty value of technological opportunities as well as the possibility of novel combinations of complementary resources. This, however, is only possible as long as the partners are close enough to understand each other.

${ }^{10}$ This is a mechanism that assures the presence of reciprocal incentives for cooperation (Kamien and Zang, 2000; Wiethaus, 2005).
} 


\subsubsection{Cognitive distance}

The relative value of knowledge spillovers can be represented by the distance between partners. If the distance is small, firms understand each other well and there is much less uncertainty (Lane and Lubatkin, 1998), but there might be no new knowledge to learn and, hence, there is the risk of lock-in. In contrast, if the distance is large, the knowledge has higher novelty but is too difficult to absorb and coordination problems may arise (Boschma, 2005). This leads to the optimal cognitive distance hypothesis which has been the subject of many studies. The consensus in the empirical literature is that technological or cognitive proximity between cooperation partners has an inverted ' $U$ 'shaped relation with the value of learning the partners obtain (or, alternatively, the innovative potential of the alliance) (Lin et al., 2012; Gilsing et al., 2008; Nooteboom et al., 2007; Wuyts et al., 2005). An understandability-novelty trade-off exists such that effective learning by interaction is better accomplished by limiting cognitive overlap while securing cognitive proximity 11

\subsubsection{Some modelling antecedents}

Historically, modelling studies have treated the R\&D investment and cooperation decisions of firms only with respect to exogenous spillovers (see De Bondt, 1996, for an overview). Typically, such spillovers, especially when they are symmetric, have a negative effect on strategic R\&D investments. At the same time, they incentivise firms to engage in cooperation and to make bilateral investment commitments. Later models account for absorptive capacity and show that technological heterogeneity, as reflected in relatively high (exogenous) spillover rates, incentivises the build-up of absorptive capacity (Hammerschmidt, 2009). Even when spillovers are endogenous, as is the case in the model of Cantner and Pyka (1998), allocating more resources to absorptive R\&D as spillovers increase tends to be a more profitable strategy when compared with other strategies such as the one in which the firm concentrates purely on invention. A limitation of these studies is their failure to account for strategic alliance formation as a way for firms to access complementarities,

\footnotetext{
${ }^{11}$ In a dynamic sense, cognitive overlap tends to increase with cooperation intensity (Mowery et al., 1998). Thus, it is expected that a firm will reconsider its cooperation decisions depending on cognitive distance. Alliances may be discontinued when partners become too close and previously discontinued alliances may be re-formed if the partners have become sufficiently distant in terms of their knowledge endowment. This dynamic aspect is taken up in the next chapter
} 
pool knowledge resources or innovate jointly.

In more recent models (Cowan et al., 2007; Baum et al., 2010), alliance formation is driven by its probability to succeed in terms of knowledge generation and innovation, as well as the proximity of the potential partner. Among other things, the models present knowledge sharing as a major motivation for alliance formation. In particular, even in the absence of any social capital consideration 12 , empirically founded network characteristics such as repeated alliances, transitivity and clustering can be observed. However, these models treat absorptive capacity as an exogenous parameter which is similar for all firms in the network. This simplification is motivated by the fact that it allows to focus on the nature of the innovation process and its effects on emergent network properties. However, this imposes the neglect of an important source of heterogeneity, that is, differences in firms' learning rates.

Although our model shares some features of these recent studies, an important contribution we make is that absorptive capacity is not modeled exogenously. In contrast, it is endogenous and is influenced by the two trade-offs described earlier. Ultimately, cooperation decision is driven by proximity considerations, endogenous absorptive capacity and the cost of partnership in terms of the knowledge spillovers that a potential partner can absorb.

\subsection{The Model}

In the model, a total of $N$ firms compete within a defined knowledge space. A firm seeks to maximise its profit from generating innovations. It does this by developing absorptive capacity to gain from knowledge spillovers while also maintaining own inventive $R \& D$. Consequently, the firm needs to decide how to allocate its R\&D investments between own invention and the development of absorptive capacity. Knowledge spillovers arise voluntarily through interfirm cooperation and involuntarily from non-cooperative sources. The decision on investment allocation is affected by cognitive distance (from both types of spillovers); larger distances correspond to higher resource heterogeneity or

\footnotetext{
${ }^{12}$ This means that technological fit, rather than social capital factors like trustworthiness and embeddedness, is a major causal force behind alliance formation (Baum et al., 2010). Firms will select partners from whom they can learn significantly and for specific (shortterm) purposes. In this sense, multiple partnerships may not be necessary and firms stop their partnership search once they find a technologically fit partner.
} 
novelty potential but also to larger investments required to absorb them.

For the analyses in this chapter, these distances are given exogenously 13 Each firm resolves the investment trade-off and makes a cooperation decision. This decision is influenced by cognitive distance, $R \& D$ investments and appropriability conditions. We are particularly interested in the conditions under which cooperation is superior to non-cooperation. To study this, we compare the R\&D investments and profits for a representative firm when it engages in $R \& D$ cooperation and when it does not.

Before describing the model elements in detail, Some important assumptions are to be noted. Firstly, in making their cooperation decisions, firms consider only their short term potential profits. This assumption reflects firms' behaviour when the frontier of knowledge is rapidly extending, in which case the pressure to innovate quickly is high, or when productive activities require a rapidly expanding knowledge base, in which case firms need to cooperate so as to gain access to complementary knowledge (Cowan et al., 2007).

Secondly, firms only select one partner and conduct one R\&D project in a given period. This is a simplifying assumption that improves the tractability of the model, allowing us to focus exclusively on knowledge sharing between unique pairs of firms, and is computationally more feasible. The cost of scanning the environment is incurred by all firms and is therefore not considered in the analyses.

Thirdly, the reliability and trustworthiness of potential partners are not taken into account in the selection of cooperation partners. This follows partly from the short-termism with which firms approach partner selection. In addition, since the potential partners both have reciprocal incentives for cooperation, their likelihood to misbehave is significantly lower. Otherwise, firms can simply discontinue the partnership in the next period preventing an access to their voluntary spillovers.

Finally, firms are assumed to have perfect information about the knowledge base of other firms 14 This assumption appears to be rather strong and is in contrast with the common perception that firms have imperfect information about partners' knowledge and motivations (Oxley, 1997). However, it

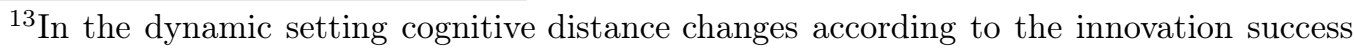
and learning of the firms.

${ }^{14}$ This does not necessarily eliminate the risks associated with innovation. First, firms need to be able to understand the information available, an endeavour which is by itself costly and risky. Then, innovation still runs the risk of failing, irrespective of how well-informed firm's cooperation decisions are.
} 
finds justification in the fact that the capabilities and strategic focus of potential partners can be easily assessed through massive information that is freely available. For example, a firm's patent portfolio (which can be freely accessed online) contains significant information on its knowledge stock and market value (Hall et al., 2005). Thus, patents constitute a comprehensive representation of the knowledge space in an industry 15 In addition, there are several other channels through which reliable information can be obtained, for example, scientific and technical articles, hiring, and informal networks (see footnote 3 in Baum et al., 2010, for more details on this).

\subsubsection{R\&D investments}

In accordance with $\mathrm{CL}$, we consider R\&D investments as an instrument to stimulate absorptive capacity. However, this capacity is considered not a byproduct of the total R\&D investments but of a separate share of it. Thus, we distinguish between investments directly in $R \& D$ that exploit identified technological opportunities $\left(r d i_{i}\right)$ and investments for exploring the environment for technological development $\left(a c i_{i}\right)$, together forming total R\&D spending $\left(R D_{i}\right)^{16}$ :

$$
R D_{i}=r d i_{i}^{t}+a c i_{i}^{t}=\rho_{i}^{t} R D_{i}+\left(1-\rho_{i}^{t}\right) R D_{i} .
$$

This investment trade-off is shaped by learning incentives including the potential quantity and complexity of external knowledge either within a partnership or beyond it, both of which, in the context of cooperation, are proportional to cognitive distance.

\subsubsection{Knowledge generation}

In line with CL, firm $i$ 's stock of knowledge in period $t\left(k_{i}^{t}\right)$ is increased by a quantity comprising the firm's own direct investment in R\&D and externally

\footnotetext{
${ }^{15}$ Note also that investments in screening and understanding this knowledge (e.g., by hiring patent lawyers) can be considered as a separate share of a firm's R\&D budget, further justifying the distinction in $\mathrm{R} \& \mathrm{D}$ investments applied in the model.

${ }^{16}$ We abstract from production and the market by treating the R\&D budgets as exogenous. In this way, the focus of the model is narrowed to the firm's investment and cooperation decisions, and innovation.
} 
generated knowledge which, in turn, consists of other firms' R\&D $\left(r d i_{h}^{t}\right)$ and knowledge generated by public institutions $(e k)$ :

$$
k_{i}^{t}=\left(r d i_{i}^{t}\right)^{\xi}+a c_{i}^{t}\left(\delta_{n} \sum_{h \neq i} r d i_{h}^{t}+e k^{t}\right),
$$

where $\xi \in(0,1)$ is a parameter which defines the rate of return to inventive $\mathrm{R} \& \mathrm{D}, \delta_{n} \in(0,1)$ reflects the fraction of knowledge not appropriated by firms and $a c_{i}^{t} \in(0,1)$ is the degree to which firm $i$ can absorb external knowledge, i.e. absorptive capacity. The summation term in (4.2) assumes no cooperation between firms, hence no voluntary knowledge spillovers. All firms want to ensure that the value of $\delta_{n}$ is as low as possible.

However, within a cooperative context the situation is different. Besides involuntary spillovers $\left(\delta_{n}\right)$, firm $i$ can also appropriate voluntary spillovers $\left(\delta_{c}\right)$ from its strategic partner. Thus,

$$
k_{i}^{t}=\left(r d i_{i}^{t}\right)^{\xi}+a c_{i}^{t}\left(\left(\delta_{c}+\delta_{n}\right) \sum_{j \neq i} r d i_{j}^{t}+\delta_{n} \sum_{j \neq h \neq i} r d i_{h}^{t}+e k^{t}\right), 1>\delta_{c}>\delta_{n}>0
$$

The term $\delta_{c}+\delta_{n}$ reflects total spillovers available to a cooperating firm and is always below 1 . In a dyadic relationship, only one partner $j$ is present, and it can be assumed that all involuntary spillovers available are included in the total external knowledge $e k 17$ Therefore,

$$
k_{i}^{t}=\left(r d i_{i}^{t}\right)^{\xi}+a c_{i}^{t}\left(\delta_{c} r d i_{j}^{t}+e k\right)
$$

As stated earlier, we assume that firms have a perfect knowledge about their distance to potential partners and about partners' R\&D budgets. Now, since any particular firm takes a decision on the investments in R\&D based on the investment decision of its potential partner, we assume that in any given period each firm forms an expectation, considering the current investment decision of the partner to be equal to the recent past. With a representative agent and

\footnotetext{
${ }^{17}$ This follows partly from our focus on dyadic partnerships. In this sense, knowledge spillovers from other firms not in the dyad and from public organisations together constitute technological opportunities for the dyad.
} 
exogenous cognitive distance, this simply translates into an assumption of perfect knowledge about the partner's investment allocation. That is,

$$
E^{i}\left(\rho_{j}\right)=\rho_{j}
$$

External knowledge, $e k$, is set as the total inventive R\&D investment of firms ( $N$ firms in total) in the knowledge space which the firm $i$ can potentially understand, rescaled by the parameter of involuntary spillovers $18 \delta_{n} \in(0,1)$ :

$$
e k^{t}=\delta_{n} \sum_{i \neq h=2}^{N} r d i_{h}^{t} .
$$

In the meantime we drop the time argument $t$ to remove the notion of dynamics. This notion is picked up again in the next chapter.

\subsubsection{Absorptive capacity}

Absorptive capacity $\left(a c_{i}\right)$ is dependent on two variables: i) the distance $\left(d_{i}\right.$. between firm $i$ 's knowledge base and external knowledge available and ii) the investments in absorptive capacity $\left(a c i_{i}\right)$ made by the firm. As explained earlier, shared knowledge is the main motivation for alliance formation between any pair $i j$ of firms. Following Wuyts et al. (2005), this knowledge can be represented as the mathematical product of its novelty value (which increases in cognitive distance) and understandability (that respectively decreases in cognitive distance):

$$
a n_{i, j}=\left(\alpha d_{i j}\right)\left(\beta_{1}-\beta_{2} d_{i j}\right)=\alpha \beta_{1} d_{i j}-\alpha \beta_{2} d_{i j}^{2},
$$

And accounting for the stimulating role of investments in absorptive capacity $\left(a c i_{i}\right)$ :

$$
a n_{i, j}=\alpha \beta_{1} d_{i j}\left(1+a c i_{i}^{\psi}\right)-\alpha \beta_{2} d_{i j}^{2}=\alpha \beta_{1} d_{i j}+\alpha \beta_{1} d_{i j} a c i_{i}^{\psi}-\alpha \beta_{2} d_{i j}^{2},
$$

where $\psi \in(0,1)$ reflects the efficiency of absorptive R\&D investment. This investment, which has has decreasing marginal returns, essentially causes an 


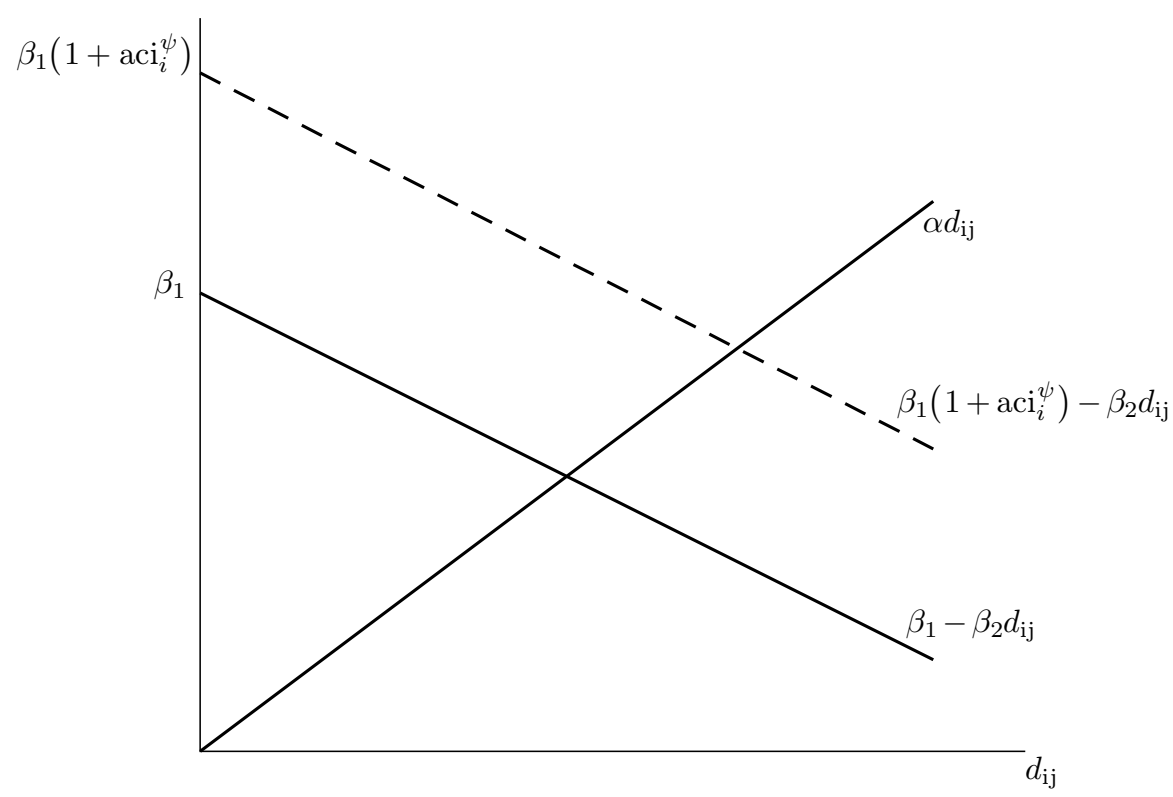

Figure 4.1: Novelty potential and understandability as functions of cognitive distance

upward shift in understandability for any given $d_{i j}$. The relationships just described are illustrated in Figure 4.1.

Since the aim of the firm is to maximise the knowledge it absorbs given its current level of absorptive capacity, we proceed by considering absorptive capacity as a function of the knowledge absorbed by $i$ from its cooperation with $j$. Specifically, it is presented as $a n_{i, j}$ normalised by its maximum value:

$$
a c_{i, j}=\frac{\alpha \beta_{1} d_{i j}+\alpha \beta_{1} d_{i j} a c i_{i}^{\psi}-\alpha \beta_{2} d_{i j}^{2}}{\frac{1}{4 \alpha \beta_{2}}\left[\alpha \beta_{1}\left(1+a c i_{i}^{\psi}\right)\right]^{2}} \in[0,1]
$$

A larger $d_{i j}$ increases the marginal impact of $a c i_{i}$ on absorptive capacity $\left(\frac{\partial a c_{i, j}}{\partial a c i_{i} \partial d_{i j}}>0\right)$, which corresponds with CL (p. 572) 19 In contrast, the effect of

\footnotetext{
${ }^{18}$ This fraction is determined by the appropriability conditions which include the patent system in a particular industry and the efficacy of secrecy or other forms of protection of firm $j$ 's internal knowledge.

${ }^{19}$ Note that while cognitive distance is symmetric (i.e. $\left.d_{i j}=d_{j i}\right), a n_{i, j}$ and $a c_{i, j}$ are asymmetric. This is because the investment trade-off is not solved by the two firms identically (i.e. absorptive R\&D investments are not necessarily the same for the two firms).
} 
$d_{i j}$ on $a c_{i, j}$ is ambiguous: for a given value of $a c i_{i}$, it is positive $\left(\frac{\partial a c_{i, j}}{\partial d_{i j}}>0\right.$ and $\left.\frac{\partial^{2} a c_{i}}{\partial d_{i j}^{2}}<0\right)$ until a certain optimal distance is reached and negative $\left(\frac{\partial a c_{i}}{\partial d_{i j}}<0\right)$ otherwise (Figure 4.2).

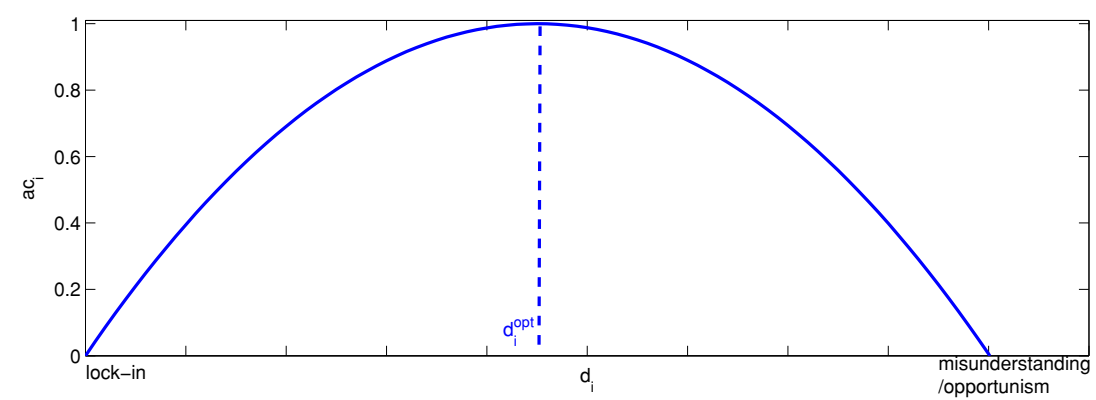

Figure 4.2: Absorptive capacity function

The maximum of the inverted ' $U$ '-shaped function shifts right (left) with increasing (decreasing) $a c i_{i}$ (Figure 4.3). It is easy to see why this is so from Figure 4.1. As absorptive R\&D increases, a firm's level of understanding also increases such that the firm can reach further in the knowledge space to search for complementary knowledge. The practical implication of this is that a firm can actually adapt its absorptive capacity to the cognitive distance from its cooperation partner. This corresponds to the empirical fact that investments in absorptive capacity raise the optimal distance between cooperation partners (de Jong and Freel, 2010; Drejer and Vindig, 2007).
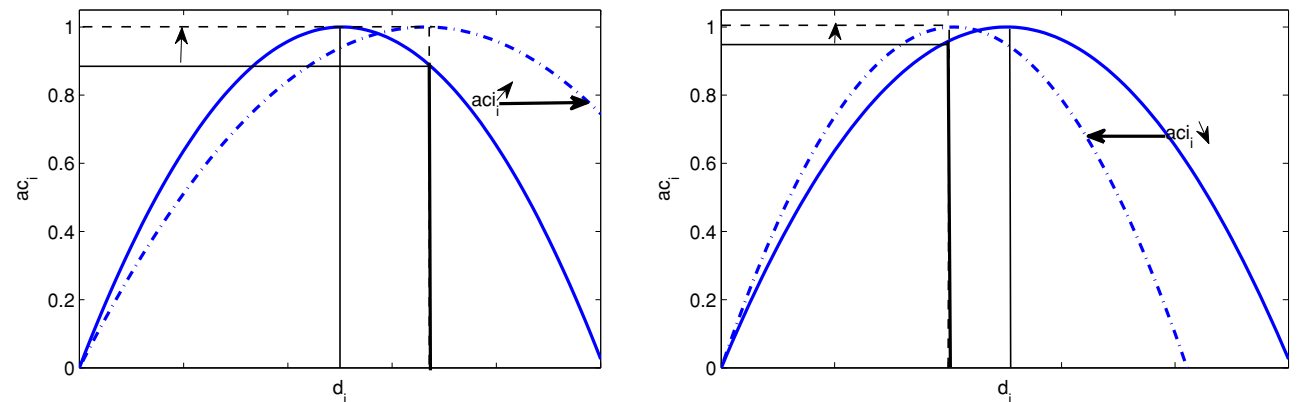

Figure 4.3: Dynamics in absorptive capacity function

Note: As firm $i$ increases its investments in absorptive capacity $\left(a c i_{i}\right)$, the optimal distance to its cooperating partner increases. Thus, for the larger distance, $i$ has a higher absorptive capacity by increasing its investments (left plot). The opposite is true for the lower distance (right plot).

It is clear from (4.8) that when $d_{i .}=0$ absorptive capacity equals zero. This is because if there is no difference between firm $i$ 's own knowledge and the 
external knowledge, the novelty value is zero even if understandability is maximal. In this way, absorptive capacity $\left(a c_{i, .}\right)$ is modeled explicitly at the level of interactive learning,20 and it captures not only the ability to understand external knowledge, but also the ability to explore the environment and to identify novel knowledge. It should be noted that even with no investments in absorptive $\mathrm{R} \& \mathrm{D}, a c_{i j}$ may be positive for some minor cognitive distances. This is based on the idea that firms working in similar fields have some level of mutual understanding even without explicit investments in absorbing R\&D spillovers from each other.

It should be noted that the cognitive distance of firm $i$ from external knowledge $e k$ (i.e. $d_{i e k}$ ) is not necessarily the same as that from firm $j$ (i.e. $d_{i j}$ ). In this study we consider it as the average distance to all other firms in the knowledge space:

$$
d_{i e k, t}=\frac{\sum_{i \neq k=2}^{N} d_{i k}}{N-1}
$$

so that the maximum distance to the external knowledge does not exceed the maximum distance to a single potential partner in this space. Thus, for the same level of absorptive $R \& D$, the absorptive capacity directed on each of the two sources of spillovers will be different 21 . When this is accounted for, (4.3) transforms into:

$$
k_{i}=r d i_{i}^{\xi}+a c_{i, j}\left(\delta_{c} r d i_{j}\right)+a c_{i, e k}(e k) .
$$

Therefore, ek should not be misinterpreted as any sort of knowledge which can be transferred automatically. Like voluntary spillovers, the involuntary ones - though codified - also require the effort of absorption: a firm has to have sufficient absorptive capacity to identify and assimilate this new knowledge.

Without an R\&D partner, the knowledge to be generated by firm $i$ is different ( $e k$ is the only source of external knowledge):

$$
k_{i}^{\text {generated alone }}=r d i_{i}^{\xi}+a c_{i, e k}(e k) \text { as } \delta_{c}=0 .
$$

\footnotetext{
${ }^{20}$ This is similar to the conceptutalisation by Lane and Lubatkin (1998) of absorptive capacity as 'a learning dyad-level construct'.

${ }^{21} \mathrm{As}$ in (4.8), $a c_{i, e k}=f\left(d_{i e k}\right)$.
} 


\subsubsection{Innovation and profit}

Innovation is perceived as a process which involves recombination of heterogeneous resources by a firm either working alone or in partnership with another firm. Thus, the size of a potential innovation is defined by the amount of knowledge $\left(k_{i}\right)$ generated. When the firm does not form a partnership, its profit $\left(\Pi_{i}\right)$ is not affected by voluntary spillovers. In a partnership, however, the profit of the firm decreases proportionally with the amount of knowledge spillovers $\left(a c_{j, i} \delta_{c} r d i_{i}\right)$ that the partner can absorb (which is essentially a constituent part of $k_{j}$ that reduces the appropriability of $k_{i}$ ). This is in contrast to CL where $\Pi_{i}$ is reduced proportional to the knowledge generated by the partner $\left(k_{j}\right) 2$ This 'cost of partnership' or, in the words of CL, 'effect of rivalry' affects the choice of an R\&D partner and is contingent upon the partner's (imperfect) absorptive capacity 23 To avoid the problem of increasing $\Pi_{i}$ for $a c_{j, i} \delta_{c} r d i_{i}<1$, we introduce a 'natural' leak-out that is fixed and equal to 1.

$$
\Pi_{i}= \begin{cases}k_{i}^{\text {generated in cooperation }} /\left(1+a c_{j, i} \delta_{c} r d i_{i}\right) & \text { if } i \text { has a partner } j \\ k_{i}^{\text {generated alone }} & \text { if } i \text { has no partner }\end{cases}
$$

The variable $\Pi_{i}$ is an output of the appropriated knowledge from a firm's continuous R\&D effort and, as the case may be, partnerships. The appropriated knowledge is applied in the recombination process to generate an incremental innovation 24 through which the firm maintains its competitiveness. Consequently, one can think of the firm's profit as being proportional to its knowledge input into the innovation process 25 In this sense, $\Pi_{i}$ is henceforth referred to as profit and used as a main indicator of firms' performance.

One way of interpreting the profit function in case of partnership in (4.12) is a split of property rights over a new technology converted into a monetary value. Since this technology may be used in different applications, the split

\footnotetext{
${ }^{22}$ Recall that in CL $\frac{\partial \Pi_{i}}{\partial k_{i}}>0, \frac{\partial \Pi_{i}}{\partial k_{j}}<0$ and $\frac{\partial \Pi_{i}}{\partial k_{i} \partial k_{j}}<0$. This is also fulfilled in (4.12) with the distinction that $\Pi_{i}$ reduces proportional to the firm's $i$ spillovers $j$ can absorb.

${ }^{23}$ Thus, the cost of partnership is endogenised in contrast to, e.g., König et al. (2011), where this cost is homogenous and is analysed in relation to emerging networks' properties.

${ }^{24}$ Once we address the dynamics of firms in the knowledge space, the notion of radical innovation will also be required. However, for the sake of brevity we do not include its discussion here.

${ }^{25}$ Obviously, we limit ourselves here to successful innovation. Nevertheless, it can be argued that the learning effects from failed innovation efforts will be proportional to the knowledge input.
} 
is not necessarily exact; however, appropriation of rights over the invention is reduced by the amount of spillovers to a competing partner. Thus, the functional form adopted here can have a meaningful (although not necessarily exclusive) economic interpretation and also follows the assumptions on the functional form from CL (see above).

\subsection{Optimal decision making}

In the following we discuss the optimal strategy of firm $i$ in solving the investment trade-off and forming a partnership. Our interest is in how absorptive capacity - derived from R\&D resource allocation, $\left.\rho_{i}\right)$, cognitive distance $\left(d_{i j}\right)$, appropriability conditions $\left(\delta_{c}\right)$ and technological opportunities $(e k)$-affects the benefits from cooperation. To study this, we resolve the investment tradeoff for a representative firm in two scenarios (cooperative and non-cooperative) and compare the results in terms of innovative profit.

\subsubsection{Investment trade-off}

For certain levels of the distance $d_{i j}$ that maximises understandability and novelty, firm $i$ is incentivised to invest in absorptive $R \& D$ to maximise the amount of external knowledge absorbed. The trade-off that the firm faces is how to optimally distribute its total $R \& D$ investment between the creation of own knowledge and the improvement of absorptive capacity. This necessitates a comparison of the marginal returns to each type of investment with respect to the profit gained. Absorptive $\mathrm{R} \& \mathrm{D}$ begins to pay off when it generates a marginal return that is equal to that of inventive $R \& D$ :

$$
\frac{\partial \Pi_{i}}{\partial a c i_{i}}=\frac{\partial \Pi_{i}}{\partial r d i_{i}}
$$

Using (4.12), (4.11), (4.10), (4.8) and (4.1), we obtain (see Appendix C.1 for derivation) the condition for the $\mathrm{R} \& \mathrm{D}$ investment that satisfies (4.13):

$$
\begin{cases}\mathrm{F}\left(\rho_{i}\right)=0 & \text { if } i \text { has a partner } j, \\ \mathrm{~F}^{\mathrm{a}}\left(\rho_{i}\right)=0 & \text { if } i \text { has no partner. }\end{cases}
$$


As (4.14) is a highly complex non-linear function with multiple local minima depending on the particular set of parameter values applied, it is a non-trivial problem to find the value of $\rho_{i}$ satisfying the condition.26 For this reason we apply a heuristic optimisation technique, in particular, Differential Evolution that is able to identify a good approximation of the global optimum in (4.14) for different sets of calibrating parameters as long as they satisfy the conditions stated above (see Appendix C.2 for details). It is important to note that, following earlier models (e.g. Klepper, 1996), this optimisation is performed solely on current expected profits. Such a short-term horizon consideration, together with the uncertainties about partners' investment decision and the exact outcome of partnership matching, does not allow pursuing any longterm equilibrium (which is also not our aim).

\subsubsection{Partnership formation}

Since larger distances (until a certain optimum level) increase the marginal returns to new knowledge generated, it follows that each firm prefers to select a cooperation partner at the largest distance possible to maximise the novelty value of the $\mathrm{R} \& \mathrm{D}$ cooperation. At the same time, the partner choice is essentially constrained by understandability such that the firm $i$ chooses a partner which it can also understand. In addition, the firm also takes into account the costs of partnership as a result of spillovers from its R\&D efforts. Ultimately, the decision to cooperate (or not) is a profit-maximising one which depends on the potential profit generated when working alone in comparison with profit generated by cooperating with the most 'fitting' partner:

$$
\max \left(\Pi_{i}^{\text {generated alone }} ; \Pi_{i}^{\text {with any of the possible partners }}\right)
$$

To this end, the simulation in the basic case can proceed as follows. First, all exogenous parameters $\left(\alpha, \beta_{1}, \beta_{2}, \psi, \xi, \eta, \gamma, \rho_{j}, \delta_{c}, e k\right.$ (the latter three can be simulated with different scenarios)) must be set 27 This also includes a random

\footnotetext{
${ }^{26}$ A deterministic iterative solution (e.g., according to the fixed-point theorem) is also not applicable as the function does not necessarily always converge to a $\rho_{i} \in[0,1]$ for all possible combinations of parameters.

${ }^{27}$ For illustrative reasons we take a single set of parameter values for two firms satisfying their constraints. In particular, $\alpha=\sqrt{2} / 50, \beta_{1}=\sqrt{2}, \beta_{2}=1, \psi=\xi=0.4, R D_{i}=R D_{j}=$ $0.2, \delta_{c}=0.5, e k=1, \rho_{j}=0.5, d_{i e k}=\sqrt{2} / 1.001$ and $d_{i j}=\sqrt{2} / 1.01$. These values were chosen to demonstrate on a single set of graphs the complex shape of the $\rho$ and $\Pi$ functions in response to changes in the variables of interest.
} 
distribution of the initial stocks of knowledge $\left(\Rightarrow\right.$ set $\left.d_{i j}\right)$ and aggregated $\mathrm{R} \& \mathrm{D}$ budgets $(R D)$ for all firms.

Second, in each period one needs to solve the investment trade-off of each firm $(\rho$.$) for all potential partners, considering the expectation about other firms'$ investments in R\&D. After that, the amount of knowledge $k$. to be generated by each firm either alone (standalone mode) or in partnership with any of the firms in the knowledge space is estimated. Based on this information the most lucrative partner for each firm can be selected by maximizing profit from $R \& D$ activity $\Pi_{i}$.

Third, although the most lucrative partner for each firm is identified, partnership formation is a non-trivial task in this model. The reason is that the incentives of a firm $i$ to build a partnership with firm $j$ are asymmetric: although distance between the partners is the same, the decision on the investment trade-off in R\&D is individual for each firm. Hence, there is no 'Nash stable network'. 28 Therefore, the model we build can be considered to be a 'non-equilibrium' one based on the functional dependencies described and following certain matching rules: unilateral, reciprocal and 'popularity contest' matching.

The matching rules and extensive simulation are described in detail in the next chapter. In what follows, only some illustrative results for one firm in two settings - cooperative and non-cooperative - are demonstrated.

\subsubsection{Comparative statics}

In CL, absorbed external knowledge is endogenous and influenced by R\&D investments, which is itself affected by the ease of learning, intra-industry spillovers and technological opportunities. For the sake of comparison, CL's ease of learning is analogous to our cognitive distance, intra-industry spillovers - to appropriability conditions and technological opportunities - to external knowledge. The effects of these parameters in CL are similar for both R\&D investment and the payoff it generates for the firm. However, the extensions we make in our study lead to different results. First, the distinction between absorptive $\left(a c i_{i}\right)$ and inventive $\left(r d i_{i}\right) \mathrm{R} \& \mathrm{D}$ implies that the learning effects of research are driven by only the investments in the build-up of absorptive capacity. Second, explicitly accounting for voluntary spillovers introduces the

\footnotetext{
28 "a stable network is one in which for each agent (or pair of agents) there is a payoff maximilsling decision about which link to form" (Cowan et al., 2007, p. 1052).
} 
effect of reciprocal incentives in resource allocation and partnership formation. In addition to its own resource allocation problem, each firm takes into account the investment decisions of the potential partners.

Moreover, in contrast to CL, we model in the context of inter-firm cooperation and, therefore, concentrate on cooperation decision and innovation-driven profit rather than just on R\&D investments. As is clear from comparing (4.1) and (4.12), the parameter effects on the firm's R\&D investments $\left(\partial R D_{i} / \partial \cdot\right)$ and its payoff in terms of profit $\left(\partial \Pi_{i} / \partial \cdot\right)$ are not necessarily similar. In Table 4.1 we summarise our results in comparison to CL focusing on the latter group of effects (since the R\&D profit presents the main motivation for firms to engage in cooperation in our study), while Figure 4.4 illustrates them in detail for the cooperating and non-cooperating scenarios. With reference to this figure, we elaborate on the effects of each parameter in the following subsections. Note at this point that the results (primarily, investment allocation) illustrate the myopic optimisation outcome (see (4.14) - a best option out of the set of alternatives, which by no means guarantees success in innovative performance.

\section{Table 4.1: Comparative static results}

\begin{tabular}{lll}
\hline \hline Effect & CL & Our model \\
\hline$\partial \Pi_{i} / \partial d_{i j}$ & positive & ambiguous \\
$\partial \Pi_{i} / \partial \delta_{c}$ & ambiguous & ambiguous \\
$\partial \Pi_{i} / \partial \rho_{j}$ & - & positive \\
$\partial \Pi_{i} / \partial e k$ & ambiguous & positive \\
\hline \hline
\end{tabular}

\section{Cognitive distance}

As seen from the bottom leftmost plot in Figure 4.4, the cognitive distance $d_{i j}$ between cooperating partners has an ambiguous effect on R\&D profits. A small distance (which does not require absorptive investments) positively affects R\&D profit. This is because the firm can dedicate most of its R\&D budget to invention and it suffers little or no negative appropriation in return (top leftmost plot). In this range, $R \& D$ profits in the cooperation scenario consistently increase and overtake the levels in the non-cooperation scenario because the cooperating firm can complement its own knowledge with increasingly novel knowledge from the partner. This, however, requires raising investments in 

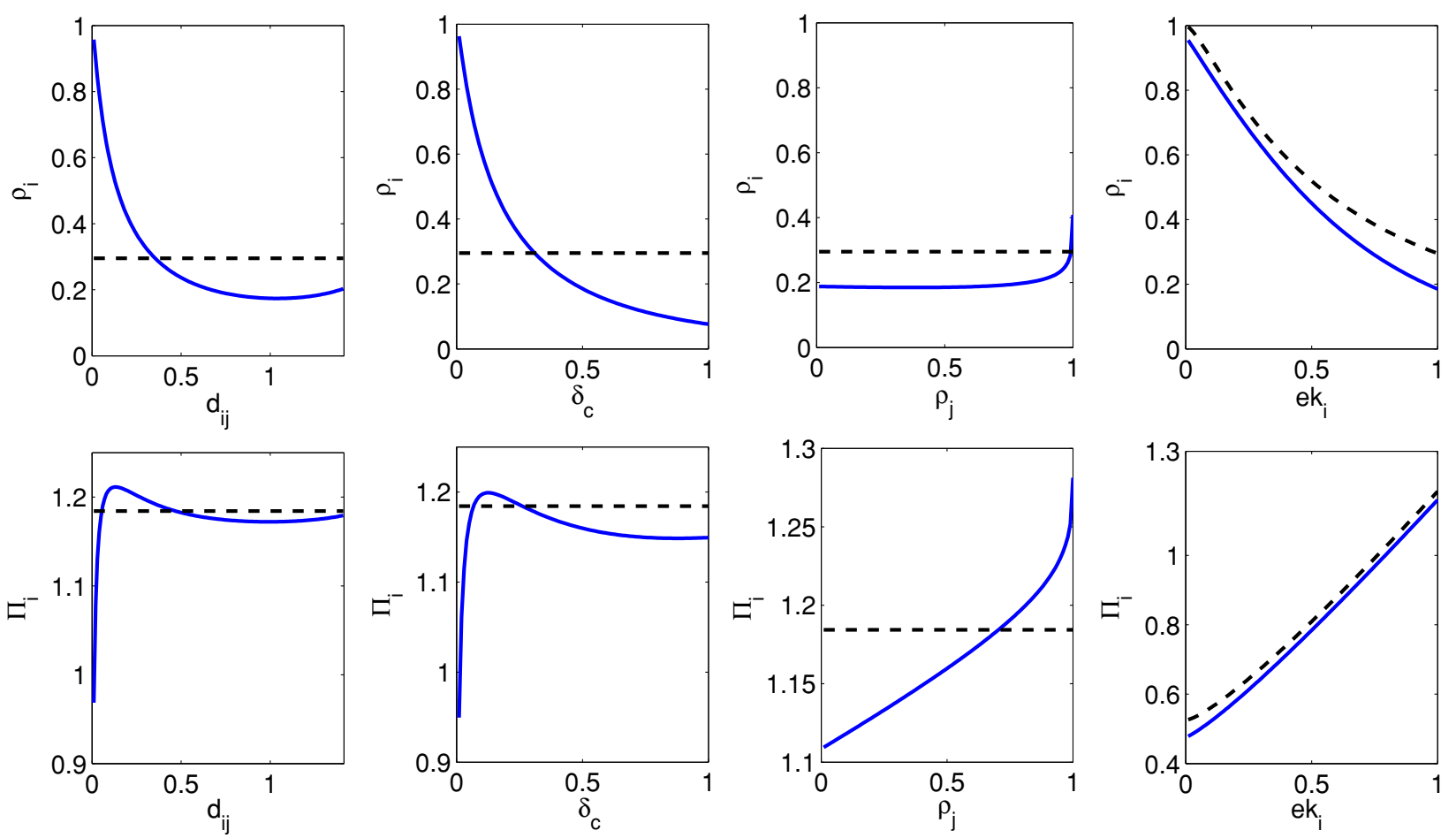

- cooperating scenario - - - non-cooperating scenario

Figure 4.4: Comparative statics for investments $\left(\rho_{i}\right)$ and profits $\left(\Pi_{i}\right)$ 
absorptive capacity to maintain the gain from the partner's knowledge. Consequently, inventive $R \& D$ reduces. The $R \& D$ profits also reduce since, with increasing cognitive distance, the cost of partnership in terms of spillovers increases as well.

At a very large distance, an 'understandability problem' arises such that new knowledge cannot be absorbed as efficiently any longer. This problem cannot be overcome by simply increasing investments in absorptive capacity. In this range, increasing absorptive $R \& D$ investments becomes sub-optimal, and as a result, some resources are shifted back to inventive R\&D. Clearly, the standalone strategy is more lucrative only when the distance to a potential partner is either too large (understandability problem) or too small (no novelty). For a range of cognitive distance between these two extremes, the cooperative strategy is better.

Taken together, these results imply that firms' decision to cooperate and the choice of a cooperation partner are heavily influenced by the investments they are willing to make in order to establish efficient collaboration. And in contrast to CL, where the ease of learning has a strictly positive effect on $R \& D$ investments and profit when cooperation is not accounted for, the effect of cognitive distance on profit is concave in the context of cooperation.

\section{Appropriability conditions and external knowledge}

Appropriability conditions $\left(\delta_{c}\right)$ and external knowledge $(e k)$ show similar effects on the amount of knowledge generated by the firm. $\partial k_{i} / \partial \delta_{c}$ and $\partial k_{i} / \partial e k$ are strictly positive suggesting that the appropriability conditions in a cooperative setting as well as the amount of external knowledge raise the ability of the firm $i$ to create new knowledge from external sources. Consequently, firm $i$ is incentivised to reallocate its investments from inventive to absorptive R\&D. More resources are devoted to absorptive capacity which generally results in a higher level of new knowledge $\left(k_{i}\right)$ generated from the cooperation.

However, appropriability conditions $\left(\delta_{c}\right)$ and external knowledge $(e k)$ show different effects on the R\&D profits generated by the firm. In contrast to ek (which has a strictly positive effect as shown in the bottom rightmost plot in Figure 4.4), $\delta_{c}$ has an ambiguous effect on R\&D profit (bottom second plot in Figure 4.4). On the one hand, the firm $i$ benefits from voluntary spillovers from its cooperation partner and experiences increasing profits. As voluntary spillovers increase, the profits rise consistently and overcome the levels in the standalone strategy. On the other hand, voluntary spillovers from $i$ also 
contribute to the knowledge stock of the cooperating partner. This causes a reduction in firm $i$ 's $\mathrm{R} \& \mathrm{D}$ profit. The combination of these two effects leads to an inverted ' $\mathrm{U}$ '-shaped relationship between $\delta_{c}$ and $\Pi_{i}$. This relationship is such that cooperation is superior to non-cooperation only for an intermediate range of voluntary spillovers. When cooperation intensity is too low, the additional knowledge gained through voluntary spillovers will be too low to justify investments made to absorb it. As cooperation intensity approaches its maximum level, the threat of large spillovers is more pronounced. In both of these latter scenarios, the non-cooperative strategy is more attractive.

The ambiguous effect of $\delta_{c}$ on profits is necessarily affected by the absorptive R\&D budget of the partner: if it is small enough, firm $i$ can benefit from intensive cooperation not being afraid that its partner absorbs much 29 In contrast, if the partner has sufficiently high absorptive capacity, firm $i$ 's losses from a larger $\delta_{c}$ can exceed its benefits. This particular result contrasts with CL where the effect of appropriability conditions is modified by the ease of learning. In our model, the effect of cognitive distance in this respect is captured in absorptive capacity which has the inverted ' $U$ '-shaped form representing the understandability/novelty trade-off. With a very large cognitive distance the appropriability conditions may not matter at all as the partners have difficulties understanding each other.

Since technological opportunities are equally available for both cooperating and non-cooperating firms, R\&D profit in relation to $e k$ is only dependent on the firm's absorptive capacity (see equation (4.11)). The relationship varies for the cooperating and non-cooperating scenarios because of the different number of factors involved in the firm's optimal decision making (see Appendix C.1). In particular, when the cost of cooperation is high, as in the representative case that we analyse, the non-cooperative strategy consistently yields superior performance benefits (bottom rightmost plot in Figure 4.4). This result is reversed at lower levels of cooperation intensity (e.g., at $\delta_{c}=0.2$ ).

\section{R\&D investments and absorptive capacity}

The investment decision of the partner $\rho_{j}$ has an ambiguous effect on firm $i$ 's investment allocation, but not on its profit (where it is strictly positive). This is because as $\rho_{j}$ increases, it contributes to the pool of external knowledge $i$ can

\footnotetext{
${ }^{29}$ For instance, with the investment decision of the partner $\rho_{j}=0.75, \Pi_{i}$ in the cooperation scenario shows only a small downturn and then rises consistently, overtaking the levels in the non-cooperation scenario.
} 
benefit from. This creates an incentive to increase investments in absorptive capacity. However, $\rho_{j}$ reaching its maximum values (close to 1 ) implies that the cooperating partner invests very little in the build-up of absorptive capacity. Thus, knowledge spillovers from firm $i$ to $j$ that can be absorbed do not present a big threat for firm $i$ 's inventive R\&D any longer. This leads to a large change in $i$ 's investment allocation and, consequently, its R\&D profit. In this context, the non-cooperative strategy is more lucrative only when the partner mostly invests in absorbing knowledge and not in its generation ('free rider' problem). When the partner heavily invests in invention, it is obviously better to cooperate.

\subsection{Conclusion}

In this chapter we set out to model absorptive capacity within the framework of inter-firm cooperation such that the capacity of a firm to appropriate external knowledge is not only a function of its R\&D efforts but also of the distance from its partner. This framework allows to account for recent empirical findings and to examine factors affecting the firm's choice on whether to engage in R\&D cooperation. In comparison with the original model of Cohen and Levinthal (1989), our results show some marked differences. Besides, some insights into the cooperation and R\&D investment preferences of firms are provided.

First of all, the cognitive distance between a firm and its cooperation partner has an ambiguous effect on the profit generated by the firm. Thus, a firm chooses its cooperation partner conditional on the investments in absorptive capacity it is willing to make to solve the understandability/novelty tradeoff. Firms possessing a larger R\&D budget have the possibility to engage in cooperation with firms located further away in terms of cognitive distance. This is in keeping with empirical studies of alliance formation (Lin et al., 2012; Nooteboom et al., 2007; Wuyts et al., 2005). If the partner is too close or too far, no efficient collaboration can be established.

Next, though appropriability conditions in the framework of cooperation also have an ambiguous effect on profits, this effect does not necessarily become greater (positive) with a larger cognitive distance as in CL. At a very large cognitive distance the appropriability conditions may not matter at all as the partners cannot understand each other. In this respect, a more important variable is the partner's absorptive capacity. In our formulation, absorptive capacity is a more complex construct capturing the interaction between a firm's 
absorptive R\&D and cognitive distance. The larger the partner's absorptive capacity, the larger the portion of knowledge spillovers that this partner can assimilate and the more risky cooperation becomes. This complex relationship, in our view, partly explains the caution that firms exercise in engaging in $\mathrm{R} \& \mathrm{D}$ cooperation and the very detailed contracts related to the respective agreements (see, e.g., (Atallah, 2003)). The finding that cooperation is a more profitable strategy than 'going it alone' only for an intermediate range of voluntary spillovers is consistent with an empirical finding in the literature on alliances. Intense cooperation between the same firms imply increasing cognitive overlap and reducing learning and innovation potential of the alliance (Mowery et al., 1996).

Finally, external knowledge, that is knowledge available outside the framework of cooperation, as well as the partner's inventive R\&D investments have positive effects on the $R \& D$ profit. While the latter distinguishes our model from CL (where such a variable is not explicitly considered), the former demonstrates an effect that somehow contradicts CL. The reason is that according to $\mathrm{CL}$ where $\mathrm{R} \& \mathrm{D}$ investments are considered as one expense item, external knowledge reduces incentives to own $\mathrm{R} \& \mathrm{D}$ on the one hand, but incentivises investments for absorptive capacity on the other hand. Since we distinguish between inventive and absorptive $\mathrm{R} \& \mathrm{D}$, the dynamics from CL is contained in the focal firm's reaction in investment allocation, while the total effect on the $R \& D$ profit is strictly positive. Also it is clear that the knowledge about the partner's R\&D investment allocation presents an important asset for any firm in our model. Ability to foresee this split allows a firm to avoid opportunistic behaviour from potential partners (i.e. 'free riders' with low inventive $\mathrm{R} \& \mathrm{D}$ ) and better resolve the two trade-offs in their decision making (optimal cognitive distance and optimal split of investments).

The analyses in this chapter have been carried out for a single representative firm. This setting permitted an explicit focus on the analyses of the conditions under which it is better to cooperate in $R \& D$ than to stand alone. Although the analyses have led to some useful results, a full-blown dynamic analysis of a population of firms is potentially more interesting. Such analysis is beyond the scope of the present chapter. In the next chapter a dynamic model of network formation where firms ally purely for knowledge sharing is analysed. Through an ABM simulation, we further examine the role of absorptive capacity in network evolution, the effects of networking on firm performance and the associated coevolutionary processes. 


\section{Chapter 5}

\section{Absorptive Capacity and Network Dynamics}

\subsection{Introduction}

The main aim of this chapter is to examine the influence of absorptive capacity on the structure and performance effects of innovation networks that emerge from bilateral R\&D collaboration. The analyses in the preceding chapter are extended in a dynamic mode 1 wherein networks emerge as a result of bilateral cooperation between firms occupying different locations in the knowledge space. The broad research question that we examine is straightforward: could the empirically observed properties of networks be reproduced by abstracting from social capital and focusing exclusively on knowledge considerations with endogenous absorptive capacity? We do not imply a contrast between absorptive capacity and social capital; rather, we examine the networks generated when cooperation is motivated primarily by knowledge gains rather than social capital.

An important contribution of this chapter is that, in contrast to earlier related models, we account for differences in firms' absorptive capacity and how these

\footnotetext{
${ }^{1}$ With many firms, analytical solution of the dynamic model becomes intractable so we simulate an ABM. ABMs have gained an increasing interest in different fields of economic research having an advantage in (i) a more realistic representation of agents' behavior than in a standard representative agent model and (ii) possibility of an extensive and fast simulation analysis for different parameter settings due to the ongoing advances in computational performance.
} 
affect their dynamics in the knowledge space. Absorptive capacity is endogenously defined by two factors: (i) a firm's distance both to a potential partner and to aggregate external knowledge, and (ii) its decision on the investment trade-off between inventive and absorptive R\&D potentially compensating for a larger distance to a partner. This way, absorptive capacity combines elements of searching for, valuing, identifying and assimilating new knowledge (Zahra and George, 2002).

Furthermore, distinguishing between voluntary and involuntary spillovers allows us to examine our hypothesis with respect to different knowledge regimes. The intuition here is that at different times in the history of an industry, different extents of voluntary and involuntary spillovers will be observed due to varying levels of inter-firm cooperation. This aspect of the analyses is a muchneeded addition to the literature because, as Malerba (2006, 2007) pointed out, a lot is still to be known about the dynamics of collaborations in innovation networks as well as the role of networks in different stages of industry evolution.

Our results do indeed replicate important empirical facts and generate some new insights. We observe networks with small world properties at all levels of spillovers that we examine. The effects of network structure on firm performance varies with changes in the knowledge regime. Aggregate profit in the networks increases with increasing involuntary spillovers but an inverted ' $U$ 'shaped relationship is observed with increasing voluntary spillovers. Moreover, when involuntary spillovers are small, networks with high average path length - implying low accessibility and inefficient information flow within the network - are especially detrimental for innovation. High betweenness - that is, occupying some kind of brokerage positions - turns out to be a very profitable network strategy at low levels of involuntary spillovers. A particularly striking result is that firms which employ different network strategies do indeed differ in absorptive capacity.

\subsection{Cognitive Distance Dynamics}

This chapter carries on with the analysis of alliance formation from the knowledge perspective as applied in the previous chapter, but with endogenous absorptive capacity. Firms form alliances for the purpose of knowledge sharing. Partner selection is entirely network-independent, implying the exclusion of network-based motives. The effectiveness of alliances is influenced by two 
factors: cognitive distance between partners and their investment allocation. Both factors determine absorptive capacity which is required to effectively deploy externally generated knowledge (Cohen and Levinthal, 1989). While the former has an inverted ' $U$ '-shaped relationship with the learning and innovation potential of the alliance (Wuyts et al., 2005), the latter presents a trade-off in the optimal distribution of total $R \& D$ investments between the creation of own knowledge and the improvement of absorptive capacity. The higher the investment in original knowledge creation, the more attractive a firm appears as an innovation partner. At the same time, the lower the investments in the build-up of absorptive capacity, the more difficult it is to exploit external knowledge.

Taken together, the foregoing hold important implications for cooperation and partner selection. On the one hand, a firm needs to carefully balance between $\mathrm{R} \& \mathrm{D}$ investments made to generate inventions and to develop absorptive capacity. On the other hand, the firm needs to select partners that are neither too close to it in the knowledge space (to facilitate novelty) nor too far away (to facilitate understandability). An additional consideration is the distinction that can be made between voluntary spillovers which exist in the context of cooperation and involuntary ones that exist elsewhere. In particular, voluntary spillovers are reciprocal, thereby constituting both a benefit and a potential risk. In this regard, firms will pay attention not only to the amount of knowledge they can get from their potential partner but also to the partner's absorptive capacity. These elements were combined in the model described in the preceding chapter. In that static model, the cognitive distance between cooperating partners was set exogenously. This simplification permitted a focus on the relationship between performance and cooperation strategy for a representative firm.

Building on research on alliance formation, we now focus on dynamic aspects of cooperation wherein the cognitive overlap between partners increases with intensity of cooperation, either in terms of duration or frequency. For instance, Wuyts et al. (2005) argue that the cognitive distance between cooperating firms is a negative function of their frequency of interaction. In other words, their knowledge bases become more similar as they cooperate more frequently. A similar argument was made by Mowery et al. (1998) for the duration of cooperation. Ex post, the knowledge overlap may be greater than its pre-cooperation level because of the mutual knowledge exchange over time. Cooperating firms may then become so close that the knowledge potential of their partnership becomes too low to permit recombinant novelty (Antonelli et al., 2010, p. 53). 
At this point, investments in absorptive capacity become less productive as far as the particular partnership is concerned. This may motivate the firms to invest more in own knowledge generation (inventive R\&D) while reducing the absorptive R\&D. In addition, when this stage is reached, the firms might reconsider their cooperation decisions and the partnership may dissolve (Broekel and Boschma, 2012).2 Heterogeneity between the firms increases again if they subsequently generate new knowledge either alone or in cooperation with other partners. The two firms may then be incentivised to re-establish partnership.

\subsection{Networks in Industry Evolution}

In the early stages, industries thrive on tacit knowledge, the diffusion of which requires face-to-face interactions (von Hippel, 1987; Audretsch and Feldman, 1996; Cowan et al., 2004). Also, uncertainty and the rate of innovation may be exceptionally high. To better anticipate major changes and position themselves for maximal access to knowledge, firms typically seek to occupy positions that place them in contact with as many different partners as possible. Consequently, inter-firm alliances may be more ubiquitous and interacting firms share knowledge, thereby generating a high proportion of what we have termed voluntary spillovers. The converse is increasingly true as the industry becomes more mature. Here, the effects of localised spillovers tend to diminish significantly (Potter and Watts, 2011) partly due to congestion, obsolescence of local knowledge and, in particular, a high amount of codifiable intra-industry spillovers. Moreover, predictability is higher and the frequency of change is comparatively lower. Consequently, the importance of networks is not so much for knowledge access as it is for maintaining competitive position. Brokerage positions become less important while triadic closure becomes more crucial.

This coevolutionary process between networks and industry evolution is a very important issue and has two facets. On the one hand, a direct relationship

\footnotetext{
${ }^{2}$ This situation arises even between asymmetric firms, that is, a technological leader and a follower, because, as long as they operate within the same technological trajectory, the leading firm has little reciprocal incentive to continue the relationship except that of opportunism or expropriation, which constitute disincentives for the follower. As noted by Nooteboom (1999a, p. 802), "Ia] problem in collaboration, especially in innovation, is that under some conditions there may be opportunities and incentives for free ridership, or for one party extracting more gain than others, or even expropriating their gain."
} 
between technology evolution itself and $R \& D$ collaboration is to be expected. It will then be of interest to know what kinds of network structures prevail under different technological regimes. On the other hand, the relationship between inter-firm cooperation and innovation may be moderated by industry evolution. Consequently, the performance effects of networks will depend largely on an industry's stage of development. If network-induced policy mechanisms such as cluster and incubation initiatives take these into account then they could be even more effective. Surprisingly, research evidence on these aspects of networks is very limited. A recent wave of empirical studies have partly addressed the issues but with several limitations.

Perhaps the first of these studies is the study by Rowley et al. (2000) which showed that the role of networks in innovation is contingent upon the industry context. In young and dynamic industries like semiconductors, open network positions and weak ties are relatively more important. In mature and stable industries like steel manufacture, closed network positions and strong ties, both culminating in higher aggregate network density, are more important. The key limitation of this study is that it contrasts two industries which were at different stages of evolution. This precludes any focus on intra-industry dynamics.

About a decade after, Ter Wal et al. (2013) and Vernet et al. (2013) show similar results based on data from the information technology and open source software contexts respectively. As actors have comparable capabilities in new technologies at the beginning of a new industry, brokerage is of high value. In fact, brokerage permits firms to anticipate innovations and allows them time to react. As diversity sets in when the industry matures - some firms become bigger and better while others shrink and stagnate or retard - closure is particularly beneficial. These studies however have a major limitation: they observed 'snapshots' of the same industry over relatively short periods. 3

Ter Wal (2013) also documents the declining (increasing) importance of geographic distance (clustering) in tie formation as the biotechnology industry shifts from a tacit to codified knowledge regime. These results are quite illuminating but one wonders whether they truly capture the industry dynamics. In the study, the changing knowledge regime was an exogenous fact rather than a variable that played a role in the observed patterns. Thus, it is still unclear whether the changing knowledge regimes actually were actually responsible for the observed network dynamics. Besides, the coevolution of distance between

3 Ter Wal et al. (2013) used annual data from 2005 to 2010 while Vernet et al. (2013) used monthly data from January 2006 to June 2008. 
partners and tie formation was omitted. This latter limitation is shared with Balland et al. (2013) where, though the importance of cognitive proximity in network evolution is recognised, its coevolution with the network was not taken into account.

The analysis of Kapoor and McGrath (2013) focused on the coevolution of collaborative R\&D efforts (among customers, suppliers and producers) and technology evolution in the semiconductor manufacturing industry. The analysis was based on author affiliation data from 12,834 articles presented at 147 conferences between 1990 and 2010. Although it showed that the pattern of collaboration coevolves with technology, an important limitation of the analysis is that the results are only relevant in industries where the main actors (i.e., customers, suppliers and producers) have comparable capabilities. This, however, is not the case in very many industries.

By focusing on inter-firm R\&D collaboration over time, our analyses overcome the limitations discussed above and offer important insight on network dynamics and industry evolution. Simulating an ABM permitted tracing the path of network evolution over long periods of time, as cognitive proximity and tie formation coevolve. Furthermore, we pinpoint a specific characteristic of the knowledge space, that is, the extent of voluntary and involuntary spillovers, as a major driver of network emergence and evolution in an industry. With this we show that changes in network structure over time are indeed driven by changes in the knowledge regime. As the composition of spillovers in the industry changes, we observe consistent changes in the attributes of the industry network. The changing attributes then have implications for the effects of networks on firm-level innovation.

\subsection{The Model}

Since the basic model is the same as in the previous chapter, there is no need for much repetition. In the model, a fixed population of firms $(N)$ seeks to generate new knowledge over a certain number of periods within a defined knowledge space. A simple representation of firms in a two-dimensional metric space 4 capturing cognitive distance is used. While firms' locations in the underlying

\footnotetext{
${ }^{4} \mathrm{~A}$ two-dimensional representation is the smallest suitable form allowing for transitive relations in the metric space and provides a clear graphical representation of network formation and evolution. The axes correspond to different knowledge 'types' that each firm may hold simultaneously.
} 
space have no particular meaning, they "translate directly into a network of strategic alliances" (Baum et al., 2010, p. 2097), because the distances affect the learning ability and, hence, partnership formation.

In each period, innovations can be generated from new knowledge created during that period 5 Each firm maximizes its potential to innovate either alone or in cooperation with another firm. The decision to cooperate is influenced by absorptive capacity not only of the firm itself but also of its potential partner. Absorptive capacity, in turn, depends on the extent to which the two firms' knowledge endowments both resemble and complement each other (cognitive distance). Bilateral partnerships among the firms yield an aggregate network. We are particularly interested in three issues:

i. the aggregate network structures that emerge: here we examine whether networks generated by our model display small world properties like many real life networks (Cowan and Jonard, 2004; Verspagen and Duysters, 2004).

ii. the effects of different knowledge regimes on aggregate network structures and performance: here we analyse how the network structures respond to varying degrees of voluntary and involuntary spillovers.

iii. the relationship between firms' network position and their innovation performance: the focus here is on individual firms and the manner in which the structural characteristics of the network relate to their performance.

The main assumptions of the model are detailed in the previous chapter. First, partnership formation is only a short-term profit-maximising decision. Second, each firm selects only one partner and conducts one R\&D project in each period. Partnerships are reconsidered in every period so that previously formed alliances may be discontinued. Third, reciprocity in partnerships is only relevant in terms of shared knowledge; partners' trust and reliability are ignored. Last, firms are well informed about the knowledge base but are uncertain about the investment decisions of other firms. In what follows, the extensions to the basic model in Chapter 4 are described.

\subsubsection{R\&D investments}

Recall Equation 4.1 from the previous chapter. In making its own R\&D investment decisions, each firm takes into account the investment decision of its

\footnotetext{
${ }^{5}$ Thus, although the new knowledge may be combined with already existing knowledge to innovate, not every recombination of knowledge is considered to be an innovation.
} 
potential partner. It does this by forming an expectation, considering the investment decision of the partner to be equal to the average from the last three investment allocations made by the partner in a cooperation setting. 6 This introduces uncertainty into the model as the expectation does not exactly coincide with the actual investment decision of the potential partner, which is itself based on an expectation. Thus,

$$
E^{i}\left(\rho_{j}^{t}\right) \neq \rho_{j}^{t}=f\left(E^{j}\left(\rho_{i}^{t}\right)\right), \quad \text { where } \quad E^{i}\left(\rho_{j}^{t}\right)=\left(\sum_{\iota=1}^{3} \rho_{j}^{t-\iota}\right) / 3 .
$$

\subsubsection{Knowledge generation}

The process of knowledge creation is already described in detail in Section 4.3.2. The specific equation to recall here is 4.10 which states that a firm's knowledge stock increases as a result of inventive R\&D and, by its interaction with spillovers, absorptive R\&D. As before, external knowledge, $e k_{i}$, is set as the total inventive R\&D investment of firms in the knowledge space which firm $i$ can potentially understand (in total, let us say, equal to $H_{i}$ ), rescaled by the parameter of involuntary spillovers $7 \delta_{n} \in(0,1)$ :

$$
e k_{i}=\delta_{n} \sum_{i \in H_{i}} r d i_{h}
$$

The understandability restriction ensures that firm $i$ can utilise the involuntary spillovers from firms located in the knowledge space and sets a certain 'radius' around the firm, within which external knowledge (also from the side of strategic cooperation) can be considered. Hence, firms having a more central position in the knowledge space have an access to potentially more spillovers than those being in the periphery.

\footnotetext{
${ }^{6}$ The expectation formation plays an important role in the model and several alternatives have been analysed. In the simplest case, the expectation was set equal to the decision made by the partner in the previous period, regardless of its decision to cooperate. Naturally, this approach was most imprecise. Alternatively, a generalisation as an average over several periods was taken, but still providing a big mismatch between the expectation and the actual decision. Finally, an average over the last three investment decisions made by the partner within a cooperation is taken. This approach provides a good approximation of the actual investments made by the partner in all the scenarios considered: correlation between expectation and actual investments is always between 0.7 and 0.95 (see Appendix D.2).

${ }^{7}$ This fraction reflects the portion of knowledge not appropriated by firms and is determined by the appropriability conditions which include the patent system in a particular industry and the efficacy of secrecy or other forms of protection of firm $j$ 's internal knowledge.
} 
In our model we focus on the situation, where $1>\delta_{c}>\delta_{n}>0$ with $\delta_{c}+\delta_{n}$ reflecting total spillovers available to a cooperating firm.

\subsubsection{Cognitive distance}

Firms select partners from whom they are likely to benefit the most. Typically, such partners may be easily understood by the focal firm or possess complementary assets and other endowments that might not be easily accessible elsewhere. Consequently, the cognitive distance of a firm $i$ from a potential partner $j\left(d_{i j}\right)$ is not necessarily equal to that from other external knowledge $e k\left(d_{i e k}\right)$. The former is modeled as the Euclidean distance between the stock of knowledge of the two partners $\left(\nu_{i}\right.$. and $\nu_{j}$.), which are independently and randomly attributed to the firms in the interval $[0,1]$ :

$$
d_{i j}=\sqrt{\left(\nu_{i 1}-\nu_{j 1}\right)^{2}+\left(\nu_{i 2}-\nu_{j 2}\right)^{2}} .
$$

Cognitive distance from external knowledge is represented as the average distance to all the firms in the knowledge space that firm $i$ is able to understand:

$$
d_{i e k}=\left(\sum_{i \in H_{i}} d_{i h}\right) / H_{i} .
$$

Thus, the maximum distance to the external knowledge does not exceed the maximum distance to a single potential partner in this space.

\subsubsection{Absorptive capacity}

The absorptive capacity function

$$
a c_{i, j}=\frac{\alpha \beta_{1} d_{i j}+\alpha \beta_{1} d_{i j} a c i_{i}^{\psi}-\alpha \beta_{2} d_{i j}^{2}}{\frac{1}{4 \alpha \beta_{2}}\left[\alpha \beta_{1}\left(1+a c i_{i}^{\psi}\right)\right]^{2}} \in[0,1]
$$

is derived and discussed in detail in Section 4.3.3. As before, $a c_{i, e k}$ has the same functional form as Equation (5.5) with the only difference that $d_{i e k}$ replaces $d_{i j}$. This reflects the fact that for the same level of absorptive R\&D investments, the ability to learn from voluntary and involuntary spillovers can differ. Note also that the investment in absorptive capacity increases the distance $\left(d_{i}\right.$.) over 
which the firm can absorb external knowledge (the radius mentioned in Section 5.4.2) 8

\subsubsection{Profit generation}

The magnitude of a successful innovation as already described in Section 4.3.4, is defined by the amount of knowledge firm $i$ can appropriate $\left(\Pi_{i}\right)$ :

$$
\Pi_{i}= \begin{cases}\left(k_{i}^{t}\right)^{\text {generated in cooperation }} /\left(1+\kappa a c_{j, i}^{t} \delta_{c} r d i_{i}^{t}\right) & \text { if } i \text { has a partner } \\ \left(k_{i}^{t}\right)^{\text {generated alone }} & \text { if } i \text { has no partner. }\end{cases}
$$

The factor $\kappa$ downsizes $a c_{j, i}^{t} \delta_{c} r d i_{i}^{t}$ to ensure that cooperation in our model brings more benefits than losses. This allows us to preclude the possible outcome that firms never cooperate 9 To sum up, the function (4.12) is meant to introduce the trade-off between cooperative and non-cooperative strategies in our model: it provides a larger pool of knowledge spillovers for a cooperating firm $i$ to benefit from, but also penalises it by the spillovers the partner $j$ can absorb. This function is later used as a main objective function of the firms reflecting the short-term profit-maximising objectives stated earlier. More information on the calibration of the function is provided in Section 5.5.

\subsubsection{Innovation and learning}

There are two sources of dynamics in the knowledge space: learning and innovation. First, firms move closer together according to their learning capacity with respect to their partner $\left(a c_{i j}\right)$, the extent to which they disclose own knowledge $\left(\delta_{c}\right)$ in a cooperation agreement and the extent to which the partner conducts inventive $\mathrm{R} \& \mathrm{D}$ in the period $\left(\rho_{j}\right)$. Logically, the higher the three variables are, the faster the two firms learn from each other, reducing their cognitive distance 10 Technically this 'convergence' in knowledge space is im-

\footnotetext{
${ }^{8}$ Specifically, this radius is set to be not greater than $\frac{\beta_{1}}{\beta_{2}}\left(1+\left(R D_{i}\right)^{\psi}\right)$ readily derived from (4.8).

${ }^{9}$ Simulations show that setting $\kappa=1$ leads firms to prefer the standalone mode in most of the situations, while correlation between firm performance and the number of partnerships becomes negative.

${ }^{10}$ In this respect, there is a clear parallel with the 'cost of partnership' operationalised in (4.12) except that instead of $\mathrm{R} \& \mathrm{D}$ budget, the firms' coordinates in the knowledge space are taken.
} 
plemented similar to Baum et al. (2010) with the distinction that learning is potentially much faster 11 and is endogenously driven by firms' investment allocation 12 :

$$
\begin{gathered}
\nu_{i 1}^{t+1}=\left(\delta_{c} a c_{i j}^{t} \rho_{j}^{t}\right) \nu_{j 1}^{t}+\left(1-\delta_{c} a c_{i j}^{t} \rho_{j}^{t}\right) \nu_{i 1}^{t} \\
\nu_{i 2}^{t+1}=\left(\delta_{c} a c_{i j}^{t} \rho_{j}^{t}\right) \nu_{j 2}^{t}+\left(1-\delta_{c} a c_{i j}^{t} \rho_{j}^{t}\right) \nu_{i 2}^{t} .
\end{gathered}
$$

In interpreting (5.7) we believe that the learning capacity $\left(a c_{i j}^{t}\right)$ itself should not be set to some small value simply by arguing that firms do not learn from each other that quickly 13 In contrast, we believe that what actually matters is how much information the two firms disclose to each other in a cooperation agreement and how much original (inventive) R\&D each of them conducts in that period.

The second driver of dynamics in cognitive distance is innovative activity. When a firm produces a radical innovation, 14 it dislocates firms in its surrounding according to its innovative success $\left(\Theta \Pi_{i}\right) 15$ where $\Theta$ is a binary outcome with one standing for a successful innovation. We set $\Theta$ equal to one for only one randomly drawn firm per period so that on the one hand, we do not have too many innovations and dislocations at each period, but also avoid the situation where all firms converge upon one specific location in the knowledge space. Important also is that we do not distinguish between probabilities to successfully innovate alone or in a cooperation in order not to introduce even more heterogeneity in an already complex model. The difference in terms of

\footnotetext{
${ }^{11} \mathrm{~A}$ standard in the literature is setting the learning capacity $\left(a c_{i j}^{t}\right)$ equal 0.01 .

${ }^{12}$ Thus, identified and assimilated knowledge spillovers are endogenised. See also Wersching (2010).

${ }^{13}$ Otherwise, why would firms put so much effort in increasing their absorptive capacity (Fabrizio, 2009), if it should always be equal to a value like $1 \%$ ?

${ }^{14}$ Here we distinguish between two types of innovation. Whereas incremental innovation in (4.12) is considered to be a consistent indicator of firms' performance in generating new knowledge, radical innovation (taking place infrequently and randomly) is an important source of firms' dynamics in the knowledge space. This distinction is useful for technical convenience. Nevertheless, it is logical because, while incremental innovations tend to encourage the status quo, radical innovations cause paradigmatic shifts with entire industries emerging or transforming (see Section 2 in Koberg et al., 2003, for a more detailed discussion). Thus, one can argue that the effects of incremental innovation reflect more in the innovator's profit without significantly shifting other firms' position in the knowledge space, whereas a radical innovation forces other firms to adjust their position within the knowledge space.

${ }^{15}$ Again, the magnitude of innovation is endogenised in this model and not drawn from any exogenous distribution as it is done in some recent studies (Baum et al., 2010).
} 
innovation between the cooperative and non-cooperative strategies is that in a partnership, firms have the potential to generate innovations of larger magnitude 16 due to voluntary spillovers.

We also restrict the effect of dislocation to the firms which are located close enough to the innovating firm at time $t$. Here again the 'radiuses' of surrounding firms are used in checking that the distance between the innovating $(i)$ and a surrounding $(h)$ firm is not too big for the latter one to comprehend the innovation. Technically, this limitation allows one not to 'shake' the entire population of firms but only a certain number of them located in the specific region of the knowledge space. Furthermore, it also matters how large is the distance of the affected firms to the innovating ones $\left(d_{i h}\right)$ - the smaller it is, the larger the dislocation:

$$
\begin{gathered}
\nu_{h 1}^{t+1}=\nu_{h 1}^{t}+\epsilon_{1} \ln \left(\Pi_{i, t}\right) / d_{i h}^{t} \\
\nu_{h 2}^{t+1}=\nu_{h 2}^{t}+\epsilon_{2} \ln \left(\Pi_{i, t}\right) / d_{i h}^{t},
\end{gathered}
$$

with $\epsilon_{1}, \epsilon_{2} \in\left[-\frac{1}{200} ; \frac{1}{200}\right]$ rescaling the entire dislocation effect on each firm below $d_{i h}^{\max } / 2=\sqrt{2} / 4$. The dislocation effect in Equation 5.8 holds irrespective of whether a firm $h$ is involved in a partnership in the specific period. Thus, moving along the knowledge space according to their learning and innovativeness, firms may essentially form clusters within which they exchange knowledge.

\subsubsection{Investment optimisation and partnership formation}

The trade-off that the firm faces is how to optimally distribute its total R\&D investment between the creation of own knowledge and the improvement of absorptive capacity at any given period $t$, and distances $d_{i j}$ and $d_{i e k}$. This trade-off has already been extensively analysed in the preceding chapter. As highlighted in Equation 4.15, the decision to cooperate (or not) is essentially a profit-maximising one which compares the potential profit generated alone with profit generated in cooperation 17

Yet, partnership formation is a non-trivial task because profits and investment allocation on which cooperation decision is based are asymmetric even though

\footnotetext{
${ }^{16}$ Here one can think of magnitude in terms of quality improvement or cost reduction that is significant enough to generate reactions from other firms in the knowledge space.

${ }^{17}$ It is important to recall the emphasis on myopic optimisation here.
} 
cognitive distance is. Hence, there is no 'Nash stable network' 18 In the light of this, a few alternatives on forming partnerships are considered:

- Unilateral partnership formation: in each period in a random order firms identify their most fitting partner (based on the estimation of $\rho_{i}$ and $\Pi_{i}$ for each potential partner). If for any given firm the standalone mode is more lucrative than cooperating with any firm in the knowledge space, it generates new knowledge alone and is excluded from further search in this period. Once a partner is found, partnership is formed (i.e. the chosen firm simply adjusts its $\rho$ to the given partner) and the two firms are excluded from the search process. The main advantage of this method is its simplicity and low computational time required. However, reciprocity is not required; therefore, a firm $i$ can exploit its partner $j$ in a given period. Hence, this method is expected to result in the largest discrepancy in firms' performance and can be considered a benchmark for comparison.

- Reciprocal partnership formation: as before, both $\rho_{i}$ and $\Pi_{i}$ of each firm for each potential partner are estimated and all firms preferring a standalone mode are excluded. Again in a randomised order in each period, firm $i$ 'makes a proposition' to firm $j$, its most lucrative cooperation partner. The offer is accepted if and only if $i$ belongs to the 'top' $5 \%$ of the firms with whom $j$ would cooperate. Then the two firms are excluded from further search. This approach is clearly more computationally intensive and sets the strictest limitation on reciprocity.

- A 'popularity contest': starts exactly as above by computing $\rho_{i}$ and $\Pi_{i}$. Based on the estimates of $\rho_{i}$ and $\Pi_{i}$ each firm ranks itself and the others in descending order of preference, 1 being the most preferred. The inverse of the rank represents the relative weight or attractiveness of a firm as a potential partner. The sum of weights gives a rating that signifies a firm's popularity among the others:

$\operatorname{Rating}_{i}=\sum_{j=1}^{N}$ weight $_{i}^{\text {by firm } j}$, where weight ${ }_{i}^{\text {by firm } j}=\frac{1}{\text { Order of } i \text { by firm } j}$.

Firms choose themselves a partner sequentially according to their rating: the most popular choose first. Although some reciprocity is present in the model, it is not ensured in every partnership. Computational cost of

\footnotetext{
${ }^{18}$ In this sense, we also differ from König et al. (2011) where the notion of equilibrium is central to the analyses.
} 
this approach is comparable to the one before, but it has some additional merits. First, the order in which partnership choice is made is not random. Second, the popularity ranking introduces some form of hierarchy (heterogeneity) among the firms. This presents a modest representation of competition: since firms ranked higher choose first, firms with the desire to form alliances may tend to adopt strategies which improve their ranking, thereby competing for alliances.

It is worth noting that the procedures just described take place every period. This implies that the process of partner selection occurs in every period, and a partnership formed in one period may be terminated in the next one depending on its profitability.

\subsection{Numerical Experiment}

For the extensive numerical simulation we set some parameters as fixed and allow only a few to vary 19 The dynamics arising from this modeling should provide us with complex network information which we discuss in Section 5.6. The entire simulation runs over two hundred periods $(T=200)$ repeated ten times. In each case, the first hundred periods are removed from further consideration to avoid any effects arising from initial random allocation of parameters.

At the beginning of each simulation restart, a population of $N=100$ firm: 20 are randomly distributed in the knowledge space $[0,1] \times[0,1]$. They are also given a certain fixed $R \& D$ budget uniformly drawn from the interval $[7.5,12.5] 21$ To form expectations about other firms' investment decision, we randomly allocate values between 0 and 1 to all firms in the first three periods. Throughout the remaining 197 periods, the firms should form alliances (or stay alone)

\footnotetext{
${ }^{19}$ The entire code is written in MATLAB except of few parts on network statistics made in $\mathrm{C}++$ by means of Microsoft Visual Studio boosting the efficiency of simulation. In this respect we want to thank Lev Muchnik for his instructive tutorial and codes on social network analysis at http://www. levmuchnik.net/Content/Networks/ComplexNetworksPackage. html. The code can be obtained from the authors on request.

${ }^{20}$ This number is considered to be neither too large nor too small for simulation purposes. Besides, it is comparable to the population of firms applied in previous related studies

${ }^{21}$ In this we attempt to introduce some moderate heterogeneity between firms in our model. Clearly, an even more ambitious idea would be to set the R\&D budgets in the future periods contingent on the firm's performance in the previous period, but this we leave for further research.
} 
according to one of the three matching alternatives described in Section 5.4.7 always solving two trade-offs: what is the preferred distance to the partner to cooperate with and how much to spend on absorbing voluntary and involuntary spillovers. After all alliances are set, firms generate knowledge in an alliance or alone and subsequently move in the knowledge space. While cooperating firms learn from each other and move towards each other in the knowledge space according to (5.7), roughly once in each period one of the firms innovates and dislocates the surrounding ones according to (5.8).

We set $\alpha=\sqrt{2} / 50, \beta_{1}=\sqrt{2} / 40, \beta_{2}=1$ and $\psi=\xi=0.5$, thus allowing i) $a c_{i, j}$ to have the inverted ' $U$ '-shaped form in $d_{i j}$ : first increasing and then decreasing. 22 ii) $a c i_{i}$ to have a positive but marginally decreasing impact on absorptive capacity; iii) $r d i_{i}$ to have a positive but marginally decreasing impact on $k_{i}$ and iv) setting the radius (within which a firm can find a partner, absorb involuntary spillovers or be affected by another firm's radical innovation) equal $\approx 0.15$ on average (depending on the exact $R \& D$ budget the firms have). We also set $\kappa$, the rescaling parameter for the costs of partnership, equal to 0.123

In this model, four parameters that determine absorptive capacity also drive the network structure and its effect on firm performance. First, cognitive distance $\left(d_{i j}\right)$ between cooperating firms influences the learning and innovation potential of an alliance. This distance changes according to the firms' learning and innovation. As a result, previously discontinued alliances may be re-

\footnotetext{
${ }^{22}$ Furthermore, as already explained in Section 4.3.3. without any absorptive R\&D $a c_{i, j}$ can still be positive for small values of $d_{i j}$. This happens for $d_{i j} \in(0,0.0353]$ and the maximum level is reached at $d_{i j}=0.0177$ (i.e. in the middle of the interval). Thus, at some very moderate level of cognitive distance, assimilation of external spillovers can be efficient without any explicit investments in absorptive capacity.

${ }^{23} \mathrm{We}$ tried different values of $\kappa$ both above and below 0.1 and it turns out that this value produces more meaningful results in terms of number of partnerships per period (10$90 \%$ of firms in the population cooperate). The following calculation example from our model according to (4.3) and (4.12) gives an idea of what forces are actually at work. Consider $\Pi^{t}=\left(\left(r d i_{i}^{t}\right)^{\xi}+a c_{i, j}^{t}\left(\delta_{c} r d i_{j}^{t}\right)+a c_{i, e k}^{t}\left(e k_{i}^{t}\right)\right) /\left(1+\kappa a c_{j, i}^{t} \delta_{c} r d i_{i}^{t}\right)$ equaling to 4.62 (for $d_{i j}=0.0375, \rho_{i}=0.5=E^{i}\left(\rho_{j}\right), \rho_{j}=0.5, \delta_{c}=0.9, R D_{i}=9.19, a c_{i j}=0.89$, $R D_{j}=10.15, a c_{j i}=0.88, e k=1.07, d_{i e k}=0.11$ and $\left.a c_{i e k}=0.07\right)$. While the knowledge generated (before the cost of partnership reduces it in $\Pi_{i}$ ) equals $6.30, \Pi_{i}$ is rescaled by factor 1.36 (and not 4.63 for $\kappa=1$ ). This makes the profit (knowledge generated and appropriated) still higher than investing only in inventive $R \& D(\Pi=3.03)$ or absorbing only involuntary spillovers with the same investing decision $(\Pi=2.22)$. As it is also clear, setting $\kappa=0.01$ would make the cost of partnership negligible. Smaller deviations, e.g., $\kappa \in[0.05 ; 0.15]$ do not change the further results dramatically.
} 
formed 24 Second, R\&D investments $(R D)$ are the major source of absorptive capacity. Allocating this investment between invention and the development of absorptive capacity is an important strategic decision that every firm makes in response to the behaviour of their potential partners. Third, appropriability conditions within a partnership $\left(\delta_{c}\right)$ determine both the pool of knowledge of its partner that each firm can benefit from and the magnitude of spillovers the partner can absorb from the firm. The size of $\delta_{c}$ is an important factor both in partner selection and learning speed. Fourth, the magnitude of involuntary spillovers $\left(\delta_{n}\right)$ generated by surrounding firms defines the pool of external knowledge.

While the first two factors are exogenously given only in the initial stage and endogenised afterward, the latter two are held as exogenous. In particular, we consider $\delta_{c} \in[0.1 ; 0.9]$ and $\delta_{n} \in[0.03 ; 0.1] 25$ This setup allows us to examine the evolution and performance effects of the other parameters - and, by extension, of the entire network - with respect to changes in the knowledge regime within the knowledge space.

In what follows, we describe both the firms and the arising networks over ten histories each lasting hundred periods (after discarding the first hundred periods in each case). In particular, we concentrate on:

i. the network statistics, taking the whole population as one network.

ii. firms' ego-network statistics and their correlation to the firms' performance.

\subsection{Results}

In order to understand the results contained in this section, some knowledge of network analysis is necessary. To help readers to follow the discussion we clarify the relevant network measures (both the unweighted ones and their weighted generalisations) in Appendix D.1.

\footnotetext{
${ }^{24}$ As noted by Rosenkopf and Schilling (2007), alliance duration often ranges from one to five years. Thus, over a sufficiently long time horizon and in a sufficiently large population of firms, alliances will repeat often enough that firms will re-select partners with whom they had cooperated in the past.

${ }^{25}$ Here we restrict the amount of involuntary spillovers from below to ensure the emergence of a network in the 'popularity contest' matching rule.
} 


\subsubsection{Network measures and characteristic networks}

To give an idea of what networks emerge from our model, we provide some descriptive information on networks formed with the three different matching rules applied, using intermediate values of $\delta_{c}(=0.5)$ and $\delta_{n}(=0.05)$. These results are given both on a single simulation run (first and last panel in Figure 5.1) as well as for ten restarts.

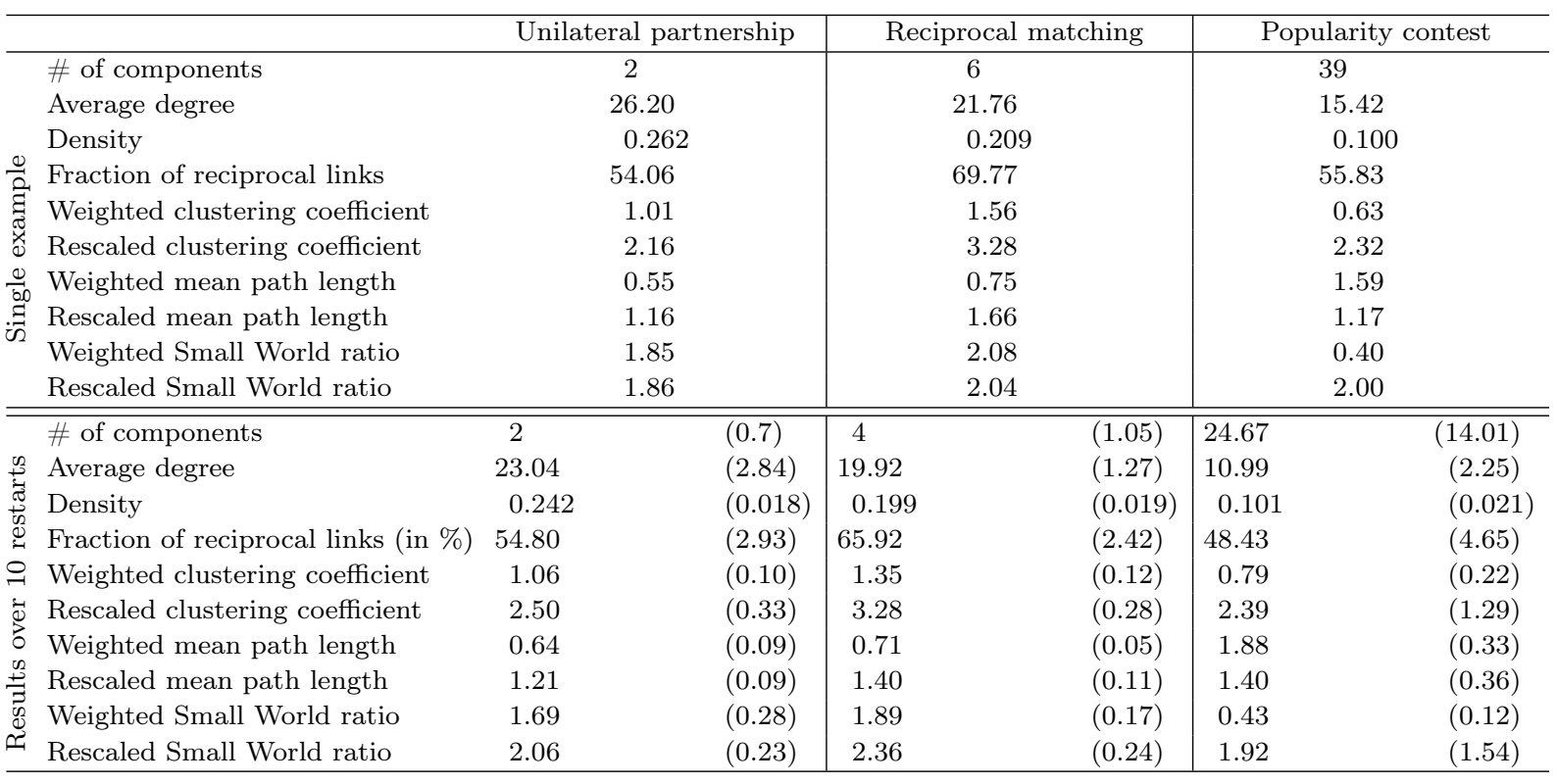

Note: The lower panel reports average values (standard deviations).

Unilateral partnership Reciprocal matching Popularity contest

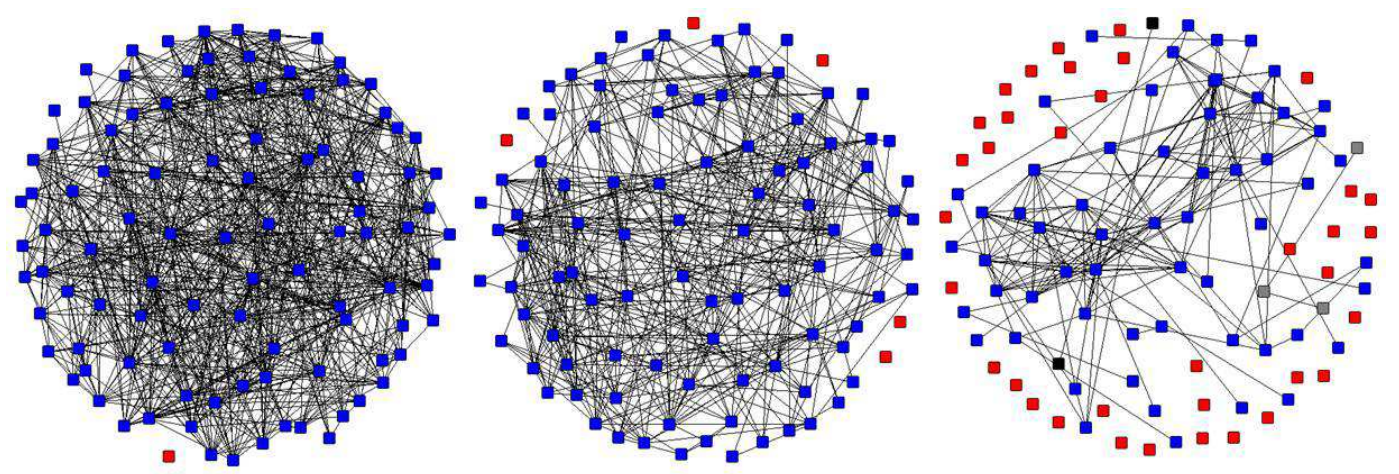

Note: Isolated nodes in red.

Figure 5.1: Characteristic networks 
The network based on unilateral partnership formation (presented to the left in Figure 5.1) has the largest density and contains all except one firm in its largest component. The density of the network generated in the popularity contest scenario is much smaller, indicating relatively few alliances taking place in each period. Even more, in this scenario the total number of unconnected components, several of which contain more than one firm, is above 20 . However, the network appears to be highly centralised (as seen in the network representation on the bottom right of Figure 5.1). This feature, to some extent, is an effect of the fact that network formation is based on reputation such that much fewer firms form alliances and repeatedly connect with each other 26 An interesting measure in the context of this study is the fraction of reciprocal links (i.e. the share of alliances formed on the 'initiative' from both sides). This is one of the few characteristics where we account for link direction and examine differences among the three matching rules. Clearly as a result of the barter-like setup, mutual linkages - most likely driven by double coincidence of wants (Cowan and Jonard, 2004) - are significantly higher in the network generated from the reciprocal partnership rule. The other two networks are not particularly different in this respect; they both have relatively fewer mutual linkages.

To see how dense the resulting networks are (in other words, to what extent partners of partners are connected to each other), we measure the clustering coefficient. Since our networks are cumulated over 100 periods with many alliances taking place several times, a weighted generalisation of this coefficient is more suitable. From the values, it is seen that the local structure of the network with reciprocal partnership is the most dense. Another important network measure is the mean path length 27 which proxies the efficiency of information flow within a network - the smaller the value, the more efficient a network is in terms of information diffusion. The network with unilateral partnership has the shortest average path, while the popularity contest network has the longest. The network with reciprocal partnership lies between these two extremes but has a mean path length much closer to the former one.

Combining the two measures, we can assess the small world property of each network structure. The most common quantitative measure of this is the

\footnotetext{
${ }^{26}$ This feature reflects in most of the other measures that we examine subsequently. Thus, the discussions in the rest of the paper rely more on the results from the other two matching rules.

${ }^{27}$ This should not be confused with distance. Mean path length is the average number of nodes separating two distinct nodes $i$ and $j$ in the network, while the distance refers to the (Euclidean) distance $d_{i j}$ between the two nodes in the knowledge space.
} 
small world ratio obtained from dividing clustering coefficient by mean path length. Typically, values greater than one have been used in previous studies to indicate that a network is small worldly (Davis et al., 2003). Judging from the weighted version of this measure, the networks generated from our model, with the exception of the one with popularity contest, seem to represent small worlds.

By definition, a small world network will be much more clustered than a corresponding random network but the average path length between its nodes will be comparable to that of the random network (Watts and Strogatz, 1998). Thus, to make sure that the resulting networks truly represent small worlds, one has to compare the relevant measures with an equivalent random network (benchmark). Specifically, the benchmark is one with not only the same number of nodes and links (which would have been sufficient for an unweighted one-period network), but also the same distribution of weights. For that we generate random networks having the same number of nodes and links as those observed in our ABM. We then randomly assign weights to the links in the benchmark from the distribution of weights of our observed networks. This procedure was replicated 100 times 28 and average values for clustering coefficient, mean path length and small world ratio were obtained. After that, we divide measures derived from the ABM by the values from benchmark networks, denoting the resulting network characteristics as rescaled 29

The characteristic networks generated in our model have rescaled small world ratios about twice as high as the one from a corresponding random network. This is primarily because of the much denser local structures generated in our model and not shorter paths. Whereas the random networks have systematically shorter paths than the model-generated networks, their clustering coefficients are two to three times smaller 30 In general, this implies that even

\footnotetext{
${ }^{28}$ As before, this figure is in keeping with earlier studies.

${ }^{29}$ In doing so and given the types of networks we obtain in our model, we concentrated our comparison on the largest connected components only. This is because in the popularity contest scenario, there are potentially several disconnected components with a relatively moderate total number of links. This gives rise to very sparsely connected random networks and thus very low clustering coefficients. Whereas in the first two matching rules (unilateral and reciprocal) this approach leads to only marginal differences in the rescaled values, the difference for the popularity contest approach is dramatic. The implication of this approach is that the network with popularity contest is not necessarily small worldly as a whole but its largest connected component is.

${ }^{30}$ Note, however, that the result for the popularity contest approach is not that stable. In certain restarts, the small world ratio of the generated network was close to that of the benchmark.
} 
unilateral partnership
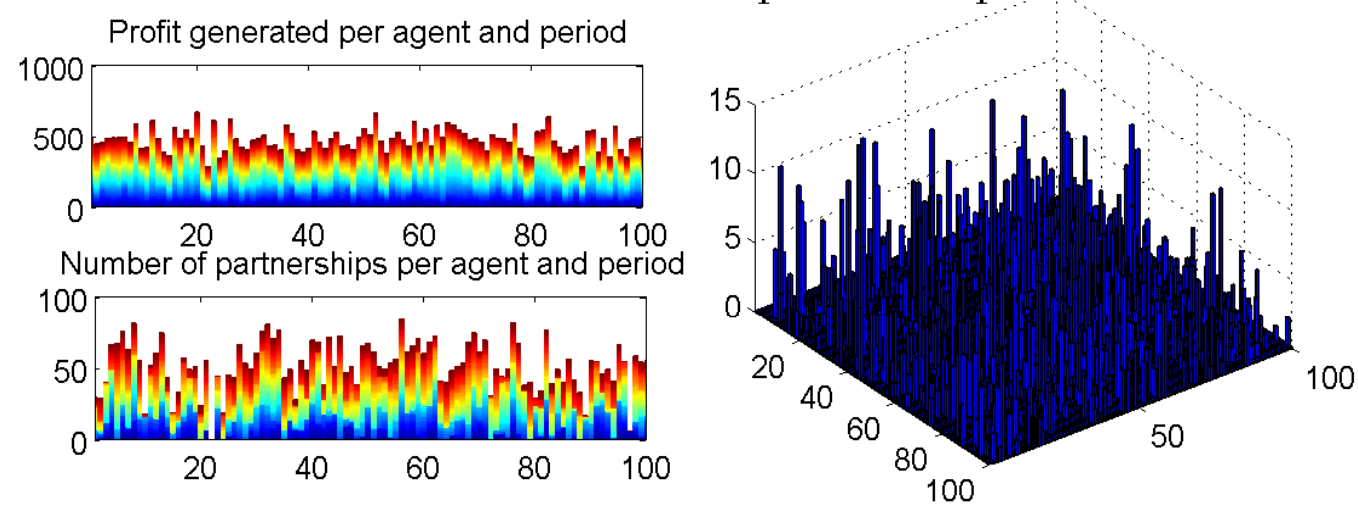

reciprocal partnership

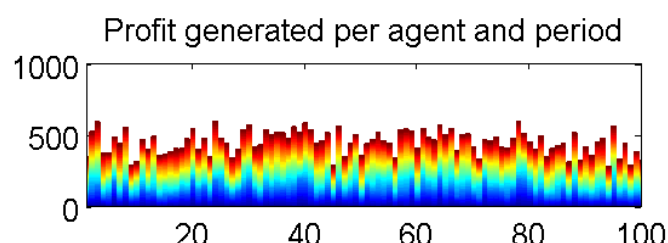

Number of partnerships per agent and period
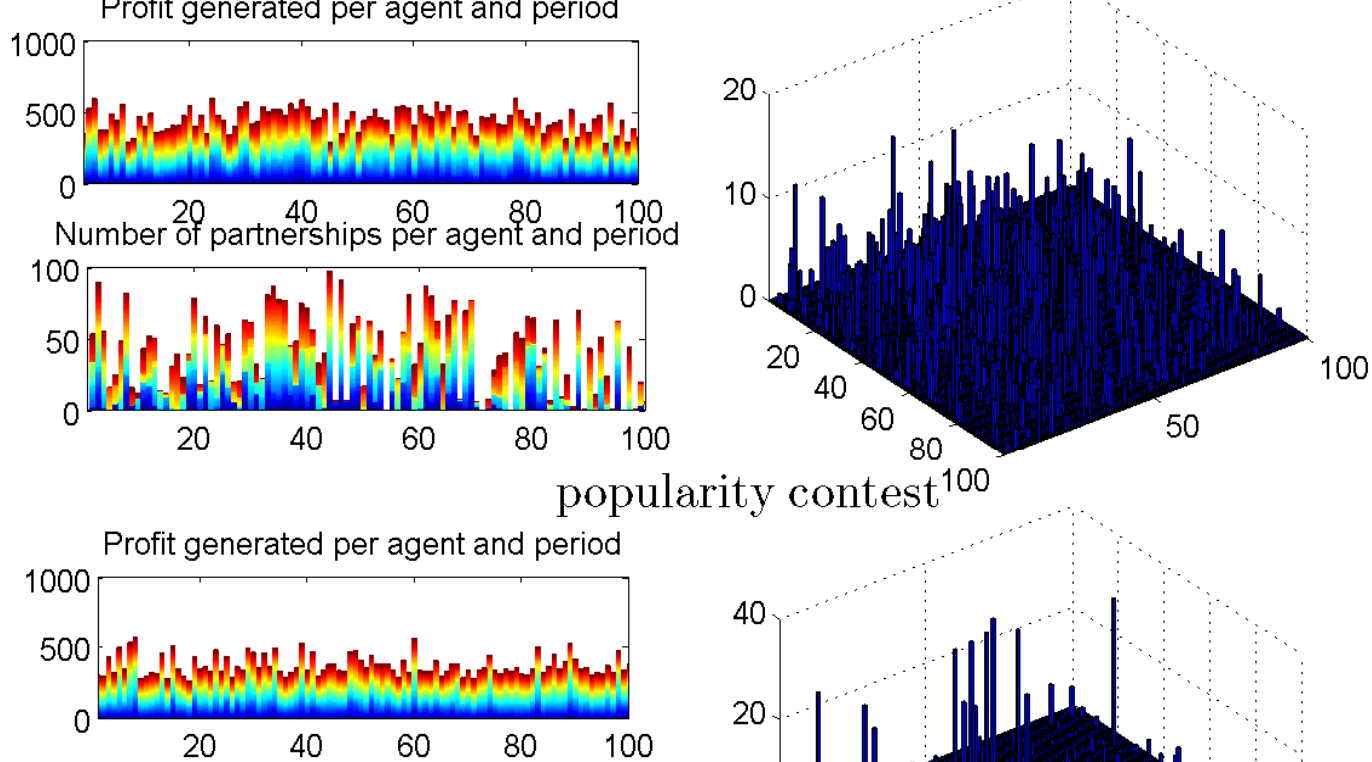

Number of partnerships per agent and period
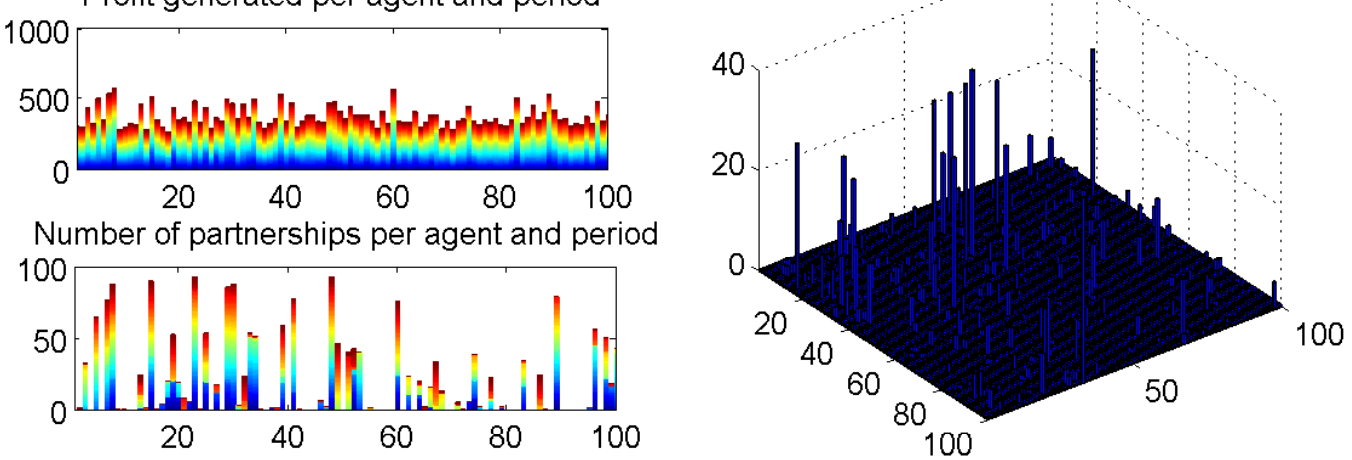

Figure 5.2: Descriptive network information

Notes for Figure 5.2. On the left upper plots firms are given on the X-axis, while aggregated profits over 100 periods are on the Y-axis. Colors in the stacked bars indicate attribution of the profits to a particular period. On the lower left plots of the respective matching rule again firms are on the X-axis, while the total number of alliances firm have participated in are on the Y-axes. Similarly, the color on the stacked bars represent a particular period a partnership was taking place in. On the right plots the weighted adjacency matrices are given: the $\mathrm{X}$-axis (left side of the 3-D plot) indicates a firm successfully 'offering' an alliance, while Y-axis - the firm accepting it. Z-axis illustrates the total number of alliances between the firms. 
in the absence of network-based structural and strategic motives, networks that emerge from bilateral partnership based on knowledge considerations with endogenous absorptive capacity demonstrate small world properties.

The 3-D graphs on the right in Figure 5.2, also obtained from a single simulation run, display the 'matrices of cooperation' (also refered to as weighted adjacency matrices) for the different matching rules. This refers to the number of partnerships aggregated over the 100 periods, distinguishing whether a particular alliance was 'initiated' by partner $i$ : in such a case the partnership is attributed to $i$ 's raw - left axis. We see a much larger number of alliances in the unilateral partnership formation resulting also in a larger density. In contrast, in the reciprocal partnership scenario, the alliances are more symmetrically dispersed in the matrix resulting in a higher reciprocal rate of partnerships. To illustrate their difference, we compare these two networks in terms of the amount of profits generated by firms over the time interval under consideration. It is seen that although on average firms in the unilateral setting generate more (474 versus 448), this comes at the cost of a slightly larger disproportion between the firms. The coefficient of variation 31 in the unilateral setting is 0.20 (versus 0.18 in the reciprocal partnership setting).

The popularity contest scenario results in the smallest average profit and coefficient of variation: 377 and 0.16 , respectively. As earlier pointed out, in this scenario there is some level of competition for alliances among the firms which detrimentally affects aggregate performance (though particular firms perform well). Here only a moderate number of firms forms an alliance more than ten times, and many of those firms cooperate only with each other. Those firms performing well, as expected, are the ones allying most (correlation between the aggregated profits and the total number of partnerships $\approx 82 \%$ ). The dramatic difference in the number of partnerships cannot be explained by the $\mathrm{R} \& \mathrm{D}$ budget allocation (correlation is merely $\approx 32 \%$ ), but rather the network location of those firms (correlation with weighted betweenness centrality is $\approx 74 \%$ ).

\subsubsection{Different knowledge regimes}

To provide a more systematic insight about the network characteristics and the contingent effects of firms' position (both in the network and the knowledge space), we analyse results by varying the magnitude of voluntary and

\footnotetext{
${ }^{31}$ Simply the standard deviation divided by the mean.
} 
involuntary spillovers. In particular, we fix $\delta_{n}=0.05$ varying the voluntary spillovers and then similarly alter involuntary ones by fixing $\delta_{c}=0.2$. The results are produced for ten restart. 32 and reported in medians together with $5-95 \%$ quantiles to account for the variance in those results.

The logic is as follows. Alliance formation in our model is solely for knowledge sharing, and partner selection is driven not by social capital but mainly by absorptive capacity. Firms therefore tend to select partners from whom they expect to gain the largest amount of knowledge at the lowest cost (Bala and Goyal, 2000). Thus, changes in the quantity of knowledge available through partnership (voluntary spillovers) should affect partnership formation. Moreover, the knowledge gained from an alliance is combined with externally available knowledge (involuntary spillovers) as inputs into the innovation process. Consequently, changes in the quantity of involuntary spillovers should also affect alliance formation.

Taken together, changes in those spillovers reflect in aggregate network structure and performance as well as the contingent effects of firms' network position on their innovativeness. As already explained in Section 5.3, such changes are supposed to occur at different times in the history of an industry. Typically, when an industry is young, knowledge is more tacit and requires cooperation to gain access. Thus, a higher intensity of voluntary spillovers can be observed. In contrast, in a mature industrial setting, knowledge is more codified and thus firms do not necessarily need to cooperate to gain access to external knowledge (higher involuntary spillovers).

\section{Network structures in different knowledge regimes}

Figures $5.3 \mathrm{~A}$ - show the effects of involuntary spillovers $\left(\delta_{n}\right)$ on the aggregate network structure and performance. The effects of voluntary spillovers are shown in Figures 5.4A C. In all cases, we report first the dynamics in the small world ratios (subplot (a)). In subplot (b) we illustrate the dynamics in the length of cooperation (or duration of alliances). Here we count all the cooperations between any two firms actually taking place, measure how long they were lasting without discontinuation - irrespective of whether an alliance was formed on the 'initiative' of one or the other firm - and take the average. The same plot shows the trend in the total number of alliances in each period. Subplot (c) shows the trend in aggregated profits generated within the network.

\footnotetext{
${ }^{32} \mathrm{~A}$ single restart for a given parameter setting requires from 130 to 250s, depending on the matching rule applied, using Matlab 7.11 and Pentium IV $3.3 \mathrm{GHz}$.
} 
Recall that the absorptive capacity within the context of cooperation $\left(a c_{i j}\right)$ is different from that which is directed on external knowledge $\left(a c_{i e k}\right)$, due to different distances between the firm and these knowledge sources. How these two capacities respond to changes in the quantity of knowledge is shown in subplot (d). In subplot (e) the trend in \% of reestablished cooperations is shown. This is defined during a given period as the share of cooperations which did not exist in the preceding period, but existed during one of the three periods before that. That is, $i$ and $j$ form an alliance in period $t$, but not in period $t-1$, while they also had an alliance at least once between $t-2$ and $t-433$ Finally, in all of Figures 5.3A $5.4 \mathrm{C}$, subplot (f) shows the relative benefits (i.e. amount of knowledge generated from inventive R\&D as well as voluntary and involuntary spillovers) and costs of cooperation. The costs are calculated not as the denominator in equation (4.12), but as the difference between $\left(k_{i}^{t}\right)^{\text {generated in cooperation }}$ and $\Pi_{i}$, i.e. by how much knowledge generated in cooperation has been reduced due to outgoing spillovers to the partner.

First we discuss how different $\delta_{n}$ affect aggregate network characteristics and performance (Figures $5.3 \mathrm{~A} C \mathrm{C}$ ). In general, the networks retain their small world properties for different amount of involuntary spillovers. Clearly, the networks with unilateral and reciprocal matching are more small worldly, mostly because changes in $\delta_{n}$ do not affect the average mean path length and clustering in these networks (subplots (a) and (b), Figures D.1A C in Appendix D.2).

Specifically, an increase in the magnitude of involuntary spillovers from firms located close enough (in particular, within the radius discussed in Section 5.4) has no substantial impact on the rescaled small world ratio (being $\approx 2$ ). In comparison, the network with popularity contest is less small worldly. Only $\delta_{n} \approx 0.1$ (i.e. $10 \%$ of knowledge from surrounding firms 'spilling over' at no cost to a given firm) allows to reach a small world ratio comparable to the other two networks. For smaller $\delta_{n}$ the rescaled ratio sometimes also reaches this value, but this result is not robust.

In general, alliance durations are relatively short and not very responsive to changes in $\delta_{n}$. The values range from $\approx 1.35$ periods in the unilateral matching

\footnotetext{
${ }^{33}$ The choice of exactly three periods here is meant to be a trade-off: to consider on the one hand a potentially larger time horizon (since only one period is too short to account for), and on the other hand to avoid too much of double counting (since the larger the time horizon, the higher the chance that within it a cooperation might have been discontinued and re-formed several times).
} 

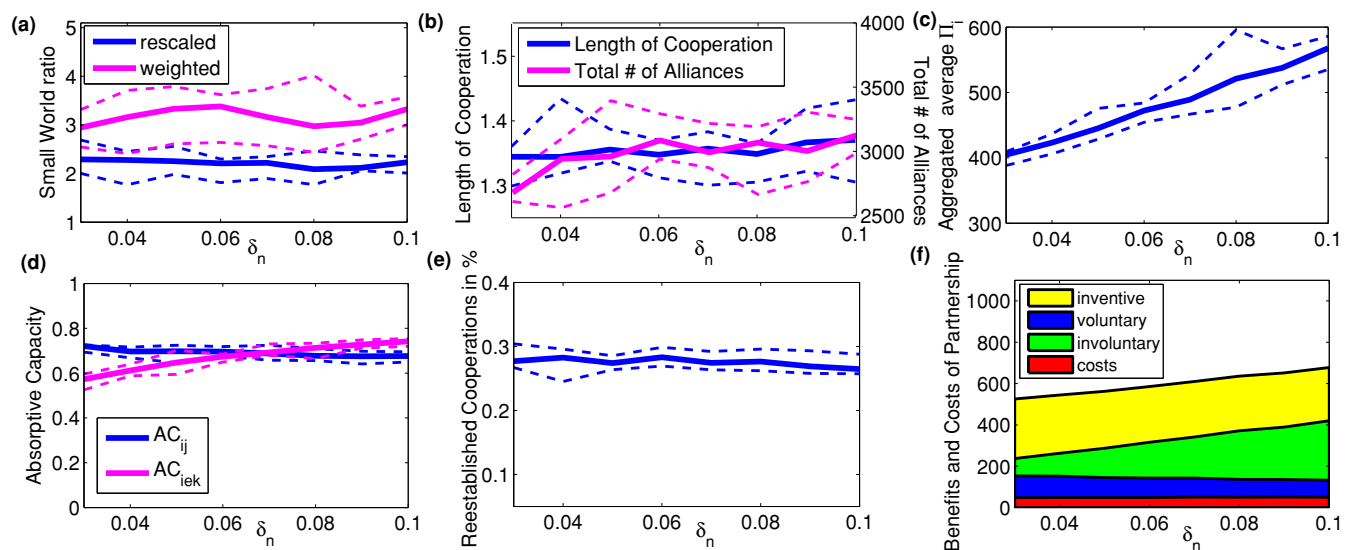

\section{(A) Unilateral partnership}
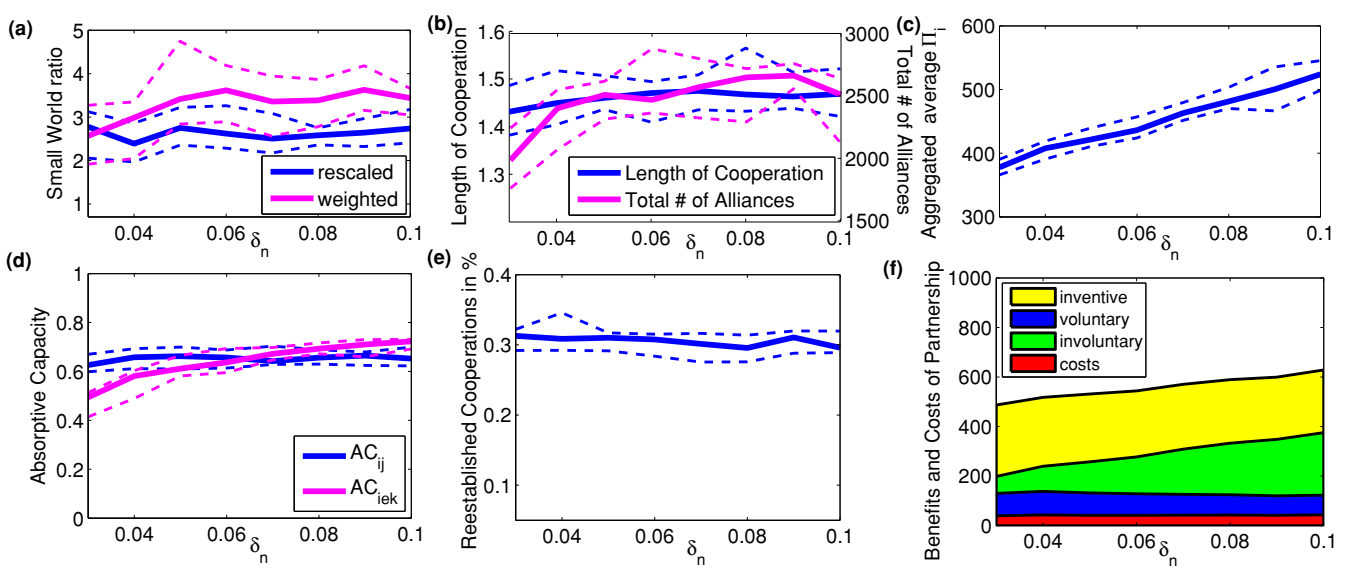

(B) Reciprocal partnership
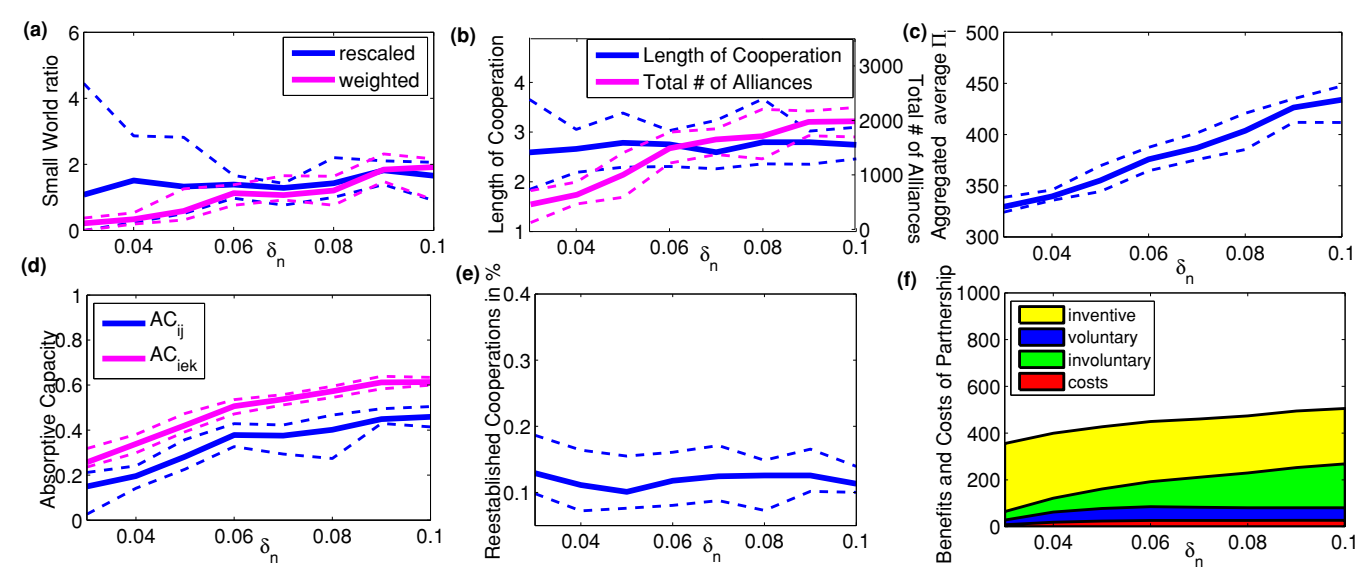

(C) Popularity contest

Figure 5.3: Network characteristics and involuntary spillovers $\left(\delta_{n}\right)$ 
to $\approx 1.45$ periods in the reciprocal matching and $\approx 2.5$ periods in the popularity contest. These figures are generally consistent with empirically observed alliance duration averages of between 1 and 5 years (Rosenkopf and Schilling, 2007). The average duration of cooperation maps directly onto the total number of alliances. The generally short durations imply increasing number of partnerships as $\delta_{n}$ increases. Shorter durations in the unilateral matching context correspond to higher alliance rates (and, by extension, a highly dense and clustered network) while comparatively longer durations lead to relatively lower alliance rates in the popularity contest scenario. A related measure in this respect is reestablished cooperations (subplot (e)). Now, reversely, the popularity contest network has the lowest share of about $10 \%$. Since partners tend to stay longer together in this context, the possibility for alliances between them to re-occur is comparatively lower than in the other two networks. Moreover, there are fewer alliances in the popularity contest network. In the other two matching rules, repeated partnerships are close to $30 \%$, with the reciprocal partnership having a marginally higher share.

It is worth noting that despite the relatively longer average duration of alliances in the popularity contest network, alliance formation increases consistently across the entire range and more than doubles at the upper limit of $\delta_{n}$. The trend may be explained by the fact that for low $\delta_{n}$ cooperations are 'initiated' only by the most 'popular' firms which benefit from their central position and invest funds in absorbing both voluntary and involuntary spillovers from more distinct partners whereas majority of the other firms prefer the standalone strategy. This is confirmed by looking at the average distance between partners in cooperation (subplot (d) in Figures D.1A C in Appendix D.2): for $\delta_{n}=0.03$ this distance is about twice as high in the popularity contest network than in the other two. However, as involuntary spillovers rise, firms located in the 'periphery' of the knowledge space become incentivised to invest more in absorbing new knowledge and engaging in $R \& D$ cooperation, and the average distance falls 34

Increasing alliance rates, especially at low levels of $\delta_{n}$, can also be explained by the fact that when involuntary spillovers are small, firms rely more on cooperation partners as sources of additional knowledge for innovation. But as $\delta_{n}$ rises, firms start to pay more attention to involuntary spillovers while maintaining their access to knowledge from alliances. Consequently, the number of

\footnotetext{
${ }^{34}$ In the other scenarios, this distance increases in $\delta_{n}$ as there are more spillovers to absorb and firms engage in cooperation relatively more equitably. The distance is slightly higher in the unilateral matching because of the absence of reciprocity; firms 'offering an alliance' may ex parte impose a partnership if they find it profitable.
} 
alliances in any given period tends to level out at higher levels of $\delta_{n}$. This may also be the reason for the slightly lower clustering coefficients and mean path lengths observed for higher $\delta_{n}$ in Figures D.1A C in Appendix D.2.

This trend is even better observed by looking at the dynamics in learning capacities (subplot (d)). The absorptive capacity directed towards external knowledge $\left(a c_{i e k}\right)$ is seen to rise consistently in all the matching scenarios while the absorptive capacity within alliances $\left(a c_{i j}\right)$ slightly falls in the unilateral and reciprocal matching networks and increases only in the popularity contest approach as more and more firms start to cooperate 35 These results imply that when involuntary spillovers increase, firms' capacity to appropriate them also increase. This is quite logical since, in the scenarios observed here, the level of voluntary spillovers is fixed; firms may, therefore, shift their learning attention towards involuntary spillovers which are consistently increasing.

Nevertheless, aggregate profits increase (subplot (c)) mostly due to increasing amounts of involuntary spillovers assimilated. Profits due to inventive R\&D reduce as firms tend to invest less in invention (subplot (e) of Figures D.1AC in Appendix D.2). The contribution of assimilated voluntary spillovers to the R\&D profit (darkest area in subplot (f)) as well as the costs related to $\mathrm{R} \& \mathrm{D}$ cooperation do not change much. This is to be expected since $\delta_{c}$ is fixed and firms do not necessarily become better at appropriating spillovers from cooperation.

Now we consider how changes in voluntary spillovers $\left(\delta_{c}\right)$ affect aggregate network structure and performance (Figures $5.4 \mathrm{~A}, \mathrm{C}$ ). We find that higher voluntary spillovers - which increase the speed of learning and convergence in the knowledge space according to (5.7) - cause the networks to become somewhat less small worldly: the weighted small world ratios reduce by nearly half 36 However, the rescaled measures which compare our networks to the random benchmarks do not change much as voluntary spillovers increase (subplot(a)); though in the popularity contest network, this result is not robust. The small world properties of these networks appear to be more sensitive to changes in voluntary spillovers than to involuntary ones.

When voluntary spillovers are small, alliance durations are generally much longer (also in comparison to the regime of involuntary spillovers) but fall

\footnotetext{
${ }^{35}$ Note here that estimating average absorptive capacity in cooperation $A C_{i j}$ we ignore periods when firms do not form an alliance in order not to downsize the actual absorptive capacity and highlight its level in cooperation periods.

${ }^{36}$ Figures D.2A C show also that weighted clustering reduces and mean path length increases marginally.
} 
rapidly as the spillovers increase. This is primarily due to increased pace of learning which makes continuous cooperation with the same partner less profitable over time. Thus, alliances are more often discontinued and firms either find other partners or innovate on their own. This reflects in the reducing total number of alliances, since, in reality, it takes time for firms to adjust their investments appropriately and to find other suitable partners. The share of reestablished cooperations remains rather stable: it only slightly falls in the unilateral matching, while a marginal increase can be observed in the popularity contest (subplot (e)). This could be because, as earlier demonstrated with the characteristic networks (Figure 5.2), cooperation intensity is lower in the popularity contest scenario, and many cooperating firms repeatedly ally only with each other. Thus, there is an increased likelihood that previously discontinued alliances are re-formed in this scenario.

Another pronounced effect of the learning rate is on the dynamics in absorptive capacity (subplot $(\mathrm{d})$ ). Learning from involuntary spillovers increases when $\delta_{c}$ is high and remains stable above the learning that occurs from voluntary spillovers. Combined with what was observed earlier in the case of $\delta_{n}$, this suggests that firms tend to put more effort into absorbing spillovers when they are high. More of this learning takes place from involuntary spillovers because the costs are much lower than for voluntary ones.

Moreover, $a c_{i j}$ slightly falls for some intermediate levels of $\delta_{c}$ and rises afterwards. This can be explained by changes in cognitive distance. As shown in subplot (d) of Figures D.2A C in Appendix D.2, average cognitive distance between partners first falls in $\delta_{c}$ since learning implies that firms move closer in the knowledge space. As $\delta_{c}$ reaches its middle range $\left(\delta_{c} \approx>0.4\right)$, average distance increases. This may be a result of increasing absorptive $R \& D$ (subplot (e) of Figures D.2A C in Appendix D.2), where firms reach further in the knowledge space to find cooperation partners with novel knowledge. In fact, firms first reduce investments in absorbing external knowledge (with smaller distance less investments are required) but then increase them back to roughly the same level. This causes $a c_{i j}$ to rise. The combined dynamics here further illustrate the ambiguous relationship between cognitive distance and absorptive capacity that we analysed in the previous chapter.

It is worth noting that aggregate profit reaches its maximum at an intermediate level of $\delta_{c}$ in all matching scenarios (subplot (c)). This happens because firms' learning capacities allow them to benefit from the combination of shorter distances to partners and increasing investments in inventive R\&D. However, at high levels of $\delta_{c}$, aggregate profit drops in spite of the benefits from invent- 

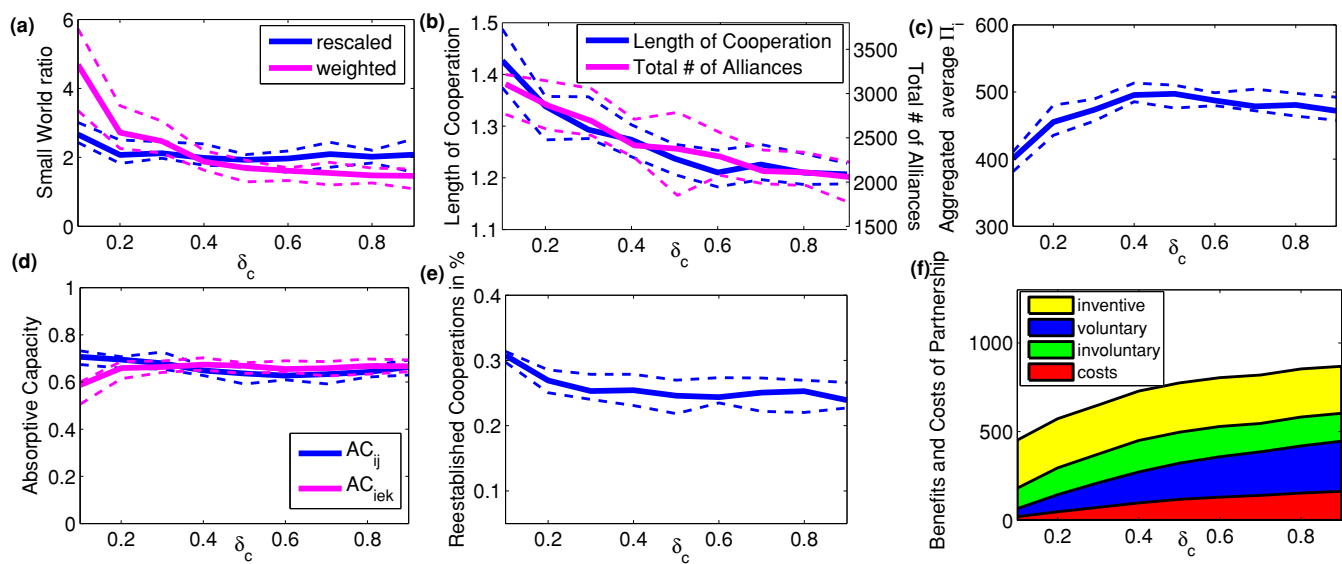

\section{(A) Unilateral partnership}
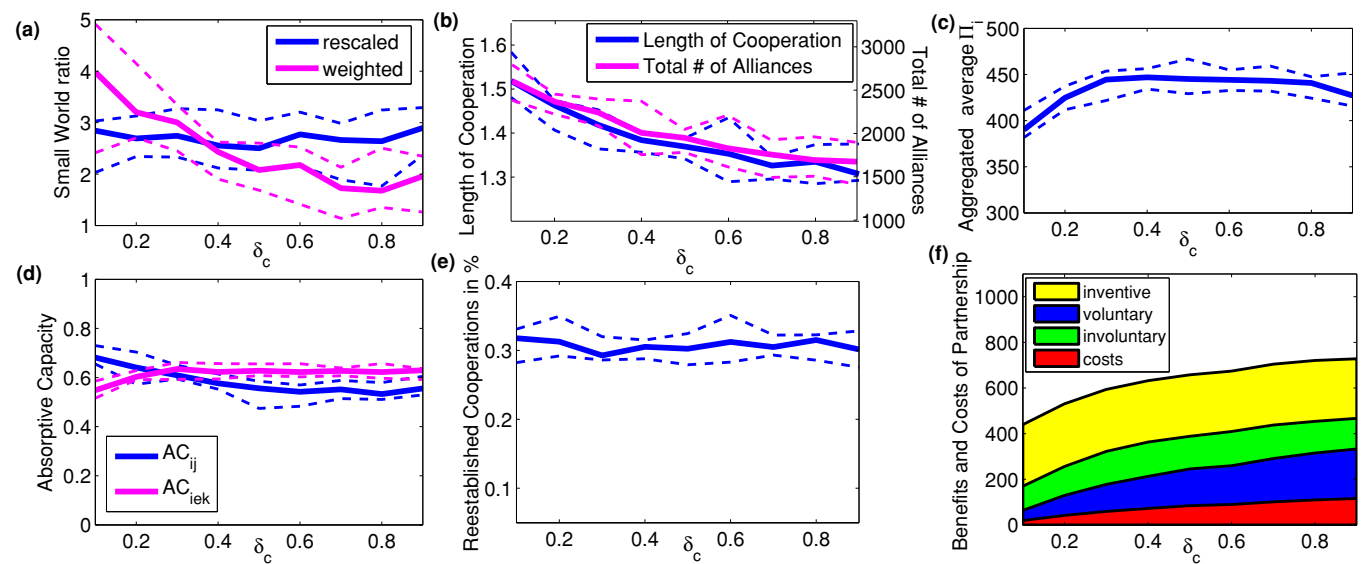

(B) Reciprocal partnership
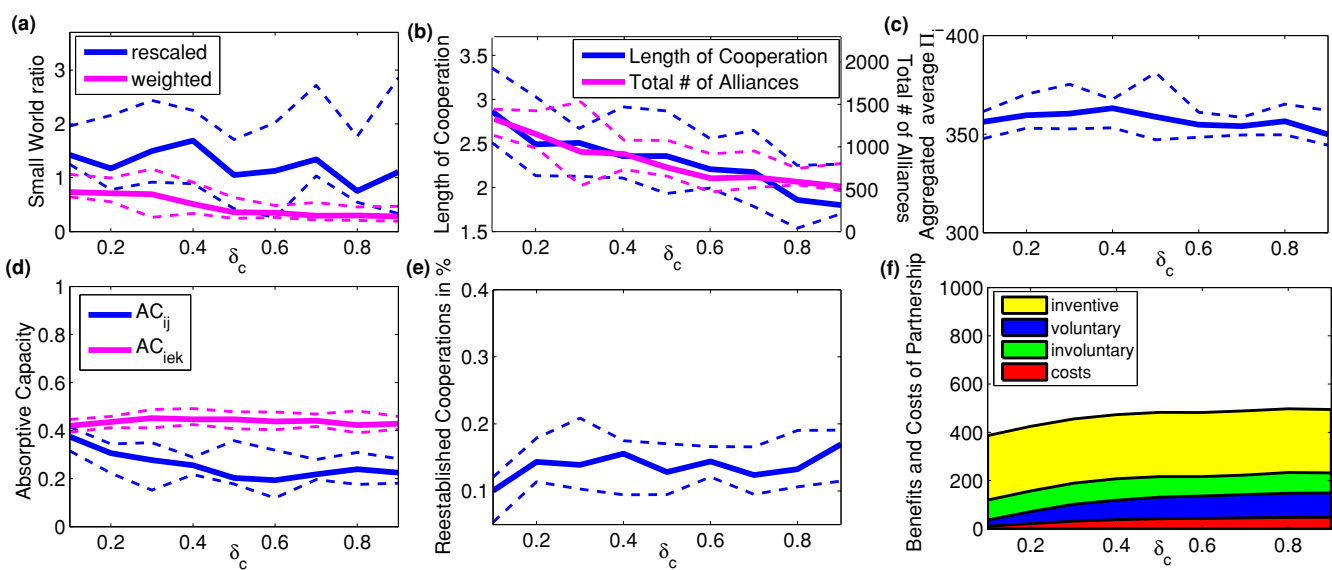

(C) Popularity contest

Figure 5.4: Network characteristics and voluntary spillovers $\left(\delta_{c}\right)$ 
ive $R \& D$ and involuntary spillovers as well as increasing assimilated voluntary spillovers observed in subplot (f). The reason for this is that the costs of cooperation rise consistently and become more dominant as cooperation becomes more intense. The inverted ' $U$ '-shaped dynamics draws attention to the potential pitfalls of cooperation as emphasised in the empirical literature. Intense cooperation, whether in terms of repeatedness or persistence, limits the potential for recombinant novelty, thereby reducing innovative profits. Again, networks with popularity contest consistently demonstrate the worst aggregate performance due to the low number of alliances which, in turn, is a result of competition.

\section{Firms' network position and performance}

A widely held belief in the literature on alliances and firm networks is that the diffusion of knowledge in networks characterised by short path lengths is more efficient. Also, it is thought to be beneficial for firms to occupy influential positions - such as having high betweenness centrality which allows them to act as knowledge brokers - in networks. These results are normally explained in terms of social capital. Yet, our model in which networking is entirely knowledge-driven shows results which are consistent with the empirical regularities. The value in this is that knowledge and technological fit, rather than just social capital, contribute to the observed performance effects of inter-firm cooperation. An important extension derived from the results here is how the relationship between network structure and innovativeness varies in response to changes in the characteristics of the knowledge space. In this section we discuss the relationship between an individual firm's performance 37 and the structure of the network. Figures 5.5A C contain the results for varying levels of involuntary spillovers and Figures $5.6 \mathrm{~A} C \mathrm{C}$ for varying levels of voluntary spillovers.

In all cases, we report first the correlation between profits and betweenness centrality (subplot (a)). In subplot (b) we illustrate the correlation between absorptive capacity to a partner and betweenness centrality. The same plot shows the correlation of absorptive capacity to external knowledge and betweenness. Subplot (c) shows the correlation between profits and number of partnerships. In subplot (d) the correlation between profits and mean path length is shown. The correlations between the two different absorptive capacities and mean path

\footnotetext{
${ }^{37}$ Recall that performance refers to the amount of $R \& D$ profit that the firm generates in each period.
} 
length are given in subplot (e). Finally, in all of Figures $5.6 \mathrm{~A} 5.6 \mathrm{C}$, subplot (f) shows the correlation between profits and absorptive capacity.

First, we consider changes in the level of involuntary spillovers (Figures 5.5AC). In subplot (a), betweenness is positively correlated with performance, suggesting that occupying a brokerage position pays off for the firm. At least in the unilateral and reciprocal matching networks, the highest correlations coincide with very low values of $\delta_{n}$. The correlation then reduces greatly but remains positive as $\delta_{n}$ increases. The extreme values of $\delta_{n}$ correspond to different stages of an industry's life cycle. Typically, in the early stages, involuntary spillovers are low. In this context, being in a brokerage position improves access to tacit knowledge. In the later stages when knowledge is mostly codified and freely available, although being in a brokerage position is good, it becomes less relevant.

This is quite logical because, in such scenarios, networks are less clustered and brokers tend to become redundant to gain access to spillovers which are freely available. The only real constraint that each firm faces then is its capacity to absorb and not necessarily the absence of a broker in its ego-network. The correlation of profit with mean path length (subplot (d)) tells a consistent story. High values imply late arrival of knowledge and potentially lower innovation performance. However, when freely available knowledge becomes more abundant, the severity of this effect reduces significantly. Simply put, a combination of high betweenness and short path length becomes less critical for performance in mature industries wherein involuntary spillovers are generally high.

The total number of alliances is positively correlated with performance at all levels of $\delta_{n}$ but the strength of the correlation reduces as $\delta_{n}$ increases (subplot (c)). In particular, the correlation of a firm's performance with 'directed' partnerships (that is, when it initiates the partnership) is consistently lower than the 'undirected' partnerships (that is, when it either initiates or accepts a partnership). This is consistent with the empirical finding that too many partnerships can be problematic (Uzzi, 1997; Ahuja and Lampert, 2001), mostly for social capital reasons. In contrast, our result here is driven by changes in the underlying knowledge regime. When intra-industry spillovers are high, it is less efficient to maintain a large portfolio of alliances. As we have noted earlier, this situation is characteristic of the later stages of an industry when firms might be more dispersed and localised spillovers are less useful (Potter and Watts, 2011).

Also, as expected, absorptive capacity is positively correlated with perform- 

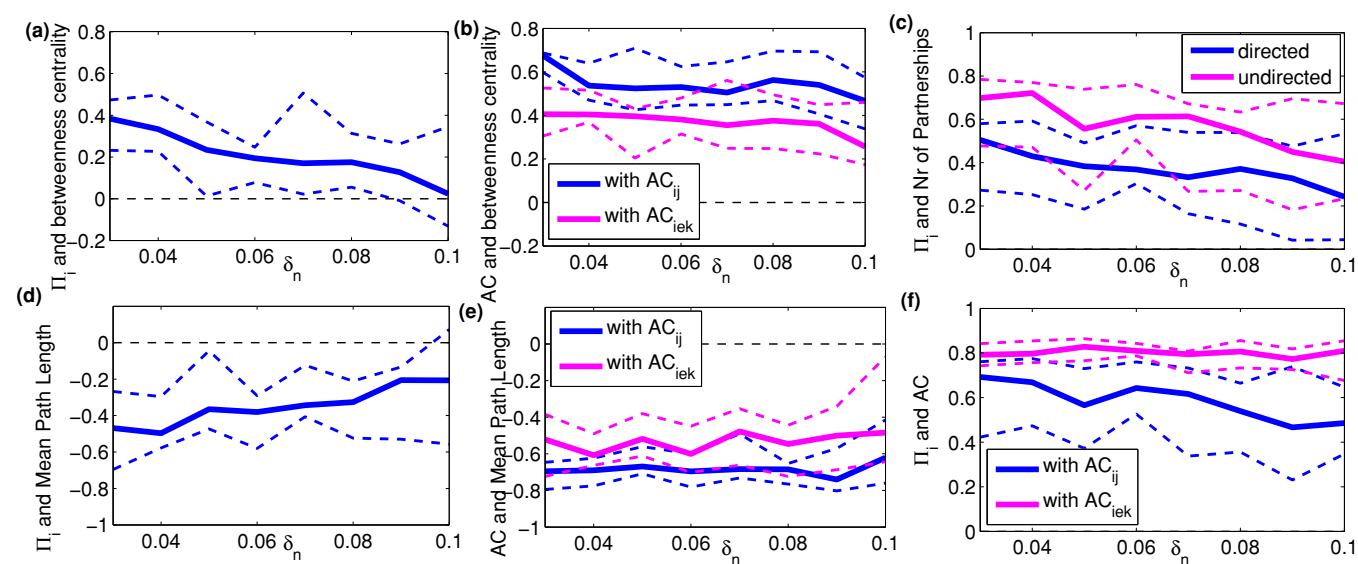

\section{(A) Unilateral partnership}
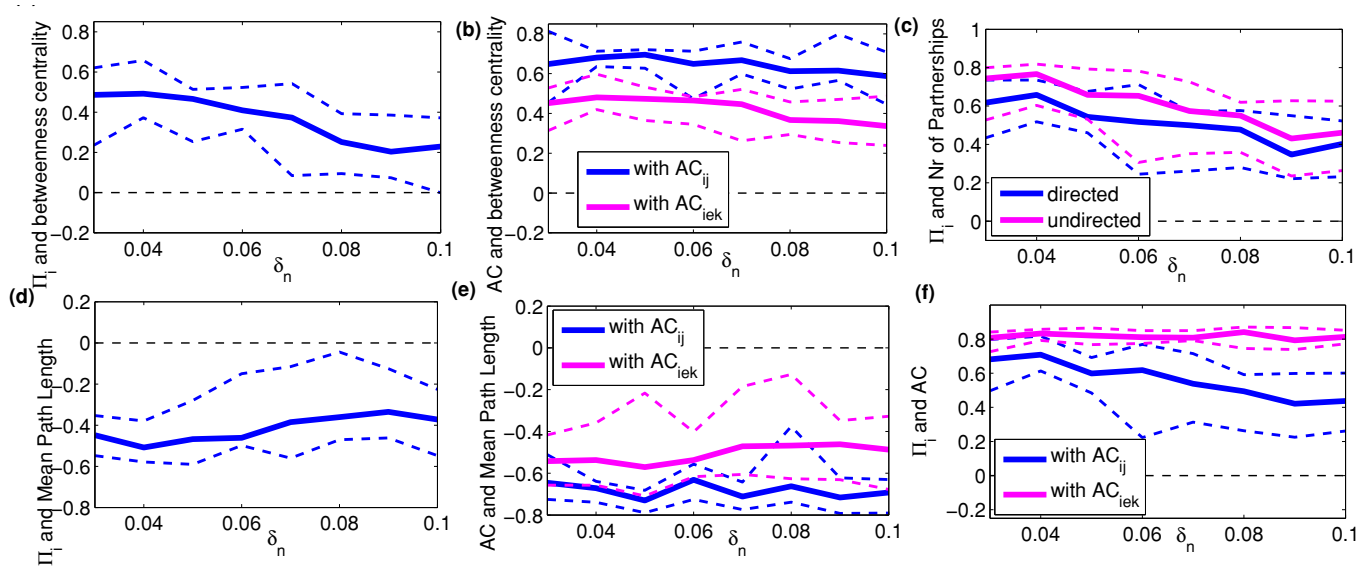

(B) Reciprocal partnership
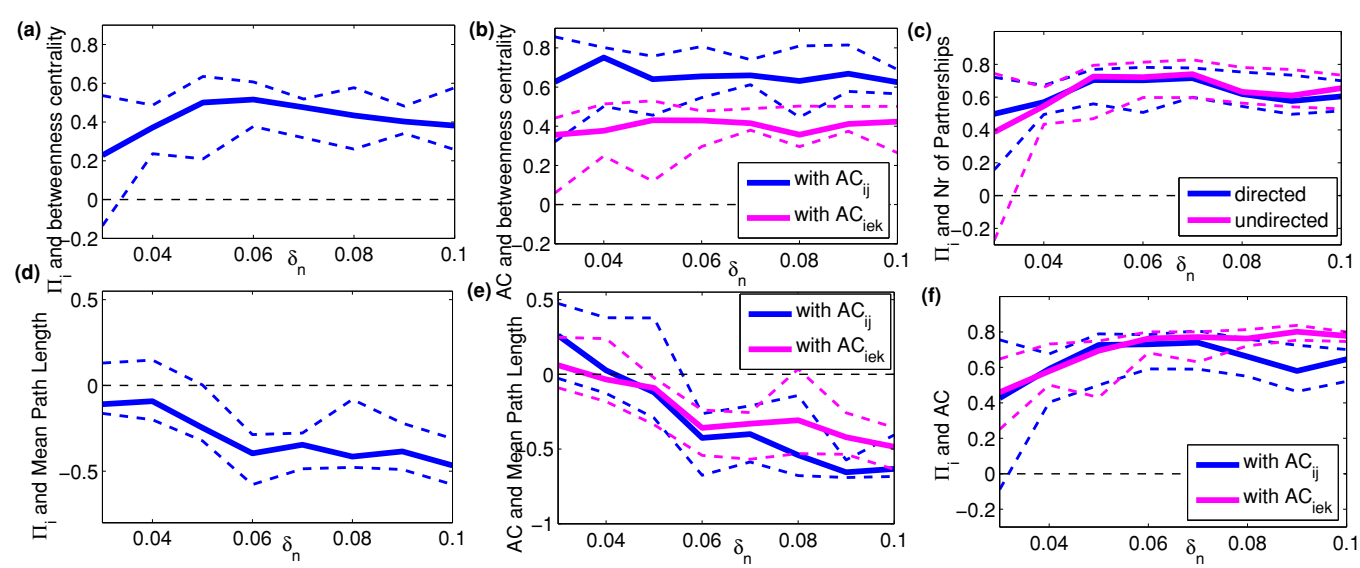

(C) Popularity contest

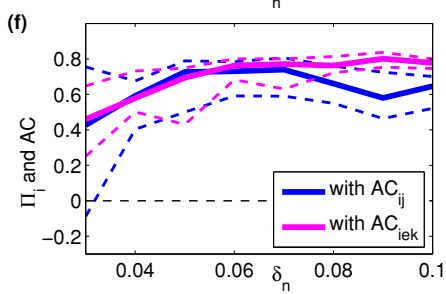

Figure 5.5: Correlations under varying involuntary spillovers $\left(\delta_{n}\right)$ : firms' network position and performance 
ance (subplot (f)). The reducing correlation of $a c_{i j}$ further emphasises the view that at higher levels of involuntary spillovers, learning from cooperation becomes less important. Particularly interesting is to observe the correlations of absorptive capacity with betweenness (subplot (b)) and mean path length (subplot (e)). The correlations somewhat reflect the relationship between profits and these network measures. It seems that firms having favourable network positions (high betweenness and short paths) are motivated to build up absorptive capacity. This implies that firms adjust their learning (particularly from partners) depending on their position.

Now we turn to the effect of changes in voluntary spillovers (Figures $5.6 \mathrm{~A}$ C). First, we observe from the correlation in subplot (a) that betweenness is highly positively correlated with performance. The correlation does not change much with variations in $\delta_{c}$. This suggests that brokerage positions are consistently favourable in a regime characterised by increasing voluntary spillovers. In such regimes, tacitness is high and cooperation is considered to be essential (von Hippel, 1987). Occupying brokerage positions thus confers some controlling power on firms. Again, it is crucial to note that this result arises not from social capital but out of knowledge-driven alliance formation. In this sense, a high betweenness value can be interpreted as being located in a clustered part of the knowledge space and having influence in the knowledge diffusion process.

Mean path length is negatively correlated with performance (subplot (b)), meaning that low accessibility impairs innovativeness. In contrast to involuntary spillovers, this relationship here does not vary much for different voluntary spillovers. In sum, a combination of high betweenness and short path length are consistently important for innovation performance in a highly tacit knowledge regime.

The performance effects of the number of partnerships (subplot (c)) fluctuates as $\delta_{c}$ rises. It is highest at some intermediate values of $\delta_{c}$, falling otherwise. This seems to reflect an empirically observed problem associated with alliances. As Ahuja (2000) argued, at high levels of embeddedness, the marginal costs of every additional linkage will outweigh the marginal benefits. Absorptive capacity is consistently positively associated with profits. This correlation does not change much with changes in the amount of voluntary spillovers (subplot (f)). As observed with involuntary spillovers, the correlations of absorptive capacity with betweenness and mean path length somewhat reflect the relationship between profits and the network measures. Taken together with the earlier observation, these results indicate that firms display heterogeneity in building 

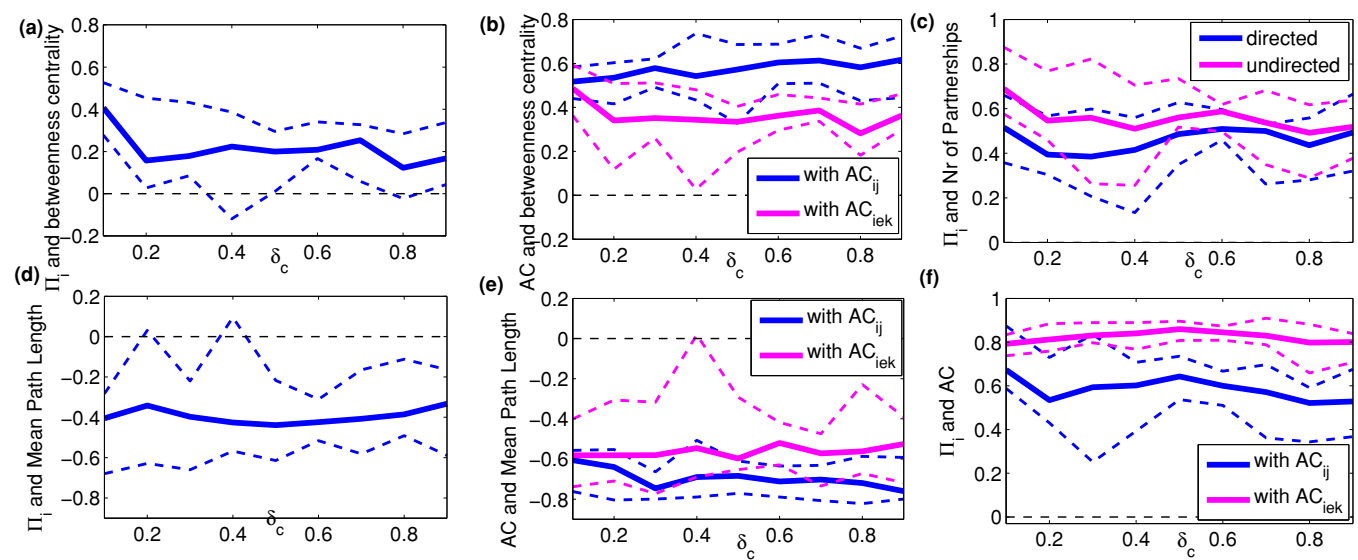

\section{(A) Unilateral partnership}
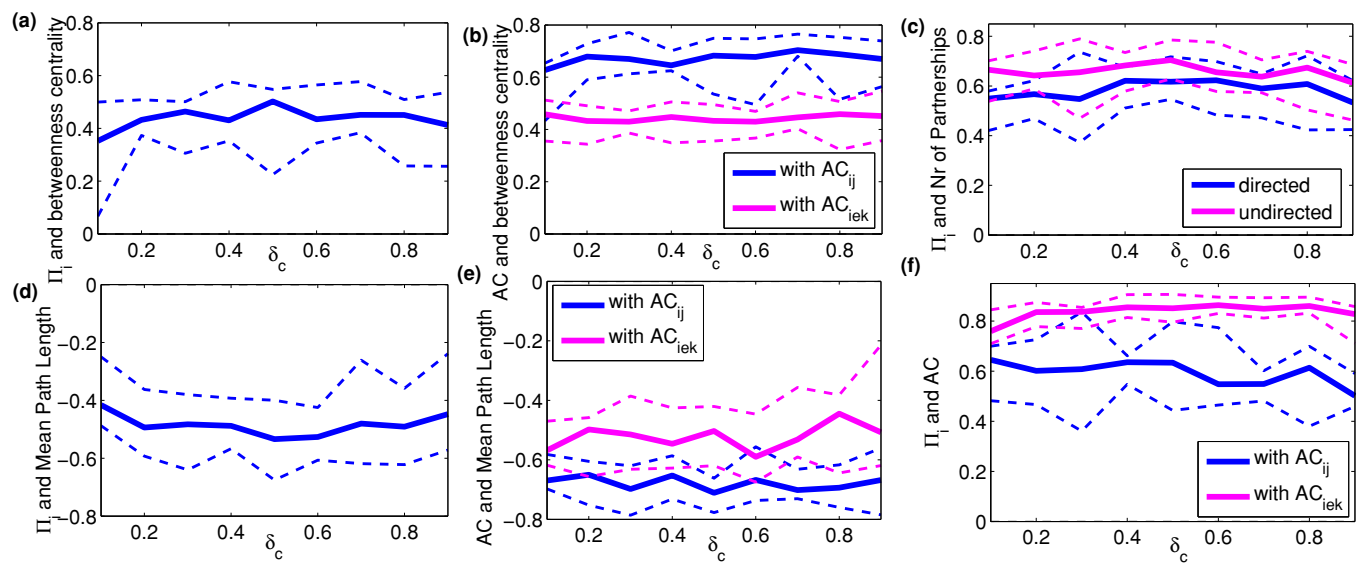

(B) Reciprocal partnership
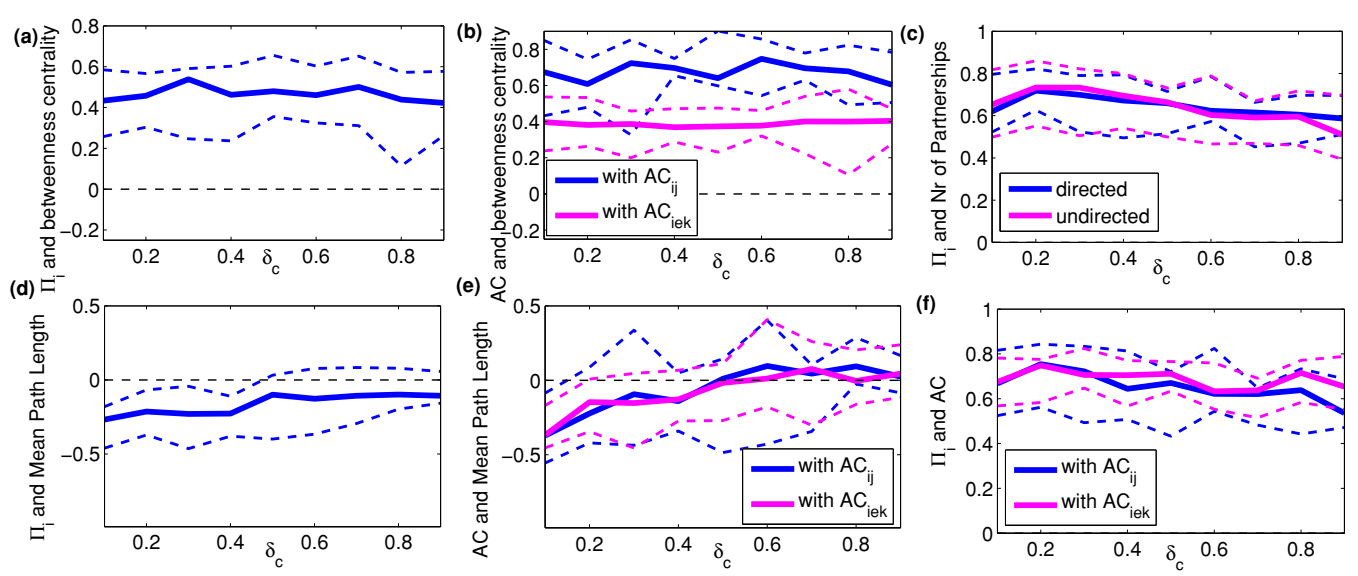

(C) Popularity contest

Figure 5.6: Correlations under varying voluntary spillovers $\left(\delta_{c}\right)$ : firms' network position and performance 
up absorptive capacity depending on the network positions they occupy.

\subsubsection{Robustness checks}

To analyse robustness of the results discussed above, a number of alternative settings are examined 38 First, in the simulation, we have set the marginal returns to both inventive and absorptive $\mathrm{R} \& \mathrm{D}$ as equal 39 It is appealing, however, to try out scenarios where this does not hold (that is, $\psi \neq \xi$ ). To this end, we set either $\psi$ or $\xi$ equal to 0.75 leaving all other parameters unchanged, repeat the simulation and then compare the results with the baseline scenario (the results described before).

What we find is that for $\xi=0.75$, investments in inventive $\mathrm{R} \& \mathrm{D}$ become naturally more lucrative ( $\rho$ s rise close to 90\%) and firms' absorptive capacity in all matching scenarios (between 0.2 and 0.6) are on average lower than in the baseline setting. These make partnerships less efficient and considerably less prevalent (reduced by almost half). Consequently, the weighted small world ratios become lower (due to lower clustering coefficients). However, rescaled small world ratios remain robust and consistently above one at least in the unilateral and reciprocal partnership contexts. Similarly, the correlation patterns identified in the baseline scenario between the firms' $R \& D$ profits and network position (betweenness and mean path length) as well as between absorptive capacity and network position remain stable.

Second, we have assumed that firms have perfect knowledge about cognitive distance between them and others. In other words, firm $i$ knows how far it is from $j$ in the knowledge space and $j$ also has the same information. To see, how crucial this assumption is, we introduce some uncertainty in this knowledge by adding some uniformly distributed error term $\epsilon$ reaching in its absolute maximum $50 \%$ of the distance between two firms, $\epsilon \in\left[-\frac{1}{2} d_{i} ; \frac{1}{2} d_{i}\right]$ This estimation error is added as well to the distance from involuntary spillovers. Hence, it affects both partner choice and investment allocation. The R\&D profits are, however, estimated with actual distances.

What we observe is that the main findings (on small world properties as well

\footnotetext{
${ }^{38}$ Detailed results are available upon request, but are not included in the paper for the sake of brevity.

${ }^{39}$ In doing this we were aiming to obtain more general results not giving any preference to one of the investment directions.

${ }^{40}$ In this way, the higher the distance between the two firms, the larger the potential error in estimating the cognitive distance between them.
} 
as the interdependencies between firms' network positions and profits/learning capacities) remain remarkably robust both qualitatively and quantitatively. Among the most noticeable changes are:

- clearly lower quality of expectation about other firm's investment decision (correlation between $E^{i}\left(\rho_{j}\right)$ and $\rho_{j}$ is about $50 \%$ only). This is to be expected since the uncertainty in the evaluation of distances affects investment allocation, making it less predictable;

- lower average absorptive capacity of firms (0.4-0.6 for unilateral and reciprocal matching, 0.2-0.4 for popularity contest). Again, failing to estimate the distance exactly naturally leads to under-/over-investments in absorptive R\&D and, hence, lower ability to learn (recall the inverted 'U'-shaped function in (4.8) );

- some lower aggregate R\&D profits of firms (by 10-20\% maximum compared to the baseline scenario) which is primarily due to lower absorptive capacity.

It is worth mentioning that increasing $\epsilon$ further (up to $100 \%$ of the distance between two firms) causes the emerging networks to lose their small world properties and profits to plummet. Thus, the ability to approximate cognitive or technological distance with a sufficient precision is established to be a very important competence firms must have to be efficient.

In brief, one can conclude that the main findings remain robust for different settings although it is impossible to try out all the different parameter combinations given the complexity of the model and the number of parameters included. A possible further step along this line would be to estimate some of the model parameters as described, for instance, in Gilli and Winker (2003) and Gilli and Winker (2003). However, due to lack of suitable and readily available data, this is left for further research.

\subsection{Conclusion}

As an important determinant of learning, absorptive capacity plays a key role in firm-level innovativeness. Its role in the formation of R\&D partnerships, and the resulting networks, is however, not well understood. This chapter started with the observation that earlier work on alliances has heavily focused on social capital explanations and that recent works which attempt to overcome this limitation seem to understate the role and the complexity of the absorptive 
capacity phenomena neglecting an important source of heterogeneity between firms resulting from it. We developed and simulated an agent-based model in which social capital is absent and alliances are formed based on knowledge fit depending on endogenous absorptive capacity. Three different matching scenarios are tested, one of which presents a simplified representation of competition 41 The remarkable result from the modelling exercise is that wellknown empirical characteristics of networks are replicated. What this tells is that disregarding the knowledge dimension in trying to explain the emergence, evolution and performance effects of networks gives, at best, a partial picture of reality.

The networks generated in the model display small world properties which respond to different extents to changes in the underlying knowledge regimes. The effects of these networks on performance vary depending on whether the knowledge space is characterised by intense cooperation and high voluntary spillovers (regime of high tacitness) or by relative dispersion and high involuntary spillovers (regime of high codification). In particular, in a regime of high tacitness, it seems to be more profitable for firms to occupy some kind of brokerage (high betweenness) and easily accessible (short path length) positions. This effect is less pronounced in a regime of high codification. Thus, at different stages of an industry's history, firms require different network strategies to achieve and maintain competitiveness through innovation.

A particularly important result relates to the role of absorptive capacity in network evolution. We observed a consistently strong and positive correlation between firms' absorptive capacity and their network centrality. This implies that being in a favourable network position relies on a higher level of absorptive capacity than being on the periphery. The consistently negative relationship between absorptive capacity and mean path length tells a consistent story. Efficient knowledge diffusion within a network requires that firms build up sufficient levels of absorptive capacity. To maximise their benefits, therefore, firms tend to adjust their absorptive capacity depending on their network positions. This heterogeneous behaviour is pronounced at extreme spillover levels.

Echoing recent studies (Cowan et al., 2007; Baum et al., 2010), our model further advances the possibility that empirically observed properties of inter-firm networks may be due to the characteristics of the knowledge space rather than

\footnotetext{
${ }^{41}$ What we generally find in this way is that competition reducing the number of alliances detrimentally affects firms' innovativeness. On the complexity of modelling competition in this type of models see, e.g., Baum et al. (2010, p. 2108).
} 
purely social capital. Beyond this, however, we identify a time-varying characteristic of the knowledge space which helps to explain the network properties - that is, variations in the amount of knowledge spillovers. Network structures observed in mature industries characterised by high amounts of involuntary spillovers affect firm-level performance differently from the structures observed in early-stage industries characterised by high amounts of voluntary spillovers. By extension, network-based policy mechanisms (such as clustering initiatives) need to take into account the stage of an industry's development.

This study may serve as a basis for a large number of extensions. Among those, one may set firms' $R \& D$ budgets dependent on their past profits, instead of time invariant and randomly allocated. Besides, we hope that the results of this modelling exercise will guide a fresh wave of empirical investigations. In particular, analyses of strategic alliances (especially in industries where networking is pervasive such as biotechnology, pharmaceuticals and information and communication technologies) may benefit from the results stated above. It is believed that the empirical literature will be enriched if analyses of the relationship between networking and performance take into account changes in knowledge regimes. On this, Ter Wal (2013) noted "the fact that changes in the technology regime and in the network dynamics of an industry run in parallel does not necessarily mean that one is causing the other. Future research could... further scrutinize the relationship between knowledge and networks from a dynamic perspective." Along this line, applying empirical measures of the extent of spillovers may significantly advance knowledge on the role of technological regimes in driving network evolution. 


\section{Part III}

CONCLUDING THOUGHTS 


\section{Chapter 6}

\section{Conclusion}

The specific issues that we set out to address in this thesis relate to the

i. correlation between interactive learning and innovation in a developing country while distinguishing between formal and informal linkages (Chapters 2 and (3),

ii. knowledge-based analysis of innovation networks, paying particular attention to the coevolution of knowledge regimes, absorptive capacity and networks (Chapter 4 and 5), and

iii. role of absorptive capacity in the deployment of external knowledge for innovation (Chapters 2- 5).

This chapter is a kind of one-stop shop for the the main results, implications and constraints of the whole work.

\subsection{Overview of Main Findings}

\subsubsection{Interactive learning and innovation}

It is widely acknowledged that innovation benefits from external knowledge and the interaction of various economic agents. This notion is fundamental to the innovation systems approach as well as the recent open innovation mantra. The relationship between interactive learning and innovation, while not taken for granted, has so far not been questioned with respect to the level of 
innovativeness of a firm and in consideration of the differences that may be inherent in whether interactions are formalised or not.

Taking the foregoing observations as point of departure, we have demonstrated in this thesis that the correlation of external knowledge with innovation is punctuated by at least two factors: innovation strategy and level of innovativeness. Consistent with the extant literature, innovation is generally positively associated with the use of external knowledge. However, in this respect technological product and process innovation are different from non-technological marketing and organisational innovation. This difference persists when we take the variety of linkages into account. With ordinal measures of innovation we have identified that the level of innovativeness influences the pattern of association between interactive learning and innovation.

\subsubsection{Coevolutionary processes}

Despite the extensive theoretical and empirical knowledge that exists on the importance of networks for innovation, surprisingly little is known about the dynamics of collaboration as well as the coevolution of networks arising from these collaborations and the industrial context within which they occur. Understanding these issues requires identifying the dynamics-inducing characteristics of innovation networks and the knowledge space.

In this thesis, we have pinpointed a specific characteristic of the knowledge space, that is, the extent of voluntary and involuntary spillovers, as a major driver of network emergence and evolution in an industry. With this we have demonstrated that changes in network structure over time are indeed driven by changes in the knowledge regime. As the composition of spillovers in the industry changes, consistent changes in the attributes of the industry network are observed.

These changing attributes - herein we have focused only on mean path length and betweenness centrality - bring about variations in the importance of networks as the knowledge regime evolves. In highly tacit regimes, firms benefit more from centralised network positions but when knowledge is largely codified network embeddedness and brokerage positions are much less relevant. 


\subsubsection{On the importance of absorptive capacity}

The absorptive construct is undoubtedly one of the most widely diffused in the study of learning and innovation. Yet, over two decades after it first appeared in its current form little is known about its role in network emergence and evolution. In this thesis a new model of absorptive capacity that is considered relevant for the context of inter-firm cooperation has been introduced. Explicitly, absorptive capacity was formalised as a function of targeted absorptive $R \& D$ and convex-shaped in cognitive distance. Upon applying this formulation in a model of knowledge-based alliance formation, a firm's cooperation decisions was found to be conditioned by its absorptive capacity which is applied in resolving the understandability/novelty trade-off that arises from cognitive distance to external knowledge.

Furthermore, using different measures of absorptive capacity, it has been shown empirically that it plays an important role in latecomer learning. This role does not appear as much in moderating the effect of external knowledge as it does in directly improving a firm's ability to innovate.

\subsection{Novelty}

Some of the results presented in this thesis are novel in the sense of either appearing for the first time or addressing some gaps in the literature which hitherto have been unattended. To start with, the evidence presented on the relationship between innovation and interactive learning in a latecomer economic context is fresh, being based on unique pioneer datasets. And, to the best of my knowledge, this is the first time that the relationship between interactive learning and innovation is reported to vary as a firm's level of innovativeness changes.

Regarding networks per se, new evidence is presented in this thesis on the changing importance of specific network attributes as industries evolve. In particular, network embeddedness is more or less important depending on the current stage in an industry's life cycle. The coevolution of absorptive capacity and networks is also uncovered: partnership decisions are the basis for the emergence and evolution of networks but themselves are shaped by absorptive capacity. In this aspect, the new formulation of absorptive capacity as dependent upon cognitive distance and targeted investments is especially well-suited to the context of cooperation. 
In terms of methodology, this thesis has demonstrated that the role of networks and external knowledge in innovation is better understood by combining different conceptual and methodological approaches. A combination of microeconometrics, ABMs and social network analysis permits detailed exploration of the role of networks in innovation from different perspectives. In fact, the analyses is enriched significantly because the combination of analytical approaches is far stronger than the sum of isolated methods. Drawing insight from multiple theoretical traditions is also an asset rather than being merely eclectic.

In addition to that, it is believed that studies of innovation will benefit from an operational distinction between different modes of linkages. Beyond the usual distinction between, say, joint ventures, marketing agreements, etc, distinguishing between formal and informal linkages also permits an enriched analysis. Similarly, a multidimensional view of innovation, rather than the narrow focus on technological product and process innovation that is pervasive in the extant literature, is more representative of reality.

\subsection{Policy and Practical Implications}

For policy, the indications are clear. It is useful to drive interactions among firms and with other economic agents but the limits of networking must be kept in sight. Besides, given the emphasis that many developing countries especially in sub-Saharan Africa place on university-industry interaction, it is important to point out that variety is needed. The combination of external sources of innovation is far more beneficial than overly exploiting any single source.

The coevolutionary process between networks and industry evolution is a very important issue. If network-induced policy mechanisms such as cluster and incubation initiatives take cognisance of this fact, then their effectiveness is strengthened. On a related note, the finding that the importance of external knowledge varies with the level of innovativeness is interesting. It suggests that there is no one size fits all approach to network-induced innovation policy. Depending on the current level of innovativeness, firms will not benefit uniformly from such policies. This diversity is something that policy makers need to keep in mind.

For firms, a number of implications can be distilled from the findings in this thesis. As hinted earlier on, the acquisition and deployment of external knowledge augment firms' internal capabilities and reduce the risk of failure by 
minimising their self-reliance. However, care has to be exercised in selecting a networking strategy and in choosing the specific partners to include in the portfolio of partners. This is because networking does not seem to hold significant benefits for all innovation types. Moreover, it is crucial for each firm to invest time and effort into knowing when to combine strategies, and more importantly, when to reconsider partnership decisions. The best networking strategies will be those that take into account the firm's current innovative efforts and absorptive capacity since it seems that different kinds of linkages and network strategies are required depending on what types of innovation the firm seeks to achieve and how much spillovers it can absorb.

\subsection{Constraints and Future Outlook}

The empirical analyses have been constrained in some aspects which, in most cases, provide avenues for future research. This being the first time that such comprehensive data as used in these chapters is available in Nigeria, one could safely say that the problems are somewhat inevitable. It is hoped that subsequently, more data will be available to overcome these challenges. First, the cross-sectional nature of the data was a limiting factor. Also, the sample included a fair share of micro-sized firms and some firms that would otherwise be classified as belonging to the informal sector. As more data become available after subsequent rounds of the innovation surveys, it is hoped that at least pooled cross-sectional datasets can be constructed which will permit inter-temporal analyses of the learning-capability relationship. Moreover, larger samples will permit sectoral analyses in a way that will shed light on sector-specific effects of networks on innovation. And as the quality of data gets better, the role of absorptive capacity could be better explored empirically.

The role that networks play in innovation is definitely worth a closer look in developing countries. As it has been argued, the evidence on this is currently thin. It is a potentially fruitful path to follow if one considers gathering data on formal and informal networks in latecomer contexts, and applying tools of social network analysis. As far as I can tell, only a handful of studies have so far treaded this path, and possibly none in Africa. The role of geography may be explored by comparing domestic sources to international ones. The aspect of diversity of linkages and the various contingencies involved is also potentially interesting. 
The theoretical analyses offer a basis for some future research directions. For instance, the role of learning by firms can be examined more explicitly in the model. It seems interesting to imagine a setting in which firms take better partnership decisions contingent upon the success or failure of their previous alliances. On a related note, rather than an exogenous representation, total R\&D budget could be considered as a function of sales or profits from earlier periods in the model. That way, the market is brought into the model and a relatively more complete representation of firm behaviour is thus achieved. These extensions will undoubtedly make the model even more complex but it is also conceivable that the model be simplified in other aspects so as to permit the extensions.

Finally, some empirically testable implications arise from the modeling results. The formulation of absorptive capacity which incorporates cognitive distance is in need of empirical validation. Besides, the empirical literature will be enriched if analyses of network-innovation relationship account for industry evolution. One way of doing this, taking cue from the simulation results in this thesis, is to apply measures of spillover rates. 
Appendices 


\section{Appendix A}

\section{Appendices to Chapter 2}

\section{A.1 The Logit and Multivariate Probit Specific- ations}

\section{A.1.1 The logit model}

The logit model is specified as follows. Given that the probability of a firm implementing an innovative activity as a result of external knowledge search is $p$, then the probability that this will not occur is $1-p$. The logit model suggests that the quantity $\ln \frac{p}{1-p}$, which is the log-odds of a firm exhibiting technological capabilities is a linear function of the explanatory variables, $X_{i}$. This is represented mathematically as:

$$
\operatorname{logit}(p)=\ln \frac{p}{1-p}=\beta_{0}+\beta_{i} X_{i}+\epsilon_{0},
$$

where $\beta_{0}$ is the intercept, $X_{i}$ represents the vector of explanatory variables, $\beta_{i}$ the vector of estimates and $\epsilon_{0}$ the residual. The ratio $\frac{p}{1-p}$, which compares the probability of a firm being innovative with the probability of it being noninnovative conditional upon each explanatory variable, is easily obtained by exponentiating the coefficients obtained from estimating equation A.1. This ratio, alongside the average marginal effects of each independent variable, is reported in Table 2.5. Its interpretation is straightforward. Values greater than one suggest that, conditional upon the explanatory variables, a firm has a higher likelihood of possessing technological capabilities. Values lower than 
one mean the direct opposite. The marginal effects simply capture the increase in the probability of capabilities as the independent variables increase in value.

\section{A.1.2 The multivariate probit model}

The implementation of one type of innovation is associated with the likelihood of the other types (Table A.11). Consequently, if separate equations are estimated for each innovation type, the error terms from the independent equations are likely to be pairwise correlated, leading to biased and possibly inconsistent point estimates. This is a problem ignored in some studies such as the one by Carvalho et al. (2013). By allowing the error terms to be freely correlated across equations, the multivariate probit makes it possible to obtain unbiased estimates when the dependent variables, say $y$, in a set of equations are potentially interdependent (Greene, 2002; Freedman and Sekhon, 2010). The specification takes the form

$$
\begin{gathered}
y_{n}^{*}=\beta_{n}^{\prime} X+\epsilon_{0} \\
y_{n}= \begin{cases}1, & y_{n}^{*}>0 \\
0, & \text { otherwise. }\end{cases}
\end{gathered}
$$

where $y_{n}$ is the $n$th unobserved variable in which we are interested, and $y_{n}^{*}$ the $n$th observed variable. In the empirical set-up of this paper, $n$ ranges from 1 to 4 since there are four independent variables.

Table A.1: Correlation between different innovation types

\begin{tabular}{lcccc}
\hline & Product & Process & Marketing & Organisational \\
\hline \hline Product & - & & & \\
Process & $0.6414^{* * *}$ & - & & \\
Marketing & $0.3636^{* * *}$ & $0.3946^{* * *}$ & - & \\
Organisational & $0.4956^{* * *}$ & $0.4858^{* * *}$ & $0.5452^{* * *}$ & - \\
\hline Note: ${ }^{* * *} p<0.001$. & &
\end{tabular}

Solving this system of equations requires the evaluation of multivariate normal distribution functions, a problem that is best solved by simulated maximum 
likelihood (SML). The problem is solved in STATA by the mvprobit routine which uses the Geweke-Hajivassiliou-Keane (GHK) simulator developed by Cappellari and Jenkins (2003). This method is known to be sensitive to the number of observations drawn in each step of the iteration procedure. In particular, the SML becomes more and more asymptotically equivalent to the true maximum likelihood (ML) estimator as the number of random draws increases. It is recommended to use draws at least as large as the square root of the total number of observations. This is because the SML estimates approach the ML values as the ratio of the square root of the sample size to the number of draws tends to zero. I used 100 draws instead of the default 5. The mvprobit routine does not report a pseudo- $\mathrm{R}^{2}$ measure by default. The one reported in the results is the normalised Aldrich-Nelson pseudo- $\mathrm{R}^{2}$ which gives reliable approximations of the goodness of fit for models with discrete dependent variables (Veall and Zimmermann, 1996; Hagle and Mitchell II, 1992) and is very easy to calculate using the estimated log-likelihood for the null and alternative models.

\section{A.2 The Obstacles Measure}

Firms were asked to rate the extent to which each of the following items constituted obstacles to them: high cost of innovation, lack of financing, lack of skilled personnel, bureaucracy within the firm, lack of information on technology, domestic economic conditions (inflation, recession etc), legislation, and weak customer demand. Rating was done on a scale of 0 (not significant) to 3 (very significant). To reduce the number of variables, the 8 categorical items were subjected to factor analysis. One factor with eigenvalue greater than unity and explaining about $71 \%$ of the variance was extracted. All the 8 items load significantly onto this factor (Table A.2). Consequently, the obstacles measure was obtained as the sum of the 8 original items rescaled as 1 (very significant) and 0 (otherwise). Reliability of this variable was found to be high (Cronbach's $\alpha=0.942$ ). 
Table A.2: Results of factor analysis

\begin{tabular}{lcc}
\hline Variable & Factor loadings & Uniqueness \\
\hline \hline High cost & 0.846 & 0.285 \\
Lack funding & 0.848 & 0.281 \\
Lack skilled personnel & 0.866 & 0.250 \\
Bureaucracy & 0.860 & 0.261 \\
Lack technological information & 0.851 & 0.277 \\
Domestic economic conditions & 0.840 & 0.295 \\
Legislation & 0.846 & 0.284 \\
Weak demand & 0.805 & 0.352 \\
\hline N = 170, Method: principal-component factors, Rotation: orthogonal varimax,
\end{tabular}

\section{A.3 First Stage Probit Results}

Table A.3: Results of first-stage probit model

\begin{tabular}{lc}
\hline & Innovation \\
\hline \hline TRAINING & 0.065 \\
AGE & $0.293)$ \\
& 0.124 \\
INNO_BUDGET & $1.659^{* * *}$ \\
& $(0.394)$ \\
OBSTACLES & $0.601^{* * *}$ \\
& $(0.153)$ \\
CONSTANT & -0.579 \\
& $(0.351)$ \\
\hline \hline N & 170 \\
McFadden's R ${ }^{2}$ & 0.450 \\
Log lik & -40.95 \\
Akaike's IC & 91.91 \\
$\chi^{2}$ & $31.98^{* * *}$ \\
\hline Note: Robust standard errors in parentheses. \\
${ }^{*} p<0.05,{ }^{* *} p<0.01$, & ${ }^{* * *} p<0.001$. \\
\hline
\end{tabular}




\section{Appendix B}

\section{Appendices to Chapter 3}

\section{B.1 Sectoral Patterns in the Sample}

Table B.1: Share of innovative firms, 2005 - 2007

\begin{tabular}{lcc}
\hline \multirow{2}{*}{ Variable } & \multicolumn{2}{c}{ Percentage } \\
\cline { 2 - 3 } & $\begin{array}{c}\text { Manufacturing } \\
(n=308)\end{array}$ & $\begin{array}{c}\text { Service } \\
(n=164)\end{array}$ \\
\hline \hline All innovation & 96.8 & 98.8 \\
Product & 67.9 & 76.2 \\
Process & 79.2 & 76.2 \\
Marketing & 58.1 & 66.4 \\
Organisational & 69.8 & 85.3 \\
\hline
\end{tabular}


Table B.2: Pattern of collaboration in Nigerian manufacturing and service firms, $2005-2007$

\begin{tabular}{lcc}
\hline \multirow{2}{*}{ Collaboration Partners } & \multicolumn{2}{c}{ Percentage } \\
\cline { 2 - 3 } & $\begin{array}{c}\text { Manufacturing } \\
(n=308)\end{array}$ & $\begin{array}{c}\text { Service } \\
(n=164)\end{array}$ \\
\hline \hline Suppliers & 21.1 & 17.1 \\
Customers & 19.2 & 17.1 \\
Private Research Institutes & 18.8 & 11.6 \\
Competitors & 15.3 & 13.4 \\
Universities & 12.7 & 6.7 \\
Public Research Institutes & 11.4 & 6.1
\end{tabular}

Note: Multiple response items. The survey questionnaire asked firms to indicate whether they "collaborated on any of [their] innovation activities" with any of the listed actors.

Table B.3: Sources of information for innovation in Nigerian manufacturing and service firms, 2005-2007

\begin{tabular}{lcc}
\hline & \multicolumn{2}{c}{ Percentage } \\
\cline { 2 - 3 } Information Sources & $\begin{array}{c}\text { Manufacturing } \\
(n=308)\end{array}$ & $\begin{array}{c}\text { Service } \\
(n=164)\end{array}$ \\
\hline \hline Customers & 72.7 & 79.3 \\
Suppliers & 71.1 & 74.4 \\
Competitors & 61.9 & 73.2 \\
Industry associations & 55.5 & 70.1 \\
Conference, fairs & 52.9 & 63.4 \\
Scientific journals and & & \\
trade publications & 46.4 & 63.4 \\
Private Research Institutes & 41.9 & 50.0 \\
Public Research Institutes & 28.9 & 41.5 \\
Universities & 28.2 & 40.2 \\
\hline
\end{tabular}

Note: Multiple response items. The survey questionnaire asked firms "how important to [their] innovation activities were each of the [listed] information sources". Categories of degree of importance were 1(Low), 2(Medium) and 3(High). Percentages calculated with dichotomised responses. 


\section{B.2 The Partial Proportional Odds Ordered Lo- git Model}

The partial proportional odds model (henceforth, PPOM) is an enhanced form of the generalised logit model for ordinal dependent variables (Williams, 2006; Peterson and Harrell, 1990). The generalised model is formally specified as follows:

$$
P\left(Y_{i}>j\right)=g(X \beta)=\frac{\exp \alpha_{j}+X_{i} \beta_{j}}{1+\left[\exp \alpha_{j}+X_{i} \beta_{j}\right]}, j=1,2, \ldots, M-1
$$

where $M$ is the number of outcome categories and $\beta$ are the coefficients to be estimated. Clearly, for $M=2$, this is the standard logit model. For $M>2$, the model becomes a series of logit models which compares the outcome categories in grouped pairs, for instance, 0 versus $1,2,3,4$ then 0,1 versus $2,3,4$ and so on until $0,1,2,3$ versus 4 .

If the relationship between the outcome variable and an explanatory variable is independent of the number of categories $(M)$, then the series of logit models obtain the same coefficient, that is, the $\beta$ 's but not the $\alpha$ 's are the same. This is the proportional odds assumption on which the ordinal logit model is based. In practice, this assumption is often violated. In this case, one could consider that all independent variables violate this assumption and allow all the $\beta$ 's to vary. This equates to the multinomial model which, apart from potentially estimating too many parameters, ignores the ordering implicit in the dependent variable.

The PPOM lies between these two extremes and has the key advantage of providing the most parsimonious model for ordinal dependent variables while accounting for possible violations of the proportional odds requirement. It first tests the proportional odds assumption for each independent variable and then relaxes it for any independent variable that violates it. This makes it simpler than the multinomial logit model and more robust than the traditional ordered logit model.

Violation of the proportional odds assumption means that the effect of a variable is not constant across all transitions in the outcome variable. Hence, multiple coefficients are estimated for each variable that violates the proportional odds assumption. Comparing these coefficients allows one to trace changes in the effect of the independent variables over the range of the ordinal dependent 
variable. For each of the other variables, a single coefficient is estimated. The interpretation of the coefficients is exactly the same as for the standard ordered logit. They suggest increasing log-odds when positive and decreasing log-odds otherwise.

The PPOM, to the best of my knowledge, seems to be just catching on in economic research (Tartari and Breschi, 2012; Hafner, 2013) but has been applied fairly extensively elsewhere (see Lall et al., 2002; Ananth and Kleinbaum, 1997, for reviews). The method is implemented in STATA with William's (2006) gologit2 routine. This routine has been applied here with the PetersonHarrell parameterisation (Peterson and Harrell, 1990). In this approach, instead of several $\beta$ coefficients, each explanatory variable has one $\beta$ coefficient and $M-2 \gamma$ coefficients. The first coefficient represents the constant component of the log-odds while the others represent the change in log-odds. The mathematical relationship between the $\beta$ 's and the $\gamma$ 's is straightforward:

$$
\gamma_{k}=\beta_{k}-\beta, \quad k=2,3, \ldots, M-1
$$

where $\beta$ without subscript is the constant component. This relationship is important for understanding the results presented in Tables 3.7 and 3.8. 


\section{B.3 First Stage Probit Selection Equation}

Table B.4: Probit selection model

\begin{tabular}{cc}
\hline & Innovation \\
\hline \hline SIZE & -0.063 \\
GROUP & $-0.128)$ \\
& $(0.262)$ \\
TRAINING & $0.513^{*}$ \\
& $(0.254)$ \\
EXPORT & 0.647 \\
& $(0.419)$ \\
OBSTACLES & -0.009 \\
& 0.007 \\
CONSTANT & $2.013^{*}$ \\
& $(0.511)$ \\
\hline$N$ & 472 \\
McFadden $\mathrm{R}^{2}$ & 0.078 \\
Log lik & -51.57 \\
Akaike's IC & 115.1 \\
chi-sq & 10.34 \\
\hline 0.05. Standard errors in parentheses.
\end{tabular}




\section{B.4 Baseline Models}

Table B.5: Baseline models

\begin{tabular}{|c|c|c|c|c|c|}
\hline & \multicolumn{5}{|c|}{ Scope of innovation } \\
\hline & Overall & Product & Process & Marketing & Organisational \\
\hline SIZE & $\begin{array}{c}-0.103(0.214) \\
0.355(0.175)^{*} \\
0.282(0.207) \\
0.154(0.215)\end{array}$ & $\begin{array}{c}0.035(0.084) \\
0.127(0.063)^{*} \\
-1.024(0.234)^{*}\end{array}$ & $\begin{array}{l}0.196^{*}(0.084) \\
0.109(0.062) \\
0.250(0.081)^{*}\end{array}$ & $0.216^{*}(0.082)$ & $0.233^{*}(0.076)$ \\
\hline GROUP & $0.305(0.209)$ & $0.622(0.240)^{*}$ & $0.394(0.234)$ & $0.131(0.221)$ & $0.056(0.220)$ \\
\hline LOCATION & $0.215(0.207)$ & $\begin{array}{r}1.114(0.275)^{*} \\
-1.024(0.234)^{*}\end{array}$ & $0.235(0.207)$ & $0.242(0.201)$ & $-0.160(0.207)$ \\
\hline EXPORT & $0.107(0.191)$ & $-0.225(0.245)$ & $-0.250(0.239)$ & $\begin{array}{r}-0.378(0.267) \\
0.528(0.202)^{*}\end{array}$ & $-0.082(0.239)$ \\
\hline SERVICE & $0.514(0.222)^{*}$ & $-0.489(0.234)^{*}$ & $-0.729(0.221)^{*}$ & $0.501(0.230)^{*}$ & $1.246(0.241)^{*}$ \\
\hline PR(INNOVATE) & & $19.738(5.891)^{*}$ & $21.634(5.789)^{*}$ & $\begin{array}{l}-1.378(5.313) \\
-7.168(3.642)^{*}\end{array}$ & $0.712(4.450)$ \\
\hline $\begin{array}{l}{ }_{-}{ }^{\text {cons__ }} \\
- \text { cons_2 } \\
-{ }_{-}{ }^{\text {cons__3 }} \\
{ }_{-} \text {cons_4 }\end{array}$ & $\begin{array}{c}.059(0.991)^{*} \\
-0.176(0.506) \\
-1.432(0.388)^{*} \\
-2.097(0.389)^{*}\end{array}$ & $\begin{array}{l}-19.217(5.685)^{*} \\
-20.504(5.702)^{*}\end{array}$ & $\begin{array}{l}-20.801(5.594)^{*} \\
-21.860(5.612)^{*} \\
-22.605(5.623)^{*}\end{array}$ & $\begin{array}{l}0.600(5.142) \\
6.291(5.304)\end{array}$ & $\begin{array}{l}-1.030(4.291) \\
-1.856(4.298) \\
-3.119(4.298)\end{array}$ \\
\hline $\mathrm{N}$ & 472 & 460 & 460 & 460 & 460 \\
\hline McFadden's $\mathrm{R}^{2}$ & 0.070 & 0.102 & 0.084 & 0.033 & 0.041 \\
\hline Log lik & -608.7 & -439.8 & -541.3 & -478.2 & -596.9 \\
\hline Akaike's IC & 1247.3 & 907.6 & 1110.6 & 984.3 & 1217.8 \\
\hline chi-sq & $2184.8^{*}$ & $81.06^{*}$ & $78.40^{*}$ & $30.99^{*}$ & $47.98^{*}$ \\
\hline
\end{tabular}

${ }^{*} p<0.05$. PR(INNOVATE) is the predicted probability to innovate from first-stage selection model 


\section{Appendix C}

\section{Appendices to Chapter 4}

\section{C.1 Resolving the Investment Trade-off (equa- tion 4.13) to find $\rho_{i}$}

The objective is to obtain values of $\rho_{i}$ that satisfy:

$$
\frac{\partial \Pi_{i}}{\partial a c i_{i}}=\frac{\partial \Pi_{i}}{\partial r d i_{i}}
$$

Recall from (4.12) that in case of a partnership, where $i$ needs to optimise its investment allocation conditional upon the partner's investments,

$$
\Pi=\frac{k_{i}}{1+a c_{j, i} \delta_{c} r d i_{i}} .
$$

Hence,

$$
\begin{gathered}
\frac{\partial \Pi_{i}}{\partial r d i_{i}}=\frac{\partial\left(\frac{k_{i}}{1+a c_{j, i} \delta_{c} r d i_{i}}\right)}{\partial r d i_{i}}=\frac{\xi r d i_{i}^{\xi-1}\left(1+a c_{j, i} \delta_{c} r d i_{i}\right)-k_{i} \delta_{c} a c_{j, i}}{\left(1+a c_{j, i} \delta_{c} r d i_{i}\right)^{2}} \\
\frac{\partial \Pi_{i}}{\partial a c i_{i}}=\frac{\partial\left(\frac{k_{i}}{1+a c_{j, i} \delta_{c} r d i_{i}}\right)}{\partial a c i_{i}}=\frac{\left(1+a c_{j, i} \delta_{c} r d i_{i}\right)\left(\frac{\partial k_{i}}{\partial a c_{i}}\right)+k_{i} \delta_{c} a c_{j, i}}{\left(1+a c_{j, i} \delta_{c} r d i_{i}\right)^{2}}
\end{gathered}
$$


where $E^{i}\left(\rho_{j, t}\right)=\frac{\sum_{\iota=1}^{\sigma} \rho_{j}^{t-\iota}}{\sigma} \Rightarrow \frac{\partial a c_{j, i}}{\partial r d i_{i}}=0$ and $r d i_{i}=R D_{i}-a c i_{i} \Rightarrow \frac{\partial r d i_{i}}{\partial a c i_{i}}=-1$.

Next we set (C.1) equal to (C.2) as in equation (4.13):

$$
\xi r d i_{i}^{\xi-1}\left(1+a c_{j, i} \delta_{c} r d i_{i}\right)-k_{i} \delta_{c} a c_{j, i}=\left(1+a c_{j, i} \delta_{c} r d i_{i}\right)\left(\frac{\partial k_{i}}{\partial a c_{i}}\right)+k_{i} \delta_{c} a c_{j, i}
$$

and collect terms:

$$
\frac{\xi r d i_{i}^{\xi-1}}{\left(\frac{\partial k_{i}}{\partial a c_{i}}\right)}=\frac{2 k_{i} \delta_{c} a c_{j, i}}{\left(1+a c_{j, i} \delta_{c} r d i_{i}\right)}
$$

Recalling the expression for $k_{i}$ from (4.10) we obtain

$$
\frac{\partial k_{i}}{\partial a c_{i}}=\delta_{c} r d i_{j}\left(\frac{\partial a c_{i, j}}{\partial a c i_{i}}\right)+e k\left(\frac{\partial a c_{i, e k}}{\partial a c i_{i}}\right) .
$$

Accounting in $a c_{i,}$, for the difference in $d_{i j}$ and $d_{i e k}$, we obtain the derivative of the absorptive capacity function with respect to distance as follows:

$$
\frac{\partial a c_{i, \cdot}}{\partial a c i_{i}}=\frac{4 \beta_{2} \psi d_{i} . a c i_{i}^{\psi-1}}{\beta_{1}\left(1+a c i_{i}^{\psi}\right)^{2}}\left[\frac{2 \beta_{2} d_{i .}}{\beta_{1}\left(1+a c i^{\psi}\right)}-1\right]
$$

Inserting (C.5) into (C.4) accordingly:

$$
\begin{aligned}
\frac{\partial k_{i}}{\partial a c_{i}} & =\delta_{c} r d i_{j}\left(\frac{4 \beta_{2} \psi d_{i j} a c i_{i}^{\psi-1}}{\beta_{1}\left(1+a c i_{i}^{\psi}\right)^{2}}\left[\frac{2 \beta_{2} d_{i j}}{\beta_{1}\left(1+a c i^{\psi}\right)}-1\right]\right) \\
& +e k\left(\frac{4 \beta_{2} \psi d_{i e k} a c i_{i}^{\psi-1}}{\beta_{1}\left(1+a c i_{i}^{\psi}\right)^{2}}\left[\frac{2 \beta_{2} d_{i e k}}{\beta_{1}\left(1+a c i^{\psi}\right)}-1\right]\right) .
\end{aligned}
$$

Note that the absorptive capacity of firm $j$ directed on firm $i$ is:

$$
a c_{j, i}=\frac{\alpha \beta_{1} d_{i j}+\alpha \beta_{1} d_{i j} a c i_{j}^{\psi}-\alpha \beta_{2} d_{i j}^{2}}{\frac{1}{4 \alpha \beta_{2}}\left[\alpha \beta_{1}\left(1+a c i_{j}^{\psi}\right)\right]^{2}} \text { as } d_{i j}=d_{j i} .
$$


When (․6) and (C.7) are inserted in (C.3) and the latter is rearranged, we obtain

$$
\begin{aligned}
r d i_{i} & =\frac{32 \beta_{2}^{2}}{\xi \alpha \beta_{1}^{4}\left(\beta_{1}+\beta_{1} a c i_{j}^{\psi}-\beta_{2} d_{i j}\right)\left(1+a c i_{i}^{\psi}\right)^{5}}\left(\delta_{c} r d i_{j} d_{i j}\left(2 \beta_{2} d_{i j}-\beta_{1}\left(1+a c i_{i}^{\psi}\right)\right)+\right. \\
& \left.+e k d_{i e k}\left(2 \beta_{2} d_{i e k}-\beta_{1}\left(1+a c i_{i}^{\psi}\right)\right)\right) \frac{a c i_{i}^{\psi-1}}{r d i_{i}^{\xi-1}}\left(\beta_{1}+\beta_{1} a c i_{j}^{\psi}-\beta_{2} d_{i j}\right) . \\
& \cdot\left(\frac{r d i_{i}^{\xi}}{4 \alpha \beta_{2}}\left(\alpha \beta_{1}\left(1+a c i_{i}^{\psi}\right)\right)^{2}+\alpha \delta_{c} r d i_{j} d_{i j}\left(\beta_{1}+\beta_{1} a c i_{i}^{\psi}-\beta_{2} d_{i j}\right)+\right. \\
& \left.+\alpha d_{i e k} e k\left(\beta_{1}+\beta_{1} a c i_{i}^{\psi}-\beta_{2} d_{i e k}\right)\right)-\frac{\beta_{1}\left(1+a c i_{j}^{\psi}\right)^{2}}{4 \beta_{2} \delta_{c} d_{i j}\left(\beta_{1}+\beta_{1} a c i_{j}^{\psi}-\beta_{2} d_{i j}\right)} .
\end{aligned}
$$

Recall from (4.1) that $r d i_{i}=\rho_{i} R D_{i}$ and $a c i_{i}=\left(1-\rho_{i}\right) R D_{i}$; when this is applied to equation (C.8) it takes the form:

$$
\begin{aligned}
\rho_{i} & =\frac{32 \beta_{2}^{2}}{\xi \alpha \beta_{1}^{4} R D_{i}\left(\beta_{1}+\beta_{1}\left(\left(1-\rho_{j}\right) R D_{j}\right)^{\psi}-\beta_{2} d_{i j}\right)\left(1+\left(\left(1-\rho_{i}\right) R D_{i}\right)^{\psi}\right)^{5}} \cdot \\
& \cdot\left(\delta_{c} \rho_{j} R D_{j} d_{i j}\left(2 \beta_{2} d_{i j}-\beta_{1}\left(1+\left(\left(1-\rho_{i}\right) R D_{i}\right)^{\psi}\right)\right)+\right. \\
& \left.+e k d_{i e k}\left(2 \beta_{2} d_{i e k}-\beta_{1}\left(1+\left(\left(1-\rho_{i}\right) R D_{i}\right)^{\psi}\right)\right)\right) \frac{\left(1-\rho_{i}\right)^{\psi-1} R D_{i}^{\psi-\xi}}{\rho_{i}^{\xi-1}} \cdot \\
& \cdot\left(\beta_{1}+\beta_{1}\left(\left(1-\rho_{j}\right) R D_{j}\right)^{\psi}-\beta_{2} d_{i j}\right)\left(\frac{\left(\rho_{i} R D_{i}\right)^{\xi}}{4 \alpha \beta_{2}}\left(\alpha \beta_{1}\left(1+\left(\left(1-\rho_{i}\right) R D_{i}\right)^{\psi}\right)\right)^{2}+\right. \\
& +\alpha \delta_{c} \rho_{j} R D_{j} d_{i j}\left(\beta_{1}+\beta_{1}\left(\left(1-\rho_{i}\right) R D_{i}\right)^{\psi}-\beta_{2} d_{i j}\right)+ \\
& -\frac{\left.\alpha d_{i e k} e k\left(\beta_{1}+\beta_{1}\left(\left(1-\rho_{j}\right) R D_{j}\right)^{\psi}-\beta_{2} d_{i e k}\right)\right)-}{4 \beta_{2} \delta_{c} d_{i j} R D_{i}\left(\beta_{1}+\beta_{1}\left(\left(1-\rho_{j}\right) R D_{j}\right)^{\psi}-\beta_{2} d_{i j}\right)} .
\end{aligned}
$$

Shifting $\rho_{i}$ from the left to the right hand side yields $\mathrm{F}\left(\rho_{i}\right)=0$. 
Recall that $\delta_{c}=0$ for firm $i$ performing R\&D activity without a partner. It is then straightforward to show that for this firm, (C.9) takes a simpler form as follows:

$$
\begin{aligned}
F^{a}\left(\rho_{i}\right) & =e k \frac{4 \beta_{2} \psi d_{i e k}\left(\left(1-\rho_{i}\right) R D_{i}\right)^{\psi-1}}{\beta_{1}\left(1+\left(\left(1-\rho_{i}\right) R D_{i}\right)^{\psi}\right)^{2}}\left(\frac{2 \beta_{2} d_{i e k}}{\beta_{1}\left(1+\left(\left(1-\rho_{i}\right) R D_{i}\right)^{\psi}\right)}-1\right)- \\
& -\xi\left(\rho_{i} R D_{i}\right)^{\xi-1}=0 .
\end{aligned}
$$

\section{C.2 Finding an Optimal Solution for $F\left(\rho_{i}\right)$ and $F^{a}\left(\rho_{i}\right)$ by Heuristics}

Thanks to the recent advances in computing technology, new nature-inspired optimization methods (called heuristics) tackling complex combinatorial optimization problems and detecting global optima of various objective functions have become available (Gilli and Winker, 2009). Differential Evolution (DE), proposed by Storn and Price (1997), is a population based optimization technique for continuous objective functions. In short, starting with an initial population of solutions, DE updates this population by linear combination and crossover of four different solutions into one, and selects the fittest ones among the original and the updated population. This continues until some stopping criterion is met. Algorithm 1 provides a pseudocode of the DE implementation.

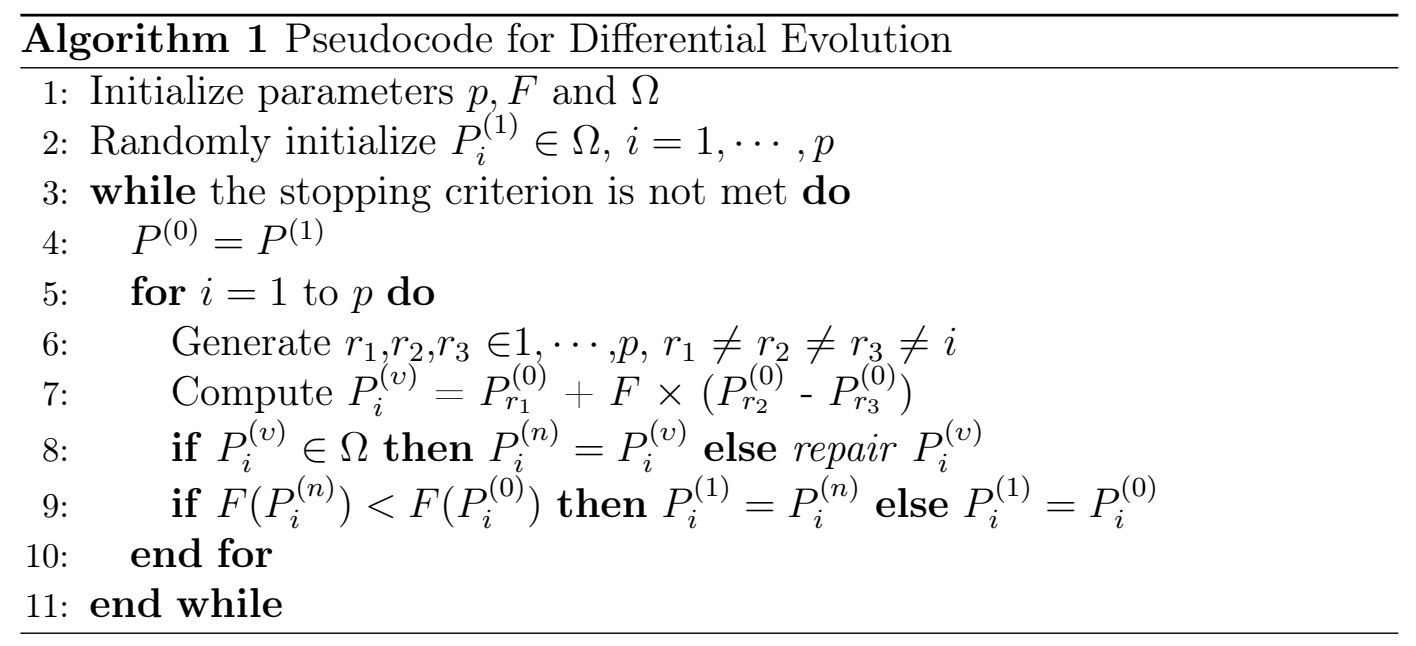


In contrast to other DE applications to optimization problems (as described in, for example, Blueschke et al., 2013), our solution is represented by a single value within $[0,1]$ according to (4.1). Therefore, DE starts with a population of size $p$ of random values drawn from $[0,1](\Omega)(2:)$. For the same reason, current DE implementation has no need in the crossover operator (otherwise, one would have to compare $F\left(P_{i}^{(0)}\right)$ with itself and potentially waste computational time). Tuning our DE code we set $p=30, F=0.8$ and as a stopping criterion we choose a combination of two conditions: either a maximum number of generations is reached (which is set to be equal 50 1 ) or the global optimum is identified $\left(F\left(P_{i}^{(1)}\right)=0\right)$. To make sure that our candidate solutions constructed by linear combination (7:) satisfy our constraint on $\rho_{i}$, we explicitly check it in (8:) - and if it is not met we 'repair' it by adding/deducting one unit - before comparing its fitness with the current solutions in (9:).

As an illustration of the DE convergence for the tuning parameters stated consider Figure C.1 below. On the left plot one can see $F\left(\rho_{i}\right)$ simulated for different $\rho_{i} \in[0,1]$, while on the right plot the cumulative density function of $F\left(\rho_{i}\right)$ for 100 restarts and different number of maximum generations $g(10,30$ and 50) is given. Obviously, with $g=50 \mathrm{DE}$ converges to zero (or a very close approximation of it) in almost $100 \%$ of restarts. To ensure a good solution, therefore, we take $g=30$ and restart DE three times. Using Matlab 7.11 on Pentium IV $3.3 \mathrm{GHz}$ a single DE restart with thirty generations requires about 0.02 second.
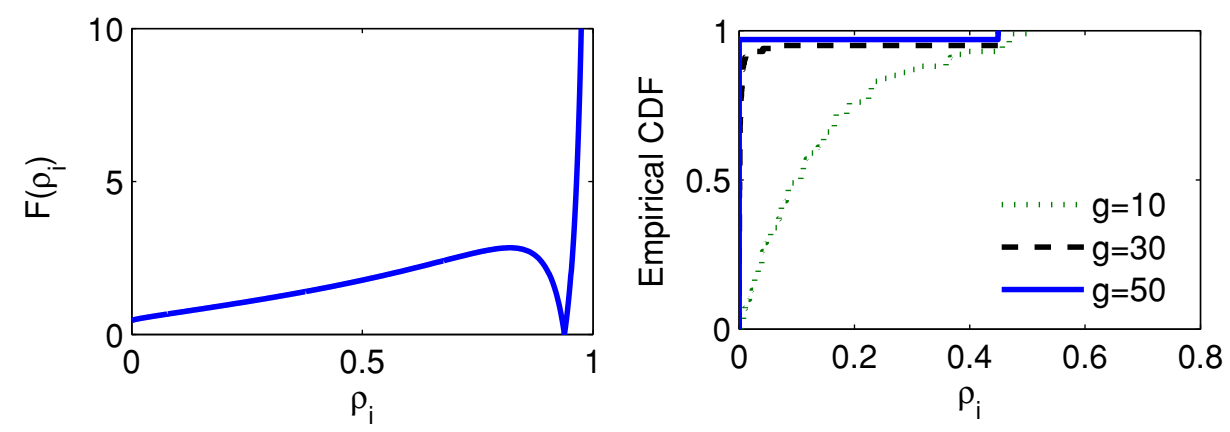

Figure C.1: $F\left(\rho_{i}\right)$ for different $\rho_{i}$ and empirical distribution of $F\left(\rho_{i}\right)$ for different $g$

\footnotetext{
${ }^{1}$ At this point DE population always converges to very similar values.
} 


\section{Appendix D}

\section{Appendices to Chapter 5}

\section{D.1 Formal Definitions on Network Analysis}

The definitions of the networks and its characteristics used in this study are consistent with the latest studies in this research area (see, e.g. Baum et al., 2010). However, some minor differences are possible. This section is meant to clarify them.

\section{D.1.1 Networks}

The simulated population of firms $N$ and the $L$ links (or 'partnerships', or 'alliances' throughout the paper) over 100 periods represent the resulting network. The two firms (nodes) are connected if there exists a link $l_{i j}$ in the network $L$. The more links to distinct partners firm $i$ has, the larger its neighbourhood (firms to whom $i$ is directly connected) $N e_{i}^{L}=\{i j \in L, i \neq j\}$, which is sometimes denoted as degree (the number of links to distinct partners held by $i$ : $l_{i}$ ). The average degree of a network, therefore, is simply an average over all nodes' degrees. Another related measure in this context is density measured as the sum of all links presented in the network $L$ divided by the number of all possible ties (repeated alliances do not count here), i.e.

$$
\text { Density }^{L}=\frac{\sum l_{i j} \in L}{N(N-1) / 2}
$$

with $N(N-1) / 2$ being the total possible number of (undirected) links in the network. 


\section{D.1.2 Unweighted measures}

Considering network characteristics we are most interested in the following three:

- The clustering coefficient measured as an average over neighbourhood clustering of each firm in the network, where the neighbourhood clustering of firm $i$ is the proportion of neighbours who are neighbours of each other, i.e. are directly connected:

$$
c_{i}=\frac{\sum l_{j h} \in L: j, h \in N e_{i}^{L}}{l_{i}\left(l_{i}-1\right) / 2} .
$$

- The mean path length is the average of all pairwise shortest distances between two nodes in a given network (computed by means of the Dijkstra's algorithm). The more the distinct nodes are located on the shortest path, the larger the resistance of the path. To cope with infinite distances (if the population of firms is split in two distinct networks), we equalize them to the maximum distance within the network containing the node and adding one more unit to the distance, i.e. making the distance largest available within the given network.

- The betweenness centrality of firm $i$ in the network $L$ is the proportion of the shortest paths between any two other nodes in the network which pass through $i\left(p_{h, i, j}\right)$ to total number of shortest paths between these two nodes $\left(p_{h, j}\right)$ :

$$
b_{i}=\frac{\sum_{h, j \neq i} p_{h, i, j} \in L}{p_{h, j}} .
$$

\section{D.1.3 Weighted measures}

To take into account the number of times each partnership was over the last 100 periods, we construct a cumulative matrix of firms' past alliances $W$ (an example of such matrix with the distinction between direction of links is illustrated in Figure 5.2). Hence, each element of the matrix has a weight $0 \leq w_{i, j} \leq 100$, with $\forall i \neq j, \sum w_{i, j}$ capturing the strength of the link, i.e. its weighted degree.

Using the matrix $W$ all three network characteristics described in Section D.1.2 can be 'weighted'. For the weighted clustering coefficient there is a large 
variety of ways of doing this (a brief but comprehensive review is provided by Saramäki et al. (2007)). In this study we implemented the version described in Onnela et al. (2003), which is similar to the one used in Baum et al. (2010) (e.g., by taking into account weights of all links of triangles in which firm $i$ is involved). In particular, weighted clustering coefficient of each node is defined as the geometric average of subgraph link weights:

$$
c_{i}^{w}=\frac{1}{l_{i}\left(l_{i}-1\right)} \sum_{j, h}\left(\hat{w}_{i j} \hat{w}_{i h} \hat{w}_{j h}\right)^{1 / 3},
$$

where $\hat{w}_{i j}$ are node weights normalised by the maximum weight in the network $L: \hat{w}_{i j}=w_{i j} / \max (w)$. Thus, $c_{i}^{w} \in[0,1]$ due to the normalisation and if $\hat{w}_{i j} \in[0,1]$ an unweighted clustering coefficient can be recovered. Furthermore, contribution of each triangle to $c_{i}^{w}$ is proportional to the weight of each link in the triangle.

As for weighted mean path length, the Dijkstra's algorithm finds the least resistance paths with the distinction that the each link's resistance equals the inverse weight, $w_{i, j}^{\prime}=1 / w_{i, j}$, indicating the lowest resistance by the most frequently activated partnership.

Finally, the weighted betweenness centrality again uses each link's resistance set equal to the inverse weight.

\section{D.2 Further Results}



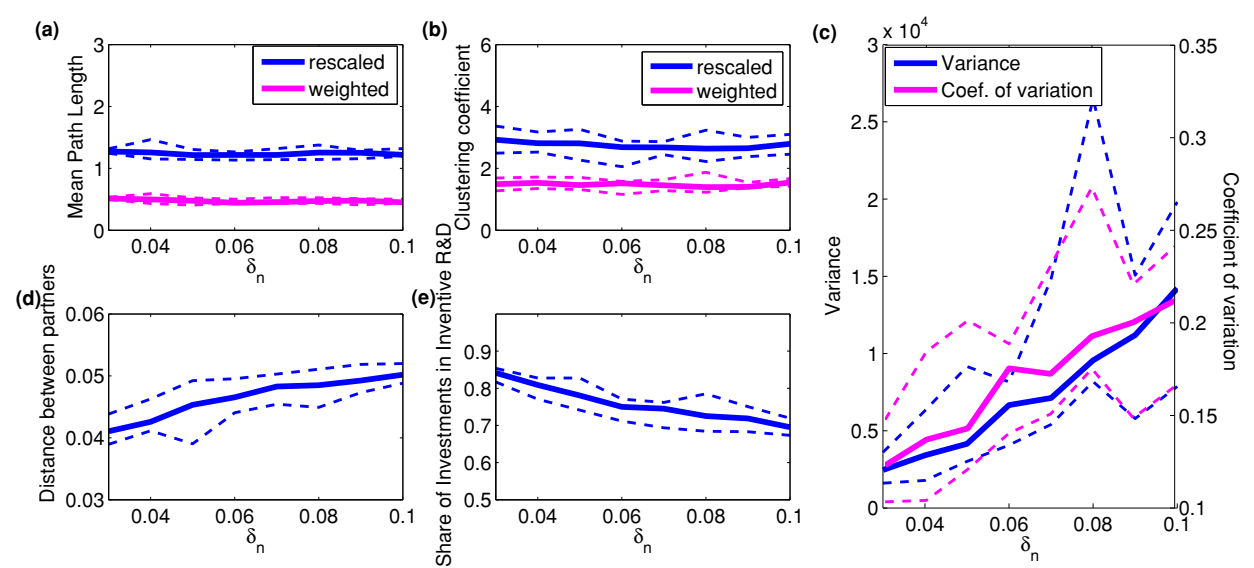

\section{(A) Unilateral partnership}
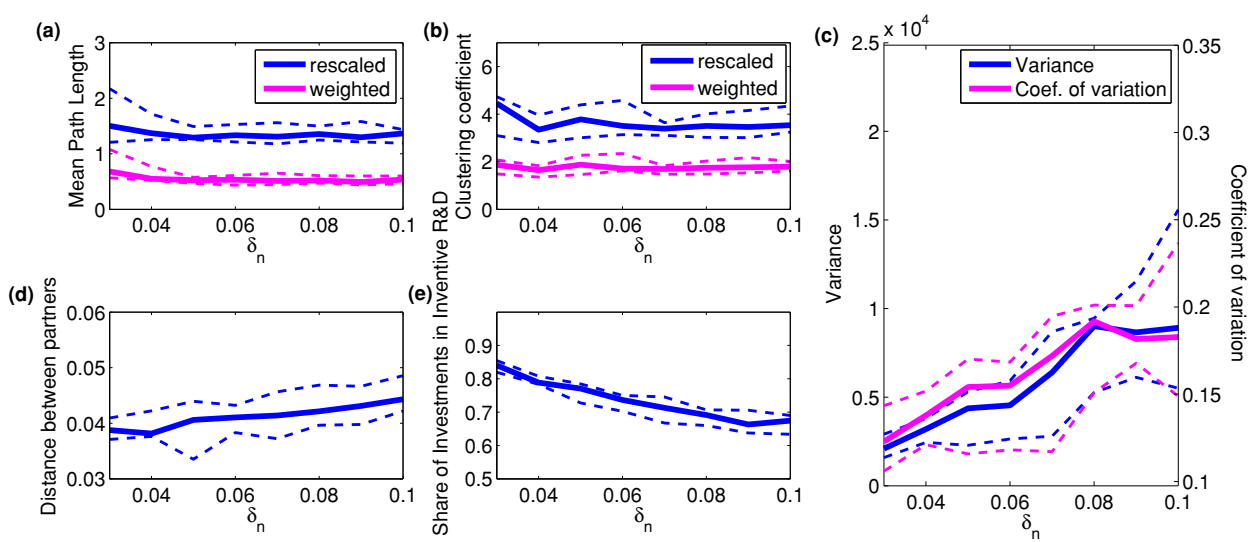

(B) Reciprocal partnership
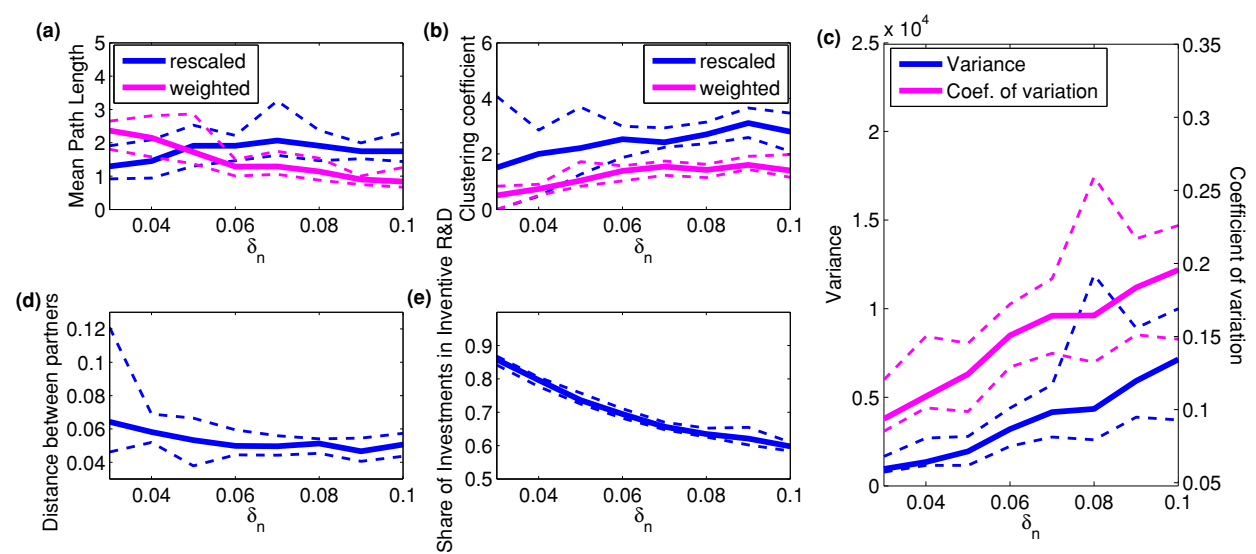

(C) Popularity contest

Figure D.1: More network characteristics and involuntary spillovers $\left(\delta_{n}\right)$ 

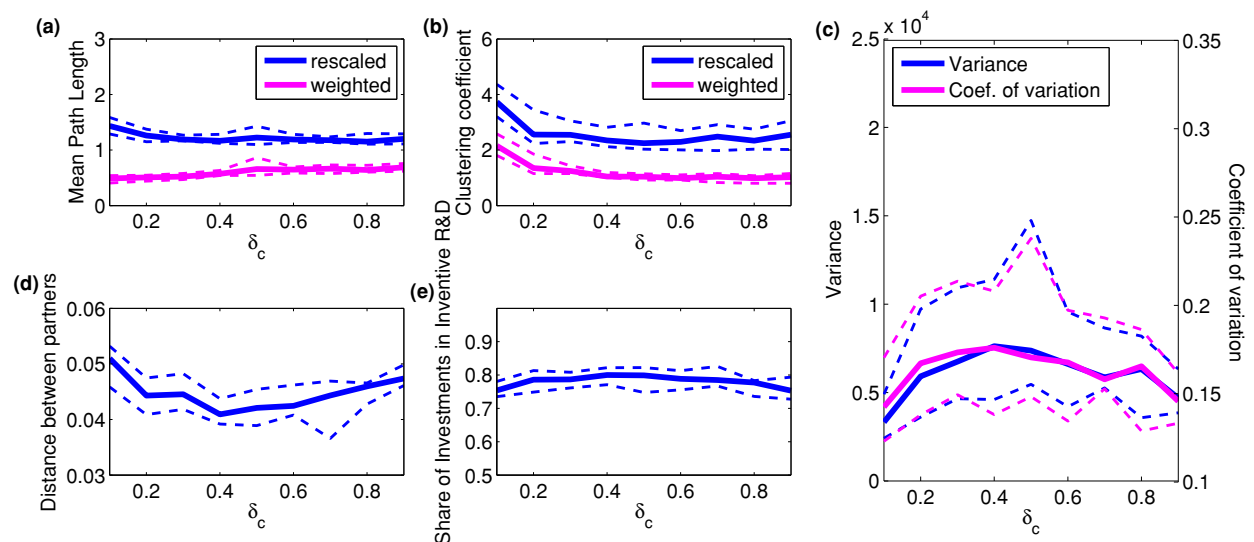

(A) Unilateral partnership
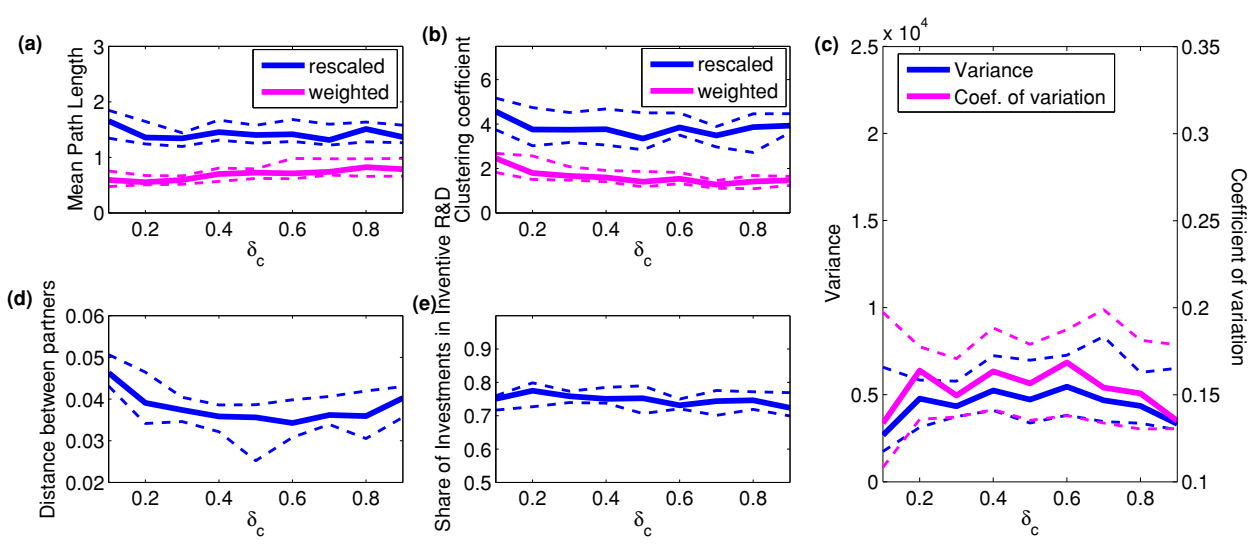

(B) Reciprocal partnership
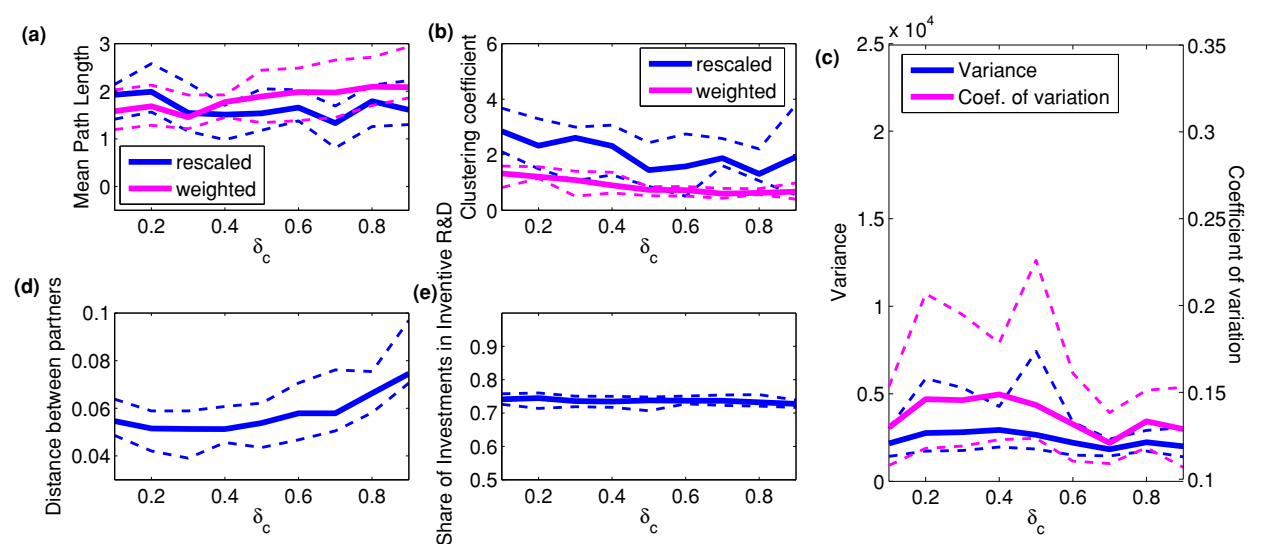

(C) Popularity contest

Figure D.2: More network characteristics and voluntary spillovers $\left(\delta_{c}\right)$ 

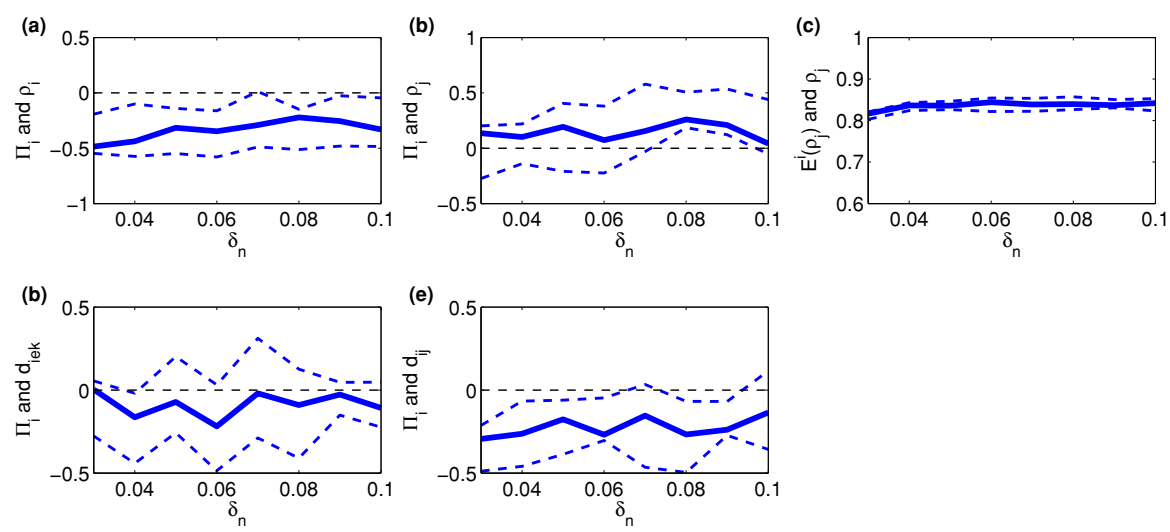

\section{(A) Unilateral partnership}
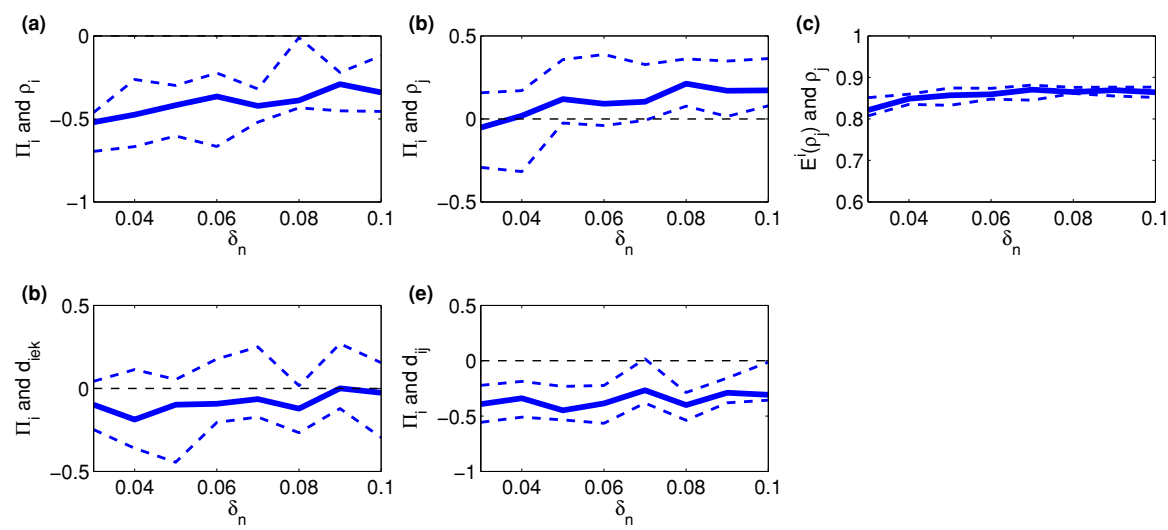

(B) Reciprocal partnership
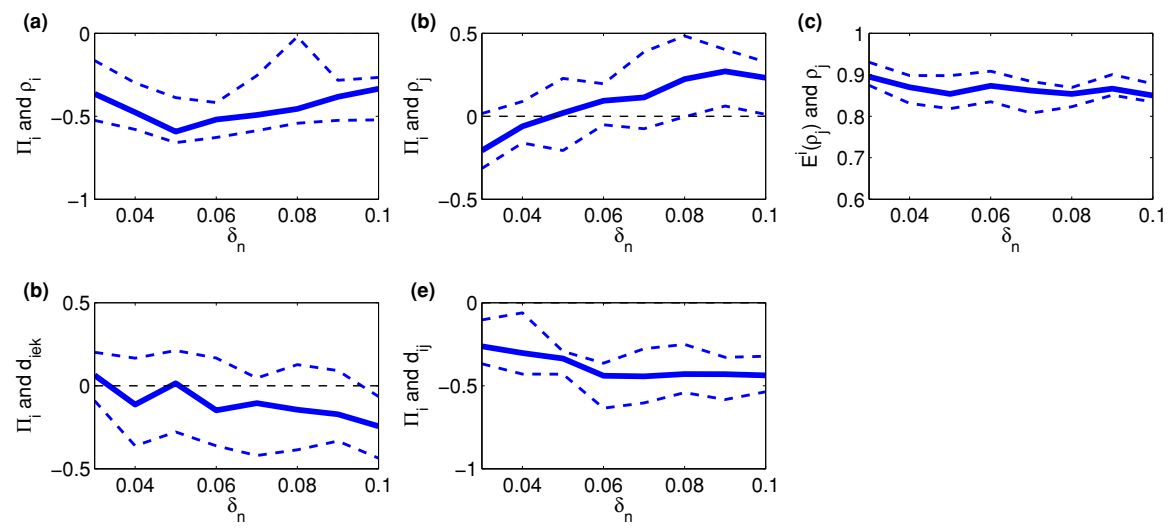

(C) Popularity contest

Figure D.3: Further correlations under varying involuntary spillovers $\left(\delta_{n}\right)$ : investments, distances and performance 

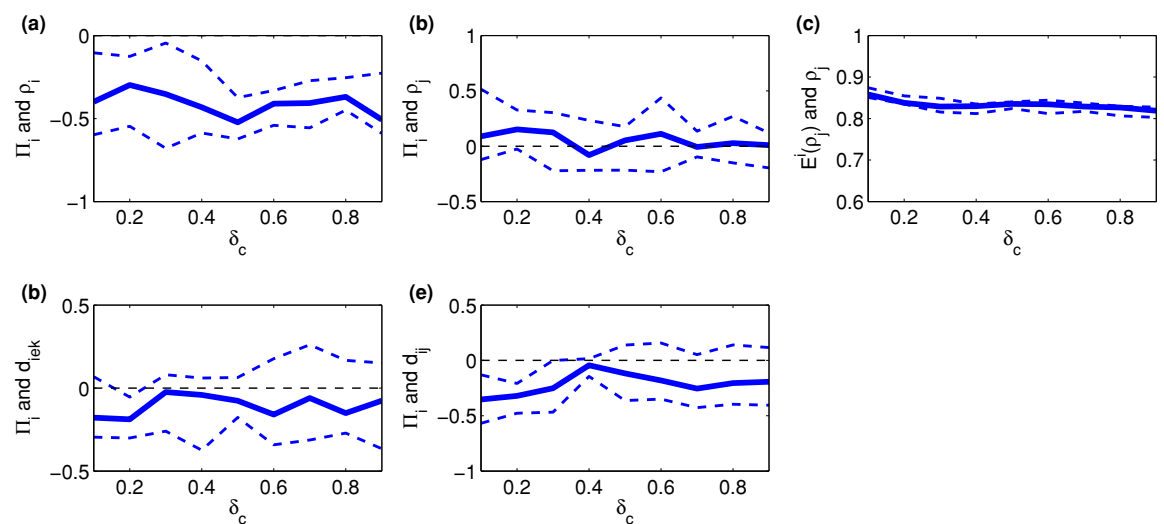

\section{(A) Unilateral partnership}
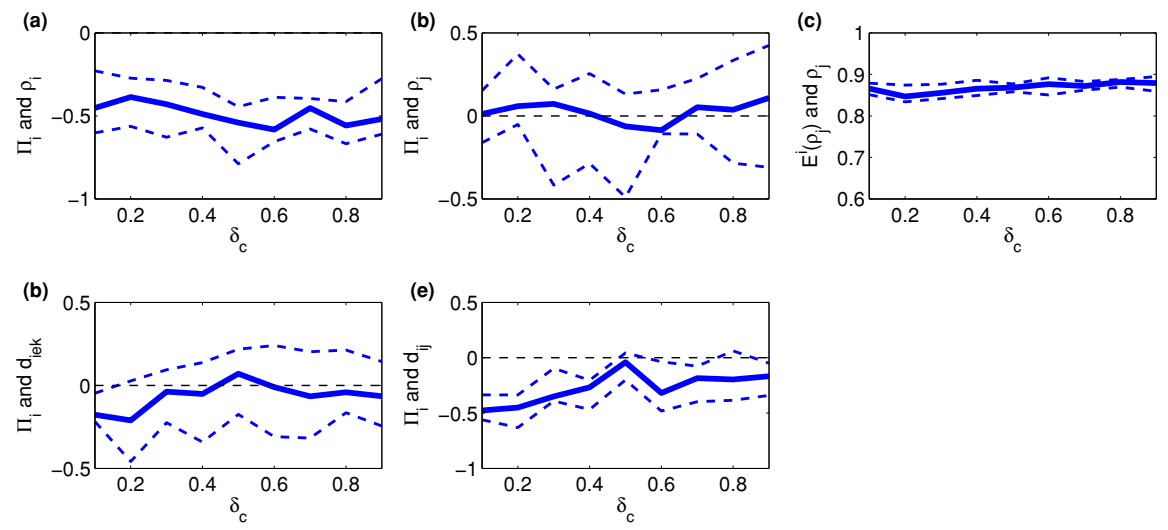

(B) Reciprocal partnership
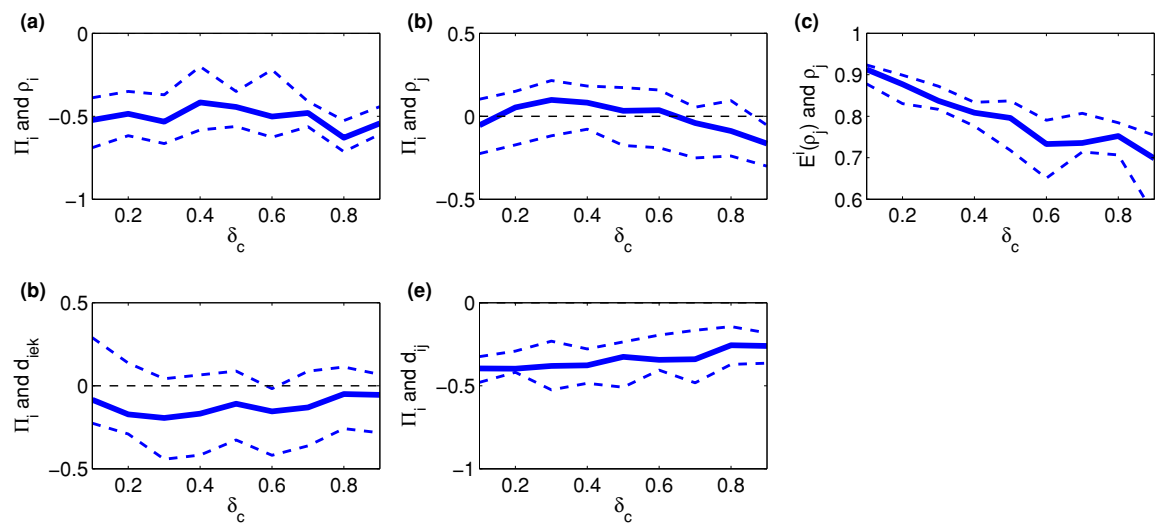

(C) Popularity contest

Figure D.4: Further correlations under varying voluntary spillovers $\left(\delta_{c}\right)$ : investments, distances and performance 


\section{Deutschsprachige Zusammenfassung}

Diese Arbeit hat das Ziel, bekanntes Wissen, über die Wichtigkeit der absorptive Fähigkeit von Unternehmen, und die Verwendung von extern generierten Wissen in Innovationsprozess, zu erweitern. Eine zentrale Aussage aktueller Literatur spricht Unternehmen eine höhere Effizienz bei Innovationstätigkeiten zu, falls diese externes Wissen in firmeninterne Innovationsanstrengungen einbeziehen. Damit dies geschehen kann, benötigen die Unternehmen einen adäquaten Bestand an Vorwissen, welcher auch als absorptive Fähigkeite bekannt ist. Dabei bilden Netzwerke zwischen Unternehmen untereinander und Beziehungen mit anderen ökonomisch relevanten Akteuren die grundlegende Infrastruktur für die Verbreitung von Wissen. Die absorptive Fähigkeit von Unternehmen bestimmen dabei den Umfang des externen Wissens, welches Unternehmen sich aneignen können. Obwohl bereits viel über Netzwerke, absorptive Fähigkeiten und Innovationen in der Wissenschaft bekannt ist, gibt es dennoch an wichtigen Stellen entscheidende Lücken.

Erstens besteht ein Bedarf an detaillierteren Mikrostudien in Entwicklungsländern. Zweitens ist wenig über die unterschiedlichen Rollen von formellen und informellen Beziehungen zwischen Unternehmen bekannt. Drittens sind Vorteile aus der Einbettung in Netzwerke größtenteils dem Sozialkapital zugeschrieben worden, wohingegen die zentrale Bedeutung von Wissen in Netzwerken in der Regel wenig beachtet worden ist. Viertens sind strukturelle Unterschiede von Netzwerken sowie die Wichtigkeit von Industriedynamiken wichtige Themen, die bislang kaum untersucht worden sind. Schließlich stellt sich auch die Rolle von absorptive Fähigkeit innerhalb von Innovationsnetzwerken überraschenderweise als wenig untersucht heraus. Aus den genannten Gründen ergibt sich der Bedarf, die Beziehung zwischen Innovationen und Netzwerkressourcen und die dabei wichtige Rolle von absorptive Fähigkeit tiefergehend zu untersuchen. 
Mit Daten aus Nigeria, die zwei empirischen Kapiteln wird nach der Verwendung von externem Wissen und der Anzahl externer Quellen der Unternehmen, aus denen die Firmen ihre Innovationsfähigkeit ziehen, gefragt und diese auf nigerianische Daten angewendet. Die vorliegende Arbeit schließst mit zwei theoretischen Kapiteln, in welchen ein komplexes Modell über absorptive Fähigkeiten und Innovationsnetzwerken entwickelt und umfangreich diskutiert wird.

Die gesamten Analysen basieren auf den Ansätzen der Evolutionsökonomk, des strategischen Managements und der „latecomer learning"-Literatur. Der evolutionsökonomische Ansatz ist sehr hilfreich, da er Innovationen und Volkswirtschaften realitätsnäher betrachtet, als dies in traditionellen Theorien erfolgt. Innovationen werden dabei insbesondere als Neukombinationen von Wissen verstanden und entstehen durch Lernprozesse von begrenzt rational agierenden Individuen. Die innovierenden Akteure, insbesondere Unternehmen, sind sehr vielfältig in ihren Fähigkeiten und ihrem Verhalten. Die ökonomie befindet sich damit in einem dynamischen Zustand mit verschiedenen Akteuren, Technologien und Institutionen, die nebeneinander koexistieren und sich wechselseitig beeinflussen. Die sich daraus ergebende Frage ist nicht die der optimalen Ressourcenallokation im Gleichgewichtszustand, sondern vielmehr die nach den Gründen von endogenem Wandel, der sich innerhalb von Unternehmen, Institutionen und ökonomien vollzieht. Die beschriebene Betrachtungsweise wird in der Arbeit mit dem Ansatz des strategischen Managements ergänzt, welcher ein Unternehmen als Bündel von Ressourcen versteht, welches in sich und für sich nicht vollständig ist, sondern komplementäre Ressourcen von außerhalb seiner Grenzen benötigt. Schließlich ist es für die Analyse von Entwicklungsländern hilfreich, geeignete Theorie über Prozesse des technologischen Lernens einzubeziehen, welche zu einer Akkumulation von technologischen Fähigkeiten führen, mit daran Hilfe die Unternehmen innovieren können.

Nach einer Einführung die die Richtung der Arbeit beschreibt, setzt sich das zweite Kapitel der Arbeit mit interaktivem Lernen und damit dem Aufbau von technologischen Fähigkeiten von Firmen in Entwicklungsländern auseinander. $\mathrm{Zu}$ Beginn wird aufgezeigt, dass ein Großteil der Literatur die Akkumulation von Fähigkeiten bei Nachzügler -Unternehmen beschreibt und dabei die Dominanz von ausländischen Technologien betont. Dadurch ergeben sich Möglichkeiten, das Lernen innerhalb lokaler Innovationssysteme in Entwicklungsländern intensiver zu betrachten. Zusätzlich wird in einigen Untersuchungen, die lokale Interaktionen betrachten, die Rolle von informellen Interaktionen auf Kosten von formellen Zusammenarbeiten herausgehoben. Obwohl argumentiert werden kann, dass letztere weniger beduetend sind, führt ein vernachlässigen von 
formellen Interaktionen zu einer Unterbewertung der Rolle des interaktiven Lernens.

Um die Verwirrung in vielen Studien, die technologische Fähigkeiten als Inputs und Outputs simultan betrachten, entgegenzutreten, wird zu Beginn des Kapitels zunächst deutlich zwischen Kompetenzen und Fähigkeiten unterschieden. Letztere werden als Ergebnis technologischen Lernens dargestellt und durch die Innovationstätigkeit des Unternehmens signalisiert. Diese Tätigkeiten können technologisch (produkt- oder prozessbezogen) oder nicht-technologisch (marketing- oder organisationsbezogen) sein. Studien die diesen multidimensionalen Ansatz von Innovationen verwenden sind rar, insbesondere für Entwicklungsländer. Zusätzlich wird zwischen formellen und informellen Formen der Interaktionen zwischen Unternehmen und anderen Akteuren innerhalb des lokalen Innovationssystems unterschieden. Diese konzeptuellen Sichtweisen werden dann auf Daten einer nigerianischen Pionierstudie von Produktionsbetrieben angewendet. Dabei wird ein starker Zusammenhang zwischen den Fähigkeiten des Unternehmens auf der einen Seite und formellem und informellem interaktivem Lernen auf der anderen Seite deutlich. Diese Relation variiert jedoch bei verschiedenen Typen von Fähigkeiten. Beispielsweise zeigen prozessbezogene Fähigkeiten keine statistische Signifikanz mit informellen Interaktionen, während organisationsbezogene Fähigkeiten nicht signifikant mit formellen Interaktionen zusammenhängen. Insgesamt betrachtet, scheinen Fähigkeiten auf der Unternehmensebene eher auf informelle als auf formelle Interaktionen zu beruhen. Als Implikation für Entwicklungsländer ergibt sich, dass der Fokus auf die weniger teuren informellen Formen der Interaktion ein vielversprechender Treiber für Innovativität sein könnte.

Das dritte Kapitel erweitert die Betrachtung um verschiedene Wissenquellen, aus denen Unternehmen externes Wissen beziehen, um eigene Fähigkeiten auszubauen. Diese Aussagen basieren auf einem neueren und umfangreicheren Datensatz über nigerianischen Firmen. Obwohl in der Vergangenheit schon oft gezeigt wurde, dass ein Portfolio von verschiedenen externen Quellen vorteilhaft für die Innovationskraft ist, ist es bisher unberücksichtigt geblieben, ob dies unabhängig vom Innovativitätsniveau des jeweiligen Unternehmens Gültigkeit behält. Bei der Anwendung von ordinalen Bewertungsmaßstäben und einem teilweise verhältnismäßigen Wahrscheinlichkeitsmodell, wird die variierende Bedeutung von interaktivem Lernen bei zunehmender Innovationskraft der Unternehmung hervorgehoben. Während die Anzahl von informellen Quellen im Allgemeinen positiv mit der Innovationsperformance korreliert ist, behält dieser Zusammenhang bei den formellen Interaktionen nur Gültigkeit bei niedrigen Innovativitätsniveaus. Je innovativer ein Unternehmen wird, 
umso weniger hilfreich erscheinen formale Kollaborationen mit verschiedenen Akteuren. Damit werden die Grenzen von wechselseitigem Lernen aufgezeigt, insbesondere bei formellen Interaktionen. Dies stellt darüber hinaus auch die uneingeschränkte Empfehlung des sogenannten Open-Innovation-Ansatzes in Frage.

Darüber hinaus wird versucht, die Idee der absorptive Fähigkeit zu operationalisieren und ihre Rolle beim interaktiven Lernen zu bewerten. Obwohl oft angenommen wird, dass Innovationsaktivität nicht nur aus interner Forschung \& Entwicklung ( F\&E) erwächst, ist interne $\mathrm{F} \& \mathrm{E}$ wichtig um Innovationsfähigkeit aufzubauen, besonders in Entwicklungsländern. Dieses Argument ist allerdings bisher kaum empirisch belegt. In dieser Arbeit wird versucht dies nachzuholen, indem die Kontinuität der F\&E-Tätigkeit in die Analyse einbezogen wird. Infolgedessen ist es nicht mehr ausschließlich das reine Engagement in $\mathrm{F} \& \mathrm{E}$, welches entscheidend ist, sondern die Kontinuität, welche dem Unternehmen einen kumulativen Lernvorteil einbringt. Somit wird die Wichtigkeit von absorptive Fähigkeit hervorgehoben. Von Bedeutung dabei ist, dass diese nicht so entscheidend für die Moderation von Kooperationen sind, sondern einen wichtigen direkten Effekt auf die Innovationsfähigkeit eines Unternehmens hat.

Eine wichtige Einschränkung der vorangegangenen empirischen Analysen ist die eingeschränkte Messbarkeit der absorptive Fähigkeit. Messungen von F\&E oder Lernprozessen erlauben es nicht, effektiv zwischen den Bestrebungen für ein erhöhtes schöpferisches Vermögen und denen zur Steigerung der Lernfähigkeit zu unterscheiden. Kapitel vier stellt ein repräsentatives Agenten-Modell vor, welches eine bessere Darstellung von absorptive Fähigkeit gegenüber bestehenden empirischen Analysen zulässt. Für den gegenseitigen Nutzen von Kooperationen, speziell im F\&E-Bereich, ist es notwendig, dass ein Unternehmen sein vorhandenes Wissen mit dem Partner teilt, um später einen Anspruch auf die geschaffene Wissensbasis zu erhalten. Das inhärente Risiko dabei ist, dass wenn der Partner schneller dieses Wissen aufnehmen kann bzw. fähiger ist Innovationen zu schaffen, man durch eine Kooperation seinen Wettbewerber zusätzlich stärkt. Aus diesem Grund sind freiwillige Spillover oder Appropriationsbedingungen zwischen den Kooperationspartnern als ein kritischer Faktor für Kooperationen zu betrachten. Aus dem gleichen Grund sind die F\&EAnstrengungen des potentiellen Partners ernst zu nehmen, da es sich um die Hauptquelle absorptiver Fähigkeiten handelt. Diese Gründe, kombiniert mit den Herausforderungen kognitiver Entfernung zwischen den Partnern, implizieren eine wichtige praktische Frage: Wann ist es für ein Unternehmen vorteilhaft Kooperationen einzugehen? Und wenn die Entscheidung für eine Kooperation 
getroffen wurde, wie lässt sich ein angemessener Partner finden?

In diesem Kapitel wird ein Modell entwickelt und angewendet, welches Kooperationen zwischen Unternehmen anhand von kognitiver Entfernung, Appropriationsbedingungen und externem Wissen erklärt. Damit sollen die Bedingungen untersucht werden, unter denen eine kooperative Strategie, im Sinne der Generierung von Gewinnen, einer nicht kooperativen Alternative überlegen ist. Diese Analyse erfordert eine explizite Formalisierung des Konstrukts absorptiver Fähigkeiten, was bis dato in theoretischen Netzwerkanalysen vermieden wurde. Dieses Kapitel nimmt sich dieser Herausforderung an und bietet eine überarbeitete Fassung des ursprünglichen Modells von Cohen und Levinthal. Dabei werden aktuelle empirische Ergebnisse mit in Betracht gezogen und absorptive Fähigkeiten explizit im Rahmen interaktiven Lernens modelliert. Die absorptive Fähigkeit von Unternehmen wird als Ergebnis aus der Interaktion zwischen absorptiver F\&E und der kognitiven Entfernung durch freiwillige und unfreiwillige Wissensspillover entwickelt. Die Ergebnisse aus der verwendeten Methode für die Analyse von Unternehmenskooperationen und Investitionspräferenzen in F\&E zeigen, dass die kognitive Entfernung und die Appropriationsbedingungen zwischen den Unternehmen und dessen Partnern einen mehrdeutigen Effekt auf die Gewinngenerierung des Unternehmens besitzen. Folglich wird ein Unternehmen die Kooperations- beziehungsweise Partnerauswahl unter Berücksichtigung der Investitionen in die absorptive Fähigkeit treffen. Dabei besteht ein Tradeoff zwischen der Möglichkeit etwas voneinander $\mathrm{zu}$ lernen und etwas neues zu lernen.

Das fünfte Kapitel baut auf diesem Modell auf und erweitert die vorangegangene Analyse anhand der Simulation von Innovationsnetzwerken mit einem dynamischen Multi-Agenten-Modell. Das Kapitel erweitert zusätzlich die vorhandene Literatur über strategische F\&E-Allianzen durch die Einbeziehung absorptiver Fähigkeiten. Aufbauend auf der Forschung zur Bildung von Allianzen, fokussiert sich das Kapitel auf den dynamischen Aspekt von Kooperationen, wobei sich die kognitive überlappung der Partner mit der Intensität der Kooperation erhöht. In dem Model entstehen Netzwerke als Ergebnis bilateraler Kooperationen zwischen Unternehmen über den Zeitverlauf, die in unterschiedlichen Bereichen im Wissensraum agieren. Soziales Kapital wird dabei ignoriert und Unternehmen verbünden sich nur unter dem Gesichtspunkt der Erkenntnisgewinnung. Die Auswahl eines geeigneten Partners wird getrieben durch die Absorptionsfähigkeit, welche selbst wieder durch die kognitive Entfernung und die Investitionsverteilung zwischen schöpferischer und absorptiver F\&E beeinflusst wird. 
Innerhalb unterschiedlicher Wissenssysteme, welche verschiedene Stufen in der Evolution einer Industrie darstellen, behandelt das Kapitel die Struktur von Netzwerken und die Leistungen der jeweiligen Unternehmen in diesen Netzwerken. Diese Analyse ist eine notwendige Erweiterung der vorhandenen Literatur, da bereits hervorgehoben wurde, dass noch eine Menge über die Dynamik von Kollaborationen in Innovationsnetzwerken, wie auch die Rolle von Netzwerken in unterschiedlichen Evolutionsstufen einer Industrie, herauszufinden ist. Das Modell repliziert einige stilisierte empirische Ergebnisse über die Struktur von Netzwerken und die möglichen Effekte der Position in einem Netzwerk auf die Innovationsleistung. Beispielsweise wurden Netzwerke beobachtet, welche Small-World-Eigenschaften aufweisen. Es hat sich gezeigt, dass diese Eigenschaften generell robust gegenüber einem Wechsel des Wissenssystems sind. Das Model schafft darüber hinaus neue Einsichten: Erstens zeigt es sich, dass der Einfluss der Netzwerkstruktur auf die Innovationsleistung tatsächlich mit fortschreitender Evolution der Industrie variiert. ändert sich das vorherrschende Wissenssystem von implizitem zu explizitem Wissen, so werden bestimmte Netzwerkstrategien, wie die Beanspruchung der „Broker“-Position oder die Maximierung der Zugänglichkeit für potentielle Partner, weniger wichtig. Zweitens spielt die Absorptionsfähigkeit eine nachweislich entscheidende Rolle in der Evolution von Netzwerken: Unternehmen mit unterschiedlichen Netzwerkstrategien unterscheiden sich in der Tat im Aufbau absorptiver Fähigkeiten.

Zusammenfassend betrachtet, liefert die vorliegende Arbeit mindestens drei neuartige Beiträge zum aktuellen Forschungsstand. Zunächst wird erneut der Zusammenhang zwischen Innovationen und interaktivem Lernen in einem ökonomischen „latercomer"-Kontext belegt. Insbesondere wird verdeutlicht, dass der Zusammenhang zwischen den beiden genannten Größen nicht konstant ist, sondern sich mit dem wandelnden Niveau der Innovativität von Unternehmen verändert. Als zweiter zentraler Punkt wird gezeigt, dass die Wichtigkeit der Netzwerke mit einer wandelnden Industrie variiert. In frühen Entwicklungsstadien der Industrie, wenn Wissen noch hochgradig implizit ist, profitieren Unternehmen von einer zentralen Netzwerkposition, während das Gegenteil der Fall ist, wenn sich die Industrie weiter entwickelt hat. Drittens wird schließlich deutlich, dass die absorptive Fähigkeit der Unternehmen tatsächlich die Geschwindigkeit und Richtung der Netzwerkevolution beeinflussen. So entstehen oder verändern sich Netzwerke in Abhängigkeit der Entscheidungen von Unternehmen über ihre Kooperationen, welche von deren absorptive Fähigkeit und ihrer Partner abhängen. Methodisch zeigt diese Arbeit, dass die Rolle von Netzwerken und externem Wissen bei Innovationstätigkeiten besser durch eine Kombination von verschiedenen konzeptuellen und methodischen Ansätzen 
verstanden werden kann. Die Verbindung von Mikroökonometrie, „Social Network Analysis" und agentenbasierender Modellierung führt zu einer größeren Aussagekraft.

Auch die politischen Implikationen sind eindeutig. Es erscheint wichtig, Interaktionen zwischen Unternehmen sowie anderen ökonomischen Akteuren zu fördern, ohne dabei die Grenzen der Netzwerkbildung unberücksichtigt zu lassen. Zusätzlich erscheint es notwendig, den Bedarf von Variation bei Interaktionen zu berücksichtigen, insbesondere in Entwicklungsländern, wie beispielsweise der Sub-Sahara-Region, die auf Universitäts-Industrie-Interaktionen setzen. Dabei ist die Kombination von verschiedenen externen Quellen für Innovationen vorteilhafter, als das Ausschöpfen einer einzelnen Quelle. Schließlich stellt der koevolutorische Prozess zwischen Netzwerken und der Industrie ein bedeutendes Thema dar. In diesem Zusammenhang sind netzwerkfördernde Politikmechanismen, wie Clusterbildung und Inkubationsinitiativen, erfolgreicher, wenn der politische Entscheider sachkundig über die hier angesprochenen Gesichtspunkte informiert ist. 


\section{References}

Adebowale, B. O. A. and Oyelaran-Oyeyinka, B. (2012). Determinants of productivity and inter-firm collaboration in Nigerian clusters. International Journal of Technology and Globalisation, 6(3):188-205.

Adeoti, J. O. (2012). Technology-related factors as determinants of export potential of Nigerian manufacturing firms. Structural Change and Economic Dynamics, 23(4):487-503.

Africa Vanguard (2009). Nigeria: 820 manufacturing companies close down in 9 years - MAN. http://allafrica.com/stories/200907240878.html. (Online newspaper article, retrieved April 23, 2012).

Aggarwal, A. (2000). Deregulation, technology imports and in-house R\&D efforts: an analysis of the Indian experience. Research Policy, 29(9):1081 1093.

Ahuja, G. (2000). Collaboration networks, structural holes, and innovation: A longitudinal study. Administrative Science Quarterly, 45(3):425-455.

Ahuja, G. and Lampert, M. C. (2001). Entrepreneurship in the large corporation: a longitudinal study of how established firms create breakthrough inventions. Strategic Management Journal, 22(6-7):521-543.

Almeida, R. and Carneiro, P. (2009). The return to firm investments in human capital. Labour Economics, 16(1):97-106.

Amara, N. and Landry, R. (2005). Sources of information as determinants of novelty of innovation in manufacturing firms: evidence from the 1999 Statistics Canada innovation survey. Research Policy, 25(3):245-259.

Amara, N., Landry, R., Becheikh, N., and Ouimet, M. (2008). Learning and novelty of innovation in established manufacturing SMEs. Technovation, 28(7):450 - 463 . 
Amsden, A. H. (1992). Asia's next giant: South Korea and late industrialization. Oxford University Press on Demand.

Ananth, C. V. and Kleinbaum, D. G. (1997). Regression models for ordinal responses: a review of methods and applications. International Journal of Epidemiology, 26(6):1323-1333.

Andreu, R. and Ciborra, C. (1996). Organisational learning and core capabilities development: the role of IT. The Journal of Strategic Information Systems, 5(2):111-127.

Antonelli, C., Krafft, J., and Quatraro, F. (2010). Recombinant knowledge and growth: the case of ICTs. Structural Change and Economic Dynamics, 21(1):50-69.

Aralica, Z., Račić, D., and Radić, D. (2008). Innovation propensity in Croatian enterprises: results of a Community Innovation Survey. South East European Journal of Economics and Business, 3(1):77-88.

Archibugi, D. (2001). Pavitt's taxanomy sisxteen years on: a review article. Economics of Innovation and New Technology, 10(5):415-425.

Arrow, K. (1962a). Economic welfare and the allocation of resources for invention. In Nelson, R., editor, The Rate and Direction of Inventive Activity, pages 609-626. Princeteon University Press, Princeteon, NJ.

Arrow, K. J. (1962b). The economic implications of learning by doing. Review of Economic Studies, 29:155-173.

Atallah, G. (2003). Information sharing and the stability of cooperation in research joint ventures. Economics of Innovation and New Technology, 12(6):531-554.

AU-NEPAD (2010). African Innovation Outlook 2010. African Union-New Partnership for Africa's Development, Pretoria. Retrieved January 26, 2012 from http://www.nepad.org/system/files/June2011_NEPAD_AIO_2010_ English.pdf.

Audretsch, D. and Feldman, M. (1996). Innovative clusters and the industry life cycle. Review of Industrial Organisation, 11:253-273.

Bala, V. and Goyal, S. (2000). A noncooperative model of network formation. Econometrica, 68(5):1181-1229.

Balasubramanian, N. and Lee, J. (2008). Firm age and innovation. Industrial and Corporate Change, 17(5):1019-1047. 
Balland, P.-A. (2012). Proximity and the evolution of collaboration networks: evidence from research and development projects within the global navigation satellite system (GNSS) industry. Regional Studies, 46(6):741-756.

Balland, P.-A., De Vaan, M., and Boschma, R. (2013). The dynamics of interfirm networks along the industry life cycle: the case of the global video game industry, 1987-2007. Journal of Economic Geography, 13(5):741-765.

Bamford, J. and Ernst, D. (2002). Managing an alliance portfolio. The McKinsey Quartely, 3:29-39.

Barney, J. (2001). Resource-based theories of competitive advantage: a tenyear retrospective on the resource-based view. Journal of Management, 27(6):643-650.

Barr, A. (2000). Social capital and technical information flows in the Ghanaian manufacturing sector. Oxford Economic Papers, 52(3):539-559.

Barr, A. M. (2002). The functional diversity and spillover effects of social capital. Journal of African Economies, 11(1):90-113.

Baum, J., Shipilov, A. V., and Rowley, T. J. (2003). Where do small worlds come from? Industrial and Corporate Change, 12(4):697-725.

Baum, J. A. C., Cowan, R., and Jonard, N. (2010). Network-independent partner selection and the evolution of innovation networks. Management Science, 56(11):2094-2110.

Beaudry, C. and Schiffauerova, A. (2009). Who's right, Marshall or Jacobs? the localization versus urbanization debate. Research Policy, 38(2):318 337.

Belderbos, R., Carree, M., and Lokshin, B. (2004). Cooperative R\&D and firm performance. Research Policy, 33(10):1477-1492.

Bell, M. (1984). Learning and the accumulation of industrial technological capability in developing countries. In Fransman, M. and King, K., editors, Technological Capability in the Third World, pages 187-209. Macmillan, London.

Bell, M. and Pavitt, K. (1993). Technological accumulation and industrial growth: contrasts between developed and developing countries. Industrial and Corporate Change, 2(2):157-210.

Biggs, T., Shah, M., and Strivastava, P. (1995). Technological capabilities 
and learning in African enterprises. World Bank Technical Paper No.288 Washington, D.C.

Biggs, T. and Shah, M. K. (2006). African SMES, networks, and manufacturing performance. Journal of banking \& Finance, 30(11):3043-3066.

Bigsten, A. and Söderbom, M. (2006). What have we learned from a decade of manufacturing enterprise surveys in Africa? The World Bank Research Observer, 21(2):241-265.

Bloom, N., Schankerman, M., and Van Reenen, J. (2013). Identifying technology spillovers and product market rivalry. Econometrica, 81(4):1347-1393.

Blueschke, D., Blueschke-Nikolaeva, V., and Savin, I. (2013). New insights into optimal control of nonlinear dynamic econometric models: application of a heuristic approach. Journal of Economic Dynamics and Control, 37(4):821837.

Bönte, W. and Keilbach, M. (2005). Concubinage or marriage? Informal and formal cooperations for innovation. International Journal of Industrial Organization, 23(3):279-302.

Boschma, R. (2005). Proximity and innovation: a critical assessment. Regional Studies, 39(1):61-74.

Breschi, S. and Lissoni, F. (2005). "Cross-firm" inventors and social networks: localized knowledge spillovers revisited. Annales d'Economie et de Statistique, (79-80):189-209.

Breschi, S. and Lissoni, F. (2009). Mobility of skilled workers and co-invention networks: an anatomy of localized knowledge flows. Journal of Economic Geography, 9(4):439-468.

Breschi, S. and Malerba, F. (2005). Clusters, networks and innovation. Oxford University Press.

Broekel, T. and Boschma, R. (2012). Knowledge networks in the Dutch aviation industry: the proximity paradox. Journal of Economic Geography, 12(2):409-433.

Brusoni, S., Prencipe, A., and Pavitt, K. (2001). Knowledge specialization, organizational coupling, and the boundaries of the firm: why do firms know more than they make? Administrative Science Quarterly, 46(4):597-621.

Burt, R. (2004). Structural holes and good ideas. American Journal of Sociology, 110(2):349-399. 
Cantner, U. and Meder, A. (2007). Technological proximity and the choice of cooperation partner. Journal of Economic Interaction and Coordination, $2(1): 45-65$.

Cantner, U. and Pyka, A. (1998). Absorbing technological spillovers: simulations in an evolutionary framework. Industrial and Corporate Change, $7(2): 369-397$.

Cappellari, L. and Jenkins, S. (2003). Multivariate probit regression using simulated maximum likelihood. The Stata Journal, 3(3):278-294.

Carvalho, L., Costa, T., and Caiado, J. (2013). Determinants of innovation in a small open economy: a multidimensional perspective. Journal of Business Economics and Management, 14(3):583-600.

Cassi, L., Corrocher, N., Malerba, F., and Vonortas, N. (2008). Research networks as infrastructure for knowledge diffusion in European regions. Economics of Innovation and New Technology, 17(7-8):663-676.

Cassiman, B., Pérez-Castrillo, D., and Veugelers, R. (2002). Endogenizing know-how flows through the nature of $\mathrm{R} \& \mathrm{D}$ investments. International Journal of Industrial Organization, 20(6):775 - 799.

Cassiman, B. and Veugelers, R. (2002). R\&D cooperation and spillovers: some empirical evidence from Belgium. The American Economic Review, 92(4):pp. 1169-1184.

Cassiman, B. and Veugelers, R. (2006). In search of complementarity in innovation strategy: internal R\&D and external knowledge acquisition. Management Science, 52(1):68-82.

Chesbrough, H. W. (2003a). The era of open innovation. Sloan Management Review, Summer:35-41.

Chesbrough, H. W. (2003b). Open Innovation. Harvard University Press, Cambridge, MA.

Chesbrough, H. W. (2003c). Open Innovation: The New Imperative for Creating and Profiting from Technology. Oxford University Press, Oxford.

Chinedu, E., Titus, O., and Thaddeus, E. (2010). Achieving Vision 2020 in Nigeria: a review of the economic and market-oriented business reforms. Journal of Sustainable Development in Africa, 12(4):58-71.

Cohen, W. (2005). Empirical studies of innovative activity. In Stoneman, P., 
editor, Handbook of the Economics of Innovation and Technological Change, pages 182-264. Blackwell Publishers, Oxford.

Cohen, W. (2010). Fifty years of empirical studies of innovative activity and performance. In Hall, H. B. and Rosenberg, N., editors, Handbook of the Economics of Innovation, volume 1, pages 129-213. North-Holland/Elsevier, Amsterdam.

Cohen, W. and Levinthal, D. (1989). Innovation and learning: the two faces of R\&D. The Economic Journal, 99(397):569-596.

Cohen, W. and Levinthal, D. (1990). Absorptive capacity: a new perspective on learning and innovation. Administrative Science Quarterly, 35(1):128152.

Cohen, W. and Levinthal, D. (1994). Fortune favours the prepared firm. Management Science, 40(2):227-251.

Coleman, J. (1988). Social capital in the creation of human capital. American Journal of Sociology, 94(Supplement):95-120.

Collis, D. J. (1994). Research note: how valuable are organizational capabilities? Strategic Management Journal, 15(S1):143-152.

Cooper, C. (1991). Are innovation studies on industrialized economies relevant to technology policy in developing countries? Working Paper No. 3. UNUINTECH, Maastricht. Retrieved March 20, 2013 from http://archive. unu.edu/hq/library/Collection/PDF_files/INTECH/INTECHwp03.pdf.

Corporate Guides (2011). Corporate Nigeria: the Business, Trade and Investment Guide 2010/2011. Corporate Guides Int. Ltd. Retrieved June 21, 2012 from http://www.corporate-nigeria.com/assets/pdf/2010/ cn-2010-industry . pdf.

Cowan, R. (2005). Network models of innovation and knowledge diffusion. In Breschi, S. and Malerba, F., editors, Clusters, Networks and Innovation. Oxford University Press.

Cowan, R. and Jonard, N. (2004). Network structure and the diffusion of knowledge. Journal of Economic Dynamics and Control, 28(8):1557-1575.

Cowan, R. and Jonard, N. (2009). Knowledge portfolios and the organization of innovation networks. Academy of Management Review, 34(2):320-342.

Cowan, R., Jonard, N., and Özman, M. (2004). Knowledge dynamics in a 
network industry. Technological Forecasting and Social Change, 71(5):469 484.

Cowan, R., Jonard, N., and Zimmermann, J. (2007). Bilateral collaboration and the emergence of innovation networks. Management Science, 53(7):1051-1067.

Dahlander, L. and Gann, D. M. (2010). How open is innovation? Research Policy, 39(6):699 - 709.

Dahlman, C. J., Ross-Larson, B., and Westphal, L. E. (1987). Managing technological development: lessons from the newly industrializing countries. World Development, 15(6):759 - 775.

Dasgupta, P. and Stiglitz, J. (1980). Uncertainty, industrial structure, and the speed of R\&D. The Bell Journal of Economics, 11(1):1-28.

Davis, G. F., Yoo, M., and Baker, W. E. (2003). The small world of the American corporate elite, 1982-2001. Strategic Organization, 1(3):301-326.

Davis, K. E. and Kruse, M. B. (2007). Taking the measure of law: The case of the Doing Business project. Law \&5 Social Inquiry, 32(4):1095-1119.

De Bondt, R. (1996). Spillovers and innovative activities. International Journal of Industrial Organization, 15(1):1-28.

de Fraja, G. (1993). Strategic spillovers in patent-races. International Journal of Industrial Organization, 11(1):139-146.

de Jong, J. and Freel, M. (2010). Absorptive capacity and the reach of collaboration in high technology small firms. Research Policy, 39(1):47-54.

de Jong, J. P. and Marsili, O. (2006). The fruit flies of innovations: a taxonomy of innovative small firms. Research Policy, 35(2):213 - 229.

de Man, A.-P. and Duysters, G. (2005). Collaboration and innovation: a review of the effects of mergers, acquisitions and alliances on innovation. Technovation, 25(12):1377 - 1387.

Dettmann, A. and von Proff, S. (2010). Inventor collaboration over distancea comparison of academic and corporate patents. Technical Report 2010-01, Working Papers on Innovation and Space.

Dodgson, M. (1993). Organizational learning: A review of some literatures. Organization Studies, 14(3):375-394. 
Dosi, G. (1982). Technological paradigms and technological trajectories: a suggested interpretation of the determinants and directions of technical change. Research Policy, 11(3):147-162.

Dosi, G. (1988). The nature of the innovative process. In Dosi, G., Freeman, C., Nelson, R., Silverberg, G., and Soete, L., editors, Technical Change and Economic Theory, pages 221-238. Pinter London.

Dosi, G. and Marengo, L. (2007). Perspective - on the evolutionary and behavioral theories of organizations: a tentative roadmap. Organization Science, 18(3):491-502.

Drejer, I. and Jørgensen, H. B. (2005). The dynamic creation of knowledge: analysing public-private collaborations. Technovation, 25(2):83-94.

Drejer, I. and Vindig, A. (2007). Searching near and far: determinants of innovative firms' propensity to collaborate across geographical distance. Industry and Innovation, 14(3):259-275.

Dutrénit, G. (2004). Building technological capabilities in latecomer firms: a review essay. Science, Technology \& Society, 9(2):209-241.

Dutta, S., Narasimhan, O., and Rajiv, S. (2005). Conceptualizing and measuring capabilities: methodology and empirical application. Strategic Management Journal, 26(3):277-285.

Dutta, S. and Weiss, A. M. (1997). The relationship between a firm's level of technological innovativeness and its pattern of partnership agreements. Management Science, 43(3):343-356.

Duysters, G. and Lokshin, B. (2011). Determinants of alliance portfolio complexity and its effect on innovative performance of companies. Journal of Product Innovation Management, 28(4):570-585.

Duysters, G. and Vanhaverbeke, W. (1996). Strategic interactions in DRAM and RISC technology: a network approach. Scandinavian Journal of Management, 12(4):437-61.

Edquist, C., editor (1997). Systems of innovation: Technologies, institutions and organizations. Pinter, London.

Edquist, C. (2005). Systems of innovation: Perspectives and challenges. In Fagerberg, J., Mowery, D., and Nelson, R., editors, The Oxford Handbook of Innovation, pages 181-208. Oxford University Press, Oxford. 
Egbetokun, A. (2012). Cooperation behaviour and innovation performance in the Nigerian manufacturing industry. Jena Economic Research Papers 2012037. Friedrich-Schiller-University Jena, Max-Planck-Institute of Economics. Available at http://pubdb.wiwi.uni-jena.de/pdf/wp_2012_037.pdf.

Egbetokun, A., Adeniyi, A., and Siyanbola, W. (2012). On the capability of SMEs to innovate: the cable and wire manufacturing sub-sector in Nigeria. International Journal of Learning and Intellectual Capital, 9(1/2):64-85.

Egbetokun, A. and Savin, I. (2014). Absorptive capacity and innovation: When is it better to cooperate? Journal of Evolutionary Economics, forthcoming.

Egbetokun, A., Siyanbola, W., and Adeniyi, A. (2010). Learning to innovate in Nigeria's cable and wire manufacturing sub-sector: inferences from a firmlevel case study. International Journal of Learning and Intellectual Capital, $7(1): 55-74$.

Egbetokun, A. A. (2009). An assessment of innovation capability in the cable and wire manufacturing industry in Nigeria. Msc thesis, Obafemi Awolowo University, Ile-Ife, Nigeria.

Eisenhardt, K. M. and Martin, J. A. (2000). Dynamic capabilities: what are they? Strategic Management Journal, 21(10-11):1105-1121.

Ernst, D. (2007). Beyond the 'Global Factory' model: innovative capabilities for upgrading China's IT industry. International Journal of Technology and Globalisation, 3(4):437-459.

Fabrizio, K. (2009). Absorptive capacity and the search for innovation. Research Policy, 38(2):255-267.

Faems, D., Van Looy, B., and Debackere, K. (2005). Inter-organizational collaboration and innovation: towards a portfolio approach. Journal of Product Innovation Management, 22(3):238-250.

Fafchamps, M. (2001). Networks, communities and markets in sub-Saharan Africa: implications for firm growth and investment. Journal of African Economies, 10(suppl 2):109-142.

Fafchamps, M. and Söderbom, M. (2013). Network proximity and business practices in African manufacturing. World Bank Economic Review, forthcoming. Retrieved August 1, 2013 from http://economics.ouls.ox.ac . uk/15191/1/fafchamps_soderbom_april11.pdf. 
Fagerberg, J. (1987). A technology gap approach to why growth rates differ. Research Policy, 16(2-4):87 - 99.

Fagerberg, J., Srholec, M., and Verspagen, B. (2010). The role of innovation in development. Review of Economics and Institutions, 1(2):Article 2. Retrieved January 11, 2012 from http://www.rei.unipg.it/rei/article/ view/15.

Fehr, E. and Gächter, S. (2000). Fairness and retaliation: The economics of reciprocity. Journal of Economic Perspectives, 14(3):159-181.

Figueiredo, P. (2002a). Learning processes features and technological capability-accumulation: explaining inter-firm differences. Technovation, 22(11):685-698.

Figueiredo, P. N. (2002b). Does technological learning pay off? Inter-firm differences in technological capability-accumulation paths and operational performance improvement. Research Policy, 31(1):73-94.

Figueiredo, P. N. (2003). Learning, capability accumulation and firms differences: evidence from latecomer steel. Industrial and Corporate Change, 12(3):607-643.

Fisman, R. (2001). Trade credit and productive efficiency in developing economies. World Development, 29(2):311-321.

Fontana, R., Geuna, A., and Matt, M. (2006). Factors affecting universityindustry R\&D projects: The importance of searching, screening and signalling. Research Policy, 35(2):309-323.

Freedman, D. A. and Sekhon, J. S. (2010). Endogeneity in probit response models. Political Analysis, 18(2):138-150.

Freeman, C. (1991). Networks of innovators: a synthesis of research issues. Research Policy, 20(5):499-514.

Freeman, C. (1995). The 'National System of Innovation' in historical perspective. Cambridge Journal of Economics, 19(1):5-24.

Freeman, C. and Soete, L. (1997). The economics of industrial innovation. Routledge.

Freitas, I. M. B., Clausen, T., Fontana, R., and Verspagen, B. (2011). Formal and informal external linkages and firms' innovative strategies. a crosscountry comparison. Journal of Evolutionary Economics, 21:91-119. 
Frenz, M. and letto Gillies, G. (2009). The impact on innovation performance of different sources of knowledge: evidence from the UK Community Innovation Survey. Research policy, 38:1125-1135.

Ganter, A. and Hecker, A. (2013). Deciphering antecedents of organizational innovation. Journal of Business Research, 66(5):575 -584.

Garcia-Torres, M. A. and Hollanders, H. (2009). The diffusion of informal knowledge and innovation performance: a sectoral approach. Working Paper No. 2009-013. UNU-MERIT, Maastricht. Retrieved May 13 from http:// www. merit. unu .edu/publications/wppdf/2009/wp2009-013.pdf.

Gault, F. and Mawoko, P. (2011). Towards web resources for analysis of science, technology and innovation in Africa. Innovation and Development, 1(2):329330 .

Gemünden, H., Ritter, T., and Heydebreck, P. (1996). Network configuration and innovation success: an empirical analysis in German high-tech industries. International Journal of Research in Marketing, 13(5):449-462.

Gilli, M. and Winker, P. (2003). A global optimization heuristic for estimating agent based models. Computational Statistics 85 Data Analysis, 42(3):299312.

Gilli, M. and Winker, P. (2009). Heuristic optimization methods in econometrics. In Belsley, D. and Kontoghiorghes, E., editors, Handbook of Computational Econometrics, pages 81-119. Wiley, Chichester.

Gilsing, V., Nooteboom, B., Vanhaverbeke, W., Duysters, G., and van den Oord, A. (2008). Network embeddedness and the exploration of novel technologies: technological distance, betweenness centrality and density. Research Policy, 37(10):1717 - 1731.

Giuliani, E. (2013). Network dynamics in regional clusters: evidence from Chile. Research Policy, in press(http://dx.doi.org/10.1016/j.respol. 2013.04.002).

Giuliani, E. and Bell, M. (2005). The micro-determinants of meso-level learning and innovation: evidence from a Chilean wine cluster. Research Policy, $34(1): 47-68$

Glaeser, E. L., Kallal, H. D., Scheinkman, J. A., and Shleifer, A. (1992). Growth in cities. Journal of Political Economy, 100(6):1126-1152.

Goedhuys, M. (2007a). The impact of innovation activities on productivity 
and firm growth: evidence from Brazil. Working Paper No. 2007-02. UNUMERIT, Maastricht. Retreived December 8, 2009 from http://merit.unu . edu/publications/wppdf/2007/wp2007-002 .pdf.

Goedhuys, M. (2007b). Learning, product innovation, and firm heterogeneity in developing countries; evidence from Tanzania. Industrial and Corporate Change, 16(2):269-292.

Goedhuys, M., Janz, N., and Mohnen, P. (2008). What drives productivity in tanzanian manufacturing firms: technology or business environment? The European Journal of Development Research, 20(2):199-218.

Goedhuys, M. and Veugelers, R. (2012). Innovation strategies, process and product innovations and growth: firm-level evidence from Brazil. Structural Change and Economic Dynamics, 23(4):516 - 529.

Graf, H. (2006). Networks in the innovation process: Local and regional interactions. Edward Elgar.

Greene, W. H. (2002). Econometric Analysis. Prentice Hall, New York, 5th edition.

Griliches, Z. (1998). Issues in assessing the contribution of research and development to productivity growth. In Griliches, Z., editor, RESD and Productivity: The Econometric Evidence, pages 17-45. University of Chicago Press, Chicago.

Grillitsch, M., Tödtling, F., and Höglinger, C. (2013). Variety in knowledge sourcing, geography and innovation: evidence from the ICT sector in Austria. Papers in Regional Science, advance access(http://dx.doi.org/10. 1111/pirs.12050).

Gronum, S., Verreynne, M.-L., and Kastelle, T. (2012). The role of networks in small and medium-sized enterprise innovation and firm performance. Journal of Small Business Management, 50(2):257-282.

Gulati, R. (1995). Social structure and alliance formation patterns: a longitudinal analysis. Administrative Science Quarterly, 40(4):619-652.

Gulati, R. (1998). Alliances and networks. Strategic Management Journal, 19(4):293-317.

Haas, M. and Hansen, M. (2005). When using knowledge can hurt performance: The value of organizational capabilities in a management consulting company. Strategic Management Journal, 26(1):1-24. 
Hadjimanolis, A. (2000). An investigation of innovation antecedents in small firms in the context of a small developing country. R\&D Management, $30(3): 235-246$.

Hafner, K. A. (2013). Agglomeration economies and clustering - evidence from German and European firms. Applied Economics, 45(20):2938-2953.

Hagedoorn, J. (1993). Understanding the rationale of strategic technology partnering: inter-organizational modes of cooperation and sectoral differences. Strategic Management Journal, 14(5):371-385.

Hagedoorn, J. (2002). Inter-firm R\&D partnerships: an overview of major trends and patterns since 1960. Research Policy, 31(4):477-492.

Hagedoorn, J., Link, A. N., and Vonortas, N. S. (2000). Research partnerships. Research Policy, 29(4):567-586.

Hagle, T. M. and Mitchell II, G. E. (1992). Goodness-of-fit measures for probit and logit. American Journal of Political Science, 36(3):762-784.

Håkansson, H. (1989). Corporate technological behaviour: co-operation and networks. Routledge London.

Hall, B., Jaffe, A., and Trajtenberg, M. (2005). Market value and patent citations. RAND Journal of Economics, 36(1):16-38.

Hammerschmidt, A. (2009). No pain, no gain: An R\&D model with endogenous absorptive capacity. Journal of Institutional and Theoretical Economics, 165(3):418-437.

Hansen, J. A. (1992). Innovation, firm size, and firm age. Small Business Economics, 4(1):37-44.

Hoffman, K., Parejo, M., Bessant, J., and Perren, L. (1998). Small firms, R\&D, technology and innovation in the UK: a literature review. Technovation, 18(1):39-55.

Hoppe, H. and Ozdenoren, E. (2005). Intermediation in innovation. International Journal of Industrial Organization, 23(5):483-503.

Howells, J., James, A., and Malik, K. (2004). Sourcing external technological knowledge: a decision support framework for firms. International Journal of Technology Management, 27(2):143-154.

Huber, G. P. (1991). Organizational learning: the contributing processes and the literatures. Organization Science, 2(1):88-115. 
Huergo, E. and Jaumandreu, J. (2004). How does probability of innovation change with firm age? Small Business Economics, 22(3):193-207.

Iammarino, S., Padilla-Pérez, R., and von Tunzelmann, N. (2008). Technological capabilities and global-local interactions: the electronics industry in two Mexican regions. World Development, 36(10):1980-2003.

Iammarino, S., Piva, M., Vivarelli, M., and von Tunzelmann, N. (2013). Firm capabilities and cooperation for innovation: evidence from the UK regions. In Crescenzi, R. and Percoco, M., editors, Geography, Institutions and Regional Economic Performance, Advances in Spatial Science, pages 281-302. Springer, Berlin/Heidelberg.

Ilori, M., Oke, J., and Sanni, S. (2000). Management of new product development in selected food companies in Nigeria. Technovation, 20(6):333-342.

Jacobs, J. (1969). The Economy of Cities. Random House, New York.

Jaffe, A. (1989). Real effect of academic research. American Economic Review, 79(5):957-970.

Jaruzelski, B. and Dehoff, K. (2007). The customer connection: the global innovation 1000. strategy + business, 49(Winter):68-85.

Jensen, M., Johnson, B., Lorenz, E., and Lundvall, B. (2007). Forms of knowledge and modes of innovation. Research Policy, 36(5):680-693.

Kamien, M. and Zang, I. (2000). Meet me halfway: research joint ventures and absorptive capacity. International Journal of Industrial Organization, 18(7):228-240.

Kapoor, R. and McGrath, P. J. (2013). Unmasking the interplay between technology evolution and r\&d collaboration: evidence from the global semiconductor manufacturing industry, 1990-2010. Research Policy, in press(http://dx.doi.org/10.1016/j.respol.2013.08.002).

Katz, R. and Allen, T. (1982). Investigating the not invented here (NIH) syndrome: a look at the performance, tenure, and communication patterns of 50 R\&D project groups. R\&D Management, 12(1):7-20.

Keizer, J., Dijkstra, L., and Halman, J. (2002). Explaining innovative efforts of SMEs: an exploratory survey among SMEs in the mechanical and electrical engineering sector in the Netherlands. Technovation, 22(1):1-13.

Kim, L. (1997). Imitation to innovation: The dynamics of Korea's technological learning. Harvard Business School Press, Harvard. 
Kim, L. (1998). Crisis construction and organizational learning: capability building in catching-up at Hyundai Motor. Organization Science, 9(4):506521.

Klepper, S. (1996). Entry, exit, growth, and innovation over the product life cycle. American Economic Review, 86(3):562-583.

Koberg, C. S., Detienne, D. R., and Heppard, K. A. (2003). An empirical test of environmental, organizational, and process factors affecting incremental and radical innovation. The Journal of High Technology Management Research, 14(1):21-45.

König, M., Battiston, S., Napoletano, M., and Schweitzer, F. (2011). Recombinant knowledge and the evolution of innovation networks. Journal of Economic Behavior \& Organization, 79(3):145-164.

Lall, R., Campbell, M. J., Walters, S. J., Morgan, K., and Co-operative, M. C. (2002). A review of ordinal regression models applied on health-related quality of life assessments. Statistical Methods in Medical Research, 11(1):4967 .

Lall, S. (1992). Technological capabilities and industrialization. World Development, 20(2):165-186.

Lane, P. J., Koka, B., and Pathak, S. (2002). A thematic analysis and critical assessment of absorptive capacity research. In Academy of Management Proceedings, volume 2002, pages M1-M6.

Lane, P. J. and Lubatkin, M. (1998). Relative absorptive capacity and interorganizational learning. Strategic Management Journal, 19(5):461-477.

Laursen, K. and Salter, A. (2004). Searching high and low: what types of firms use universities as a source of innovation? Research Policy, 33(8):1201-1215.

Laursen, K. and Salter, A. (2006). Open for innovation: the role of openness in explaining innovation performance among UK manufacturing firms. Strategic Management Journal, 27(2):131-150.

Lee, S., Park, G., Yoon, B., and Park, J. (2010). Open innovation in SMEs an intermediated network model. Research Policy, 39(2):290-300.

Leiponen, A. and Helfat, C. (2010). Innovation objectives, knowledge sources and the benefits of breadth. Strategic Management Journal, 31(2):224-236.

Leonard-Barton, D. (1992). Core capabilities and core rigidities: a paradox 
in managing new product development. Strategic Management Journal, 13(S1):111-125.

Lim, K. (2009). The many faces of absorptive capacity: spillovers of copper interconnect technology for semiconductor chips. Industrial and Corporate Change, 18(6):1249-1284.

Lin, C., Wu, Y.-J., Chang, C., Wang, W., and Lee, C.-Y. (2012). The alliance innovation performance of $\mathrm{R} \& \mathrm{D}$ alliances: the absorptive capacity perspective. Technovation, 32(5):282 - 292.

Lundvall, B.-A. (1988). Innovation as an interactive process: From userproducer interaction to the national system of innovation. In Dosi, G., Freeman, C., Nelson, R., Silverberg, G., and Soete, L., editors, Technical Change and Economic Theory, pages 349-369. Pinter Publishers, London.

Lundvall, B.-A., editor (1992). National Systems of Innovation. Towards a Theory of Innovation and Interactive Learning. Pinter Publishers, London.

Lundvall, B.-A., Johnson, B., Andersen, E. S., and Dalum, B. (2002). National systems of production, innovation and competence building. Research Policy, 31(2):213 - 231.

Lundvall, B.-A., Joseph, K., Chaminade, C., and Vang, J., editors (2009). Handbook of Innovation Systems and Developing Countries: Building Domestic Capabilities in a Global Setting. Edward Elgar, Cheltenham.

Malerba, F. (1992). Learning by firms and incremental technical change. The Economic Journal, 102(413):845.

Malerba, F. (2002). Sectoral systems of innovation and production. Research Policy, 31(2):247-264.

Malerba, F. (2006). Innovation and the evolution of industries. Journal of Evolutionary Economics, 16(1-2):3-23.

Malerba, F. (2007). Innovation and the dynamics and evolution of industries: Progress and challenges. International Journal of Industrial Organization, 25(4):675-699.

Malerba, F. and Mani, S. (2009). Sectoral Systems of Innovation and Production in Developing Countries: Actors, Structure and Evolution. Edward Elgar, Cheltenham.

Malerba, F. and Nicholas, S. V., editors (2009). Innovation Networks in Industries. Edward Elgar Publishing, Cheltenham. 
Malerba, F. and Orsenigo, L. (2000). Knowledge, innovative activities and industrial evolution. Industrial and Corporate Change, 9(2):289-314.

March, J. G. (1991). Exploration and exploitation in organizational learning. Organization Science, 2(1):71-87.

Marrocu, E., Paci, R., and Usai, S. (2013). Proximity, networking and knowledge production in Europe: what lessons for innovation policy? Technological Forecasting and Social Change, 80(8):1484-1498.

Marshall, A. (1890). Principles of Economics. Macmillan, London.

Mention, A. (2011). Co-operation and co-opetition as open innovation practices in the service sector: which influence on innovation novelty? Technovation, 31(1):44-53.

Molina-Domene, M. A. and Pietrobelli, C. (2012). Drivers of technological capabilities in developing countries: An econometric analysis of Argentina, Brazil and Chile. Structural Change and Economic Dynamics, 23(4):504515 .

Moran, P. (2005). Structural vs. relational embeddedness: social capital and managerial performance. Strategic Management Journal, 26(12):1129-1151.

Mowery, D., Oxley, J., and Silverman, B. (1996). Strategic alliances and interfirm knowledge transfer. Strategic Management Journal, 17:77-91.

Mowery, D. C. (1983). The relationship between intrafirm and contractual forms of industrial research in American manufacturing, 1900-1940. Explorations in Economic History, 20(4):351-374.

Mowery, D. C. and Oxley, J. E. (1995). Inward technology transfer and competitiveness: the role of national innovation systems. Cambridge Journal of Economics, 19(1):67-93.

Mowery, D. C., Oxley, J. E., and Silverman, B. S. (1998). Technological overlap and interfirm cooperation: implications for the resource-based view of the firm. Research Policy, 27(5):507-523.

Muchie, M. and Baskaran, A. (2011). Book review: African Innovation Outlook 2010. African Journal of Science, Technology, Innovation and Development, 3:300-303.

Murphy, J. T. (2002). Networks, trust, and innovation in tanzania's manufacturing sector. World Development, 30(4):591-619. 
Mytelka, L. (2000). Local systems of innovation in a globalized world economy. Industry and Innovation, 7(1):33-54.

NACETEM (2010). Assessment of innovation capability in the manufacturing sector in Nigeria. Monograph Series No. 4, National Centre for Technology Management, Ile-Ife.

Narayanan, K. and Bhat, S. (2009). Technology sourcing and its determinants: a study of basic chemical industry in India. Technovation, 29(8):562 - 573 .

NBS (2010). The Review of the Nigerian Economy 2010. Technical report, National Bureau of Statistics, Abuja. Retrieved March 20, 2012 from http://www.nigerianstat.gov.ng/ext/latest_release/ 2010_Review_of_the_Nigerian_Economy.pdf.

Nelson, R. and Rosenberg, N. (1993). Technical innovation and national systems. In Nelson, R., editor, National innovation systems: A comparative analysis, pages 3-21. Oxford University Press, Oxford.

Nelson, R. and Winter, S. (1982). An Evolutionary Theory of Economic Change. Belknap Press, Cambridge.

Nieto, M. J. and Santamaría, L. (2007). The importance of diverse collaborative networks for the novelty of product innovation. Technovation, 27(67):367-377.

Niosi, J. (2002). National systems of innovations are "x-efficient" (and xeffective): why some are slow learners. Research Policy, 31(2):291-302.

Niosi, J. (2010). Building National and Regional Innovation Systems: Institutions for Economic Development. Edward Elgar Publishing, Cheltenham.

Nooteboom, B. (1994). Innovation and diffusion in small firms: theory and evidence. Small Business Economics, 6(5):pp. 327-347.

Nooteboom, B. (1999a). Innovation and inter-firm linkages: new implications for policy. Research Policy, 28(8):793 - 805.

Nooteboom, B. (1999b). Inter-firm alliances: Analysis and design. Routledge, London.

Nooteboom, B., Van Haverbeke, W., Duysters, G., Gilsing, V., and Van Den Oord, A. (2007). Optimal cognitive distance and absorptive capacity. Research Policy, 36(7):1016-1034. 
O'Brien, R. (2007). A caution regarding rules of thumb for variance inflation factors. Quality \& Quantity, 41(5):673-690.

Ocasio, W. (1997). Towards an attention-based view of the firm. Strategic Management Journal, 18(S1):187-206.

OECD (2005). Proposed guidelines for collecting and interpreting technological innovation data: Oslo Manual. Organisation for Economic Cooperation and Development, Paris, 3rd edition.

Oerlemans, L., Knoben, J., and Pretorius, M. (2013). Alliance portfolio diversity, radical and incremental innovation: the moderating role of technology management. Technovation, 33(6-7):234 - 246 .

Onnela, J.-P., Chakraborti, A., Kaski, K., Kertesz, J., and Kanto, A. (2003). Dynamics of market correlations: taxonomy and portfolio analysis. Physical Review E, 68(5):056110.

Oxley, J. (1997). Appropriability hazards and governance in strategic alliances: A transaction cost approach. Journal of Law, Economics, and Organization, 13(2):387-409.

Oyebisi, T., Ilori, M., and Nassar, M. (1996). Industry-academic relations: an assessment of the linkages between a university and some enterprises in Nigeria. Technovation, 16(4):203-209.

Oyelaran-Oyeyinka, B. (2005). Inter-firm collaboration and competitive pressures: SME footwear clusters in Nigeria. International Journal of Technology and Globalisation, 1(3/4):343-360.

Oyelaran-Oyeyinka, B. (2006a). Learning to compete in African industry: institutions and technology in development. Ashgate Publishing Coy., Hampshire.

Oyelaran-Oyeyinka, B. (2006b). Systems of innovation and underdevelopment: an institutional perspective. Science, Technology and Society, 11(2):239269.

Oyelaran-Oyeyinka, B. (2007). Learning in local systems and global linkages: the Otigba computer hardware cluster in Nigeria. In Oyelaran-Oyeyinka, B. and McCormick, D., editors, Industrial clusters and innovation systems in Africa. United Nations University Press, Tokyo.

Oyelaran-Oyeyinka, B., Laditan, G., and Esubiyi, A. (1996). Industrial innov- 
ation in sub-Saharan Africa: the manufacturing sector in Nigeria. Research Policy, 25(7):1081-1096.

Oyelaran-Oyeyinka, B. and Lal, K. (2006). Learning new technologies by small and medium enterprises in developing countries. Technovation, 26(2):220 231.

Oyelaran-Oyeyinka, O. (1997). Nnewi: An emergent industrial cluster in Nigeria. Technopol, Ibadan.

Oyewale, A. A. . (2010). The Nigerian national innovation system: issues on the interaction of the key elements. Monograph Series No. 1, National Centre for Technology Management, Ile-Ife.

Özman, M. (2009). Inter-firm networks and innovation: a survey of literature. Economic of Innovation and New Technology, 18(1):39-67.

Panda, H. and Ramanathan, K. (1996). Technological capability assessment of a firm in the electricity sector. Technovation, 16(10):561-588.

Penrose, E. (1959). The Theory of the Growth of the Firm. Oxford University Press, USA.

Pérez Pérez, M. and Sanchez, A. (2002). Lean production and technology networks in the spanish automotive supplier industry. Management International Review, 42(3):261-277.

Peterson, B. and Harrell, Frank E., J. (1990). Partial proportional odds models for ordinal response variables. Journal of the Royal Statistical Society. Series $C$ (Applied Statistics), 39(2):205-217.

Pisano, G. P. (1990). The R\&D boundaries of the firm: an empirical analysis. Administrative Science Quarterly, 35(1):153-176.

Pittaway, L., Robertson, M., Munir, K., Denyer, D., and Neely, A. (2004). Networking and innovation: a systematic review of the evidence. International Journal of Management Reviews, 5/6(3/4):137-168.

Potter, A. and Watts, H. D. (2011). Evolutionary agglomeration theory: increasing returns, diminishing returns, and the industry life cycle. Journal of Economic Geography, 11:417-455.

Powell, W. (1998). Learning from collaboration: knowledge and networks in the biotechnology and pharmaceutical industries. California Management Review, 40(3):228-240. 
Powell, W., Koput, K., and Smith-Doerr, L. (1996). Interorganizational collaboration and the locus of innovation: Networks of learning in biotechnology. Administrative Science Quarterly, 41(1):116-145.

Powell, W., Koput, K., Smith-Doerr, L., and Owen-Smith, J. (1999). Network position and firm performance: Organizational returns to collaboration in the biotechnology industry. Research in the Sociology of Organizations, 16(1):129-159.

Powell, W. W. and Grodal, S. (2005). Networks of innovators. In Fagerberg, J., Mowery, D. C., and Nelson, R. R., editors, Oxford Handook of Innovation, chapter 3, pages 56-85. Oxford University Press, Oxford.

Prahalad, C. K. and Hamel, G. (1990). The core competence of the corporation. Harvard Business Review, May-June:79-91.

Pyka, A. (1997). Informal networking. Technovation, 17(4):207-220.

Radwan, I. and Pellegrini, G. (2010). Knowledge, productivity, and innovation in Nigeria. Technical report, World Bank, Washington D. C. Retrieved April 30, 2010 from http://siteresources.worldbank. org/EDUCATION/Resources/278200-1099079877269/Knowledge_ productivity_innovation_Nigeria.pdf.

Rank, O. N. (2008). Formal structures and informal networks: structural analysis in organizations. Scandinavian Journal of Management, 24(2):145161.

Romer, P. M. (1986). Increasing returns and long run growth. Political Economics, 94(5):1002-1037.

Romijn, H. (1997). Acquisition of technological capability in development: a quantitative case study of Pakistan's capital goods sector. World Development, 25(3):359-377.

Romijn, H. and Albaladejo, M. (2002). Determinants of innovation capability in small electronics and software firms in southeast England. Research Policy, 31(7):1053-1067.

Rosenberg, N. (1982). Inside the black box: Technology and economics. Cambridge University Press, Cambridge.

Rosenberg, N. and Nelson, R. R. (1994). American universities and technical advance in industry. Research Policy, 23(3):323-348. 
Rosenkopf, L. and Schilling, M. (2007). Comparing alliance network structure across industries: observations and explanations. Strategic Entrepreneurship Journal, 1(3-4):191-209.

Rowley, T., Behrens, D., and Krackhardt, D. (2000). Redundant governance structures: an analysis of structural and relational embeddedness in the steel and semiconductor industries. Strategic Management Journal, 21(3):369386.

Saramäki, J., Kivelä, M., Onnela, J., Kaski, K., and Kertesz, J. (2007). Generalizations of the clustering coefficient to weighted complex networks. Physical Review E Stat Nonlin Soft Matter Phys, 75(2):027105.

Sattler, H., Schrader, S., and Lüthje, C. (2003). Informal cooperation in the US and Germany: cooperative managerial capitalism vs. competitive managerial capitalism in interfirm information trading. International Business Review, 12(3):273-295.

Savin, I. and Egbetokun, A. (2013). Emergence of innovation networks from R\&D cooperation with endogenous absorptive capacity. Working Papers CEB 13-022. ULB - Universite Libre de Bruxelles. Available at https:// dipot.ulb.ac.be/dspace/bitstream/2013/143871/1/wp13022.pdf.

Schilling, M. and Phelps, C. (2007). Interfirm collaboration networks: the impact of large-scale network structure on firm innovation. Management Science, 53(7):1113-1126.

Schmidt, T. (2010). Absorptive capacity-one size fits all? A firm-level analysis of absorptive capacity for different kinds of knowledge. Managerial and Decision Economics, 31(1):1-18.

Schmitz, H. (1982). Growth constraints on small-scale manufacturing in developing countries: a critical review. World Development, 10(6):429-450.

Schmitz, H. (1995). Collective efficiency: growth path for small-scale industry. Journal of Development Studies, 31(4):529-566.

Schmoch, U. (2003). Service marks as novel innovation indicator. Research Evaluation, 12(2):149-156.

Schumpeter, J. A. (1934). The Theory of Economic Development. Harvard University Press, Harvard.

Schumpeter, J. A. (1942). Capitalism, Socialism and Democracy. Harper, New York. 
Shelanski, H. A. and Klein, P. G. (1995). Empirical research in transaction cost economics: a review and assessment. Journal of Law, Economics and Organization, 11(2):335-361.

Siyanbola, W., Egbetokun, A., Adebowale, B. A., and Olamade, O., editors (2012). Innovation Systems and Capabilities in Developing Regions. Gower, Surrey.

Siyanbola, W. O., Adeyeye, A. D., Oluwatope, O., Sanni, M., and Egbetokun, A. A. (2013). From indicators to policy: issues from the Nigerian research and experimental development survey. International Journal of Technology, Policy and Management, in press.

Smith, A. (1776). An Inquiry into the Nature and Causes of the Wealth of Nations. W. Strahan and T. Cadell, London.

Soboyejo, W. (2006). A network of excellence for African development. Opinion, SciDev.net. Retrieved January 23, 2007 from http://www.scidev. net/en/science-and-innovation-policy/aid-for-higher-education/ opinions/a-network-of-excellence-for-african-development.html.

Söderbom, M. and Teal, F. (2002). The Performance of Nigerian Manufacturing Firms: Report on the Nigerian Manufacturing Enterprise Survey 2001. Technical report, UNIDO and Centre for the Study of African Economies, University of Oxford.

Souitaris, V. (2001). External communication determinants of innovation in the context of a newly industrialized country: a comparison of objectives and perceptual results from Greece. Technovation, 21(1):25-34.

Storn, R. and Price, K. (1997). Differential evolution: a simple and efficient adaptive scheme for global optimization over continuous spaces. Journal of Global Optimization, 11(4):341-359.

Sutz, J. (2012). Measuring innovation in developing countries: some suggestions to achieve more accurate and useful indicators. International Journal of Technological Learning, Innovation and Development, 5(1):40-57.

Szirmai, A. (2011). Industrialisation as an engine of growth in developing countries, 1950-2005. Structural Change and Economic Dynamics, 23(4):406420 .

Tartari, V. and Breschi, S. (2012). Set them free: scientists' evaluations of the benefits and costs of university-industry research collaboration. Industrial and Corporate Change, 21(5):1117-1147. 
Teece, D. and Pisano, G. (1994). The dynamic capabilities of firms: an introduction. Industrial and Corporate Change, 3(3):537-556.

Teece, D., Rumelt, R., Dosi, G., and Winter, S. (1994). Understanding corporate coherence: theory and evidence. Journal of Economic Behavior and Organization, 23(1):1-30.

Teece, D. J. (1986). Profiting from technological innovation: Implications for integration, collaboration, licensing and public policy. Research Policy, 15(6):285-305.

Teece, D. J. (2007). Explicating dynamic capabilities: the nature and microfoundations of (sustainable) enterprise performance. Strategic Management Journal, 28(13):1319-1350.

Teece, D. J., Pisano, G., and Shuen, A. (1997). Dynamic capabilities and strategic management. Strategic Management Journal, 18(7):509-533.

Ter Wal, A., Alexy, O., Block, J., and Sandner, P. (2013). The best of both worlds: The benefits of specialized-brokered and diverse-closed syndication networks for new venture success. In 35th DRUID Celebration Conference 2013, Barcelona, Spain, June 17-19.

Ter Wal, A. L. J. (2013). The dynamics of the inventor network in German biotechnology: geographic proximity versus triadic closure. Journal of Economic Geography, advance access(http://dx.doi.org/10.1093/jeg/ Ibs063).

Tether, B. (2002). Who co-operates for innovaton, and why? An empirical analysis. Research Policy, 31:pp. 947-967.

Todorova, G. and Durisin, B. (2007). Absorptive capacity: valuing a reconceptualization. Academy of Management Review, 32(3):774-786.

Tödtling, F., Lehner, P., and Kaufmann, A. (2009). Do different types of innovation rely on specific kinds of knowledge interactions? Technovation, 29(1):59-71.

Tomlinson, P. (2010). Co-operative ties and innovation: some new evidence for UK manufacturing. Research Policy, 39(6):762-775.

UN-DESA (2013). World population prospects: the 2012 revision. Retrieved July 22, 2013 from http://esa.un.org/unpd/wpp/Excel-Data/ population.htm. 
UNCTAD (2007). The Least Developed Countries Report 200\%: Knowledge, Technological Learning and Innovation for Development. United Nations Conference on Trade and Development, Geneva/New York.

UNU-INTECH (2004). Designing a policy-relevant innovation survey for NEPAD. mimeo: United Nations University Institute for New Technologies, Maastricht, the Netherlands.

Uzzi, B. (1997). Social structure and competition in interfirm networks: the paradox of embededdness. Administrative Science Quartely, 42(1):35-67.

Van der Panne, G. (2004). Agglomeration externalities: Marshall versus Jacobs. Journal of Evolutionary Economics, 14(5):593-604.

van der Panne, G., van Beers, C., and Kleinknecht, A. (2003). Success and failure of innovation: a literature review. International Journal of Innovation Management, 7(3):1-30.

Veall, M. and Zimmermann, K. (1996). Pseudo- $R^{2}$ measures for some common limited dependent variable models. Journal of Economic Surveys, 10(3):241259.

Vega-Jurado, J., Gutiérrez-Gracia, A., and de Lucio, I. F. (2009). Does external knowledge sourcing matter for innovation? Evidence from the Spanish manufacturing industry. Industrial and Corporate Change, 18(4):634-670.

Vernet, A., Kilduff, M., and Salter, A. (2013). Information, control, and small worlds: studying returns to individual network positions under different global structures. In 35th DRUID Celebration Conference 2013, Barcelona, Spain, June 1\%-19.

Verspagen, B. and Duysters, G. (2004). The small worlds of strategic technology alliances. Technovation, 24(7):563 - 571 .

von Hippel, E. (1987). Cooperation between rivals: informal know-how trading. Research Policy, 16(6):291-302.

von Hippel, E. (1988). The Sources of Innovation. Oxford University Press, New York.

von Hippel, E. (2005). Democratizing Innovation. MIT Press, Cambridge.

von Tunzelmann, N. (2009). Competencies versus capabilities: a reassessment. Economia Politica, 26(3):435-464. 
von Tunzelmann, N. and Wang, Q. (2003). An evolutionary view of dynamic capabilities. Economie Appliquee, 56(3):33-64.

von Tunzelmann, N. and Wang, Q. (2007). Capabilities and production theory. Structural Change and Economic Dynamics, 18(2):192-211.

Wang, C. and Ahmed, P. (2007). Dynamic capabilities: a review and research agenda. International Journal of Management Reviews, 9(1):31-51.

Watts, D. J. and Strogatz, S. (1998). Collective dynamics of small-world networks. Nature, 393(6684):440-442.

Wernerfelt, B. (1984). A resource-based view of the firm. Strategic Management Journal, 5(2):171-180.

Wernerfelt, B. (2007). The resource-based view of the firm: ten years after. Strategic Management Journal, 16(3):171-174.

Wersching, K. (2010). Schumpeterian competition, technological regimes and learning through knowledge spillover. Journal of Economic Behavior \&5 Organization, 75(3):482-493.

Westphal, L., Kim, L., and Dahlman, C. (1985). Reflections on the Republic of Korea's acquisition of technological capability. In Rosenberg, N. and Frischtak, C., editors, International Technology, pages 167-221. Praeger Publishers, New York.

Wiethaus, L. (2005). Absorptive capacity and connectedness: why competing firms also adopt identical R\&D approaches. International Journal of Industrial Organization, 23(5-6):467 - 481.

Wignaraja, G. (2002). Firm size, technological capabilities and marketoriented policies in Mauritius. Oxford Development studies, 30(1):87-104.

Williams, R. (2006). Generalized ordered logit/partial proportional odds models for ordinal dependent variables. Stata Journal, 6(1):58-82(25).

Williamson, O. E. (1979). Transaction-cost economics: the governance of contractual relations. Journal of Law and Economics, 22(2):233-261.

Williamson, O. E. (1998). Transaction cost economics: how it works; where it is headed. De Economist, 146:23-58.

Winter, S. G. (2003). Understanding dynamic capabilities. Strategic Management Journal, 24(10):991-995. 
WIPO (2011). World Intellectual Property Report 2011: Changing the face of innovation. WIPO Economics and Statistics Series, World Intellectual Property Organisation, Geneva.

Witt, U. (2003). The Evolving Economy. Edward Elgar, Cheltenham.

Witt, U. (2008). Evolutionary economics. In Durlauf, S. N. and Blume, L. E., editors, The New Palgrave Dictionary of Economics (Online). Palgrave Macmillan, Basingstoke. Retrieved 23 July 2013 from http://www. dictionaryofeconomics.com/article?id=pde2008_E000295.

Wooldridge, J. M. (2010). Econometric Analysis of Cross Section and Panel Data. MIT Press, Cambridge, Massachusetts, 2nd edition.

World Bank (2013). World Development Indicators (online). Accessed June 1, 2013 at http://databank. worldbank.org/data/home.aspx.

World Bank and International Finance Corporation (2006). Doing Business 200\%: How to Reform. World Bank, Washington.

Wuyts, S., Colombo, M., Dutta, S., and Noteboom, B. (2005). Empirical tests of optimal cognitive distance. Journal of Economic Behaviour $\& 3$ Organization, 58(2):277-302.

Zahra, S. and George, G. (2002). Absorptive capacity: a review, reconceptualization, and extension. Academy of Management Review, 27(2):185-203.

Zeng, S., Xie, X., and Tam, C. (2010). Relationship between cooperation networks and innovation performance of SMEs. Technovation, 30(3):181194.

Zheng, W., Yang, B., and McLean, G. N. (2010). Linking organizational culture, structure, strategy, and organizational effectiveness: mediating role of knowledge management. Journal of Business Research, 63(7):763-771.

Zollo, M. and Winter, S. G. (2002). Deliberate learning and the evolution of dynamic capabilities. Organization Science, 13(3):339-351.

Zott, C. (2003). Dynamic capabilities and the emergence of intraindustry differential firm performance: insights from a simulation study. Strategic Management Journal, 24(2):97-125. 


\section{Erklärung}

Hiermit erkläre ich,

1. dass mir die geltende Promotionsordnung bekannt ist;

2. dass ich die Dissertation selbst angefertigt, keine Textabschnitte eines Dritten oder eigener Prüfungsarbeiten ohne Kennzeichnung übernommen und alle von mir benutzten Hilfsmittel, persönlichen Mitteilungen und Quellen in meiner Arbeit angegeben habe;

3. dass ich bei der Auswahl und Auswertung des Materials sowie bei der Herstellung des Manuskriptes keine unzulüssige Hilfe in Anspruch genommen habe;

4. dass ich nicht die Hilfe eines Promotionsberaters in Anspruch genommen habe und dass Dritte weder unmittelbar noch mittelbar geldwerte Leistungen von mir für Arbeiten erhalten haben, die im Zusammenhang mit dem Inhalt der vorgelegten Dissertation stehen;

5. dass ich die Dissertation noch nicht als Prüfungsarbeit für eine staatliche oder andere wissenschaftliche Prüfung eingereicht habe;

6. dass ich nicht die gleiche, eine in wesentlichen Teilen ähnliche oder eine andere Abhandlung bei einer anderen Hochschule bzw. anderen Fakultät als Dissertation eingereicht habe.

Abiodun A. Egbetokun 